Iris Amati Martins

Análise Geográfica Computadorizada na Estimativa de Qualidade Ambiental para Mamíferos de Médio e Grande Porte 
Iris Amati Martins

\section{Análise Geográfica Computadorizada na Estimativa de Qualidade Ambiental para Mamíferos de Médio e Grande Porte}

Dissertação apresentada ao Instituto de Biociências da Universidade de São Paulo, para a obtenção de Título de Mestre em Ciências, na Área de Ecologia de Ecossistemas Terrestres e Aquáticos.

Orientadora: Profa. Dra. Marisa Dantas Bitencourt

São Paulo 2009 
Martins, Iris Amati

Análise Geográfica Computadorizada na

Estimativa de Qualidade Ambiental para

Mamíferos de Médio e Grande Porte

167 páginas

Dissertação (Mestrado) - Instituto de Biociências da Universidade de São Paulo. Departamento de Ecologia.

1. Qualidade de Habitat; 2. Modelo de Tomada de Decisão; 3. Sensoriamento Remoto; 4.

Geoprocessamento; 5. Fragmentação de Habitat

Universidade de São Paulo. Instituto de

Biociências. Departamento de Ecologia.

\section{Comissão Julgadora:}

Prof(a). Dr(a).

Prof(a). Dr(a).
Prof(a). Dr(a).

$\operatorname{Prof}(\mathrm{a}) . \operatorname{Dr}(\mathrm{a})$.

Profa. Dra. Marisa Dantas Bitencourt

Orientadora 
A todos aqueles que acreditam que a conservação da biodiversidade não é um obstáculo intransponível quando há envolvimento de comunidades locais 
A ignorância só degrada o homem quando se encontra em companhia da riqueza Arthur Schopenhauer," Über Lesen und Bücher" 


\section{Agradecimentos}

À minha querida orientadora, Profa. Dra. Marisa Dantas Bitencourt, pela orientação, apoio e confiança durante o desenvolvimento deste trabalho, sempre pronta a solucionar os problemas, propor melhorias e auxiliar na obtenção de subsídios para o desenvolvimento deste projeto.

Aos meus queridos orientandos de Iniciação Científica, Carlos Felipe P. da Silveira e Kitaro S. Jardineiro, por todo auxílio e companheirismo. Este trabalho não estaria completo se não houvesse a ajuda de vocês.

À Coordenação de Aperfeiçoamento de Pessoal de Nível Superior (CAPES) pela concessão da bolsa de mestrado.

À Neotropical Grassland Conservancy por fornecer as armadilhas fotográficas por meio do Programa de Doação de Equipamentos de Pesquisa e por conceder financiamento através do Programa de Bolsa para Estudantes.

Ao Sr. Eliezer Steinbruch (in memorian) e ao Grupo Vicunha por permitir a realização dos trabalhos de campo na fazenda Alvorada de Bragança em Campos Novos Paulista, SP.

Aos especialistas que auxiliaram na elaboração dos pesos dos critérios por meio de consulta Ad Hoc.

Ao Laboratório de Ecologia da Paisagem e Conservação (LEPaC) do Departamento de Ecologia (IB-USP) pelo apoio logístico durante o desenvolvimento deste trabalho. Aos amigos Milton Cezar e Giordano do LEPaC pelas contribuições.

À Profa. Dra. Astrid M. P. Kleinert pela prontidão e apoio e ao Prof. Dr. Sérgio Tadeu Meirelles, por auxiliar nas dúvidas estatísticas.

A todos que me ensinaram e me incentivaram: Carlos C. Alberts, Aldo L. Klein, Flávio H. G. Rodrigues, Fernanda Michalski e Eduardo Eizirik.

Aos meus amigos que sempre estiveram ao meu lado durante estes anos.

$\mathrm{E}$, finalmente, à minha querida família que sempre acreditou, incentivou e apoiou minhas decisões. 


\section{Índice Geral}

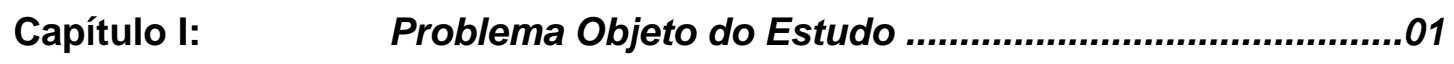

Capítulo II: Elaboração da Base Cartográfica para Amostragem e Análise de Dados de Mamíferos de Médio e Grande Porte

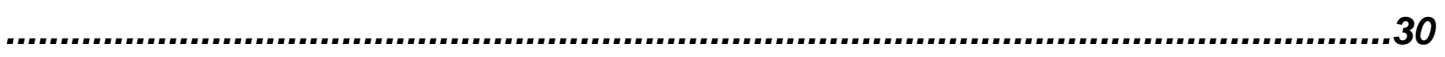

Capítulo III: Riqueza de Espécies de Mamíferos de Médio e Grande Porte em um Fragmento de Cerrado no Estado de São Paulo...........................67

Capítulo IV: $\quad$ Análise Espacial da Qualidade de Habitat para Mamíferos de Médio e Grande Porte em um Fragmento de Cerrado.................................124

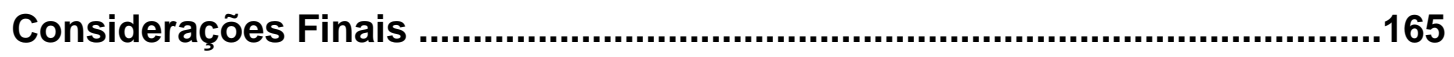

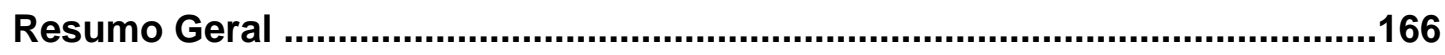


Capítulo I

Problema Objeto do Estudo

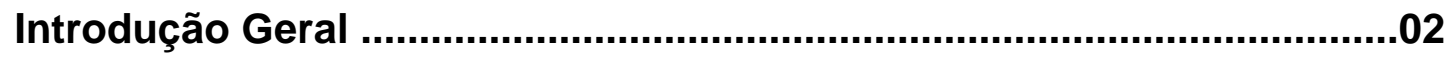

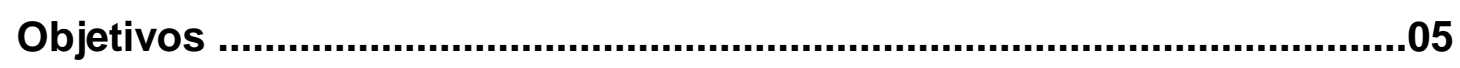

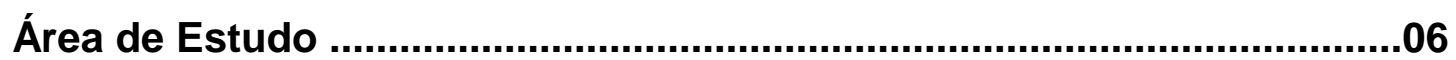

Revisão Bibliográfica ......................................................................12

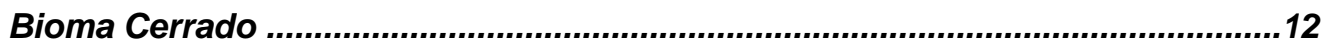

Fragmentação de Áreas Naturais .............................................................15

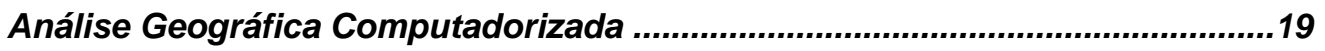

Referências Bibliográficas ............................................................22 


\section{Introdução Geral}

O bioma Cerrado, o segundo maior do Brasil, foi considerado por Myers et al. (2000) um dos dois hotspots brasileiros, em vista da importância de sua biodiversidade e do grau de deterioração em que se encontra esse bioma nos dias de hoje. A degradação ambiental neste bioma tem afetado sobremaneira a disponibilidade de ambientes adequados a muitas espécies animais (Bitencourt, 2004).

Neste cenário, torna-se imperativa a busca por metodologias que possam ser utilizadas como ferramentas de conservação de espécies, auxiliando tomadores de decisão a direcionar com mais embasamento as suas estratégias de manejo e conservação. Conceitos de Ecologia da Paisagem, juntamente com técnicas de sensoriamento remoto e geoprocessamento, em particular os Sistemas de Informação Geográfica (SIG), podem ser algumas dessas ferramentas.

No mundo existem aproximadamente 5.000 espécies de mamíferos (Nowak, 1999). Destas, aproximadamente 654 espécies são conhecidas para o Brasil (Reis et al., 2006) e cerca de 187 espécies de mamíferos terrestres para o estado de São Paulo (de Vivo, 1996), das quais 23 encontram-se ameaçadas (Kierulff et al., 2007).

Com relação ao bioma cerrado, a fauna de mamíferos é relativamente pequena e está principalmente associada ou restrita aos fragmentos florestais ou matas de galeria (Redford \& Fonseca, 1984; Marinho-Filho et al., 2002). Pelo menos 137 espécies de animais que ocorrem no Cerrado estão ameaçadas de extinção (Fundação Biodiversitas, 2005) devido à grande expansão agrícola e intensa exploração local de produtos nativos (Klink \& Machado, 2005).

As principais ameaças para a conservação dos mamíferos estão relacionadas ao desmatamento, fragmentação e à pressão de caça (Bodmer et al., 1997). O desmatamento e a fragmentação causam a perda de habitat, eliminação de recursos e isolamento de populações locais (Saunders et al., 1991; Terborgh, 1992; Gehring \& Swihart, 2003). A fragmentação ainda ocasiona a produção em larga escala de habitats ruins ou negativos para a maioria das espécies, restringindo a aptidão de algumas espécies (menores taxas de sobrevivência e reprodução), levando à diminuição da abundância e podendo levar à extinção local e diminuição 
da diversidade, com conseqüente perda de grupos funcionais (Cerqueira et al., 2003).

Os mamíferos compreendem um dos grupos mais afetados pela fragmentação em função de sua necessidade de grandes áreas de vida e seu uso restrito de zonas agrícolas ou urbanas. Sendo assim, estratégias de conservação mamíferos de médio e grande porte, como a onça parda (Puma concolor), a anta (Tapirus terrestris) e o tamanduá bandeira (Myrmecophaga tridactyla), devem levar em conta a necessidade de grandes extensões de habitats preservados que abriguem populações viáveis, capazes de sobreviverem por um longo prazo (Michalski \& Peres, 2007; Kierulff et al., 2008).

Entretanto, no estado de São Paulo, muitas destas espécies sobrevivem em remanescentes de cerrado com áreas muito menores em relação às suas áreas de vida. Segundo Kronka (1998), eram 8.353 os fragmentos de cerrado em áreas particulares em todo o estado de São Paulo, variando em tamanho de 4 a 2.000 hectares. As Unidades de Conservação (32 UC's) de cerrado são apenas 18\% da área remanescente de cerrado, que é de menos de $1 \%$ do estado todo (SMA, 1999).

De alguma maneira as espécies de mamíferos de médio e grande porte ainda conseguem persistir nestes remanescentes de cerrado, mas não se sabe até quando isto poderá ocorrer caso não haja fluxo destas espécies entre remanescentes.

Esforços que visando à conservação de mamíferos de médio e grande porte também devem ser direcionados para a compreensão de como estes animais estão fazendo uso destes habitats alterados. Dados espaciais podem ser associados às informações sobre as necessidades ecológicas (ambientais) das espécies para que sejam elaborados modelos de qualidade de habitat, como o desenvolvido neste trabalho. Estes modelos podem contribuir para o entendimento de como as espécies estão interagindo com os habitats alterados.

A Análise Geográfica Computadorizada também pode ser utilizada para manejo da paisagem, como por exemplo, determinar melhores locais para estabelecimento das áreas de reserva legal, buscando aumentar proximidade, permitindo a conectividade 
entre fragmentos e, conseqüentemente, possibilitar o fluxo de espécies entre os remanescentes.

Em suma, a partir de dados espaciais (ou georreferenciados) e do conhecimento das necessidades ambientais das espécies, as estratégias de conservação podem ser melhor direcionadas, partindo-se de informações mais próximas da realidade e tornando-se mais objetivas e efetivas. 


\section{Objetivos}

O objetivo geral é elaborar um modelo espacial de qualidade ambiental de habitats em função das exigências ambientais de espécies de mamíferos de médio e grande porte, que possa ser aplicado a qualquer situação (habitats intactos ou impactados), utilizando análise geográfica computadorizada.

Os objetivos específicos são:

1. Elaborar base cartográfica (mapas temáticos), para caracterizar a área de estudo, sistematizar e otimizar as coletas de dados de riqueza de espécies de mamíferos de médio e grande porte e inserir no Modelo de Tomada de Decisão;

2. Estimar a riqueza e freqüência de ocorrência de espécies de mamíferos de médio e grande porte no remanescente de cerrado;

3. Elaborar proposta metodológica que mostre espacialmente a qualidade de habitats por meio de Mapas de Oportunidades (qualidade ambiental) compatíveis com espécies de mamíferos de médio e grande porte num fragmento de cerrado - Modelo de Tomada de Decisão:

a. Determinar critérios (variáveis) físicos e bióticos que possam influenciar a qualidade do habitat;

b. Padronização e atribuição de pesos aos critérios;

c. Agregação dos critérios em um mapa temático final (Mapa de Oportunidades) para cada espécie.

4. Avaliação da Eficácia do Modelo de Tomada de Decisão desenvolvido, por meio da inserção dos dados de ocorrência das espécies de mamíferos de médio e grande porte em seus respectivos Mapas de Oportunidades.

Espera-se que o modelo desenvolvido possa ser aplicado posteriormente na predição da provável ocorrência de espécies de mamíferos de médio e grande porte, assim como um instrumento de medida de eficácia, na compreensão do comportamento das espécies de mamíferos em ambientes intactos ou alterados. 


\section{Área de Estudo}

A área de estudo compreende um fragmento de cerrado inserido em área particular - Fazenda Alvorada de Bragança, município de Campos Novos Paulista, sudoeste

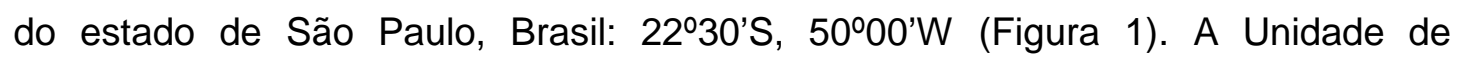
Gerenciamento de Recursos Hídricos compreende o Médio Paranapanema.

Este remanescente foi mapeado pelo Inventário Florestal do Estado de São Paulo (Kronka et al., 1993) e indicado como de prioridade máxima para conservação segundo o Workshop do Cerrado (1995), em vista de seu tamanho e de seu bom estado de conservação (Bitencourt \& Mendonça, 2004). Trata-se de um dos maiores remanescentes de cerrado no estado, com área total de 2.098ha (área maior do que a estipulada como Reserva Legal da fazenda).

O grupo temático de mamíferos do Workshop Biota/FAPESP (2008) indicou este remanescente em seu produto final, Mapa de Ações Prioritárias para a Conservação de Mamíferos, para realização de inventário biológico, criação de unidade de conservação de proteção integral e incremento de conectividade.

A figura 1 apresenta em destaque a área de estudo, visualizada por meio de imagem obtida do sensor Enhanced Thematic Mapper Plus (ETM+) do satélite Landsat 7. As áreas em verde escuro correspondem à vegetação natural, as em verde claro correspondem às culturas anuais, enquanto as áreas em magenta correspondem ao solo exposto ou aos primeiros estágios de desenvolvimento da vegetação.

O fragmento objeto de estudo é constituído predominantemente por cerradão e cerrado sensu stricto (Bitencourt et al., 2007), com variação em relação à intensidade da cobertura vegetal, sendo subdividido em cerrado sensu stricto denso, cerrado sensu stricto típico e fisionomias associadas ao cerrado, tais como campos úmidos e mata ripária (Durigan et al., 1999; Durigan et al., 2004) (Figura 2).

O mesmo encontra-se inserido em uma matriz antrópica constituída por pastagens e culturas agrícolas, tais como mandioca e milho (Figura 2). 


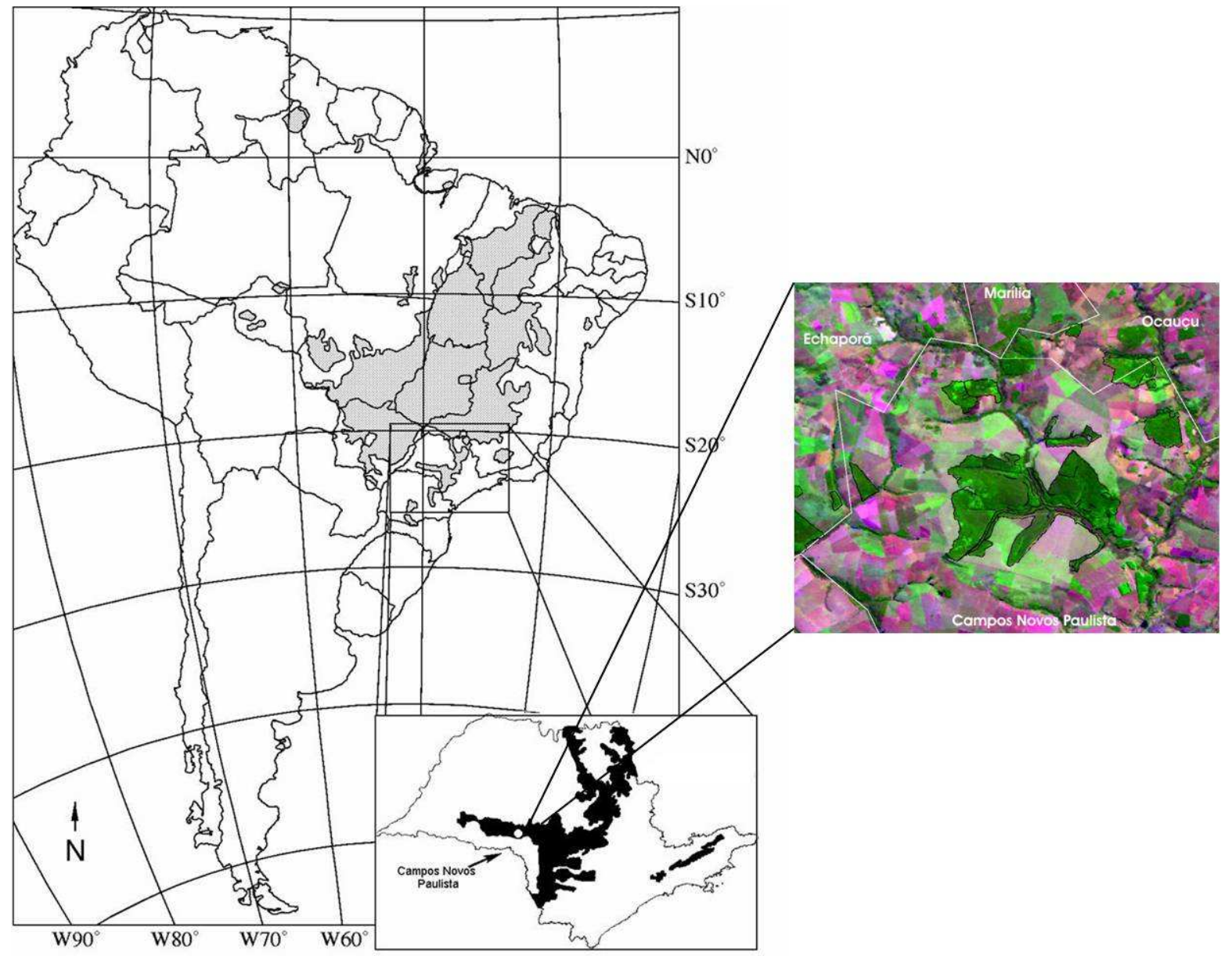

Fig.l.1. - Distribuição do Domínio do Cerrado na América do Sul. Os mapas em destaque apresentam a extensão do cerrado no Estado de São Paulo (IBGE, 1993) e a localização da área de estudo - imagem ETM+ (Bitencourt et al. 2007). 


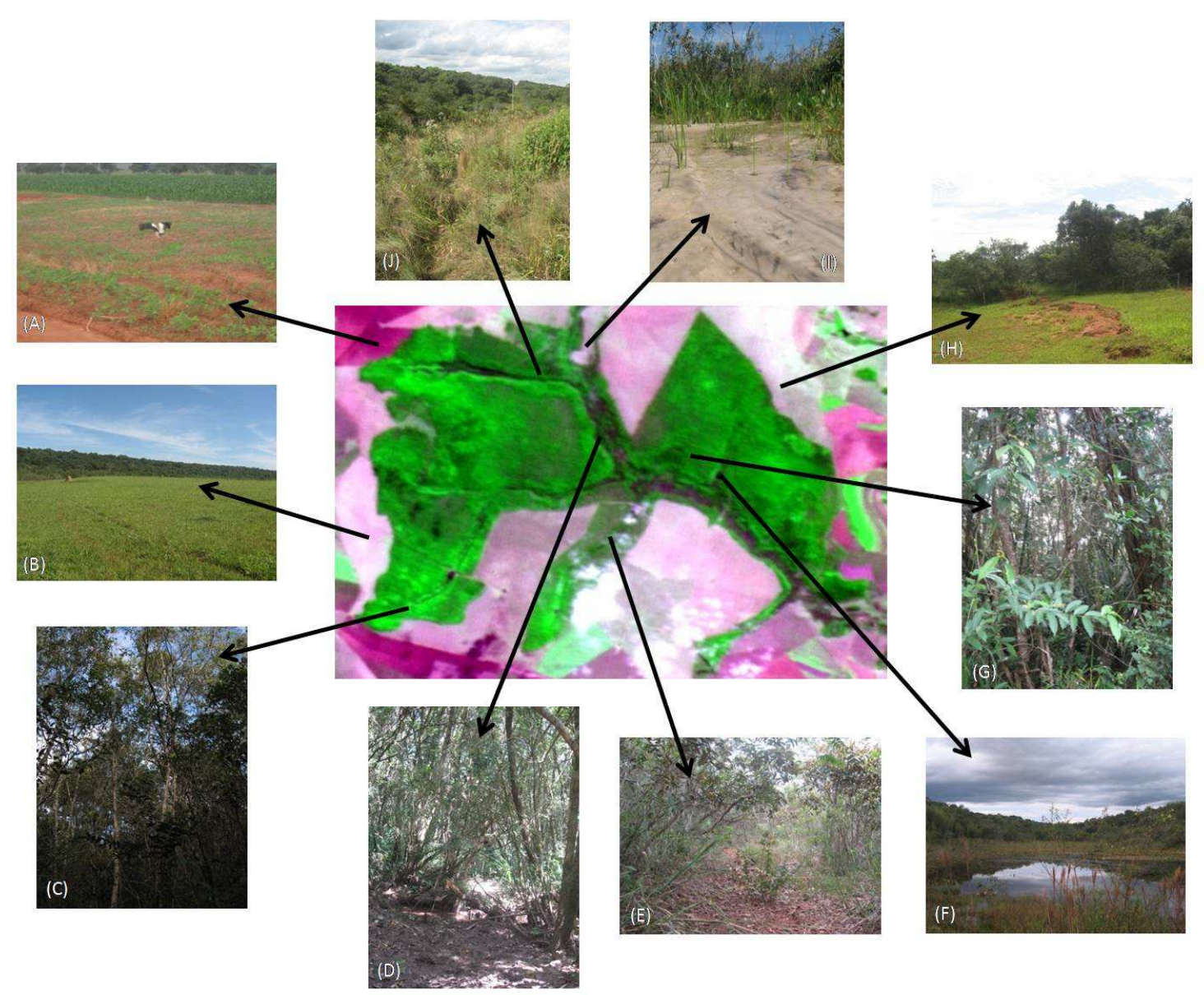

Fig.l.2. - Área de estudo (remanescente de cerrado), com detalhamento fotográfico da matriz antrópica e das fitofisionomias observadas no interior do fragmento. (A) Plantação de mandioca; (B) Pastagem; (C) Cerradão; (D) Área inundável; (E) Cerrado sensu stricto ralo; (F) Mata ripária à direita e plantação de bambuíra à esquerda do rio; (G) Cerrado sensu stricto denso; (H) Pastagem; (I) Nascente; e (J) Campo úmido. 
O fragmento está sujeito a uma série de pressões de origem antrópica, todas detectadas em visita a campo, a saber:

1. Caça de animais silvestres, que pode acarretar diminuição do tamanho populacional, podendo levar à extinção local e, conseqüentemente, à perda de diversidade biológica e de funções ecológicas (Primack \& Rodrigues, 2001; Vieira et al., 2003).

2. Entrada de gado desgarrado no fragmento, que pode acarretar o pastoreio e o pisoteio excessivos de espécies herbáceas e mudas nativas, impedir a regeneração de áreas impactadas no remanescente, acarretar o transporte de sementes de espécies exóticas e invasoras, tais como Zea mays (milho), Melinis minutiflora (capim gordura) e Brachiaria decumbens, para o interior do remanescente. $O$ gado ainda pode agir como agente transportador de doenças para as espécies da fauna (Primack \& Rodrigues, 2001; Fiszon et al., 2003);

3. Represamento de rios para dessedentação do gado, que pode acarretar alterações das características físicas e químicas dos corpos d'água. Estas alterações podem desencadear modificações na estrutura, composição e distribuição das fitofisionomias (Jones et al., 2008) e, conseqüentemente, pode causar alterações nas demais variáveis físicas ambientais, como temperatura, luminosidade e ventilação, podendo ainda interferir na estrutura, composição e distribuição de espécies da fauna;

4. Abertura de caminhos que atravessam o fragmento para manejo do gado, que pode acarretar a fragmentação do remanescente, reduzindo e isolando áreas propícias à sobrevivência das populações e, conseqüentemente, reduzindo a heterogeneidade interna do remanescente, aumentando a área sob efeito de borda, diminuindo recurso e a riqueza de espécies, aumentando a possibilidade de extinções locais, entre outros (Cerqueira et al., 2003; Pardini et al., 2005 );

5. Descarte de resíduos (animais mortos, resíduos domésticos, embalagens de ração, embalagens plásticas de insumos) próximo à margem do rio;

6. Plantação de eucalipto e bambuíra em pequena área do fragmento, que pode acarretar alterações físicas (temperatura, luminosidade, ventilação, 
evapotranspiração), químicas (composição do solo) e biológicas (estrutura, composição e dinâmica da comunidade) do remanescente;

7. Presença de espécies invasoras e exóticas, tais como a lebre européia (Lepus europaeus), gramíneas africanas (Melinis minutiflora e Brachiaria decumbens); e presença de pequenas manchas de uma pteridófita invasora neotropical comum no sudeste do Brasil, Pteridium arachnoideum, no interior do fragmento, indicando perturbação. Isto pode estar associado à supressão de madeira e queimadas nestas áreas. Espécies invasoras persistentes substituem as espécies nativas e interrompem processos sucessionais recorrentes (Primack \& Rodrigues, 2001; Fiszon et al., 2003; Xavier et al., 2008). No cerrado, Pteridium arachnoideum parece afetar negativamente a diversidade e a estrutura do componente arbóreo, demonstrando ser capaz de ocupar o espaço e explorar eficientemente os recursos disponíveis, com uma alta produção de biomassa e desenvolvimento de extensos rizomas (Miatto et al., 2008). Somando-se a isto, o acúmulo de serapilheira e a formação de um dossel denso em áreas com $P$. arachnoideum prejudicam a regeneração de espécies nativas, por meio do empobrecimento dos bancos de sementes, sombreamento ou formação de um substrato inadequado à germinação (Xavier et al., 2008).

Com relação aos aspectos climatológicos, o clima da região é classificado como do tipo AWi (Köppen, 1948), ou seja, o verão é chuvoso e o inverno é seco (Figura 3). A média das precipitações anuais é de 1.390mm (SIGRH, 2009). 


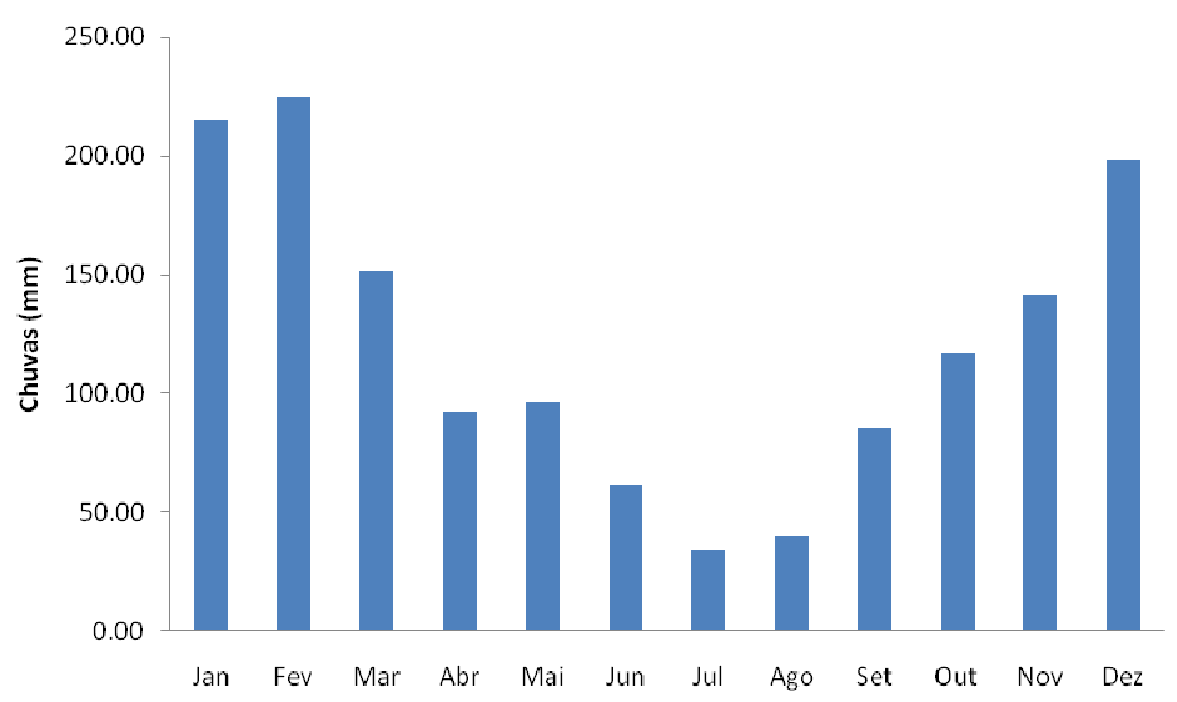

Fig.l.3. - Pluviograma acumulado médio mensal de 1982 a 2004. Dados da seqüencia histórica obtidos do Banco de Dados Pluviométricos do Estado de São Paulo para o município de Campos Novos Paulista (SIGRH, 2009).

Com relação aos aspectos pedológicos, os solos são classificados como Podzólicos Vermelhos Amarelos (PVa), eutróficos e distróficos, predominantemente arenosos, com baixa capacidade de troca de cátions e baixa saturação de bases. A região é submetida regularmente a calagem para corrigir o $\mathrm{pH}$ do solo e a queimadas para exploração comercial das terras e rebrota das pastagens (Oliveira et al., 1999; Kuntschik, 2004). 


\section{Revisão Bibliográfica}

\section{Bioma Cerrado}

O Cerrado é o segundo maior bioma brasileiro, sendo superado em área apenas pela Floresta ombrófila. É um dos hotspots mundiais de biodiversidade - área prioritária para a conservação da biodiversidade no mundo (Myers et al., 2000). O seu domínio ocupa $21 \%$ do território nacional e é considerado a última fronteira agrícola do planeta (Borlaug, 2002 apud Klink \& Machado, 2005). Hoje, contudo, $35 \%$ das áreas do domínio Cerrado já foram convertidas em pastagens cultivadas e em lavouras diversas (Coutinho, 2002).

A vegetação do bioma Cerrado não possui uma fisionomia única em toda a sua extensão, apresentando-se bastante diversificada, com formas campestres bem abertas (campos limpos) até formas relativamente densas, florestais (cerradões). Entre estes dois extremos são encontradas várias fisionomias intermediárias, como campos sujos, campos cerrados e cerrados sensu stricto. Portanto, o Cerrado é considerado um mosaico de formas fisionômicas. Tal mosaico é determinado por manchas de solo mais ou menos pobres, assim como pela irregularidade dos regimes e pelas características das queimadas de cada local (freqüência, época e intensidade) - fatores limitantes da vegetação (Coutinho, 2002).

O cerrado sensu lato apresenta um gradiente de fisionomias que varia desde formas campestres (campo limpo, campo sujo e campo cerrado) a formas florestais (cerrado sensu stricto e cerradão), conforme as condições do meio físico e conforme as pressões antrópicas (Coutinho, 1978).

No município de Campos Novos Paulista, sudoeste do estado de São Paulo, as fisionomias predominantes de cerrado são cerradão, cerrado sensu stricto denso e cerrado sensu stricto típico (Durigan et al., 2004).

O cerradão é a formação florestal do bioma com características esclerófitas, apresentando dossel contínuo, cobertura arbórea que pode oscilar de 50\% a $90 \%$ e a altura média do estrado arbóreo varia de $8 \mathrm{~m}$ a $15 \mathrm{~m}$, favorecendo a formação de estratos arbustivo e herbáceo diferenciados. O cerrado sensu stricto denso é predominantemente arbóreo e corresponde à forma mais densa e alta do cerrado 
sensu stricto, com cobertura de $50 \%$ a $70 \%$ e altura média de $5 \mathrm{~m}$ a $8 \mathrm{~m}$. 0 sombreamento resultante da cobertura das árvores faz com que o estrato arbustivo e herbáceo sejam menos adensados. O cerrado sensu stricto típico é predominantemente arbóreo-arbustivo, com cobertura arbórea de $20 \%$ a $50 \%$ e altura média de 3m a 6m (Durigan et al., 1999; Durigan et al., 2004; Ribeiro \& Walter, 2008).

A diversidade do Cerrado é elevada, embora geralmente menosprezada (Klink \& Machado, 2005). Podemos encontrar cerca de 7.000 espécies de plantas vasculares (herbáceas, arbustivas, arbóreas e cipós), sendo que $44 \%$ da flora é endêmica (Mendonça et al. 1998). A fauna de mamíferos é relativamente pequena e está principalmente associada ou restrita aos fragmentos florestais ou matas de galeria (Redford \& Fonseca, 1984; Marinho-Filho et al., 2002). A avifauna é rica, mas o nível de endemismo é baixo. Os números de peixes, répteis e anfíbios são elevados (Klink \& Machado, 2005). No entanto, pelo menos 137 espécies de animais que ocorrem no Cerrado estão ameaçadas de extinção (Fundação Biodiversitas, 2003) devido à grande expansão agrícola e intensa exploração local de produtos nativos (Klink \& Machado, 2005).

O bioma Cerrado ocorre sobre solos muito antigos, intemperizados, ácidos e depauperados de nutrientes. A pobreza dos solos, no entanto, não se constitui um obstáculo para a ocupação de grandes extensões de terra pela a agricultura moderna, já que é possível tornar tais solos produtivos para fins agrícolas através da aplicação de fertilizantes e calcário (Klink \& Machado, 2005).

Devido a isso, as transformações ocorridas no Cerrado trouxeram grandes danos ambientais, tais como a fragmentação de habitat, extinção da biodiversidade, invasão de espécies exóticas, erosão dos solos, poluição de aqüíferos, degradação de ecossistemas, alteração nos regimes de queimadas, desequilíbrios no ciclo de carbono e possivelmente modificações climáticas regionais (Klink \& Moreira, 2002 apud Klink \& Machado, 2005; Aquino \& Miranda, 2008).

No início do século, o Cerrado ocupava 14\% do Estado de São Paulo. Atualmente, os remanescentes de Cerrado cobrem menos de 1\% do Estado (espalhados por inúmeros fragmentos que, na sua maioria, estão localizados em propriedades rurais particulares) e apenas cerca da metade do que restou encontra-se protegida na forma de unidades de conservação. A forte degradação das formas florestais e 0 
quase desaparecimento das formas campestres são mudanças que se refletem na fauna reduzindo a sua diversidade de espécies. Modificações na fisionomia e principalmente a redução das áreas dos fragmentos têm levado ao desaparecimento de espécies de mamíferos de médio e grande porte neste bioma (Bitencourt \& Mendonça, 2004). 


\section{Fragmentação de Áreas Naturais}

A fragmentação de habitats existe naturalmente e vem sendo intensificado nas últimas décadas pelas atividades humanas. Assim, as práticas antrópicas de uso e ocupação da terra vêm resultando em fragmentação da vegetação natural, ocorrendo a formação de ilhas imersas em matrizes urbanas e agrosilvopastoris, com diferentes graus de permeabilidade, e que irão influenciar o tipo e a qualidade do habitat, a partir do fluxo de nutrientes e de materiais para o interior do fragmento (Collinge,1996; Cerqueira et al., 2003).

Fischer \& Lindenmayer (2007) sintetizaram os temas que estão relacionados com a modificação da paisagem e a fragmentação de habitat em um fluxograma conceitual (Figura 4).

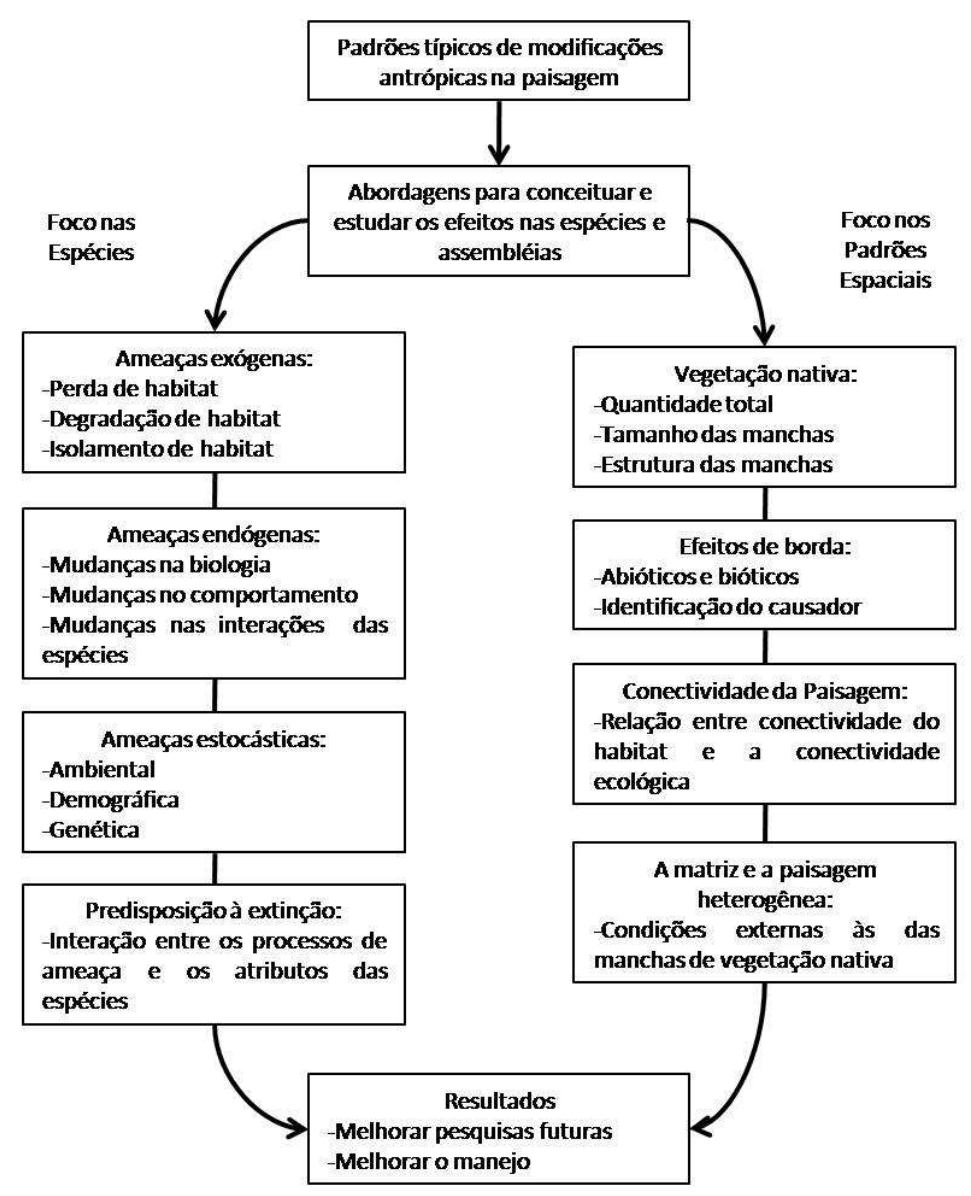

Fig.l.4. - Fluxograma conceitual sintetizando os temas relacionados à modificação da paisagem e à fragmentação de habitat (Fischer \& Lindenmayer, 2007). 
O processo de fragmentação ocasiona decréscimos no tamanho dos remanescentes, aumenta o efeito de borda, aumenta o isolamento dos fragmentos, além de ocasionar variação no grau de conectividade destes fragmentos, eliminação de espécies e redução das populações (Saunders et al., 1991; Terborgh, 1992; Noss et al., 1997; Gehring \& Swihart, 2003; Fischer \& Lindenmayer, 2007).

O aumento da extensão da margem do habitat faz com que a vegetação presente na borda de um fragmento seja exposta a uma maior quantidade de luz, o que provoca um conseqüente aumento da temperatura, e uma diminuição da umidade relativa desta região. A velocidade do vento também será maior na borda do que no interior do fragmento. Estas mudanças podem alterar significativamente as comunidades animais e vegetais residentes nesta região do fragmento. Quanto menor o fragmento, maior a extensão do efeito de borda (Murcia, 1995; Collinge, 1996; Primack \& Rodrigues, 2001; Cerqueira et al., 2003).

Em linhas gerais, a fragmentação pode ser considerada uma das mais profundas alterações ambientais causada pelo homem, já que habitats naturais contínuos são transformados em mosaicos de manchas isoladas do habitat original (Fahrig, 2003) e que possuem características diferentes em relação à área, forma, estrutura, composição, grau de isolamento, grau de conectividade, qualidade, entre outros. Para que ocorra fluxo de indivíduos de uma mancha à outra, há necessidade de que haja conectividade entre as manchas, tais como stepping Stones, corredores de mata ou ainda a presença de uma matriz permeável (Murcia, 1995; Collinge,1996; Metzger, 2000; Cerqueira et al., 2003; Creed, 2006; Paglia et al., 2006; Olifiers \& Cerqueira, 2006; Rocha et al., 2006).

A permeabilidade da matriz irá variar de acordo com o tipo (se é pasto ou lavoura, por exemplo) e é uma medida realizada em função da espécie, ou seja, uma matriz pode ser permeável para uma espécie e impermeável para outra (Primack \& Rodrigues, 2001; Jordano et al., 2006).

A fragmentação ocasiona a produção em larga escala de habitats ruins ou negativos para a maioria das espécies, restringindo a aptidão de algumas espécies (menores taxas de sobrevivência e reprodução), levando à diminuição da abundância e podendo levar à extinção local e diminuição da diversidade, com conseqüente perda de grupos funcionais (Cerqueira et al., 2003; Michalski \& Peres, 2005). 
A qualidade do habitat, a quantidade e distribuição das manchas de habitat são itens vitais para a persistência em longo prazo das espécies num determinado lugar (Vos et al. 2001, Early et al. 2008), podendo ser considerados variáveis de resposta útil para obtenção de dados de localização. Segundo Crooks (2002), a fragmentação de habitat e o isolamento dos fragmentos são os mais fortes descritores de paisagem da distribuição e abundância de predadores.

Mamíferos carnívoros são particularmente vulneráveis à extinção local em paisagens fragmentadas devido ao seu baixo número de indivíduos, às grandes áreas de vida e devido às perseguições diretas por humanos (Noss et al., 1996). Segundo Crooks \& Soulé (1999), o declínio e a extinção de predadores de topo de cadeia dos sistemas fragmentados pode gerar cascadas tróficas que alteram a estrutura das comunidades ecológicas. Sendo assim, a persistência destas espécies, sensíveis ao processo de fragmentação, pode indicar a integridade do ecossistema (Noss et al., 1996). Soulé \& Terborgh (1999 apud Crooks, 2002) afirmam que mamíferos carnívoros podem ser utilizados como ferramentas úteis para estudos de distúrbios ecológicos ou para planos de conservação e planos de implementação de reservas.

Noss et al. (1996) e Soulé \& Terborgh (1999 apud Crooks, 2002) concluem que mamíferos carnívoros podem ser excelentes organismos focais, com os quais é possível avaliar o grau funcional da conectividade da paisagem. Isto é possível porque estas espécies são dependentes da área e, sendo assim, necessitam de corredores de mata para se movimentarem e persistirem (Gehring \& Swihart, 2003).

A fauna e a flora brasileiras vêm sendo constantemente ameaçadas pelos desmatamentos, e conseqüentemente pela fragmentação das florestas (Pardini et al., 2005), o que causa a perda de habitat, a redução do tamanho populacional e o isolamento de populações locais (Saunders et al., 1991; Terborgh, 1992; Gehring \& Swihart, 2003). A preocupação com os efeitos das perturbações humanas nas comunidades biológicas é ainda mais urgente com relação aos mamíferos de médio e grande porte, pois estes necessitam de áreas comparativamente maiores (Pardini et al., 2005).

O grau de ameaça e a importância ecológica dos mamíferos terrestres de médio e grande porte tornam, portanto, evidente a necessidade de incluí-los em inventários e diagnósticos ambientais. 
Os poucos casos concretos de mitigação dos efeitos de fragmentação sempre envolveram um conjunto articulado de ações, nunca uma única ação (Rodrigues et al., 2003). Sendo assim, o trabalho em paisagens fragmentadas exige domínio de alguns métodos de trabalho totalmente divergentes em sua origem, como levantamentos da fauna e flora, geoprocessamento, Sistemas de Informação Geográfica, levantamentos históricos entre outros (Rodrigues et al., 2003). 


\section{Análise Geográfica Computadorizada}

A crescente expansão das atividades antrópicas sobre o meio ambiente tem gerado aumento expressivo da demanda por tecnologias de manejo ambiental (Trotter, 1991). A necessidade de mapeamento, manejo e monitoramento dos recursos naturais renováveis e não renováveis têm motivado o uso dos de Sistemas de Análise Geográfica Computadorizada. Tais sistemas vêm sendo cada vez mais utilizados tanto no auxílio de extração de informações como na tomada de decisões (Hara, 1997).

A utilização de imagens de satélite, de mapas existentes ou aerofotografias permite que se modelem as possíveis relações entre os habitats e as espécies. Mapas topográficos, por exemplo, podem revelar uma grande variedade de informações espaciais complexas (elevação, declividade, aspecto) em uma representação gráfica simples (Fischer et al. 2004).

Quando falamos em Análise Geográfica Computadorizada, nos referimos ao conjunto de sistemas que possibilitam o processamento e a análise de imagens de satélite (sensoriamento remoto), a geração de imagens sintéticas oriundas de mapas cartográficos e temáticos (técnicas de geoprocessamento), assim como a modelagem e as análises que os Sistemas de Informação Geográfica (SIG) proporcionam.

Os SIGs são sistemas voltados à aquisição, análise, armazenamento, manipulação e apresentação de informações referenciadas espacialmente (informações geocodificadas). Tais sistemas são ferramentas para realizar o inventário de dados geográficos, fundir dados de muitas fontes, monitorar e avaliar a condição de nosso ambiente e modelar ou predizer as conseqüências das alterações humanas no ambiente (Kimmerling, 1994; Meneguette, 1994),.

Uma vez construído, o banco de dados geo-codificado pode ser manipulado de modo a gerar novas informações importantes para tomada de decisão. Dentro do ambiente de SIG estas informações podem ser usadas para visualizar o problema, possibilitando observar, manipular e estudar os relacionamentos geográficos envolvidos, e também pode apresentar alternativas à solução do problema considerado (Egenhofer, 1990). As técnicas de geoprocessamento, assim como o 
sensoriamento remoto, vem tendo um papel relevante para o gerenciamento de recursos em todo o mundo (Hara, 1997).

Particularmente, o sensoriamento remoto é a utilização de sensores para aquisição de informações sobre objetos ou fenômenos na superfície da Terra, através da interação destes com a radiação eletromagnética. Nesse caso, a energia refletida dos "alvos", nas diferentes regiões do espectro, é registrada pelos sensores e posteriormente transformada em imagens (Lillesand \& Kiefer, 2000). É principalmente utilizado para gerar mapas temáticos que sirvam para analisar as relações estruturais e funcionais dos elementos da paisagem. Nos estudos da vegetação é utilizado para quantificar a densidade de vegetação por área através de imagens índice de vegetação, desenvolvidos para diferentes condições ambientais (Jackson \& Huete, 1991; Becerra, 2005).

Tais índices são resultantes de transformações da refletância nas faixas do vermelho e do infravermelho próximo do espectro eletromagnético, podendo incluir ainda outras faixas (Wiegand et. al,, 1991).

Segundo Becerra (2005), o índice de vegetação mais comumente utilizado é o Índice de Vegetação de Diferença Normalizada (IVDN ou NDVI), que resulta da resposta espectral da vegetação nas faixas do vermelho e do infravermelho próximo. Os valores da imagem IVDN variam de $-1 \mathrm{a}+1$ sendo a vegetação mais densa próxima de +1 .

Mesquita Jr. (1998 e 2003) testou métodos de classificação de fisionomias de cerrado utilizando imagens de satélites multiespectrais, considerando as variações fenológicas de cada fisionomia. Este autor mostrou que cada fisionomia varia diferentemente do período chuvoso ao seco: as fisionomias mais abertas sofrem grandes variações e as fisionomias mais arbustivo-arbóreas sofrem menos variações nas imagens índice de vegetação. Segundo Bitencourt (2004), o IVDN tem sido utilizado para indicar as variações estruturais destas fisionomias, bem como das florestas ripária e estacional semidecidual associadas. Assim, mapas temáticos poderão ser gerados a partir de imagens índice de vegetação os quais servirão de base para trabalhos de campo e para o desenvolvimento de modelos em ambiente de SIG. 
Becerra (2005) utilizou modelos de tomada de decisão em ambiente de SIG para modelar a pressão antrópica no entorno de fragmentos de cerrado do estado de São Paulo. Nessa tarefa, o autor relacionou espacialmente os parâmetros geomorfológicos, sócio-econômicos e vegetacionais, buscando o grau de fragilidade dos fragmentos analisados. Estes resultados também fazem parte dos produtos gerados pelo Projeto Viabilidade de Conservação dos remanescentes de Cerrado no Estado de São Paulo.

Os modelos baseados em SIG também vêm sendo utilizados comumente para determinar conectividade e dispersão de determinada espécie em paisagens complexas, além de simular movimentos de indivíduos de diversos táxons (Clevenger et al. 2002).

Dentre os modelos de tomada de decisão desenvolvidos em ambiente de SIG, existem aqueles que analisam por múltiplos critérios ou por múltiplos objetivos. Paczek (1997) utilizou Avaliação de Multicritérios (MCE - Multi Criteria Evaluation) para determinar os habitats mais apropriados para aves de estepe arbustiva e utilizou MOLA (Multi Objective Land Allocation) para alocar área para objetivos múltiplos e resolver o conflito entre o melhor habitat para as aves e o melhor habitat para o gado. 


\section{Referências Bibliográficas}

AQUINO, F.G.; MIRANDA, G.H.B. 2008. Consequencias ambientais da fragmentação de habitats no cerrado. In SANO, S.M.; ALMEIDA, S.P.; RIBEIRO, J.F. (Eds.). Cerrado: ecologia e flora. Brasília: Editora Embrapa, p.385-398.

BECERRA, J.A.B., 2005. Modelagem da Influência dos Fatores antrópicos nos remanescentes de cerrado no Estado de São Paulo. (Tese doutorado) - Programa de Ecologia IB/USP.

BITENCOURT, M.D. 2004. Diagnóstico cartográfico dos remanescentes de cerrado em São Paulo. In: BITENCOURT M.D.; MENDONÇA R.R. (Eds.) Viabilidade de conservação dos remanescentes de cerrado do estado de São Paulo. São Paulo: Annablume/FAPESP, p. 17-28.

BITENCOURT M.D.; MENDONÇA R.R. 2004. Viabilidade de conservação dos remanescentes de cerrado do estado de São Paulo. São Paulo: Annablume/FAPESP.

BITENCOURT, M D.; MESQUITA JR, H. N.; KUNTSCHIK, G.; ROCHA, H. R.; FURLEY, P. A. 2007. Cerrado vegetation study using optical and radar remote sensing: two Brazilian case studies. Canadian Journal of Remote Sensing, 33: 468480 .

BODMER, R.E.; EISENBERG, J.F., REDFORD, K.H. 1997. Hunting and the likelihood of extinction of Amazonian mammals. Conservation Biology, 11: 460-466.

CERQUEIRA, R.; BRANT, A.; NASCIMENTO, M.T.; PARDINI, R. 2003. Fragmentação: alguns conceitos. In MINISTÉRIO DO MEIO AMBIENTE SECRETARIA DE BIODIVERSIDADE E FLORESTAS. Fragmentação de ecossistemas: causa, efeitos sobre a biodiversidade e recomendações de políticas públicas. Brasília: MMA/SBF, p.23-40. 
CLEVENGER, A.P.; WIERZCHOWSKI, J.; CHRUSZCZ, B.; GUNSON, K. 2002. GIS-generated expert based models for identifying wildlife habitat linkages and mitigation passage planning. Conservation Biology, 16: 503-514.

COLLINGE, S.K., 1996. Ecological consequences of habitat fragmentation: implications for landscape architecture and planning. Landscape and Urban Planning, 36: 59-77.

COUTINHO, L. M. 2002. O bioma cerrado. In: KLEIN, A. L. 2002. Eugene Warming e o cerrado brasileiro: um século depois. São Paulo: Editora UNESP.

COUTINHO, L.M. 1978. O conceito de cerrado. Revista Brasileira de Botânica, 1: 17-23.

CREED, J.C. 2006. Perturbações em comunidades ecológicas. In ROCHA, C.F.D.; BERGALLO, H. G.; SLUYS, M.V.; ALVES, M.A.S. (Eds.). Biologia da Conservação: Essências. São Carlos: Editora Rima, p.183-209.

CROOKS, K. R.; SOULÉ M. E. 1999. Mesopredator release and avifaunal extinctions in a fragmented system. Nature, 400:563-566.

CROOKS, K.R., 2002. Relative Sensitivies of Mammalian Carnivores to Habitat Fragmentation. Conservation Biology, 16: 488-502.

De VIVO, M. 1996. Estudo da diversidade de espécies de mamíferos no Estado de São Paulo. <http://www.biota.org.br/info/historico/workshop/revisoes/mamiferos.pdf>

DURIGAN, G.; BACIC, M.C.; FRANCO, G.A.D.C. SIQUEIRA, M.F. 1999. Inventário florístico na Estação Ecológica de Assis. Hoehnea, 26:149-172.

DURIGAN, G.; FRANCO, G.A.D.C.; SIQUEIRA, M.F. 2004. A vegetação remanescente de cerrado no Estado de São Paulo. In: BITENCOURT M.D.; MENDONÇA R.R. (Eds.) Viabilidade de conservação dos remanescentes de cerrado do estado de São Paulo. São Paulo: Annablume/FAPESP, p. 17-28.

EARLY, R.; ANDRESON, B.; THOMAS, C.D. 2008. Using habitat distribution models to evaluate large scale landscape priorities for spatially dynamic species. Journal of Applied Ecology, 45: 228-238. 
EGENHOFER, M. Interation with Geographic Information Systems via spacial queries. Journal of Visual Languages and Computing, 4: 389-413.

FAHRIG, L. 2003. Effects of habitat fragmentation on biodiversity. Annual Review in Ecology and Systematics, 34: 487-515.

FISCHER, J.; LIDENMAYER, D.B.; FAZEY, I. 2004. Appreciating Ecological Complexity: habitat contours as a conceptual landscape model. Conservation Biology, 18: 1245-1253.

FISCHER, J.; LIDENMAYER, D.B. 2007. Landscape modification and habitat fragmentation: a synthesis. Global Ecology and Biogeography, 16: 265-280.

FISZON, J.T.; MARCHIORO, N.P.X.; BRITEZ, R, M.; CABRAL, D.C.; CAMELY, N.C.; CANAVESI, V.; CASTELLA, P.R.; CASTRO, E.B.V.; CULLEN, L.; CUNHA, M.B.S.; FIGUEIREDO, E. O.; FRANKE, I.L.; GOMES, H.; GOMES, L.J.; HREISEMNOU, V.H.V.; LANDAU, E.C.; LIMA, S.M.F.; LOPES, A.T.L.; NETO, E.M.; MELLO, A.L.; OLIVEIRA, L.C.; ONO, K.Y.; PEREIRA, N.W.V.; RODRIGUES, A.S.; RODRIGUES, A.A.F.; RUIZ, C.R.; SANTOS, L.F.G.L.; SMITH, W.S.; SOUZA, C.R. 2003. Causas antrópicas. In MINISTÉRIO DO MEIO AMBIENTE - SECRETARIA DE BIODIVERSIDADE E FLORESTAS. Fragmentação de ecossistemas: causa, efeitos sobre a biodiversidade e recomendações de políticas públicas. Brasília: MMA/SBF, p.66-99.

FUNDAÇÃO BIODIVERSITAS. 2005. Lista da fauna brasileira ameaçada de extinção. Belo Horizonte: Fundação Biodiversitas. <http://www.biodiversitas.org.br>

GEHRING, T.M., SWIHART, R.K., 2003. Body Size, Niche Breadth and Ecologically Scaled Responses to Habitat Fragmentation: Mammalian Predators in an Agricultural Landscape. Biological Conservation, 109: 283-295.

HARA, L. T. 1997. Técnicas de apresentação de dados em geoprocessamento. (Dissertação de Mestrado) - Instituto de Pesquisas Espaciais - INPE.

IBGE- INSTITUTO BRASILEIRO DE GEOGRAFIA E ESTATÍSTICA. 1993. Mapa de vegetação do Brasil (escala 1: 5.000.000). Rio de Janeiro. 
JACKSON, R.D.; HUETE, A.R. 1991. Interpreting vegetation indices. Preventive veterinary medicine, 11: 185-200.

JONES, K. B.; EDMONDS, C. E.; SLONECKER, E. T.; WICKHAM, J. D.; NEALE, A. C.; WADE, T. G.; RIITTERS, K..; KEPNER, W. G. 2008. Detecting changes in riparian habitat conditions based on patterns of greenness change: a case study from the upper San Pedro River Basin, USA. Ecological Indicators, 8: 89-99

JORDANO, P.; GALETTI, M.; PIZO, M.A.; SILVA, W.R. 2006. Ligando frugivoria e dispersão de sementes à Biologia da Conservação. In ROCHA, C.F.D.; BERGALLO, H. G.; SLUYS, M.V.; ALVES, M.A.S. (Eds.). Biologia da Conservação: Essências. São Carlos: Editora Rima, p.411-436.

KIMMERLING, A. J. Geographical information systems and cartography. Proceedings of the seminar on teaching convencional and digital map prodution lines, 35-47.

KIERULFF, M.C.M.; OLIVEIRA, P.P.; MARTINS, C.S.; VALLADARES-PÁDUA, C.B.; PORFÍRIO, S.; OLIVEIRA, M.M.; RYLANDS, A.B.; BEZERRA, A.R.G.F. 2007. Manejo para a conservação de primatas brasileiros. In: BICCA-MARQUES, J.C. (Ed.) A Primatologia no Brasil. Porto Alegre, p. 71-100.

KLINK, C.A.; MACHADO, R.B. 2005. A conservação do cerrado brasileiro. Megadiversidade, 1: 147-155.

KÖPPEN, W. 1948. Climatologia com um estudio de los climas de la tierra. México: Fondo de Cultura Econômica.

KRONKA, F., MATSUKUMA, C.K., NALON, M.A., DEL CALI, I.H., ROSSI, M., MATTOS, I.F.A., SHIN-IKE-YWANE, M.S. \& PONTINHAS, A.A.S. 1993. Inventário florestal do Estado de São Paulo. Instituto Florestal do Estado de São Paulo. São Paulo: SMA.

KRONKA, F. 1998. Áreas de domínio do cerrado no estado de São Paulo. São Paulo: SMA. 
KUNTSCHIK, G. 2004. Estimativa de fitomassa lenhosa por meios não destrutivos em cerrado sensu stricto e cerradão através de sensoriamento remoto óptico e banda L. (Tese doutorado) - Programa de Ecologia IB/USP.

LILLESAND, T.M.; KIEFER, R.W. 2000. Remote sensing and image interpretation. Ed. John Wiley \& Sons Inc.

MARINHO-FILHO, J.; RODRIGUES, F.H.; JUAREZ, K.M. 2002. The cerrado mammal's: diversity ecology and natural history. In: OLIVEIRA, P.S.; MARQUIS, R.J. The cerrados of Brazil: ecology and natural history of a neotropical savanna. New York: Columbia University Press, p.266-284.

MENDONÇA, R.J.; FELFILI, B. W.; SILVA, J.C.J.; REZENDE, T.F.; NOGUEIRA, P. 1998. Flora vascular do cerrado. In: SANO, S.; ALMEIDA, S. Cerrado: ambiente e flora. Brasília: Editora EMBRAPA, p 288-556.

MENEGUETTE, A. A. C. 1994. Introdução à cartografia. Presidente Prudente: [s.n.].

MESQUITA JR, H.N. 1998. Análise temporal com sensor orbital de unidades fisionômicas de cerrado na Gleba Pé-de-Gigante (Parque Estadual de Vassununga - SP). (Dissertação de Mestrado) - Programa de Ecologia IB/USP.

MESQUITA JR. H.N. 2003. Modelagem das variações da resposta espectral das fisionomias de cerrado em relação às variações climáticas sazonais. (Tese doutorado) - Programa de Ecologia IB/USP.

METZGER, J.P. 2000. Tree functional group richness and landscape structure in a tropical fragmented landscape in SE Brazil. Ecological application, 10: 1147-1161.

MIATTO, R.C.; SILVA-MATOS, D.M.; SILVA, I. A. 2008. Diversidade de espécies arbóreas em uma área de cerrado dominada por Pteridium arachnoideum (Kaulf.) Maxon (Dennstaedtiaceae) no Estado de São Paulo. Anais de Eventos da UFSCar, 4: 199.

MICHALSKI, F.; PERES, C.A. 2005. Anthropogenic determinants of primate and carnivore local extinctions in a fragmented forest landscape of southern Amazonia. Conservation Biology, 21: 1626-1640. 
MICHALSKI, F.; PERES, C.A. 2007. Disturbance-Mediated Mammal Persistence and Abundance-Area Relationships in Amazonian Forest Fragments. Conservation Biology, 124: 383-396.

MURCIA, C. 1995. Edge effects in fragmented forests: implications for conservation. Trend in Ecology and Evolution, 10: 58-62.

MYERS, N.; MITTERMEIER, R. A.; MITTERMEIER, C. G.; FONSECA, G.A.B.; KENT, J. 2000. Biodiversity hotspots for conservatin priorities. Nature, 403: 853-858.

NOSS, R. F.; QUIGLEY H. B.; HORNOCKER M. G.; MERRILL T.; PAQUET P. C. 1996. Conservation biology and carnivore conservation in the Rocky Mountains. Conservation Biology, 10: 949-963.

NOSS, R.F., CSUTI, B. 1997. Habitat fragmentation. In: MEFFE, G.K.,CARROLL, C.R. (Eds.). Principles of Conservation Biology. Sunderland: Sinauer Associates, p. 269-304.

NOWAK, R.M. 1999. Walker's mammals of the world.The Johns Hopkins University Press, 6 ed., v.1.

OLIFIERS, N.; CERQUEIRA, R. 2006. Fragmentação de habitat: efeitos históricos e ecológicos. In ROCHA, C.F.D.; BERGALLO, H. G.; SLUYS, M.V.; ALVES, M.A.S. (Eds.). Biologia da Conservação: Essências. São Carlos: Editora Rima, p.261-279.

OLIVEIRA, J.B.; CAMARGO, M.N.; ROSSI, M.; CALDERANO FILHO, B. 1999. Mapa pedológico do Estado de São Paulo. Rio de Janeiro: Embrapa.

PARDINI, R., SOUZA, S.M., BRAGA-NETO, R., METZGER, J.P., 2005. The Role of Structure, Fragment Size and Corridors in Maintaining Abundance and Diversity in a Atlantic Forest Landscape. Biological Conservation, 124: 253-266.

PACZEK, S. 1997. Habitat Management of Shrub Steppe birds in the South Okanagan: Applications of GIS. Term Project for Geography, University of British Columbia. <http://www.geog.ubc.ca/courses/klink/g470/class97/paczek/project.html>

PAGLIA. A.P.; FERNANDEZ, F.A.S.; de MARCO JR. P. 2006. Efeitos da fragmentação de habitats: quantas espécies, quantas populações, quantos 
indivíduos, e serão eles suficientes? In ROCHA, C.F.D.; BERGALLO, H. G.; SLUYS, M.V.; ALVES, M.A.S. (Eds.). Biologia da Conservação: Essências. São Carlos: Editora Rima, p.281-316.

PRIMACK, R.B.; RODRIGUES E. 2001. Biologia da Conservação. Londrina: Editora Planta.

REDFORD, K.H; .FONSECA, G.A.B. 1984. The Mammals of IBGE'S Ecological Reserve, Brasilia, and an Analysis of the Role of Gallery Forests in Increasing Diversity. Revista Brasileira de Biologia, 4: 517-523.

REIS, N.R.; PERACCHI, A.L; PEDRO, W.A.; LIMA, I.P. 2006. Mamíferos do Brasil. Londrina.

RIBEIRO, J.F.; WALTER, B.M.T. 2008. As principais fitofisionomias do bioma cerrado. In SANO, S.M.; ALMEIDA, S.P.; RIBEIRO, J.F. (Eds.). Cerrado: ecologia e flora. Brasília: Editora Embrapa, p.153-212.

ROCHA, C.F.D.; BERGALLO, H.G.; SLUYS, M.V.; ALVES, M.A.S.; JENKINS, C. 2006. Corredores ecológicos e conservação da biodiversidade: um estudo de caso na mata atlântica. In ROCHA, C.F.D.; BERGALLO, H. G.; SLUYS, M.V.; ALVES, M.A.S. (Eds.). Biologia da Conservação: Essências. São Carlos: Editora Rima, p.317-342.

RODRIGUES, E.; CAINZOS, R.L.P.; QUEIROGA, J.; HERRMANN, B. C. 2003. Conservação em paisagens fragmentadas. In: CULLEN, L.; RUDRAN, R.; PADUA, C. V. 2003. Métodos de Estudo em Biologia da Conservação e Manejo da Vida Silvestre. Curitiba: Editora UFPR.

SAUNDERS, D.A., HOBBS, R.J., MARGULES, C.R. 1991. Biological consequences of ecosystem fragmentationa review. Conservation Biology, 5: 18-32.

SMA - SECRETARIA DO MEIO AMBIENTE DO ESTADO DE SÃO PAULO. 1999. Conhecer para conservar: as unidades de conservação do estado de São Paulo. São Paulo: SMA. 
SIGRH - SISTEMA INTEGRADO DE GERENCIAMENTO DE RECURSOS HÍDRICOS. Consulta a banco de dados em 10 de junho de 2009. <http://www.sigrh.sp.gov.br/cgi-bin/bdhm.exe/plu?qwe=qwe>

TERBORGH, J. 1992. Maintenance of diversity in tropical forests. Biotropica, 24: 283-292.

TROTTER, C. M. 1991. Remontelly sensed data as an information source for GIS in natural resource management: a review. International Journal of Geographical Information Systems, 2: 225-239.

VIEIRA, M.V.; FARIA, D.M.; FERNANDEZ, F.A.S.; FERRARI, S.F.; FREITAS, S.R.; GASPAR, D.A.; MOURA, R.T.; OLIFIERS, N.; OLIVEIRA, P.P.; PARDINI, R.; PIRES, A.S.; RAVETTA, A.; MELLO, M.A.R.; RUIZ, C.R.; SETZ, E.Z.F. 2003. Mamíferos. In MINISTÉRIO DO MEIO AMBIENTE - SECRETARIA DE BIODIVERSIDADE E FLORESTAS. Fragmentação de ecossistemas: causa, efeitos sobre a biodiversidade e recomendações de políticas públicas. Brasília: MMA/SBF, p.125151.

XAVIER, R.O.; DODONOV, P.; SILVA-MATOS, D. M. 2008. Dinâmica do banco de sementes em áreas dominadas por Pteridium arachnoideum (Kaulf.) Maxon em uma área de cerrado em São Carlos, SP. Anais de Eventos da UFSCar, 4: 82.

VOS, C.C; VERBOOM J.; OPDAM, P.F.M.; TER BRAAK, C.J.F. 2001. Toward ecologically scaled landscape indices. American Naturalist,157: 24-41.

WIEGAND, C.L.; RICHARDSON, A.J.; ESCOBAR, D.E. 1991. Vegetation indices in crop assessment. Remote sensing of environment, 35: 105-119. 


\section{Capítulo II}

Elaboração da Base Cartográfica para Amostragem e Análise de Dados de Mamíferos de Médio e Grande Porte

Abstract

Resumo .32

Introdução .33

Materiais e Métodos .36

Mapa Geral de Caracterização Ambiental ...........................................................36

Mapa de Caracterização Ambiental da Mata Ripária ...........................................42

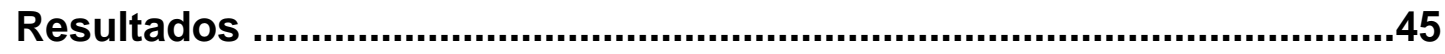

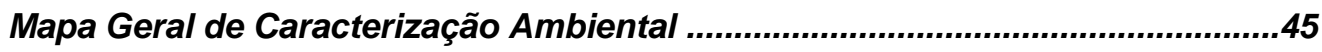

Mapa de Caracterização Ambiental da Mata Ripária .........................................51

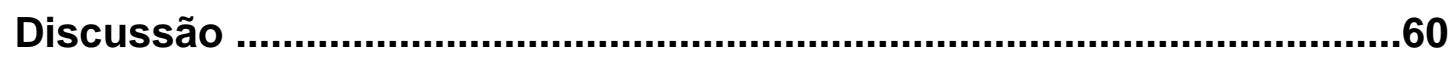

Mapa Geral de Caracterização Ambiental ........................................................60

Mapa de Caracterização Ambiental da Mata Ripária ...........................................61

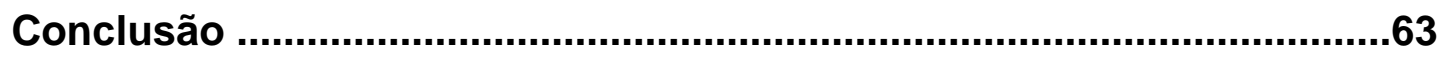

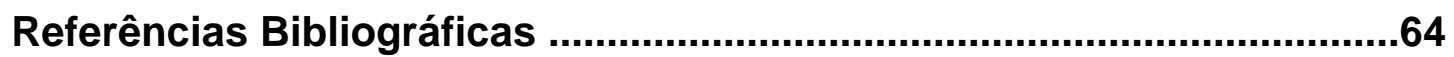




\begin{abstract}
The remote sensing allows us to extract information concerning natural areas and allows us to develop vegetation and environmental quality thematic maps. With cartographic knowledge you can create maps that optimize the field work and allow us to select the most appropriate area for data collection. However, is needed previously know of your study area by visiting field, so that spatial analysis is able to produce maps closer to reality. In this present Study a protocol of spatial analysis was presented, which aimed the generation of two thematic maps: (a) General Map of Environmental Characterization, developed to provide a simple base map of environmental quality of the study area for allocation of plots of footprints, camera traps and transects, to obtain a wealth of data and frequency of medium and largesized mammals in future stage; (b) Statement of Environmental Characterization of Riparian Forest, developed to assess the structure and quality of riparian forest and subsequently allow a better assessment of its use by mammals of medium and large-sized. The spatial analysis developed to preparation of these maps was satisfactory, reaching the goals that it was submitted. However, we could not exclude the possibility of some degree of inaccuracy of the classification of images NDVI and LAI due to the overlapping of these values between the vegetation indices that have similar spectral behavior.
\end{abstract}

Key words: Remote Sensing, Geographic Information System, Geoprocessing technics, Cerrado Biome, Riparian Forest, Habitat quality 


\section{Resumo}

O sensoriamento remoto permite extrair informações sobre áreas naturais e compor mapas temáticos de cobertura vegetal e qualidade ambiental. Em conjunto com conhecimentos de cartografia, é possível elaborar mapas que otimizem os trabalhos de campo e permitem selecionar áreas mais apropriadas para coleta dos dados. Entretanto, existe a necessidade de se conhecer o seu alvo de estudo por meio de visita a campo, para que a análise espacial seja capaz de elaborar mapas mais próximos da realidade. Neste trabalho foi apresentado um protocolo de análise espacial, que objetivou a geração de dois mapas temáticos de caracterização ambiental: (a) Mapa Geral de Caracterização Ambiental, desenvolvido para fornecer uma base cartográfica simples de qualidade ambiental da área de estudo, para alocação dos canteiros de pegadas, armadilhas fotográficas e transecções, para obtenção de dados de riqueza e freqüência de ocorrência de mamíferos de médio e grande, em etapa futura; (b) Mapa de Caracterização Ambiental da Mata Ripária, desenvolvido para avaliar a estrutura e qualidade da mata ripária, assim como para possibilitar posteriormente uma melhor avaliação de seu uso por mamíferos de médio e grande porte. A análise espacial desenvolvida para a elaboração destes mapas mostrou-se satisfatória, atingindo os objetivos a que foi submetida. Entretanto, não foi possível excluir a possibilidade de ocorrência de algum grau de inexatidão da classificação das imagens IVDN e IAF, devido à sobreposição de valores destes índices entre as fitofisionomias que apresentam comportamento espectral semelhante.

Palavras chave: Sensoriamento Remoto, Sistema de Informação Geográfica, Geoprocessamento, Bioma Cerrado, Mata Ripária, Qualidade de Habitat 


\section{Introdução}

O sensoriamento remoto orbital (aéreo ou orbital) permite extrair uma série de informações sobre áreas naturais e compor mapas temáticos de cobertura vegetal e qualidade ambiental, entre outros (Bitencourt \& Mesquita Jr., 2005).

A interpretação das informações numa imagem obtida por satélite depende do conhecimento da resolução espacial da mesma, do objeto de estudo (campo), de como o alvo interage com a radiação eletromagnética e seu comportamento espectral nas faixas conhecidas (fundamentos de sensoriamento remoto), além do conhecimento das técnicas disponíveis de geoprocessamento e Sistemas de Informação Geográfica - SIG (Moreira, 2003; Bitencourt \& Mesquita Jr., 2005).

Baseando-se no sensoriamento remoto e em conhecimentos de cartografia, é possível elaborar mapas que otimizem os trabalhos de campo e, em alguns casos, permitem selecionar áreas mais apropriadas para coleta dos dados (Bitencourt \& Mesquita Jr., 2005).

Em estudos aplicados na ecologia de paisagem, o sensoriamento remoto é principalmente utilizado para classificar e analisar as relações estruturais e funcionais dos elementos da paisagem e nos estudos da vegetação é usado para quantificar a densidade de vegetação por área através do uso de índices de vegetação desenvolvidos para diferentes condições ambientais (Jackson \& Huete, 1991; Becerra, 2005). Tais índices de vegetação são resultantes de transformações da refletância nas faixas do vermelho e do infravermelho próximo do espectro eletromagnético, podendo incluir ainda outras faixas (Wiegand et. al, 1991).

Os índices de vegetação são muito úteis para estudos ecológicos, pois quantificam a presença e a ausência de folhas verdes na superfície, tornando-se um bom indicador de fitomassa foliar. Dentre os índices de vegetação existentes, o Índice de Vegetação de Diferença Normalizada (IVDN ou NDVI) é o que tem sido mais utilizado para análise das fitofisionomias de médio porte, como o cerrado (Moreira, 2003; Becerra, 2005; Bitencourt \& Mesquita Jr., 2005; Mesquita Jr. et al., 2005; Duchemin et al. 2006; Bitencourt et al. 2007). 
Matematicamente, as imagens índice de vegetação são modelos numéricos que derivam da assinatura espectral da vegetação e guardam relação direta com a fitomassa foliar verde, enquanto que, computacionalmente, estes índices são algoritmos que transformam valores de reflectância em uma nova imagem, onde os pixels que a compõem receberão os valores do índice (Kuntschik, 2004).

As imagens índice de vegetação são relacionadas a variáveis ambientais, tais como quantidade de biomassa da vegetação fotossinteticamente ativa ou o índice de área foliar (IAF) (Bitencourt et al., 2007).

O IAF é a relação entre a superfície de folhas do dossel e a superfície de sua projeção no terreno. Duchemin et al. (2006) propuseram um índice de área foliar obtido a partir de imagens IVDN. Segundo Bitencourt et al. (2007), o IAF varia de 1 (vegetação mais rala e seca) a 8 (floresta tropical pluvial), enquanto o IVDN varia de -1 a +1 , sendo a vegetação mais densa próxima de +1 . Segundo Jackson \& Huete (1991), a relação entre a imagem IVDN e o IAF é exponencial, com o IAF saturando em 4.

Entretanto, para utilizar os índices de vegetação, há a necessidade de se conhecer o padrão sazonal do ecossistema, escolhendo imagens de datas convenientes, já que a sazonalidade (perda de folhas, por exemplo) altera estas imagens (Bitencourt \& Mesquita Jr., 2005; Bitencourt et al., 2007).

Para estudos no bioma cerrado é mais conveniente utilizar imagens obtidas durante a estação seca, pois nesta estação ocorre um maior contraste entre as fitofisionomias deste bioma. Na estação chuvosa ocorre aumento da densidade de biomassa foliar, o que causa sobreposição dos valores das imagens índice de vegetação, ou seja, os comportamentos espectrais das fitofisionomias se assemelham mais, dificultando a classificação das imagens (Mesquita Jr. et al., 2005; Martins et al., 2009; Silveira et al., 2009).

Bitencourt et al. (2007) analisaram o comportamento espectral das fitofisionomias de cerrado na estação seca e chuvosa, em uma Unidade de Conservação no estado de São Paulo. As imagens IVDN no campo cerrado apresentaram grande variação entre as estações (1,15 a 2,32), enquanto que o cerradão variou de 1,89 a 2,85 . Todas as fitofisionomias apresentaram valores de IAF abaixo de 4 , indicando 
que o IVDN é suficientemente bom para realização de análises em fitofisionomias do cerrado.

O uso de imagens IVDN ou IAF, em conjunto com informações vetoriais, tais como drenagem, estradas e linha de transmissão de energia, permite a análise da qualidade ambiental de remanescentes de cerrado. Esta análise pode ser direcionada para vários grupos de organismos, como é o caso dos mamíferos de médio e grande porte, em especial, neste trabalho.

Este capítulo apresenta um protocolo de análise espacial, que objetivou a geração de dois mapas temáticos de caracterização ambiental:

- Mapa Geral de Caracterização Ambiental: desenvolvido para fornecer uma base cartográfica simples de qualidade ambiental da área de estudo, para alocação dos canteiros de pegadas, armadilhas fotográficas e transecções, para obtenção de dados de riqueza e freqüência de ocorrência de mamíferos de médio e grande;

- Mapa de Caracterização Ambiental da Mata Ripária: desenvolvido para avaliar a estrutura e qualidade da mata ripária, assim como para possibilitar uma melhor avaliação de seu uso por mamíferos de médio e grande porte.

A análise espacial aqui desenvolvida buscou espacializar a heterogeneidade do ambiente, possibilitando a exploração da diversidade de habitats existentes no remanescente de cerrado. Desta forma, os mapas finais produzidos nesta etapa serão utilizados como uma fonte de dados preliminares e complementares que posteriormente servirão como base para a seleção dos pontos de amostragem, assim como para auxiliar a análise dos dados, de mamíferos de médio e grande porte. 


\section{Materiais e Métodos}

\section{Mapa Geral de Caracterização Ambiental}

Para a elaboração do Mapa Geral de Caracterização Ambiental, foram utilizados:

\section{(A) Materiais}

- Programa IDRISI Andes, desenvolvido pela Clark University (Eastman, 2006);

- Imagens do satélite CBERS-2 de 06/09/2006 (resolução espacial de 20 × 20 metros) na estação seca;

- Carta do IBGE (1975) - Campos Novos Paulista (escala 1:50.000);

- Base de dados do projeto Viabilidade de Conservação dos Remanescentes de Cerrado no Estado de São Paulo - Biota;

- Dados georreferenciados obtidos durante as campanhas de campo (fevereiro e julho de 2007) com o auxílio de GPS (Global Position System), datum Córrego Alegre.

\section{(B) Métodos}

Trabalhos de Campo

A primeira campanha de campo foi realizada em fevereiro de 2007, buscando conhecer previamente o objeto de estudo (fragmento de cerrado situado no município de Campos Novos Paulista). Sendo assim, foram fotografados e georreferenciados (por meio de GPS) alguns corpos d'água, as fitofisionomias de cerrado observadas em algumas áreas do fragmento e as estradas.

Este levantamento foi realizado durante três dias em áreas de fácil acesso, ou seja, por meio de estradas ou trilhas pré-existentes utilizadas pelos pesquisadores do projeto Viabilidade de Conservação dos Remanescentes de Cerrado no Estado de 
São Paulo - Biota.

Como as cartas do IBGE muitas vezes apresentam discrepância com os dados obtidos no campo (diferenças entre as posições geográficas), houve a necessidade de realização de mais uma campanha de campo, realizada em julho de 2007 durante cinco dias. Desta forma, foram coletados dados de referência, por meio de GPS, para refinar o georreferenciamento de todas as imagens e vetores (drenagem, estradas, linha de transmissão de energia e perímetro do fragmento). A imagem índice de vegetação foi levada a campo para aferição de sua classificação. Nesta etapa também foi elaborado diagrama de perfil da estrutura da vegetação para caracterizar as fitofisionomias encontradas.

\section{Análise Computacional}

Os dados referentes ao relevo foram obtidos a partir da Carta do IBGE (1975) Campos Novos Paulista (escala 1:50.000). Desta carta foram digitalizadas as curvas de nível, que foram convertidas, em ambiente computacional, numa imagem sintética de superfície com resolução espacial de $20 \times 20$ metros, denominada Modelo Numérico do Terreno (MNT).

O MNT foi gerado em ambiente de SIG (Sistemas de Informação Geográfica) a partir da técnica de interpolação espacial, que cria superfícies contínuas a partir de amostras pontuais, estimando valores de pontos desconhecidos a partir de pontos com valores conhecidos (Figura II.1).

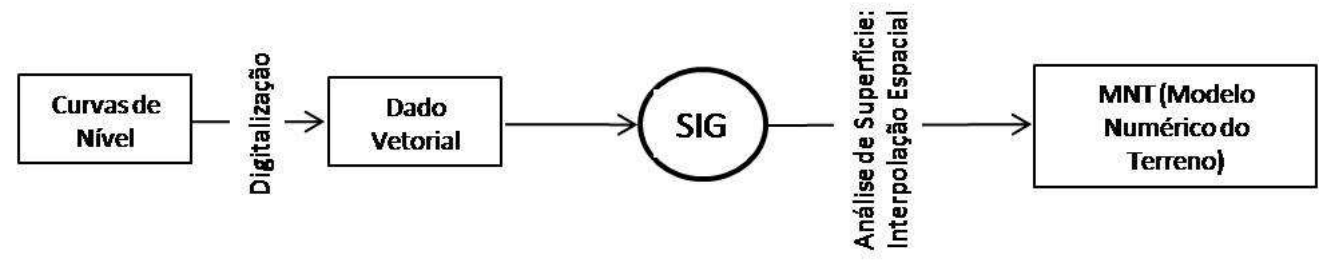

Fig.Il.1. - Procedimentos para elaboração do Modelo Numérico de Terreno (MNT). 
O Mapa Hipsométrico (classes de altitude) foi gerado a partir da reclassificação da imagem MNT, enquanto o Mapa Clinográfico (classes de declividade) foi obtido a partir do módulo SLOPE do SIG (Figura II.2).

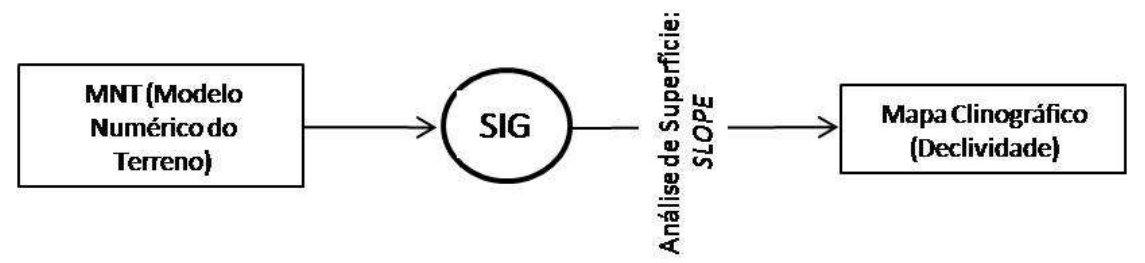

Fig.Il.2. - Procedimentos para elaboração do Mapa Clinográfico.

A tabulação cruzada dos mapas Hipsométrico e Clinográfico, em ambiente de SIG, permitiu a geração do Mapa de Relevo (Figura II.3).

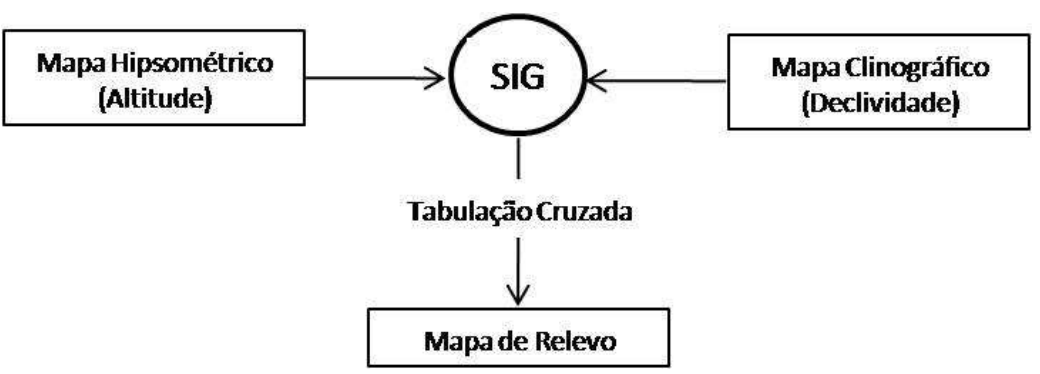

Fig.II.3. - Procedimentos para elaboração do Mapa de Relevo.

Os dados referentes ao sistema viário e drenagem foram obtidos da Carta do IBGE (1975) - Campos Novos Paulista (escala 1:50.000). Estes dados cartográficos foram transferidos para 0 ambiente digital por meio da digitalização da carta e atualizados por meio de imagens do satélite CBERS-2 de 06/09/2006, juntamente com os pontos fixos, obtidos por meio de GPS, na etapa de campo. 
A linha de transmissão de energia foi determinada por meio de imagens do satélite CBERS-2 de 06/09/2006 e de dados georreferenciados obtidos em pontos fixos, por meio de GPS, na etapa de campo.

$\mathrm{O}$ arquivo digital do polígono do fragmento foi obtido da base de dados do projeto Viabilidade de Conservação dos Remanescentes de Cerrado no Estado de São Paulo - Biota (http://eco.ib.usp.br/lepac/biota-cerrado). Este polígono foi atualizado por meio de imagens do satélite CBERS-2 de 06/09/2006 e de dados georreferenciados obtidos em pontos fixos, por meio de GPS, na etapa de campo.

O Mapa de Fitofisionomias foi desenvolvido a partir de imagens obtidas pelo satélite CBERS-2 de 06/09/2006, nas faixas do vermelho e do infravermelho próximo, transformadas em imagem Índice de Vegetação de Diferença Normalizada (IVDN) e classificadas conforme a literatura (Mesquita Jr., 1998 e 2003) (Figura II.4).

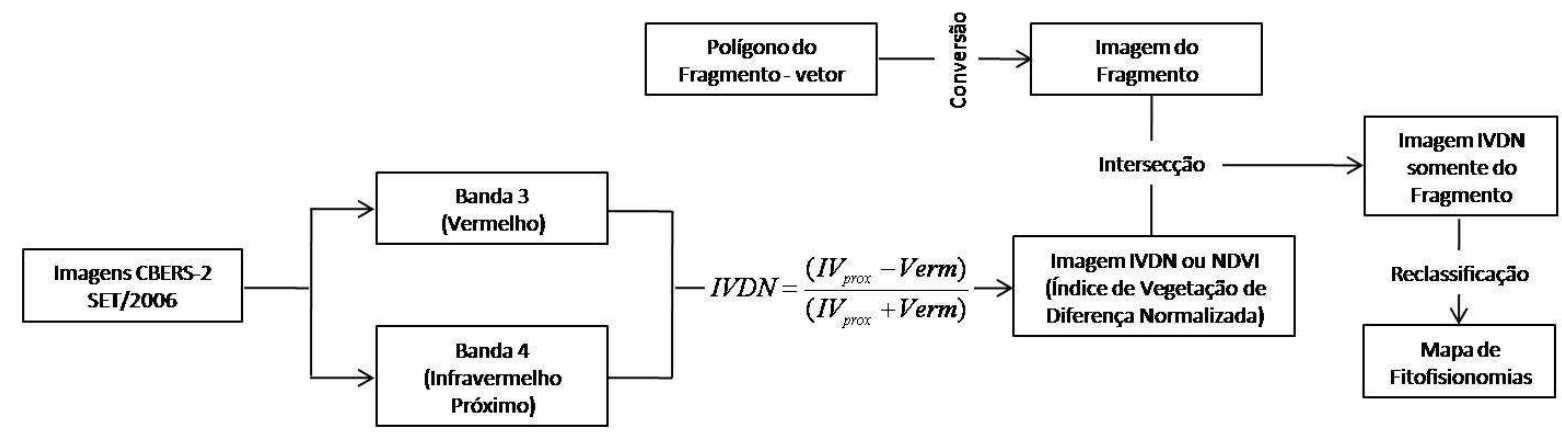

Fig.Il.4. - Procedimentos para elaboração do Mapa de Fitofisionomias.

O polígono do fragmento (vetor) foi utilizado para criar uma máscara que restringiu a análise de fitofisionomias somente ao interior do fragmento. Para isto, o vetor foi convertido para imagem com resolução de $20 \times 20$ metros. Posteriormente, a imagem do fragmento foi multiplicada com a imagem IVDN. Trata-se de uma operação matricial que promove a intersecção das duas imagens, ou seja, o produto gerado da multiplicação é um mapa que apresenta somente o que há de comum entre as duas imagens utilizadas no processo. 
A união do Mapa de Relevo, do Mapa de Fitofisionomias e dos vetores (drenagem, linha de transmissão e sistema viário) resultou no Mapa Geral de Caracterização Ambiental.

A Figura II.5 sumariza as etapas para elaboração deste mapa. 


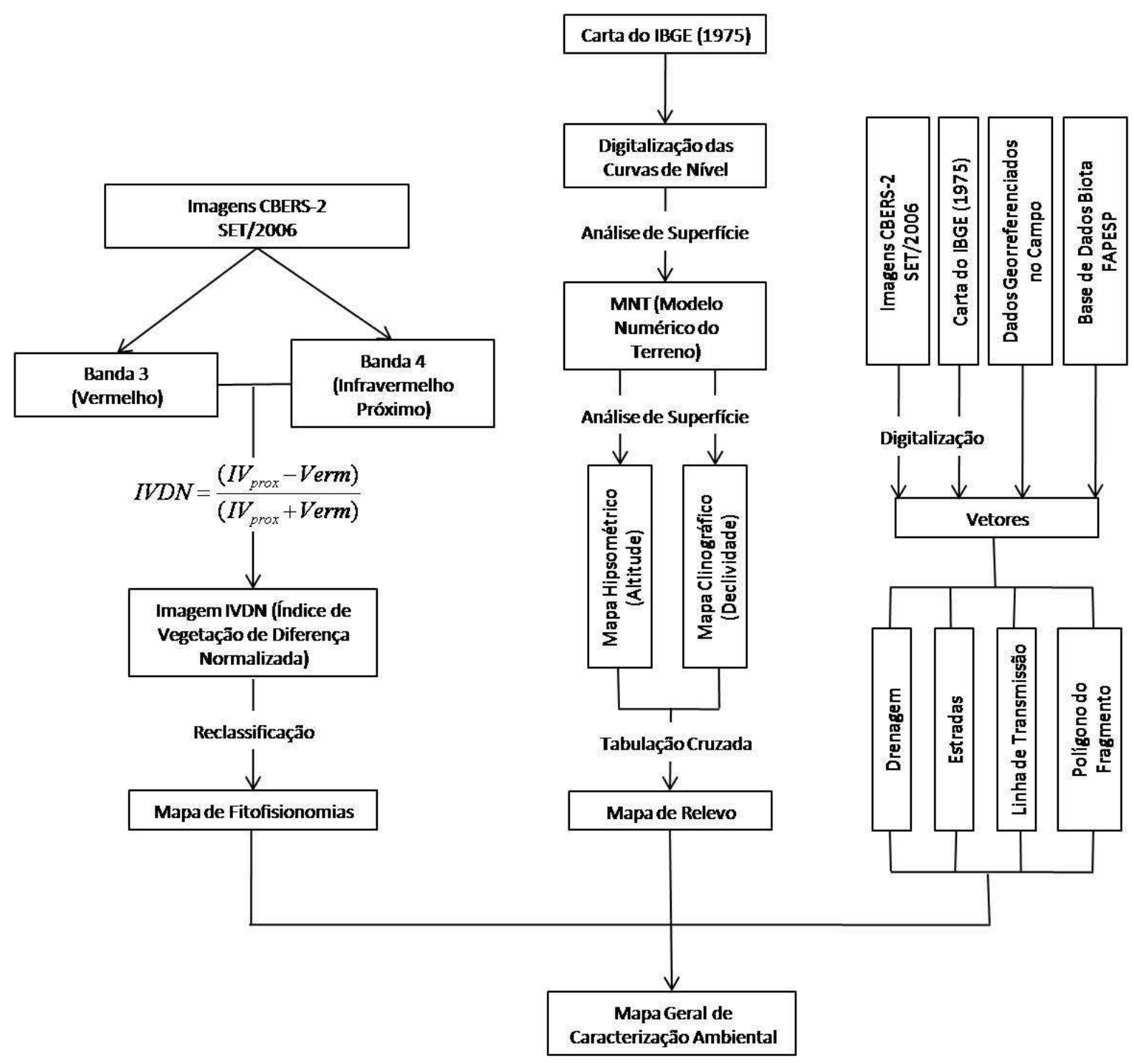

IV $V_{\text {prox: }}$ energia refletida na região do infravermelho próximo;

Verm: energia refletida na região do vermelho do espectro eletromagnético.

Fig.Il.5. - Fluxograma apresentando as etapas (obtenção dos dados, procedimentos e produtos finais) da análise em ambiente de SIG, para elaboração do Mapa Geral de Caracterização Ambiental. 


\section{Mapa de Caracterização Ambiental da Mata Ripária}

Para a elaboração do Mapa de Caracterização Ambiental da Mata Ripária, foram utilizados:

\section{(C) Materiais}

- Programa IDRISI Andes, desenvolvido pela Clark University (Eastman, 2006);

- Imagens do satélite CBERS-2 de 06/09/2006 (resolução espacial de 20 × 20 metros) na estação seca;

- Carta do IBGE (1975) - Campos Novos Paulista (escala 1:50.000);

- Dados georreferenciados obtidos durante as campanhas de campo (fevereiro e julho de 2007, março e abril de 2008) com o auxílio de GPS (Global Position System), datum Córrego Alegre.

\section{(D) Métodos}

\section{Trabalhos de Campo}

Os procedimentos referentes à primeira e à segunda campanha de campo (fevereiro e julho de 2007) equivalem ao descrito anteriormente para o desenvolvimento do Mapa Geral de Caracterização Ambiental.

No entanto, para a elaboração do Mapa de Caracterização Ambiental da Mata Ripária, foi necessária mais uma campanha de campo, que compreendeu os meses de março a abril de 2008.

Nesta campanha foram desenvolvidos diagramas de perfis de estrutura da vegetação, em oito pontos pré-estabelecidos nos complexos ripários, dentro e fora do fragmento, a partir de imagens do satélite CBERS-2 de 06/09/2006, buscando melhor descrever o relevo e a estrutura da vegetação nestes ambientes. 


\section{Análise Computacional}

Os dados referentes à drenagem foram obtidos da Carta do IBGE (1975) - Campos Novos Paulista (escala 1:50.000). Estes dados cartográficos foram transferidos para o ambiente digital por meio da digitalização da carta e atualizados por meio de imagens do satélite CBERS-2 de 06/09/2006 e de dados georreferenciados obtidos em pontos fixos, por meio de GPS, na etapa de campo.

O MNT foi utilizado nesta etapa para determinar as prováveis áreas de inundação da região estudada.

$O$ vetor de drenagem foi convertido para imagem com resolução de $20 \times 20$ metros. Em seguida, a imagem formada foi inserida no módulo DISTANCE dos operadores de distância, em ambiente de SIG. O produto gerado foi um mapa de distância euclidiana dos corpos d'água.

O Mapa de classes de vegetação foi desenvolvido a partir de imagens obtidas pelo satélite CBERS-2 de 06/09/2006, nas faixas do vermelho e do infravermelho próximo, que foram transformadas em imagem IVDN. A partir desta imagem foi calculado o Índice de Área Foliar (IAF ou LAI), segundo Duchemin et al.(2006), que foi classificado conforme a literatura (Bitencourt Jr. et al., 2007).

O Mapa de Caracterização Ambiental da Mata Ripária foi obtido a partir da intersecção (multiplicação) do mapa de distância euclidiana dos corpos d'água com o mapa de classes de vegetação.

A Figura II.6 sumariza as etapas para elaboração deste mapa. 


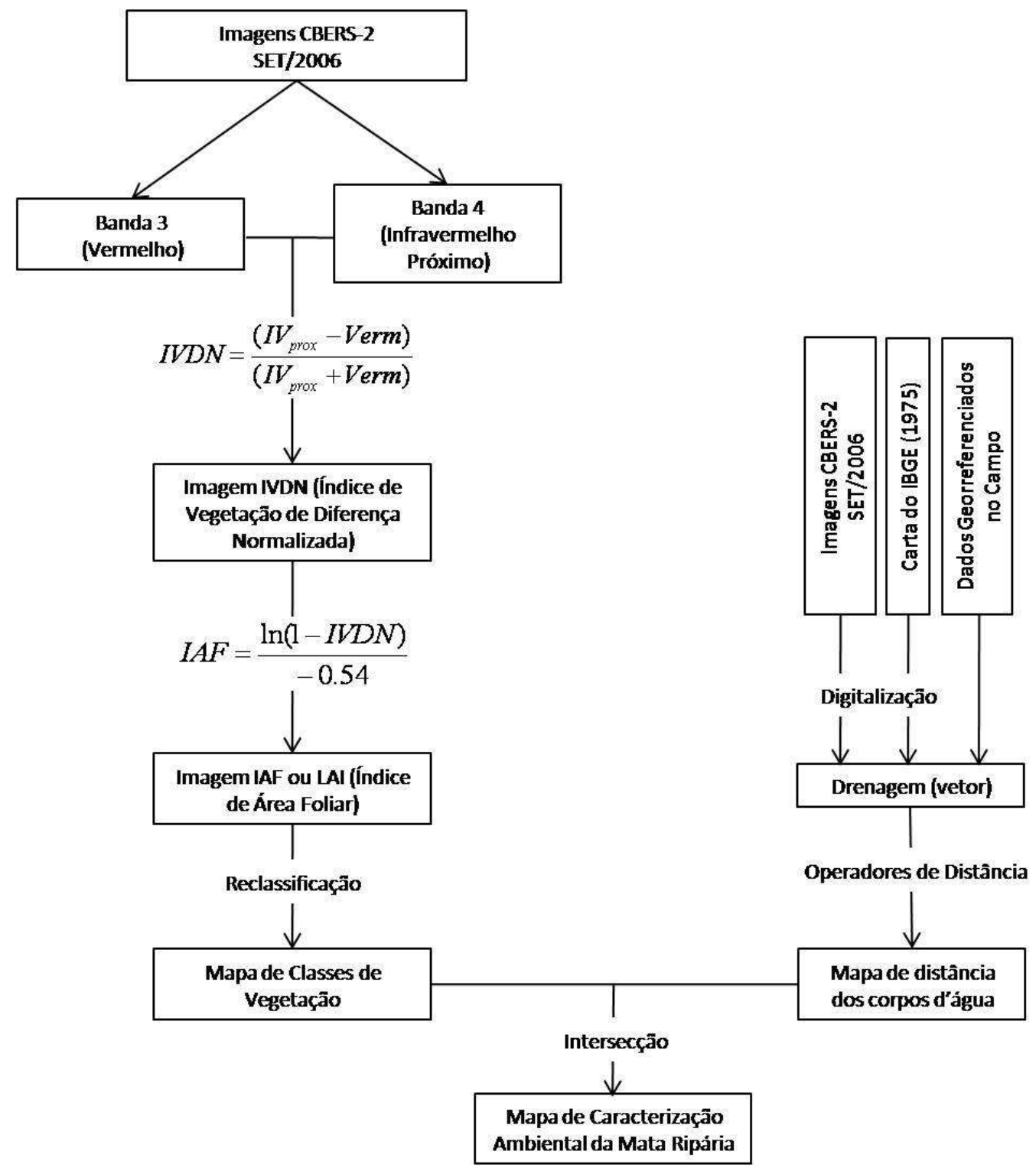

IV $V_{\text {prox: }}$ energia refletida na região do infravermelho próximo;

Verm: energia refletida na região do vermelho do espectro eletromagnético;

In: Logaritmo Neperiano.

Fig.ll.6. - Fluxograma apresentando as etapas (obtenção dos dados, procedimentos e produtos finais) da análise em ambiente de SIG (Sistema de Informação Geográfica) para elaboração do Mapa de Caracterização Ambiental da Mata Ripária (Silveira et al., 2009). 


\section{Resultados}

\section{Mapa Geral de Caracterização Ambiental}

A análise espacial do meio físico iniciou-se primeiramente a partir da produção de uma imagem MNT, derivada das curvas de nível digitalizadas da Carta do IBGE (1975).

O MNT produzido variou de $440 \mathrm{~m}$ a $584 \mathrm{~m}$ e foi reclassificado em quatro classes de altitudes (400-450m, 450-500m, 500-550m e 550-600m), dando origem ao Mapa Hipsométrico. A reclassificação permitiu uma melhor visualização da topografia local.

O Mapa Clinográfico foi gerado em ambiente de SIG a partir do MNT. A declividade neste mapa variou de $0^{\circ}$ a $44^{\circ}$, sendo reclassificado em duas classes apenas ( $0^{\circ}-9^{\circ}$ e $\left.9^{\circ}-44^{\circ}\right)$.

A tabulação cruzada do Mapa Hipsométrico com o Mapa Clinográfico produziu o Mapa de Relevo (associação das classes de altitude e declividade). Este mapa foi reclassificado em três classes (400-550m/ $\left.0^{\circ}-9^{\circ}, 550-650 \mathrm{~m} / 0^{\circ}-9^{\circ}, 400-550 \mathrm{~m} / 9^{\circ}-44^{\circ}\right)$.

A variação altimétrica observada foi baixa, podendo-se concluir que a área de estudo é predominantemente plana. As áreas com maior declive estão associadas com a drenagem.

A Figura II.7 apresenta as entradas dos dados, subprodutos e produto final (Mapa de Relevo) da análise espacial do meio físico.

A análise espacial do meio biótico refere-se à elaboração de um Mapa de Fitofisionomias.

Para isto, obtiveram-se imagens do satélite CBERS-2 de 06/09/2006 (estação seca). Estas imagens foram convertidas em imagem IVDN, produto da resposta espectral das folhas fotossinteticamente ativas nas bandas do vermelho e do infravermelho próximo, e que varia de +1 (vegetação densa) à -1(sem vegetação). 
Estas imagens variaram entre 0 e 0,66 e foram reclassificadas em quatro classes (fisionomias associadas, cerrado sensu stricto típico, cerrado sensu stricto denso e cerradão), conforme mostra a Figura II.8. Esta figura apresenta o diagrama de perfil elaborado na etapa de campo e os intervalos utilizados para a reclassificação da imagem IVDN.

A Figura II.9 apresenta a imagem IVDN e o Mapa de Fitofisionomias produzido após a reclassificação. A Tabela II.1 apresenta a área e a porcentagem equivalente às fitofisionomias encontradas no interior do remanescente, a partir do Mapa de Fitofisionomias produzido.

Tabela II.1. - Área ocupada por cada fitofisionomia no interior do remanescente estudado

\begin{tabular}{lcc}
\hline \multicolumn{1}{r}{ Fitofisionomia } & $\mathrm{Km}^{2}$ & $\%$ \\
\hline Cerradão & 1,49 & 7,10 \\
Cerrado s.s. denso & 13,59 & 64,78 \\
Cerrado s.s. típico & 3,03 & 14,44 \\
Campo úmido & 0,96 & 4,58 \\
Mata ripária & 1,91 & 9,10 \\
& & \\
Total & 20,98 & 100,00 \\
\hline
\end{tabular}

ss: sensu stricto

Nota-se, a partir da Figura II.9 e da Tabela II.1, que há predominância de cerrado sensu stricto denso na área de estudo, onde se encontram imersas manchas de cerradão e de cerrado sensu stricto típico.

O Mapa Geral de Caracterização Ambiental, objetivo da análise aqui realizada, está apresentado na Figura II.10. Nesta figura estão esquematizadas as entradas de dados e o produto final.

Este mapa foi utilizado para realização do delineamento amostral da etapa de obtenção dos dados de riqueza e freqüência de ocorrência de espécies de mamíferos de médio e grande porte (Capítulo III). 
Elaboração da Base Cartográfica para Amostragem e Análise de Dados de Mamíferos de Médio e Grande Porte

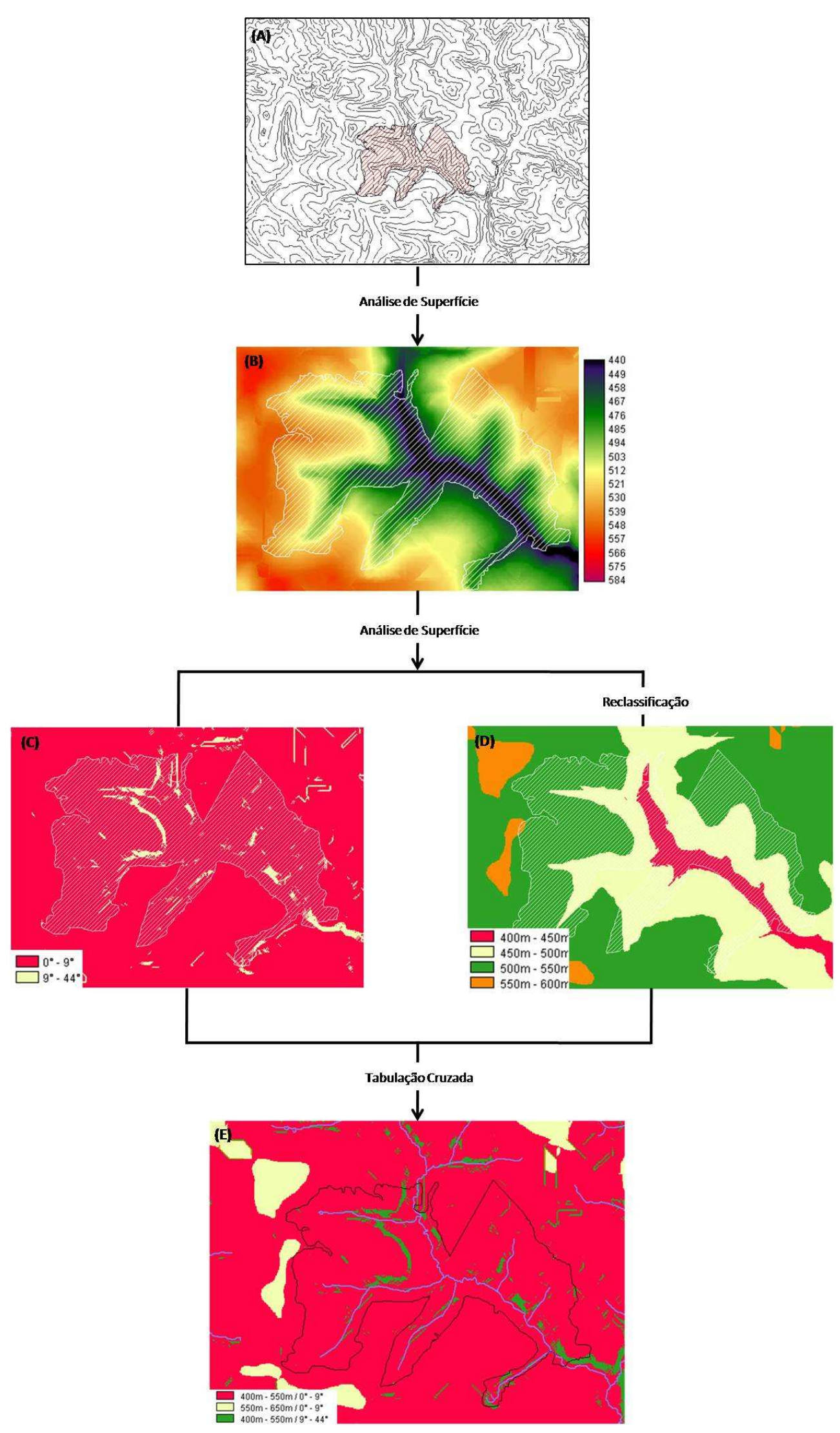

Fig.ll.7. - Esquema apresentando o vetor de curvas de nível (A), que originou a imagem sintética de superfície - MNT (B) e seus subprodutos, Mapa Clinográfico (C) e Mapa hipsométrico (D). O produto final foi o Mapa de Relevo (E). 

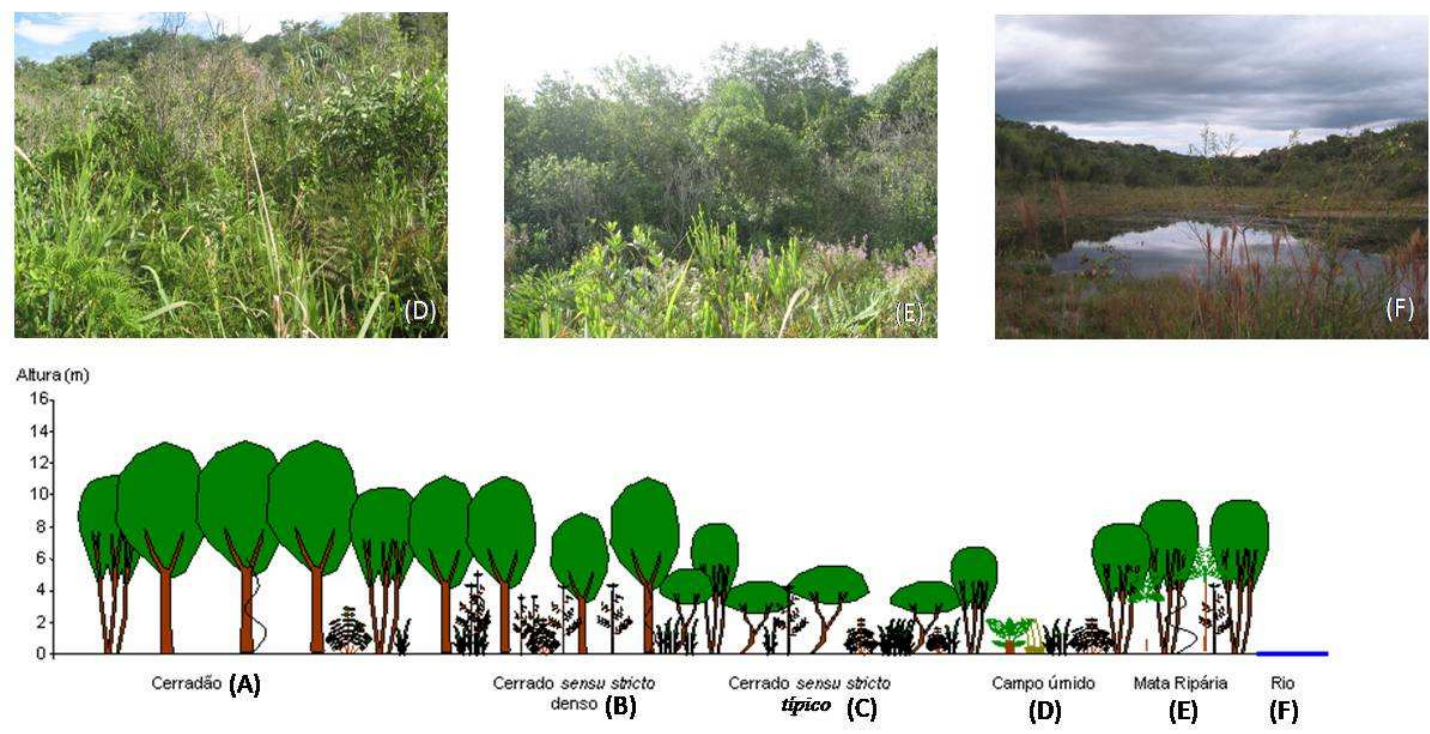

$0,54-0,59$

$0,44-0,53$

$\mathbf{0 , 3 7 - 0 , 4 3}$

$\mathbf{0 , 1 1 - 0 . 3 6}$

Intervalos Imagem Índice de Vegetapīo (IVDN)
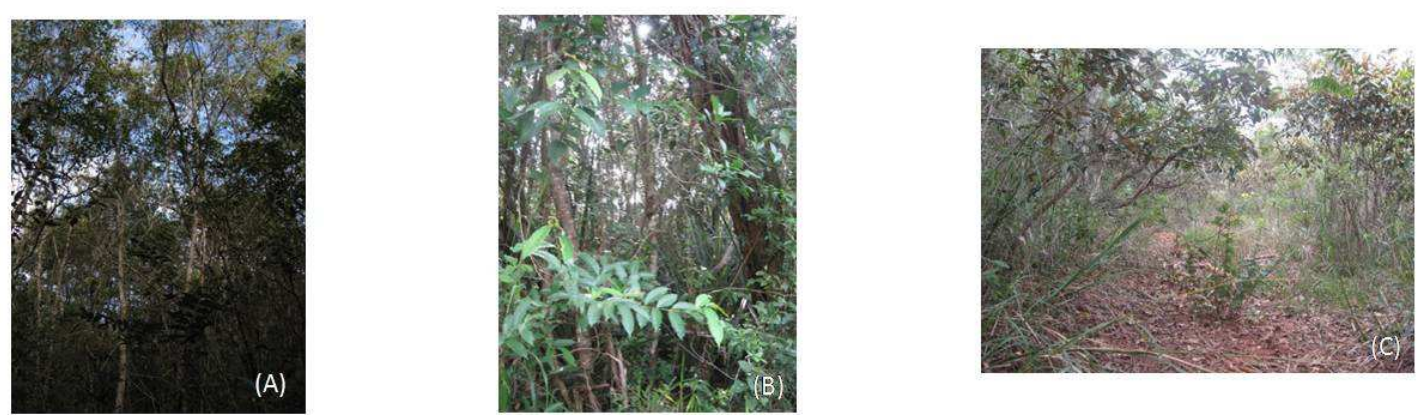

Legenda:
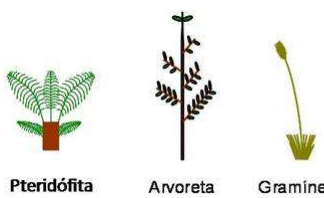

Avoreta

Graminea 1 Graminea 2
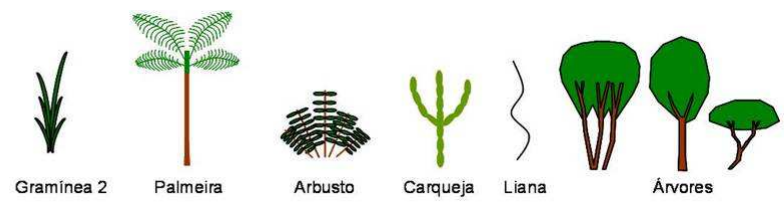

Fig.II.8. - Diagrama de perfil da estrutura da vegetação, elaborado na etapa de campo, ilustrando a classificação fitofisionômica realizada a partir da imagem Índice de Vegetação de Diferença Normalizada (IVDN), devidamente classificada segundo os intervalos acima especificados. 

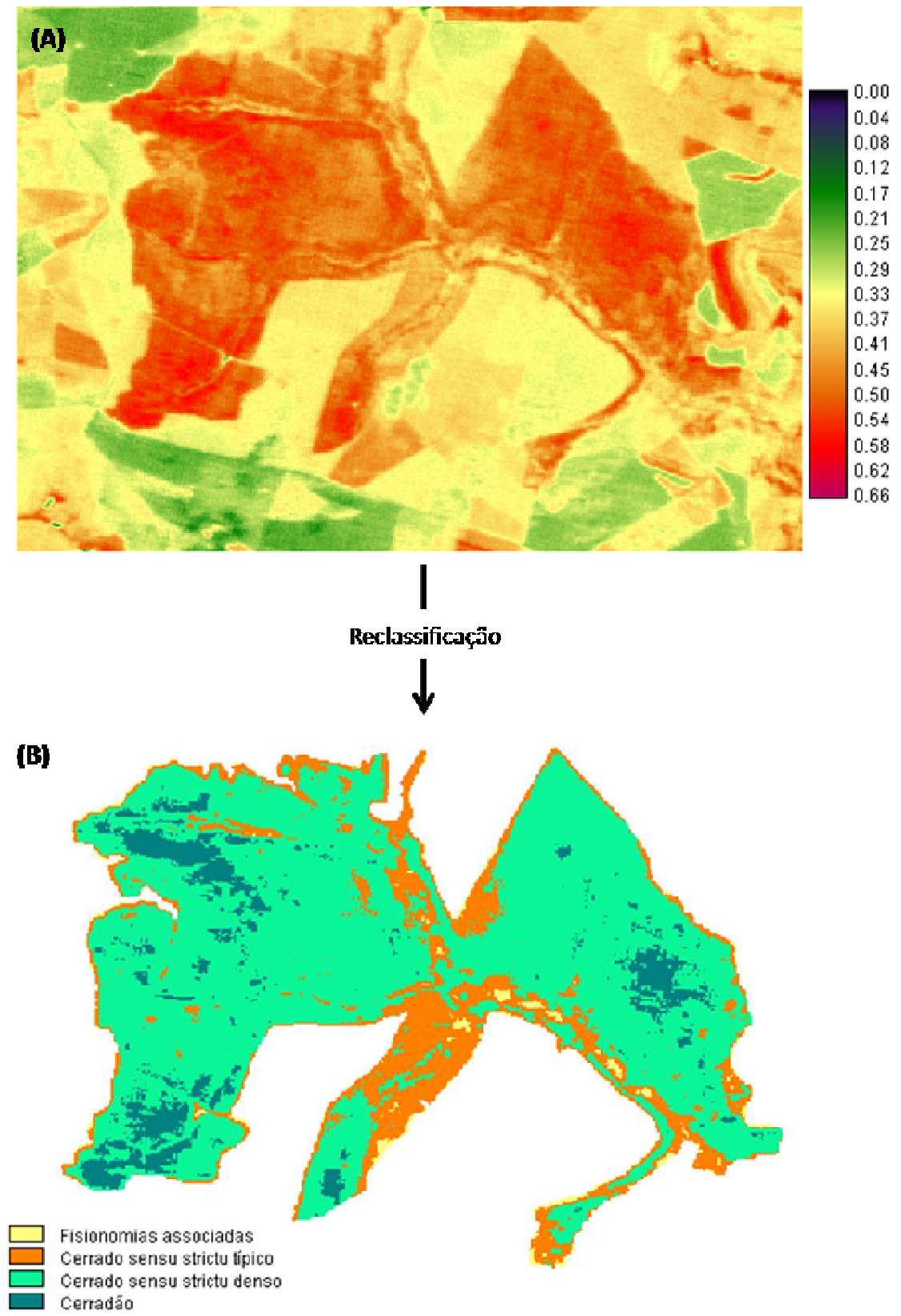

Fig.II.9. - Esquema apresentando a imagem IVDN (A), obtido a partir das bandas do vermelho e do infravermelho próximo do satélite CBERS-2 de 06/09/2006, que foi reclassificado de acordo com a literatura, originando o Mapa de Fitofisionomias (B). 

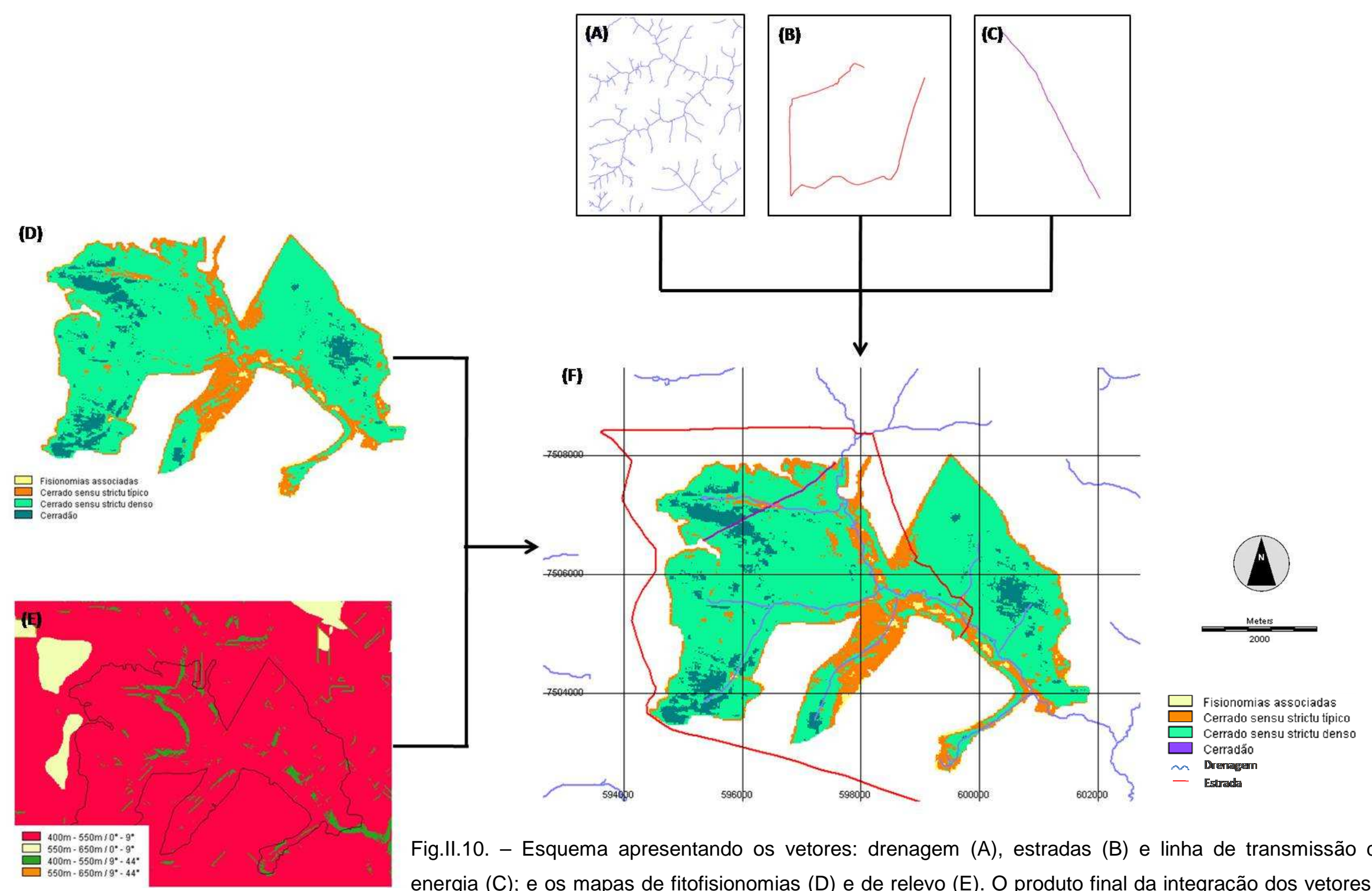

Fig.II.10. - Esquema apresentando os vetores: drenagem (A), estradas (B) e linha de transmissão de energia (C); e os mapas de fitofisionomias (D) e de relevo (E). O produto final da integração dos vetores e dos mapas foi o Mapa Geral de Caracterização Ambiental (F). 


\section{Mapa de Caracterização Ambiental da Mata Ripária}

\section{Diagramas de Perfil}

Os diagramas de perfil da estrutura da vegetação, elaborados na etapa de campo, permitiram caracterizar previamente o complexo ripário e auxiliaram na realização da análise espacial (classificação das fitofisionomias).

A Figura II.11a apresenta os oito pontos de visita no complexo de mata ripária, internos e externos ao fragmento, para elaboração dos diagramas.

As Figuras II.11b a II.11i apresentam os produtos finais (diagramas de perfil) que caracterizam o relevo e a estrutura da vegetação. As dimensões dos diagramas (alturas e distâncias) estão todas em metros.

Na Figura II.11b a largura aproximada do rio é de $40 \mathrm{~cm}$ e a fisionomia interfluvial predominante é cerrado sensu stricto denso. Corresponde ao diagrama de perfil da mata ripária da área sob efeito direto da linha de transmissão de energia.

O campo úmido nesta área pode ser constituído por capim navalha e algumas arvoretas ocorrendo entre eles a partir da margem do rio. Eventualmente, os capins dão lugar a pteridófitas, que dominam visualmente a área.

A mata ripária apresenta dossel razoavelmente fechado, com sub-bosque constituído por árvores jovens, arvoretas e arbustos, ocorrendo também uma grande quantidade de lianas.

Na Figura II.11c a largura aproximada do rio é de $15 \mathrm{~cm}$ e a fisionomia interfluvial predominante é cerradão.

Por se tratar de uma nascente, o campo úmido e a mata ripária dessa região apresentam solo permanentemente encharcado.

O campo úmido apresenta arbustos, arvoretas e pteridófitas, enquanto a mata ripária aparentemente apresenta dossel fechado e alta densidade de indivíduos.

Na Figura II.11d a largura do rio é variável $(2-5 \mathrm{~m})$ e a fisionomia interfluvial predominante é o cerrado sensu stricto denso.

Nesta área, a mata ripária encontra-se em alguns pontos em solo encharcado, onde existem árvores com adaptações para se fixar em solo lodoso. Não ocorre sub- 
bosque ou extrato herbáceo, exceto por algumas gramíneas e arvoretas crescendo junto às árvores maiores. À medida que se distancia do rio, o solo passa a ficar mais seco e as árvores passam a ocorrer em uma densidade aparentemente maior. Começa a existir também extrato herbáceo, composto por gramíneas e pteridófitas.

Na Figura II.11e a largura aproximada do rio é de $20 \mathrm{~cm}$, tratando-se de uma nascente. A fisionomia interfluvial predominante é o cerrado sensu stricto denso.

Nesta área o solo permanece encharcado e a mata ripária que lá ocorre apresenta grande diversidade de estruturas. Há uma grande densidade de lianas, além de bromélias e palmeiras (observadas somente nesta região). Na transição entre a mata ripária e o campo úmido, há uma grande densidade de árvores de baixa estatura.

$\mathrm{Na}$ Figura II.11f a fisionomia interfluvial predominante é o cerrado sensu stricto denso. Nesta área não foi possível atingir o rio devido à largura da faixa de mata ripária.

A mata ripária não apresenta sub-bosque ou estrato herbáceo definidos, salvo alguns indivíduos esparsos de gramíneas, arvoretas e pteridófitas. Há outros locais onde a densidade de árvores é um pouco menor, passando a ocorrer sub-bosque composto por arvoretas, além de estrato herbáceo. O campo úmido não foge do padrão, mas ocorrem alguns poucos indivíduos de espécies arbóreas com mais de $4 \mathrm{~m}$ de altura. Nessa área, como retratado no diagrama de perfil, há uma densidade aparente de carquejas maior que a das outras áreas.

Na Figura II.11g a largura do rio é de $70 \mathrm{~cm}$ e a fisionomia interfluvial predominante é o cerrado sensu stricto típico. A área é caracterizada por uma alta densidade de indivíduos arbóreos, com sub-bosque composto por gramíneas, arvoretas e lianas.

Na Figura II.11h a largura do rio é de 2,5m e a fisionomia interfluvial é campestre de origem antrópica (pastagem).

Esta área ripária foge do padrão em relação às outras, pois apresenta uma inversão na posição das faixas de campo úmido e de floresta. Diretamente adjacente ao rio ocorre campo úmido, que dá lugar a uma mata que mostra composição semelhante à das matas ripárias das outras áreas. 
Na Figura II.11i a largura do rio é de 2,5m e a fisionomia interfluvial predominante é campestre de origem antrópica (pastagem).

Apesar de estar inserida numa matriz de pastagens, esta área se localiza ao lado de um fragmento de cerrado. Diretamente em sua borda, a área também é cruzada por uma estrada de terra, freqüentada por tratores. No local, o rio é represado, num sistema de ductos responsável pelo abastecimento de água na fazenda. No local só ocorre floresta, não havendo faixa de campo úmido adjacente à borda da mata, apesar de a fisionomia ocorrer na margem da represa.
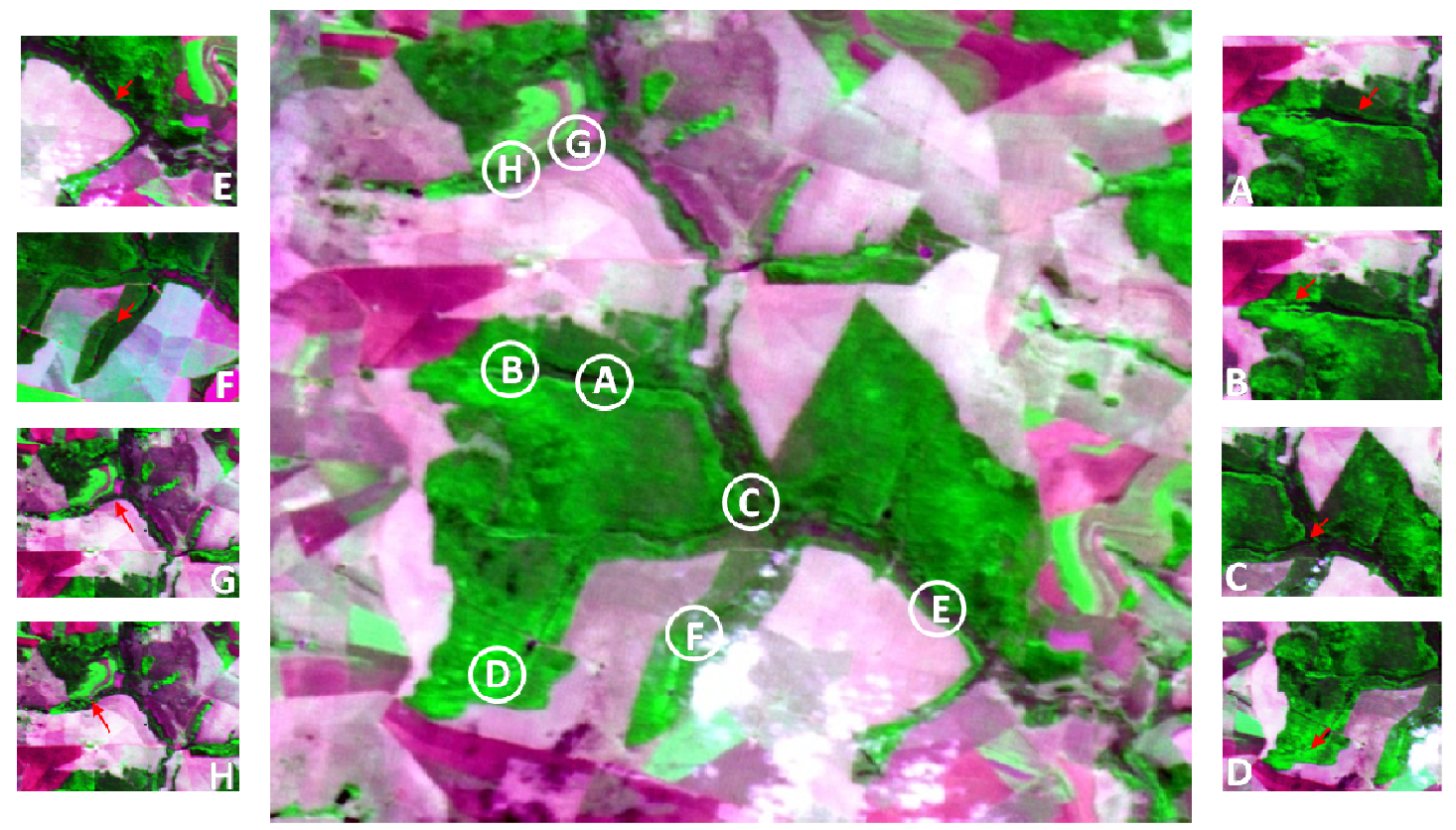

Fig.ll.11a. - Localização dos oito pontos de visita no complexo de mata ripária, internos e externos ao fragmento, para elaboração dos diagramas de perfil (Silveira et al., 2009). 


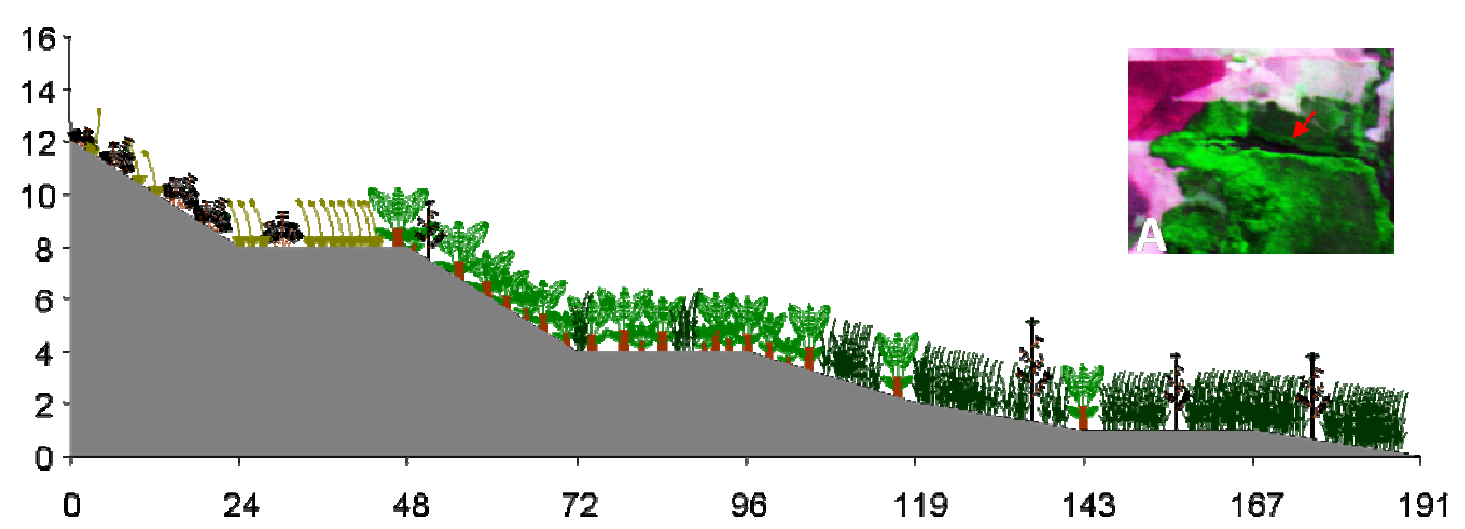

Fig.Il.11b. -Diagrama de perfil elaborado no ponto $A$, apresentando as características do relevo e da estrutura da vegetação (Silveira et al., 2009).

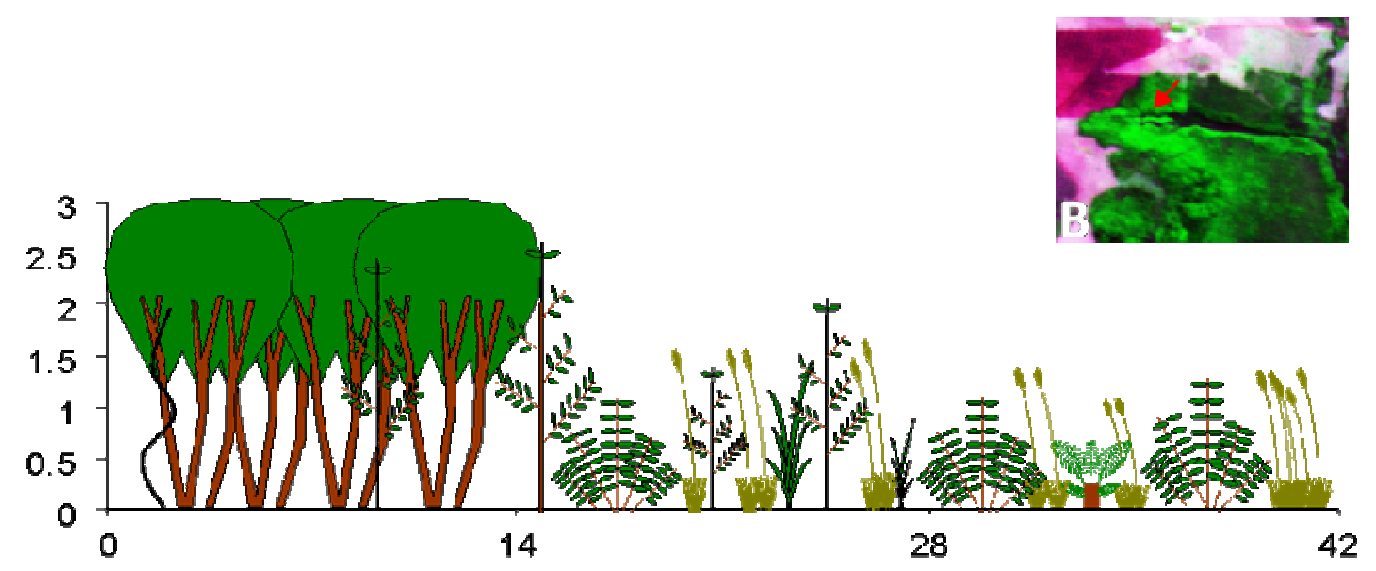

Fig.II.11c. -Diagrama de perfil elaborado no ponto B, apresentando as características do relevo e da estrutura da vegetação (Silveira et al., 2009). 

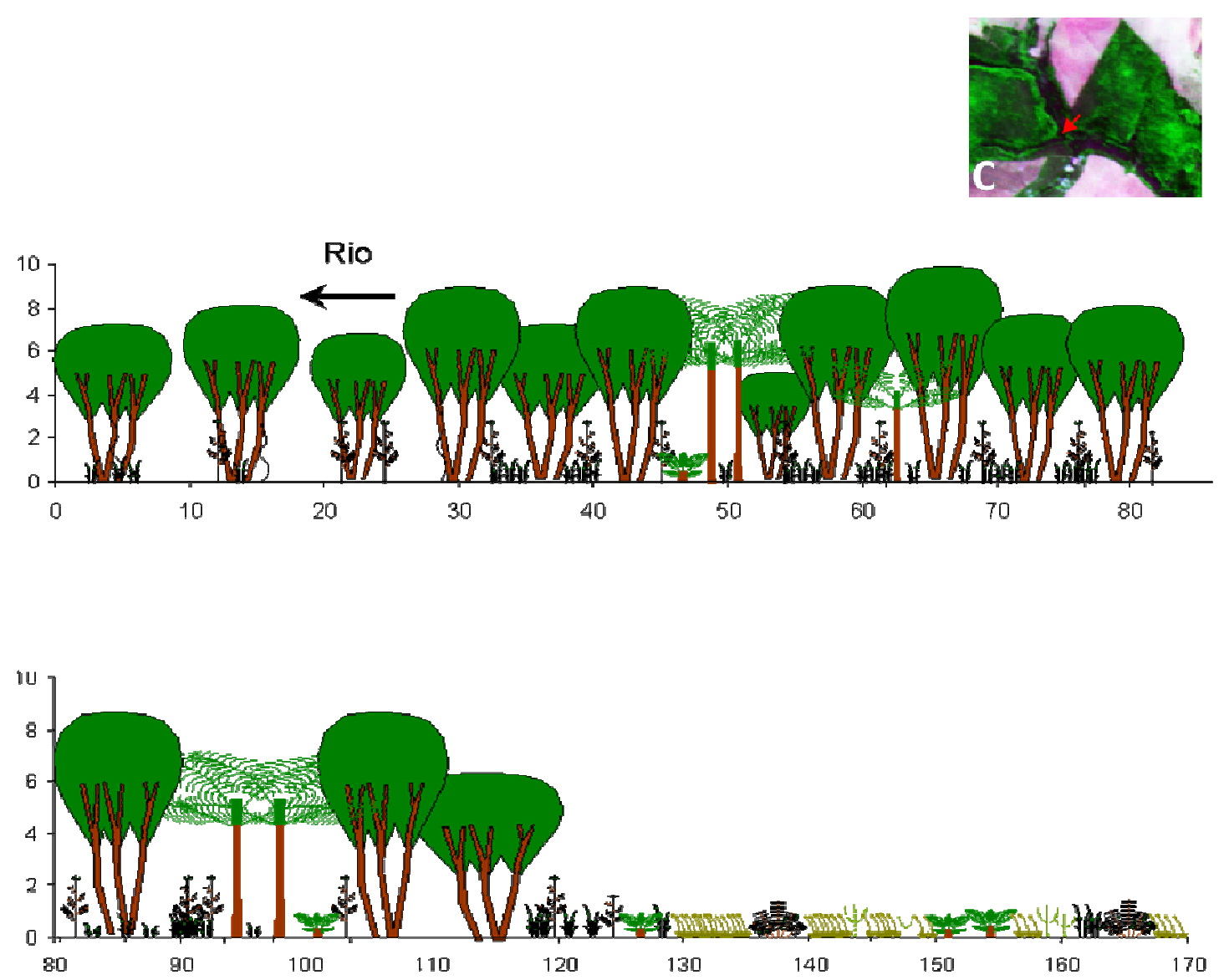

Fig.II.11d. -Diagrama de perfil elaborado no ponto C, apresentando as características do relevo e da estrutura da vegetação (Silveira et al., 2009).

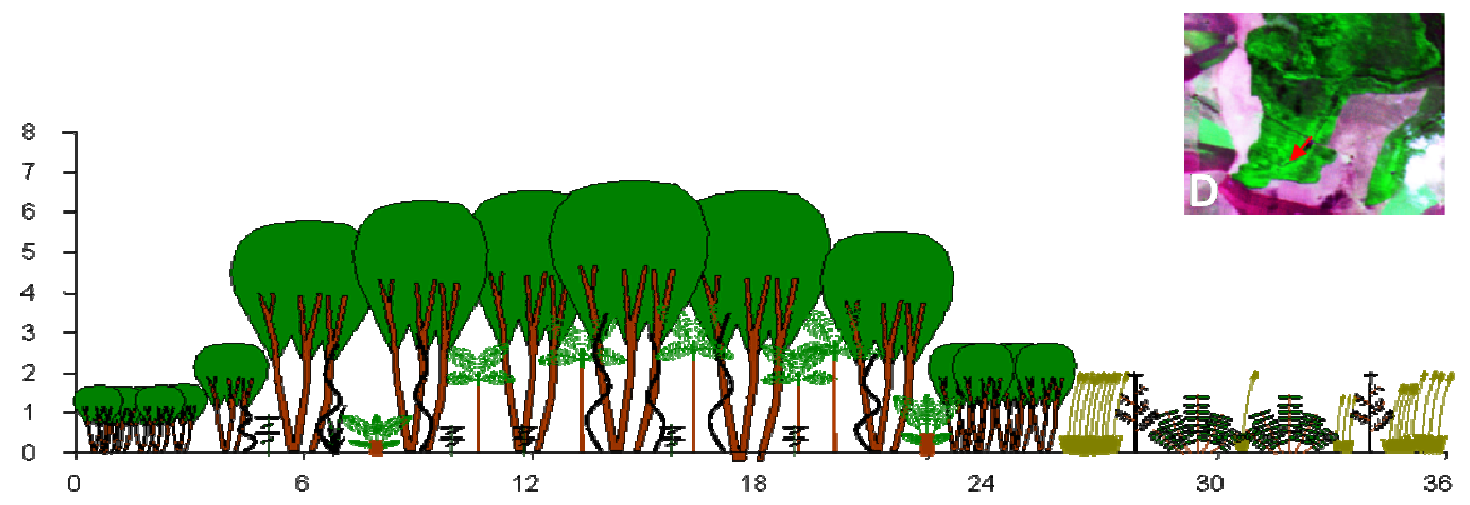

Fig.Il.11e. -Diagrama de perfil elaborado no ponto D, apresentando as características do relevo e da estrutura da vegetação (Silveira et al., 2009). 


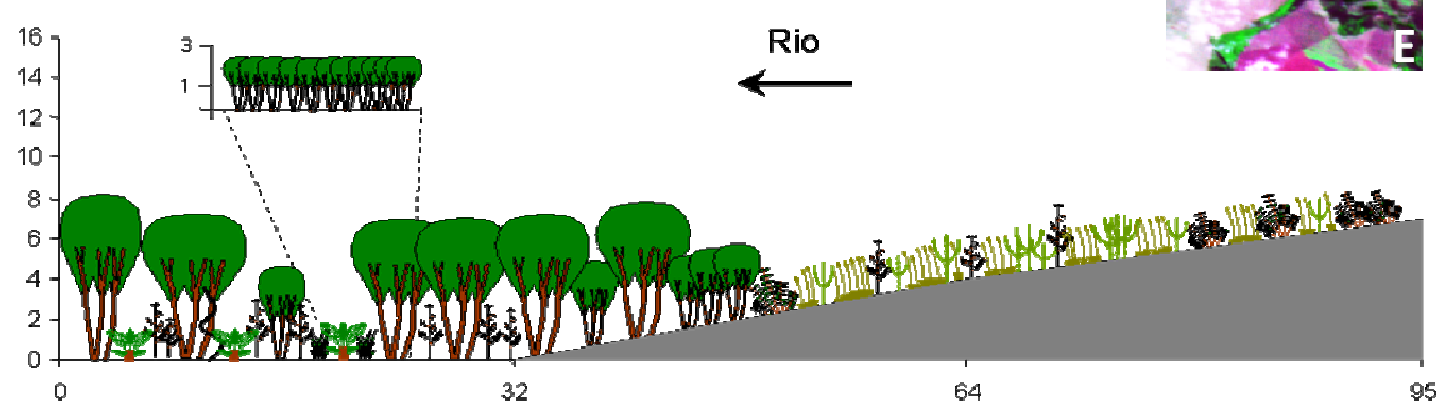

Fig.Il.11f. -Diagrama de perfil elaborado no ponto E, apresentando as características do relevo e da estrutura da vegetação (Silveira et al., 2009).

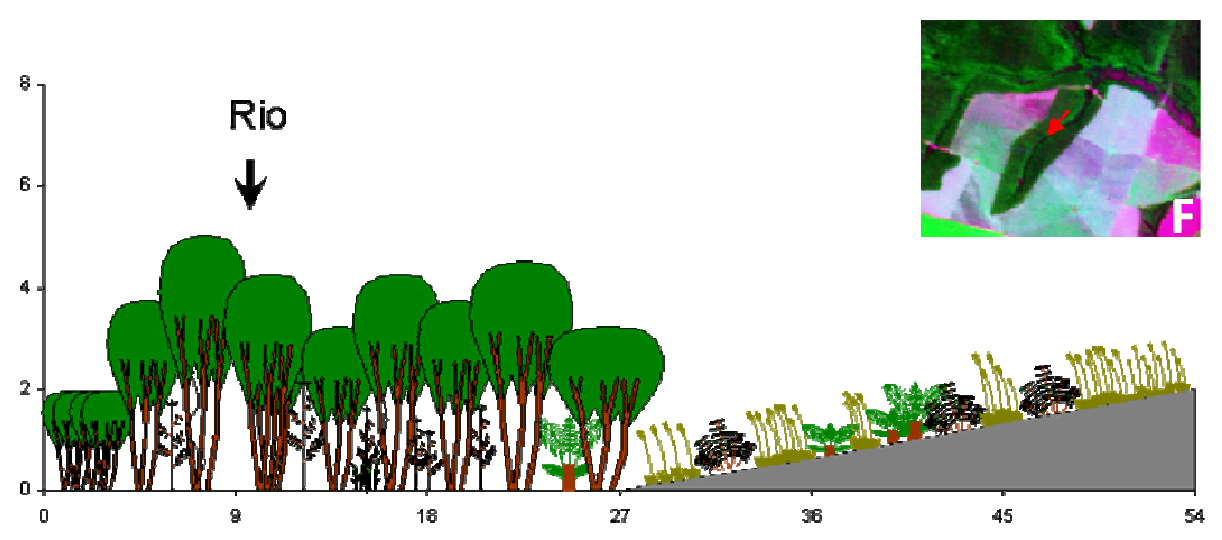

Fig.Il.11g. -Diagrama de perfil elaborado no ponto $F$, apresentando as características do relevo e da estrutura da vegetação (Silveira et al., 2009). 


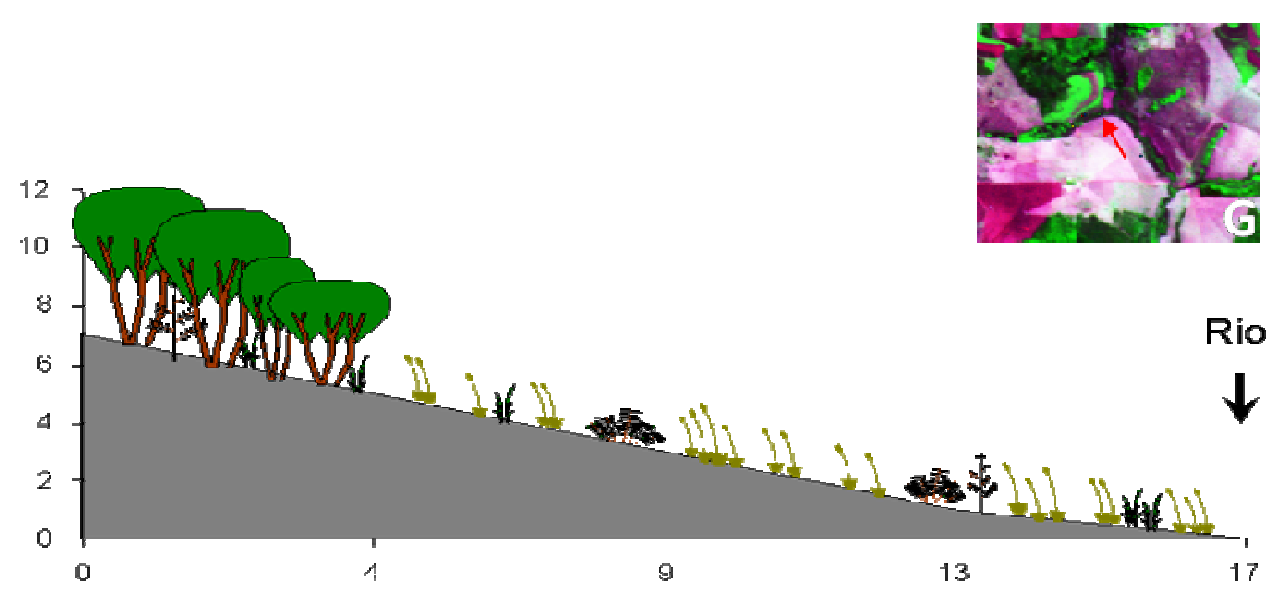

Fig.Il.11h. -Diagrama de perfil elaborado no ponto G, apresentando as características do relevo e da estrutura da vegetação (Silveira et al., 2009).
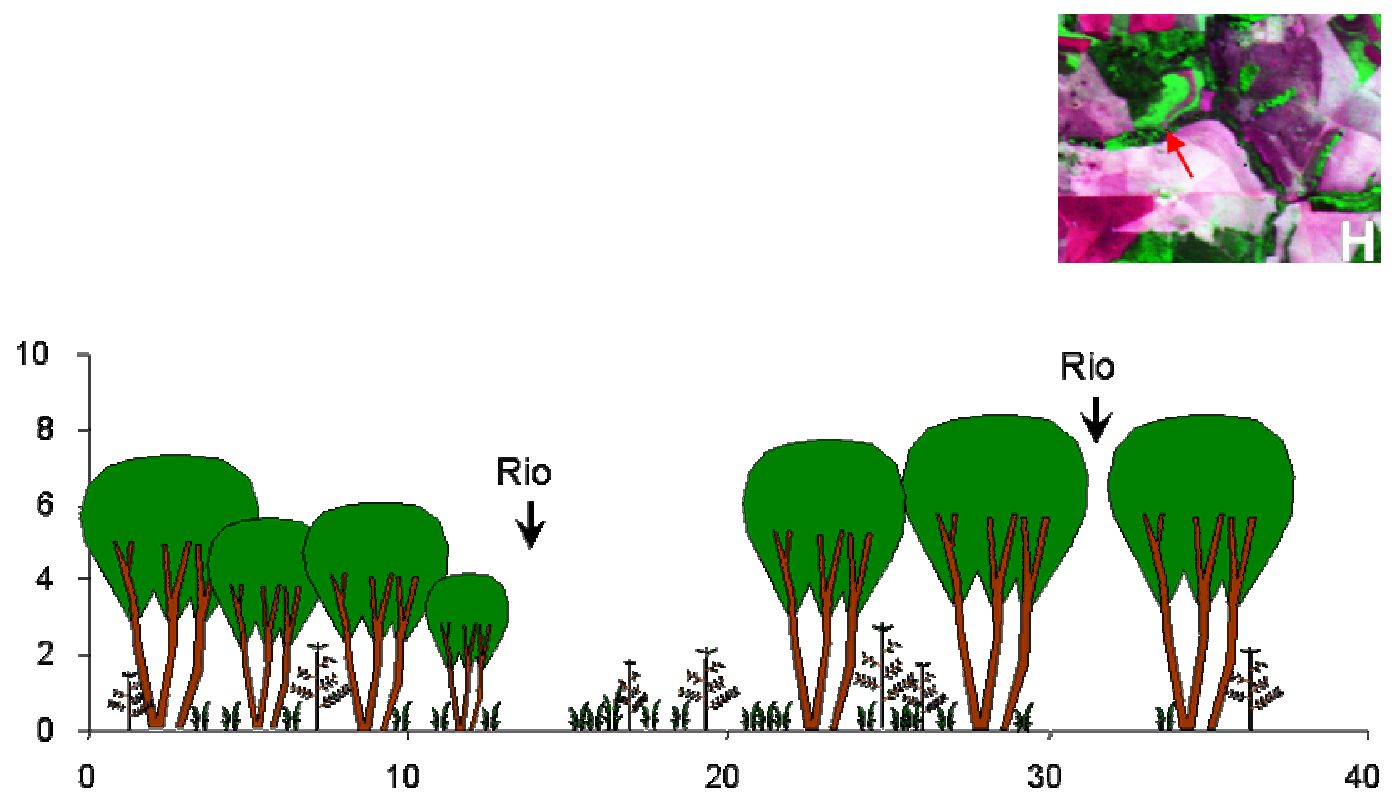

Fig.Il.11i. -Diagrama de perfil elaborado no ponto $\mathrm{H}$, apresentando as características do relevo e da estrutura da vegetação (Silveira et al., 2009).

Legenda:

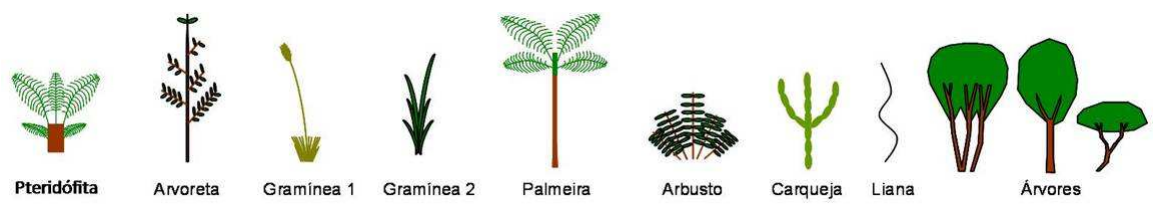




\section{Análise Espacial}

A análise espacial da mata ripária foi realizada em uma escala mais fina do que a análise realizada para a elaboração do Mapa Geral de Caracterização Ambiental, já que seu comportamento espectral se confunde com as fitofisionomias de cerrado e sua separação, somente pelas imagens de satélite utilizadas, foi praticamente impossível.

Os diagramas de perfil elaborados na etapa de campo foram utilizados para caracterizar o complexo ripário e auxiliaram na classificação das imagens IVDN e IAF.

Para elaboração do Mapa de Caracterização Ambiental da Mata Ripária foram utilizadas imagens do satélite CBERS-2 de 06/09/2006 (estação seca). Estas imagens foram convertidas em imagem IVDN.

A partir da imagem IVDN foi calculada a imagem IAF (Figura II.12), que resultou em um maior contraste entre as fitofisionomias, isto se dá porque a imagem IAF apresenta mais intervalos do que a imagem IVDN.

A interseção da imagem de IAF com a imagem sintética de distância dos corpos d'água restringiu a análise a uma faixa de $250 \mathrm{~m}$ de cada lado do rio, facilitando a classificação da imagem de IAF.

Desta forma, a imagem de IAF foi reclassificada de acordo com a literatura (Bitencourt et al., 2007) e com as informações obtidas dos diagramas de perfil. Foram, portanto, determinadas quatro classes de vegetação, a saber, campo úmido, campo úmido ou cerrado sensu stricto típico (dentro do fragmento)/Pasto (fora do fragmento), Mata Ripária, Transição Mata Ripária - Bioma Cerrado) (Figura II.13).

No Mapa de Caracterização Ambiental da Mata Ripária foram sobrepostos os dados de riqueza e freqüência de ocorrência das espécies de mamíferos de médio e grande porte, para avaliar o uso desses habitats pelo grupo (Capítulo III). 

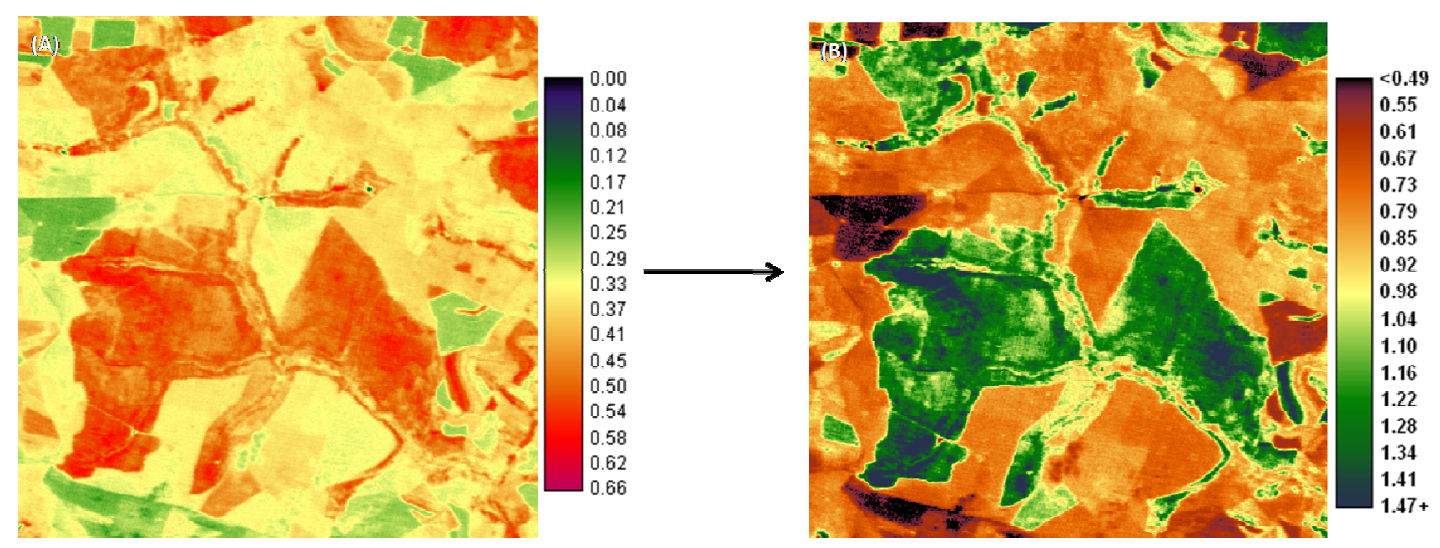

Fig.Il.12. - Transformação da imagem IVDN (A) em IAF (B) (Silveira et al., 2009).

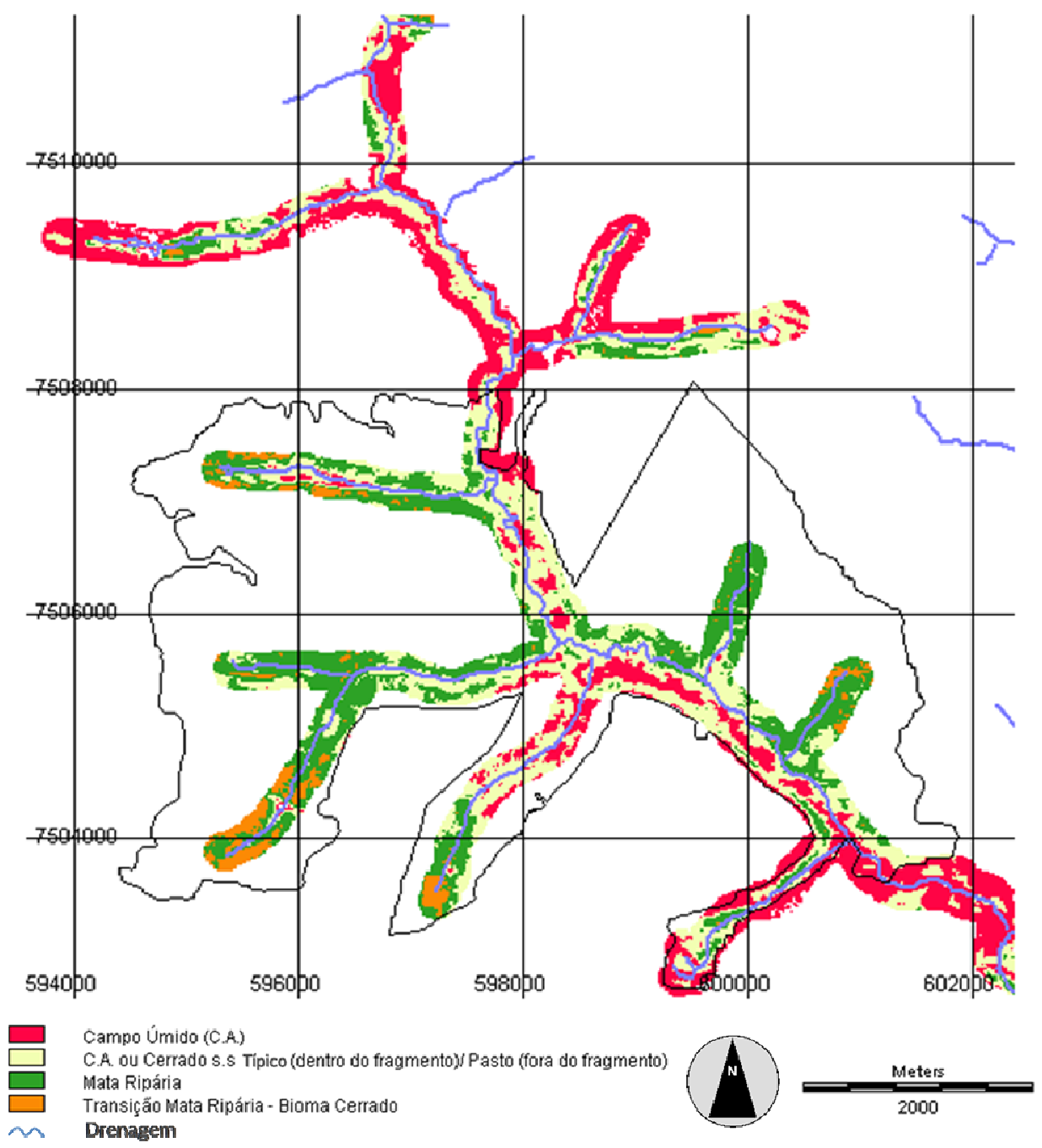

Fig.II.13. - Mapa de Caracterização Ambiental da Mata Ripária (Silveira et al., 2009). 


\section{Discussão}

\section{Mapa Geral de Caracterização Ambiental}

A análise espacial desenvolvida para a elaboração do Mapa Geral de Caracterização Ambiental (Figura II.10) mostrou-se eficaz na caracterização do meio físico (relevo) e do meio biótico (fitofisionomias), já que na visita a campo foi possível comparar os mapas elaborados com as observações realizadas na área de estudo.

Não houve a necessidade, para este fim, de desenvolvimento de uma análise espacial mais refinada do relevo ou das fitofisionomias, já que o objetivo desta análise é somente fornecer uma base cartográfica simples de qualidade ambiental da área de estudo, para alocação dos canteiros de pegadas, armadilhas fotográficas e transecções, para obtenção de dados de riqueza e freqüência de ocorrência de mamíferos de médio e grande porte.

A sobreposição da drenagem, estradas e linha de transmissão de energia no mapa, permitiu inferir sobre a qualidade ambiental dos habitats inseridos no remanescente de cerrado, ou seja, partindo-se do pressuposto de que proximidade de corpos d'água é um critério positivo para determinada espécie de mamífero e que distância das estradas é um critério negativo para a mesma, espera-se que esta espécie seja encontrada em locais com mais atributos positivos do que negativos.

Com relação às fitofisionomias, a afinidade por determinado tipo de cobertura vegetal irá variar em função das características intrínsecas de cada espécie de mamífero, assim como a tolerância pelo efeito de borda, se for o caso.

Ao observar o Mapa Geral de Caracterização Ambiental é possível notar como os critérios positivos ou negativos estão distribuídos ao longo do fragmento ou próximos a ele. Desta forma, também é possível delinear as amostragens de mamíferos de médio e grande porte em função dos critérios (diferentes graus de perturbação ou diferentes graus de qualidade de habitat, por exemplo) e das espécies alvo do estudo (cada espécie possui necessidades intrínsecas a ela). Sendo assim, as amostragens podem ser sistematizadas a partir do momento que se consegue enxergar as diversas feições ambientais da área de estudo e, 
certamente, as amostragens serão otimizadas e produzirão resultados mais próximos da realidade (aumento da precisão).

\section{Mapa de Caracterização Ambiental da Mata Ripária}

O Mapa de Caracterização Ambiental da Mata Ripária (Figura II.13) foi desenvolvido para avaliar a estrutura e qualidade da mata ripária, assim como para possibilitar uma melhor avaliação de seu uso por mamíferos de médio e grande porte (Capítulo III).

A análise espacial desenvolvida para a elaboração do mapa se mostrou satisfatória, pois foi capaz de representar cartograficamente os dados das imagens de satélite e os dados obtidos no campo, registrados por meio de diagramas de perfil da estrutura da vegetação.

Mesmo assim, existe a possibilidade de ocorrência de algum grau de inexatidão da classificação realizada, devido à sobreposição de valores do IVDN e IAF entre as fitofisionomias que apresentam comportamento espectral semelhante (quantidade de biomassa semelhante), como o cerradão e a mata ripária, por exemplo.

Houve aumento da precisão da classificação a partir da intersecção da imagem de IAF com a imagem sintética de distância dos corpos d'água, pois restringiu a análise em uma faixa de $250 \mathrm{~m}$ de cada lado da margem do rio.

Os diagramas de perfil foram satisfatórios a partir do momento que possibilitaram a delimitação das áreas de inundação e do leito dos rios, e também auxiliaram na classificação fitofisionomica. Entretanto, também estiveram sujeitos a imprecisões, uma vez que as curvas de nível não possuíam linhas suficientes para criar um MNT mais detalhado para este fim.

Com relação à estrutura da Mata Ripária, observou-se que esta se encontra margeada por uma faixa de campo úmido, não importando em qual fitofisionomia de cerrado estivessem inseridas.

As áreas de inundação equivalem às áreas de ocorrência de vegetação ripária (Figura II.13), que apresentou variações na sua estrutura. Também foi observado 
que quanto maior a largura do rio, maior era a largura da faixa de vegetação ripária, assim como maior a diversidade de estruturas.

Os locais sujeitos às pressões antrópicas, como represas, estradas e a rede de energia, mostraram perda do componente arbóreo às margens do rio em contato com o impacto, sendo assim, a mata ripária no interior do remanescente encontrase em melhor estado de conservação do que fora dele, como esperado. 


\section{Conclusão}

A análise espacial desenvolvida para a elaboração do Mapa Geral de Caracterização Ambiental do remanescente de cerrado e do Mapa de Caracterização Ambiental da Mata Ripária mostrou-se satisfatória, atingindo os objetivos a que foi submetida.

A etapa de campo foi muito importante para conhecimento dos objetos de estudo e auxiliaram a análise espacial, favorecendo 0 aumento da precisão das classificações realizadas e, conseqüentemente, produzindo resultados mais próximos da realidade.

Entretanto, não foi possível excluir a possibilidade de ocorrência de algum grau de inexatidão da classificação das imagens IVDN e IAF, devido à sobreposição de valores destes índices entre as fitofisionomias que apresentam comportamento espectral semelhante (quantidade de biomassa semelhante).

Finalmente, os mapas finais se mostraram muito úteis para a escolha de locais heterogêneos entre si, para alocação dos canteiros de pegadas, armadilhas fotográficas e transecções, considerando as necessidades ambientais dos mamíferos de médio e grande porte comuns neste bioma. 


\section{Referências Bibliográficas}

BECERRA, J.A.B., 2005. Modelagem da Influência dos Fatores antrópicos nos remanescentes de cerrado no Estado de São Paulo. (Tese doutorado) - Programa de Ecologia IB/USP.

BITENCOURT, M.D.; MESQUITA JR, H.N. 2005. Caracterização física do cerrado Pé-de-Gigante e uso das terras na região: análise ambiental espacializada da gleba Pé-de-Gigante. In PIVELO, V.R.; VARANDA, E.M. O cerrado Pé-de-Gigante, Parque Estadual do Vassununga : ecologia e conservação. São Paulo: SMA, p.44-50.

BITENCOURT, M D.; MESQUITA JR, H. N.; KUNTSCHIK, G.; ROCHA, H. R.; FURLEY, P. A. 2007. Cerrado vegetation study using optical and radar remote sensing: two Brazilian case studies. Canadian Journal of Remote Sensing, 33: 468480.

DUCHEMIN, B.; HADRI, R.; ERRAKI, S.; BOULET, G.; MAISONGRANDE, P.; CHEHBOUNI, A.; ESCADAFAL, R.; EZZAHAR, J.; HOEDJES, J.C.B.; KHARROU, M.H.; KHABBA, S.; MOUGENOT, B.; OLIOSO, A.; RODRIGUEZ, J.-C.; SIMONNEAUX, V. 2006. Monitoring wheat phenology and irrigation in Central Morocco: On the use of relationships between evapotranspiration, crops coefficients, leaf area index and remotely-sensed vegetation indices. Agricultural Water Management, 79: 1-27.

EASTMAN, J.R. 2006. IDRISI Andes. Clark University Laboratory, Clark University, Worcester, Pennsylvania.

IBGE- INSTITUTO BRASILEIRO DE GEOGRAFIA E ESTATÍSTICA. 1993. Carta do Brasil (escala 1: 50.000): Campos Novos Paulista, folha SF-22-Z-A-V-2. Rio de Janeiro.

JACKSON, R.D.; HUETE, A.R. 1991. Interpreting vegetation indices. Preventive veterinary medicine, $11: 185-200$. 
KUNTSCHIK, G. 2004. Estimativa de fitomassa lenhosa por meios não destrutivos em cerrado sensu stricto e cerradão através de sensoriamento remoto óptico e banda $L$. (Tese doutorado) - Programa de Ecologia IB/USP.

MARTINS, I.A.; BITENCOURT, M. D.; SILVEIRA, C.F.P.; JARDINEIRO, K.S. 2009. Proposta metodológica para análise espacial de qualidade de habitat para mamíferos de grande porte em fragmento de cerrado. In: Anais do XIV Simpósio Brasileiro de Sensoriamento Remoto, Natal/RN. p.4043-4051. <http://marte.dpi.inpe.br/col/dpi.inpe.br/sbsr@80/2008/11.18.00.48/doc/40434051.pdf>

MESQUITA JR, H.N. 1998. Análise temporal com sensor orbital de unidades fisionômicas de cerrado na Gleba Pé-de-Gigante (Parque Estadual de Vassununga - SP). (Dissertação de Mestrado) - Programa de Ecologia IB/USP.

MESQUITA JR. H.N. 2003. Modelagem das variações da resposta espectral das fisionomias de cerrado em relação às variações climáticas sazonais. (Tese doutorado) - Programa de Ecologia IB/USP.

MESQUITA JR, H.N.; BITENCOURT, M.D.; ROCHA, H.R. 2005. As relações entre a vegetação e o meio físico no cerrado Pé-de-Gigante: sazonalidade da vegetação e balanço de radiação. In PIVELO, V.R.; VARANDA, E.M. O cerrado Pé-de-Gigante, Parque Estadual do Vassununga : ecologia e conservação. São Paulo: SMA, p.164172.

MOREIRA. M.A. 2003. Fundamentos do sensoriamento remoto e metodologias de aplicação. Viçosa: UFV.

SILVEIRA, C.F.P.; JARDINEIRO, K.S.; MARTINS, I.A.; BITENCOURT, M. D. 2009. Análise da qualidade das matas ripárias para mamíferos, utilizando um fragmento de cerrado do estado de São Paulo, sensoriamento remoto e campo In: Anais do XIV Simpósio Brasileiro de Sensoriamento Remoto, Natal/RN. p.5451-5458. $<$ http://marte.dpi.inpe.br/col/dpi.inpe.br/sbsr@80/2008/11.17.17.41.43/doc/54515458.pdf> 
WIEGAND, C.L.; RICHARDSON, A.J.; ESCOBAR, D.E. 1991. Vegetation indices in crop assessment. Remote sensing of environment, 35: 105-119. 


\section{Capítulo III}

Riqueza de Espécies de Mamíferos de Médio e Grande Porte em um Fragmento de Cerrado no Estado de São Paulo

Abstract .68

Resumo .69

Introdução .70

Materiais e Métodos .73

Resultados .83

Discussão 113

Conclusão 117

Referências Bibliográficas 118 


\begin{abstract}
In São Paulo state's cerrado, many medium and large-sized mammals have been survived in small forest patchs regarding to their natural living areas. Somehow those species can still persist in their altered habitats. The Computerized Geographic Analysis can be used as a tool for characterize the heterogeneity of habitats and thus to help us to understand how the species make use of these altered habitats. The spatial analysis performed in this study allow us to determine the various aspects of the remnants, such as areas with more quality (near drain) or areas with negative influences (roads and close to edge of the fragment), and it was also possible the characterization of the local vegetation and, consequently, guide the sampling of species in function of the habitats types found in the study area and ecological characteristics of mammals species. In the study area where detected 22 species of medium and large-sized mammals, belonging to 12 families. The distribution of these species was influenced by vegetation $\left[\chi^{2}=230.2\right.$ and 36 degrees of freedom, with the critical value (0.01) of 58]. Taking into account that there is influence of vegetation species in the distribution and diversity of habitats, this fact certainly influences the diversity of food resources, so we can admit that the great wealth acquired in the study area are mainly related to the availability of food resources.
\end{abstract}

Key words: Computerized Geographic Analysis, Medium and Large-Sized Mammals, Cerrado Biome, Habitat quality 


\section{Resumo}

No cerrado do estado de São Paulo, muitas espécies de mamíferos de médio e grande porte sobrevivem em remanescentes com áreas muito menores em relação às suas áreas de vida. De alguma maneira estas espécies ainda conseguem persistir nestes remanescentes de cerrado. A análise geográfica computadorizada pode ser utilizada como ferramenta para caracterizar a heterogeneidade dos habitats e, desta forma, auxiliar no entendimento de como as espécies fazem uso dos habitats alterados. A partir da análise espacial realizada neste estudo, foi possível determinar as diversas feições do remanescente, como áreas com qualidades adequadas (próximas à drenagem) ou áreas com influências negativas (próximas às estradas e borda do fragmento), assim como foi possível caracterizar as fitofisionomias e, conseqüentemente, direcionar as amostragens em função dos tipos de habitats encontrados e das características ecológicas das espécies de mamíferos de médio e grande porte. A riqueza total no remanescente compreendeu 22 espécies deste grupo de mamíferos, distribuídas em 12 famílias. A distribuição das espécies foi influenciada pelas fitofisionomias $\left[\chi^{2}=230,2\right.$ e 36 graus de liberdade, com valor crítico $(0,01)$ de 58]. Levando-se em consideração que há influência das fitofisionomias na distribuição das espécies e que a heterogeneidade de habitats certamente influi na diversidade de recursos alimentares, podemos admitir que a grande riqueza obtida no remanescente estudado esteja principalmente relacionada à disponibilidade de recursos alimentares.

Palavras chave: Análise Espacial Computadorizada, Mamíferos de Médio e Grande Porte, Bioma Cerrado, Qualidade de Habitat 


\section{Introdução}

O Brasil é o primeiro país do mundo em diversidade biológica (Mittermeier et al., 1997), equivalendo a $14 \%$ da biota mundial (Lewinsohn \& Prado, 2002). Com relação à fauna de mamíferos, o Brasil também é considerado o mais diverso, com mais de 530 espécies descritas, com muitas ainda a serem descobertas e catalogadas (Costa et al., 2005). No estado de São Paulo existem cerca de 187 espécies de mamíferos terrestres (de Vivo, 1996), das quais 23 encontram-se ameaçadas (Kierulff et al., 2007).

Os mamíferos constituem o grupo mais bem conhecido no Brasil, entretanto, poucos locais foram adequadamente inventariados e listas locais de espécies são geralmente incompletas (Voss \& Emmons, 1996), isto dificulta o desenvolvimento de ações de conservação e manejo destas espécies em escala regional (Brito, 2004).

Com relação ao bioma cerrado, a fauna de mamíferos é relativamente pequena e está principalmente associada ou restrita aos fragmentos florestais ou mata ripária (Redford \& Fonseca, 1984; Marinho-Filho et al., 2002). Pelo menos 137 espécies de animais que ocorrem no Cerrado estão ameaçadas de extinção (Fundação Biodiversitas, 2005) devido à grande expansão agrícola e intensa exploração local de produtos nativos (Klink \& Machado, 2005).

Segundo Fischer \& Lindenmayer (2007), a modificação da paisagem e a fragmentação de habitats são os principais causadores da perda global de espécies. Este declínio está associado à interação entre as ameaças exógenas (perda, degradação e isolamento de habitats), endógenas (mudanças na biologia, comportamento e ecologia das espécies) e estocásticas (ambiental, demográfica e genética). A fragmentação e a perda de habitat resultam da expansão das atividades humanas e constituem, em conjunto com a pressão de caça, as maiores ameaças aos mamíferos de médio e grande porte no Brasil (Bodmer et al., 1997; Cardillo et al., 2004; Costa et al., 2005). Os mamíferos carnívoros são mais sensíveis ao processo de fragmentação e perda de habitat, já que necessitam de 
grandes áreas de vida, desta forma, o tamanho de suas populações vem reduzindo, tornando-as inviáveis a médio e longo prazo (Costa et al., 2005).

No cerrado do estado de São Paulo, muitas espécies de mamíferos de médio e grande porte sobrevivem em remanescentes com áreas muito menores em relação às suas áreas de vida. Segundo Kronka (1998), eram 8.353 os fragmentos de cerrado em áreas particulares em todo o estado de São Paulo, variando em tamanho de 4 a 2.000 hectares. As Unidades de Conservação (32 UC's) de cerrado são apenas $18 \%$ da área remanescente de cerrado, que é de menos de $1 \%$ do estado todo (SMA, 1999).

De alguma maneira estas espécies de mamíferos ainda conseguem persistir nestes remanescentes de cerrado, mas não se sabe até quando isto poderá ocorrer caso não haja fluxo destas espécies entre remanescentes. Desta forma, o grau de ameaça e a importância ecológica dos mamíferos de médio e grande porte, tornam evidente a necessidade de incluí-los em inventários e diagnósticos ambientais.

Métodos eficientes e confiáveis para uma rápida avaliação da riqueza e abundância destas espécies são também cruciais para a determinação de prioridades de conservação (Silveira et al., 2003).

No entanto, o estudo das populações de mamíferos nos trópicos é dificultado por algumas limitações impostas por suas características discretas (Karanth, 1995; Dalponte, 1999; Carbone, 2001). De um modo geral, os mamíferos silvestres brasileiros dificilmente são vistos na natureza, o que se deve, principalmente, ao fato de terem hábitos discretos, largamente crepusculares e noturnos. Quando observados, sua identificação é muitas vezes dificultada pela brevidade da visualização e pela falta de guias de identificação.

Em contra partida, durante suas várias atividades, estes animais freqüentemente deixam sinais típicos no ambiente, como pegadas, arranhões, fezes, tocas e restos alimentares que, se corretamente interpretados, podem identificar o animal que os produziu.

As pegadas são os sinais mais freqüentemente encontrados e de interpretação mais confiável. Para Dalponte (1999), além de fornecer uma identificação precisa sobre as espécies em questão, estes rastros podem auxiliar em estudos de censo 
populacional, determinação da riqueza de espécies, territorialidade, densidade relativa, tipos de atividades, movimentos e até em estudos sobre predadores.

As fezes podem ser utilizadas para a identificação interespecífica de algumas espécies de mamíferos, já que a presença de pêlos guarda em suas próprias amostras fecais, como conseqüência do seu comportamento de manutenção da pelagem (autolimpeza), viabiliza em condições de campo a utilização do método de identificação interespecífico a partir das características morfológicas e macroscópicas dos pêlos, tais como a disposição das suas escamas e o formato da medula (Quadros 2002; Martins et al., 2005).

As armadilhas fotográficas também são ferramentas muito importantes para estimar a riqueza de espécies, além de calcular índices relativos de abundância, já que proporcionam a captura e recaptura de um determinado indivíduo, caso o seu padrão de pelagem, rosetas ou manchas variem entre indivíduos de uma determinada espécie (Karanth et al., 2003; Sanderson; Carbone et al., 2001).

Espera-se que estes métodos de amostragem sejam complementares entre si, favorecendo uma coleta de dados mais representativa da riqueza de espécies de mamíferos de médio e grande porte da comunidade estudada, já que algumas espécies podem não ser capturadas por alguns destes métodos.

O objetivo deste capítulo foi utilizar a análise geográfica computadorizada para espacializar a heterogeneidade dos habitats e orientar as amostragens (delineamento amostral) para determinação da riqueza e freqüência de ocorrência das espécies de mamíferos de médio e grande porte no remanescente de cerrado de 2098 ha, indicado como prioridade para a criação de uma unidade de conservação de proteção integral, assim como para a realização de inventário da fauna de mamíferos, pelo grupo de trabalho de mamíferos do Workshop Biota (2008). 


\section{Materiais e Métodos}

Para estimar a riqueza e a freqüência de ocorrência das espécies de mamíferos de médio e grande porte, foram utilizados:

\section{(E) Materiais}

- Programa IDRISI Andes, desenvolvido pela Clark University (Eastman, 2006);

- Programa Estimate S (Colwell, 2006);

- Mapa Geral de Caracterização Ambiental;

- Mapa de Caracterização Ambiental da Mata Ripária;

- Guias de identificação de mamíferos (Emmons et al.,1998; Dalponte \& Becker, 1999; Quadros, 2002; Borges \& Tomás, 2004; Martins, 2005);

- Armadilhas fotográficas com sensor de movimento (Stealth Cam STC-AD3 $U S A)$;

- GPS Map 76S Garmin (Global Position System) datum Córrego Alegre.

\section{(F) Métodos}

Os remanescentes de cerrado do Estado de São Paulo apresentam características distintas em relação à área, composição, conectividade e grau de isolamento, geralmente constituem-se de pequenas manchas de habitats heterogêneos. Estas características também são atribuídas ao remanescente alvo deste estudo.

Por se tratar de um mosaico de habitats heterogêneos, representados por cerradão, cerrado sensu stricto típico, cerrado sensu stricto denso, mata ripária e campo úmido, optou-se pela realização de uma amostragem sistematizada das espécies de mamíferos de médio e grande porte no remanescente. 
A sistematização foi possível devido à elaboração prévia de uma base cartográfica que promoveu a espacialização da heterogeneidade do ambiente, possibilitando a exploração da diversidade de habitats existentes no remanescente de cerrado.

Desta forma, os mapas de caracterização produzidos foram utilizados como uma fonte de dados preliminares e complementares que serviram como base para a seleção dos pontos de amostragem, assim como para auxiliar a análise dos dados das espécies de mamíferos alvos deste estudo.

O Mapa Geral de Caracterização Ambiental foi utilizado para fornecer uma base cartográfica simples de qualidade ambiental da área de estudo, possibilitando a determinação de habitats com diferentes graus de perturbação ou diferentes graus de qualidade. Sendo assim, a alocação dos canteiros de pegadas, armadilhas fotográficas e transecções foi realizada buscando-se cobrir as diversas feições ambientais da área de estudo (Figura III.1).

As Figuras III.2 à III.4 apresentam o detalhamento das áreas onde foram instaladas as armadilhas fotográficas, os canteiros de pegadas e as transecções, respectivamente. Para isto, foi estipulada uma área buffer de $250 \mathrm{~m}$ a partir do local de instalação, buscando realizar a análise dos habitats que estão sendo cobertos pelo método. Em seguida, foram calculadas as porcentagens das fitofisionomias encontradas nas áreas buffer de cada método (Tabela III.1), para demonstrar que os mesmos cobriram proporcionalmente as fitofisionomias existentes no remanescente. Estes procedimentos foram realizados no programa IDRISI Andes (Eastman, 2006).

A Mata ripária não foi computada neste momento, já que o Mapa de Caracterização Ambiental da Mata Ripária foi utilizado somente após as amostragens, para avaliação de seu uso pelas espécies de mamíferos encontradas neste ambiente. 


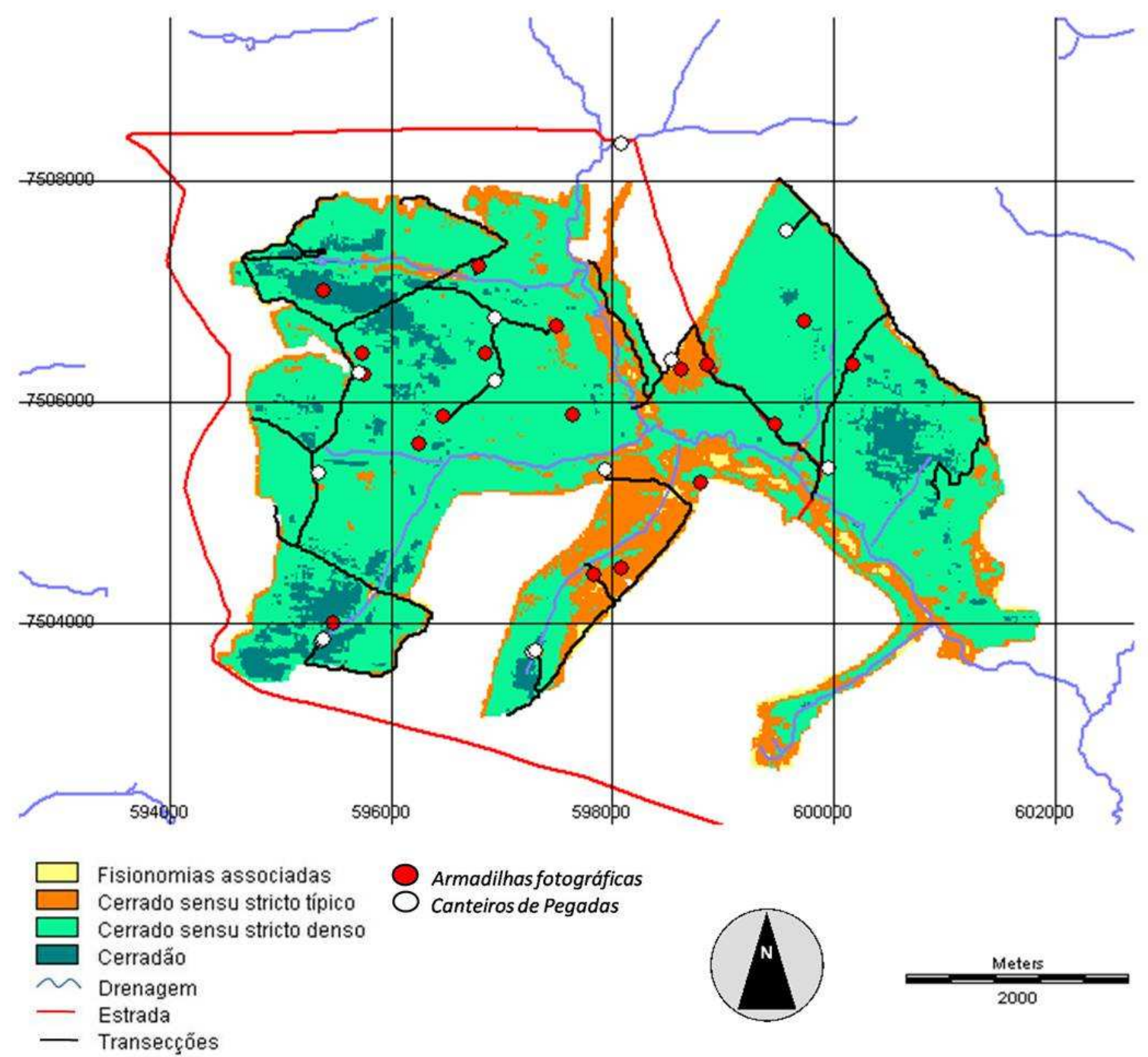

Fig.III.1. - Mapa Geral de Caracterização Ambiental contendo a localização das transecções $(n=11)$, das armadilhas fotográficas $(n=18)$ e dos canteiros de pegadas $(n=10)$. 


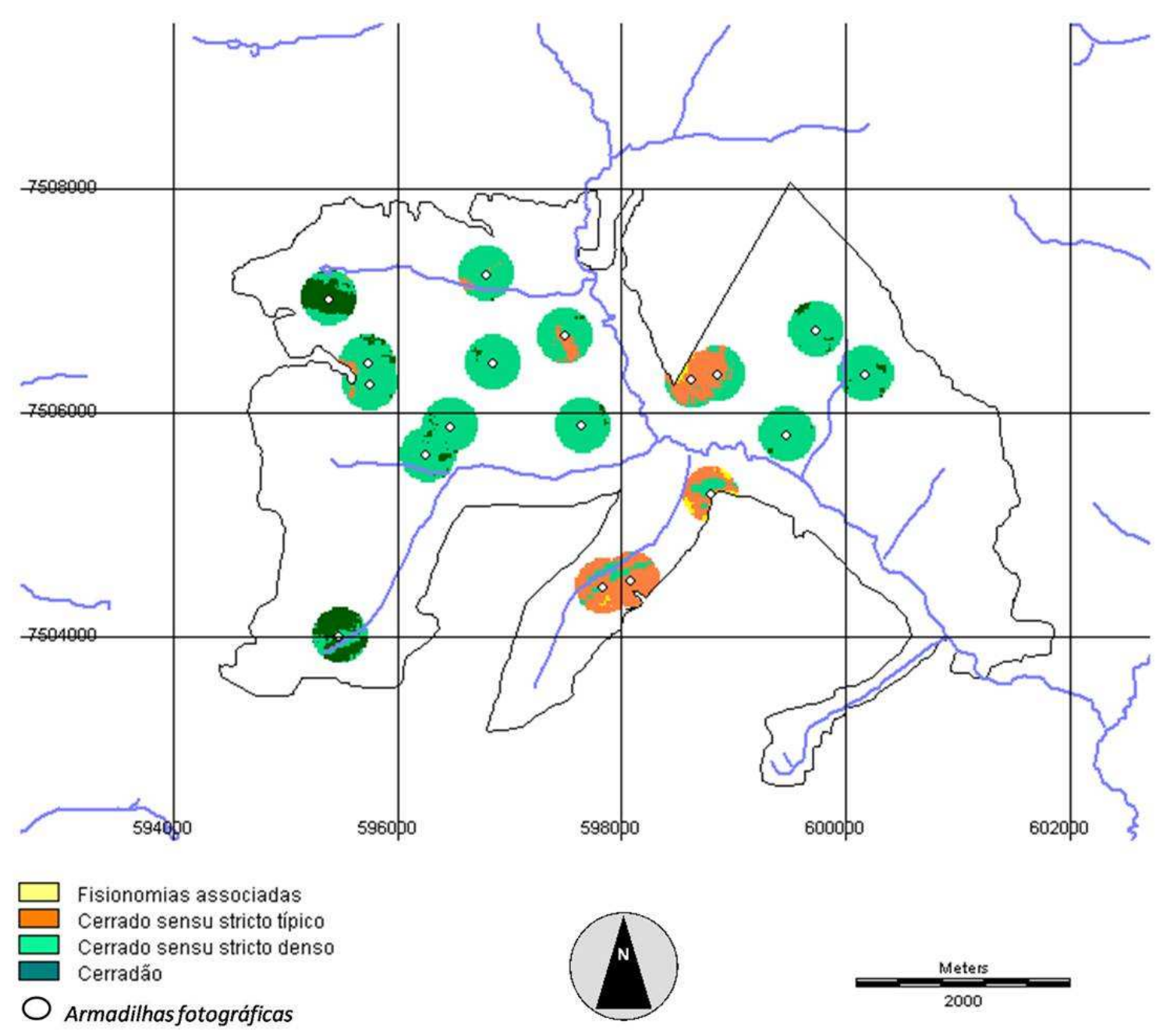

Fig.III.2. - Detalhamento das áreas onde foram instaladas as armadilhas fotográficas $(\mathrm{n}=18)$. Foi estipulada uma área buffer de $250 \mathrm{~m}$ a partir do local de instalação, para análise dos habitats que estão sendo cobertos pelo método. 


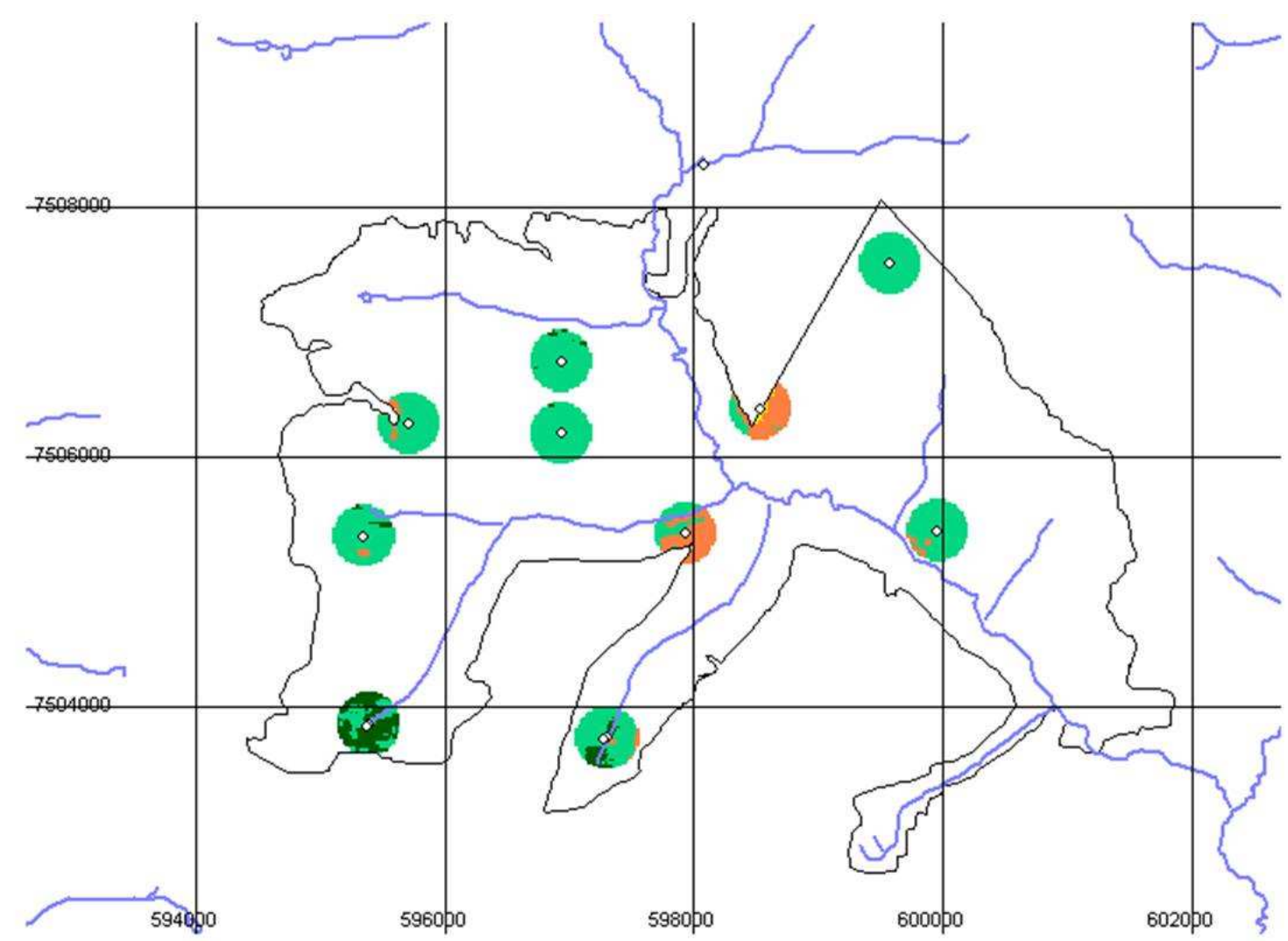

Fisionomias associadas

Cerrado sensu stricto típico

Cerrado sensu stricto denso

Cerradão

Canteiros de pegadas
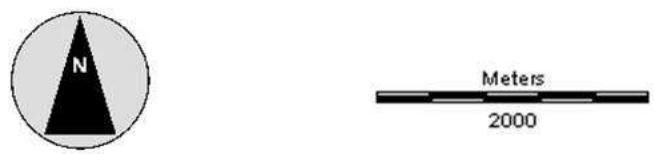

Fig.III.3. - Detalhamento das áreas onde foram instalados os canteiros de pegadas $(n=10)$. Foi estipulada uma área buffer de $250 \mathrm{~m}$ a partir do local de instalação, para análise dos habitats que estão sendo cobertos pelo método. 


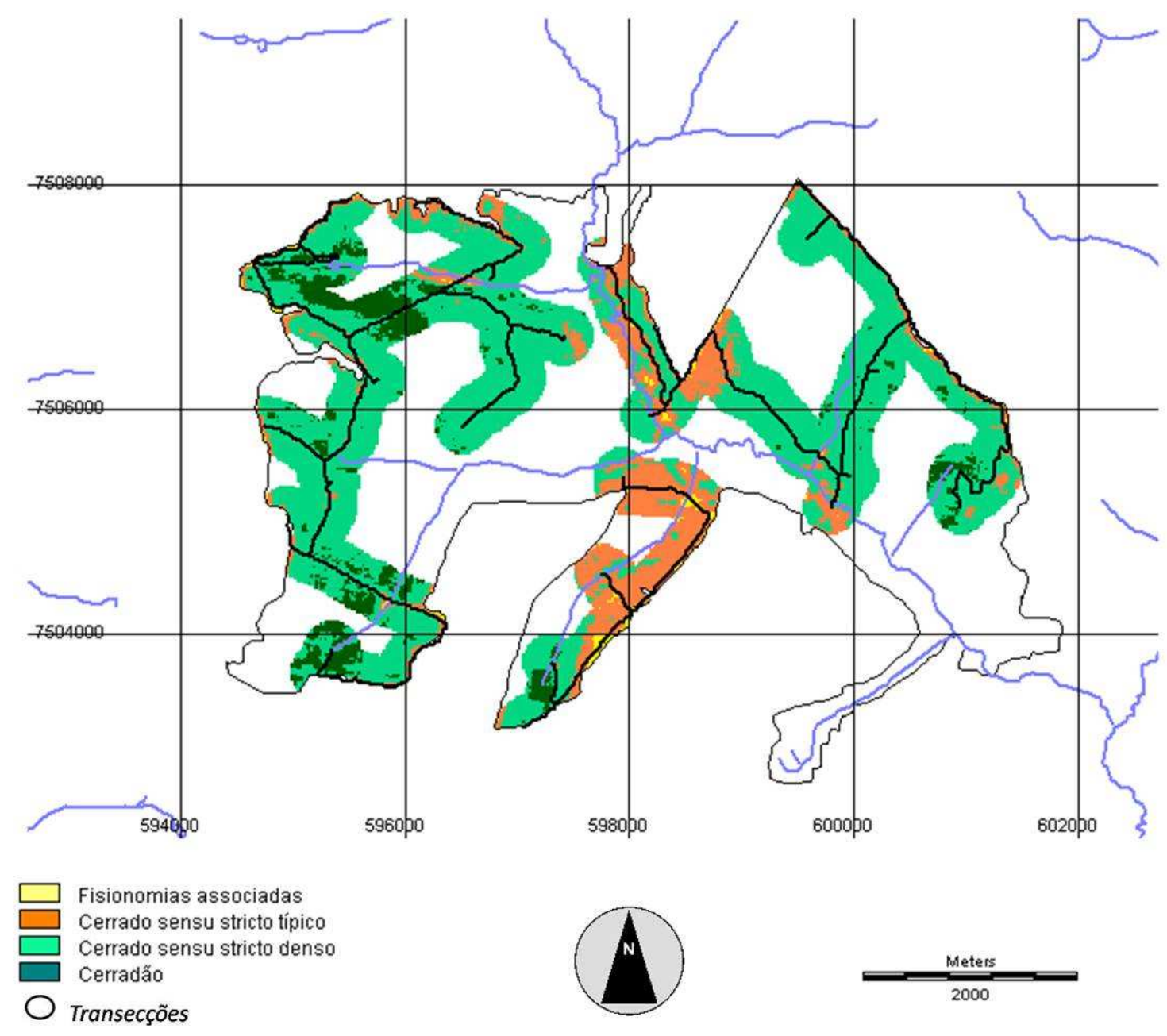

Fig.III.4. - Detalhamento das áreas onde foram realizadas as transeções $(n=11)$. Foi estipulada uma área buffer de $250 \mathrm{~m}$ a partir do local de instalação, para análise dos habitats que estão sendo cobertos pelo método. 
Riqueza de Espécies de Mamíferos de Médio e Grande Porte em um Fragmento de Cerrado no Estado de São Paulo

Tabela III.1. - Porcentagem da área ocupada por cada fitofisionomia no interior do remanescente estudado e porcentagem coberta pelos métodos de amostragem utilizados. A Mata ripária não foi computada neste momento

\begin{tabular}{lcccc}
\hline \multirow{2}{*}{ Fitofisionomias } & \multicolumn{4}{c}{$\%$} \\
\cline { 2 - 5 } & Remanescente & $\begin{array}{c}\text { Armadilhas } \\
\text { fotográficas }\end{array}$ & $\begin{array}{c}\text { Canteiros de } \\
\text { pegadas }\end{array}$ & Transectos \\
\hline Cerradão & 8,5 & 10,6 & 9,8 & 8,6 \\
Cerrado s.s. denso & 71,7 & 70,1 & 76,5 & 70,3 \\
Cerrado s.s. típico & 18,1 & 18,3 & 13,1 & 19,6 \\
Campo úmido & 1,7 & 1,0 & 0,5 & 1,4 \\
\end{tabular}

ss: sensu stricto

A amostragem foi realizada de 17/03 a 21/04/2008, utilizando o censo de pegadas e de outros vestígios (fezes, arranhões e carcaças) ao longo das transecções e do corredor de mata ripária. Também foram utilizados 28 pontos fixos de amostragem: 18 de armadilhas fotográficas com sensor de movimento (Stealth Cam STC-AD3 USA) e 10 de canteiros de pegadas (Figura III.5).

Os canteiros foram desenvolvidos com metragem de $1 \times 1$ metro e com o próprio solo da área, já que este solo é pouco compactado e arenoso o suficiente para possibilitar a impressão das pegadas. Estes canteiros foram visitados em intervalos de três dias para registro das pegadas impressas. Não foram registradas pegadas ambíguas e as pegadas de uma espécie, obtidas no mesmo canteiro e no mesmo dia foram consideradas de um único indivíduo. Não foram utilizados atrativos, como alimentos ou essências.

As armadilhas fotográficas foram instaladas dentro da mata ou no transecto, diretamente em árvores a uma altura de aproximadamente $30 \mathrm{~cm}$. A área foi limpa, ou seja, herbáceas que estivessem dentro do ângulo de visada da câmera foram retiradas para evitar a ativação do sensor de movimento. As armadilhas fotográficas ficaram operando por 30 dias consecutivos, totalizando 540 armadilhas/noite e foram visitadas uma vez por semana para averiguação de seu estado de 
funcionamento. Em algumas armadilhas foram utilizados alimentos (banana) como atrativo.

A escolha de se instalar um canteiro ou uma armadilha fotográfica em determinada área foi aleatória.

No campo, foram abertas 11 transecções ao longo do remanescente, com largura aproximada de um metro. No total, as transeções apresentaram $32,6 \mathrm{~km}$ de extensão. Os transectos foram percorridos a pé, cinco vezes durante um mês de amostragem, sempre intercalados, totalizando $162,9 \mathrm{~km}$ de transectos percorridos/mês. O corredor de mata ripária localiza-se na porção central do fragmento, totalizando $4,6 \mathrm{~km}$ de extensão. Este corredor foi percorrido duas vezes no período de amostragem, totalizando $9,2 \mathrm{~km}$ percorridos.

Assumiu-se que a capacidade de deteç̧ão das espécies de mamíferos nos três métodos (armadilhamento fotográfico, canteiro de pegadas e censo de vestígios ao longo de transectos) era homogênea e que todas as espécies eram igualmente detectáveis por estes métodos.

Os transectos, os pontos de alocação das armadilhas fotográficas e dos canteiros e os pontos de detecção dos vestígios e de eventuais vocalizações e avistamentos, foram marcados com o auxílio de GPS. Cada registro foi considerado como presença e utilização pelos animais (Smallwood \& Fitzhugh, 1995) dos mosaicos de habitat encontrados no remanescente.

Para a identificação das espécies, foram utilizados guias de identificação (Emmons et al.,1998; Dalponte \& Becker, 1999; Quadros, 2002; Borges \& Tomás, 2004; Martins, 2005). As amostras de fezes foram analisadas quanto ao seu cheiro, forma, tamanho, conteúdo e identificação dos pêlos da própria espécie, que foram engolidos devido ao seu comportamento de autolimpeza. As carcaças foram fotografadas, medidas e comparadas com peças museológicas, quando necessário. As pegadas foram fotografadas, medidas e identificadas no campo.

Não foram realizadas amostragens sazonais, pois a entrada no remanescente dependia de autorização do proprietário. Desta forma, a presente amostragem compreendeu apenas o período de estiagem. 


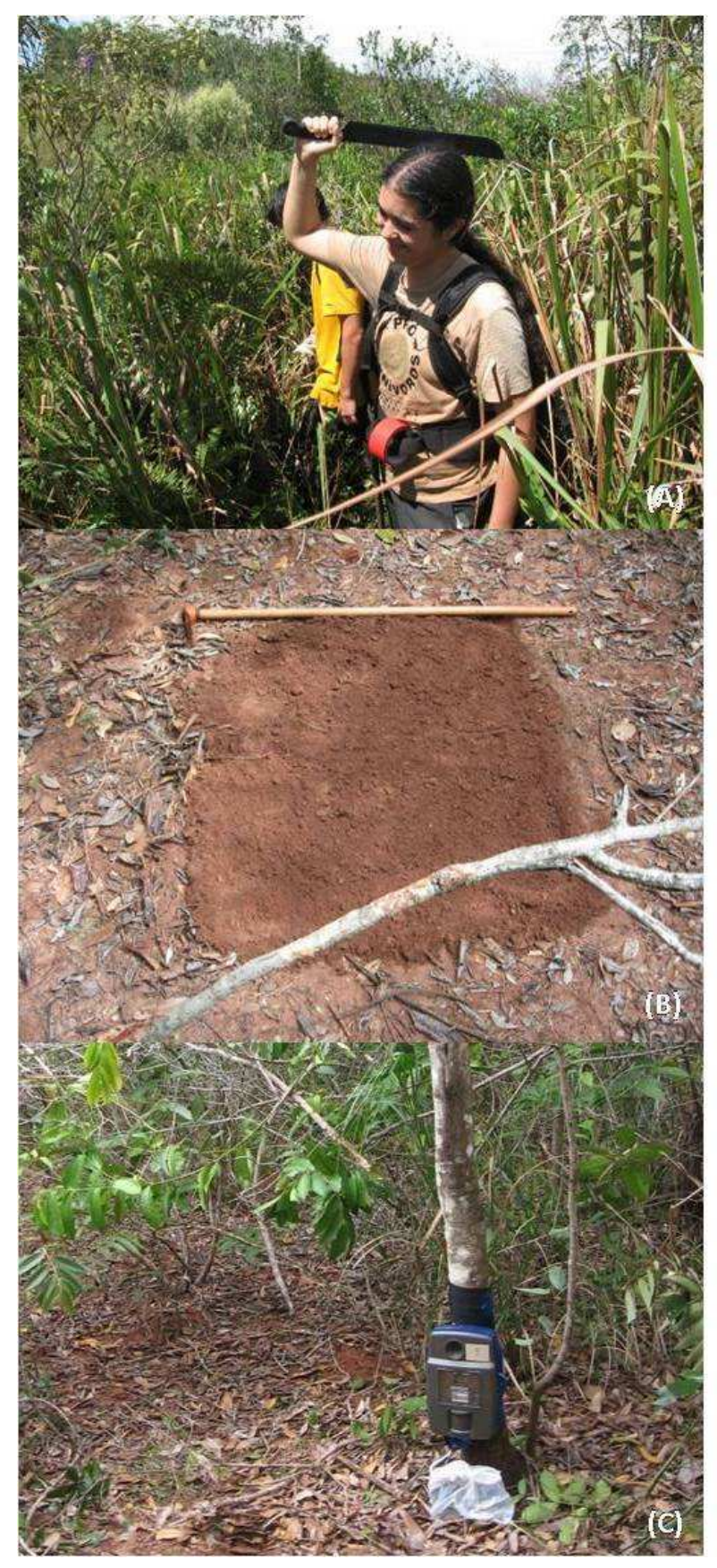

Fig.III.5. - Métodos utilizados para coleta de dados de riqueza e freqüência de ocorrência das espécies de mamíferos de médio e grande porte: (a) transectos; (b) canteiro de pegadas; e (c) armadilha fotográfica com sensor de movimento. 
A freqüência relativa (FR) das espécies foi calculada de acordo com Crooks (2002): $\mathrm{i} / \mathrm{N}$, onde $\mathrm{i}$ = número de ocorrência das espécies; e $\mathrm{N}=$ total de ocorrências no remanescente ou na fitofisionomia.

Os dados de detecção das espécies de mamíferos de médio e grande porte, obtidos no cerradão, cerrado sensu stricto típico, cerrado sensu stricto denso, mata ripária e campo úmido, foram submetidos ao teste do qui-quadrado $\left(\chi^{2}\right)$ de Pearson (Sokal \& Rohlf, 1995) para avaliar se existe influência das fitofisionomias na composição das espécies.

Os dados de riqueza de mamíferos de médio e grande porte, obtidos por meio dos três métodos de amostragem, foram inseridos no programa Estimate $S$ (Colwell, 2006) para estimativa da curva de acumulação de espécies (Sobs - Mao Tau) e da curva de riqueza estimada (Bootstrap). Foram realizadas 50 randomizações para redução do efeito da ordem da amostra.

A curva de acumulação de espécies (Sobs - Mao Tau) apresenta o acúmulo de espécies diferentes coletadas à medida que se aumenta o esforço de amostragem, com intervalo de confiança de 95\% (Gotelli \& Colwell, 2001).

Bootstrap é um teste não paramétrico que utiliza os dados de todas as espécies coletadas para estimar a riqueza total, não se restringindo às espécies raras. A estimativa pelo Bootstrap foi calculada somando-se a riqueza observada à soma do inverso da proporção das amostras em que ocorre cada espécie (Smith \& van Belle, 1984). 


\section{Resultados}

No remanescente de cerrado estudado foram detectadas 22 espécies de mamíferos de médio e grande porte, distribuídas em 12 famílias. Destas espécies, 11 pertencem à Ordem Carnivora (Tabela III.2 e Figura III.6).

Tabela III.2. - Espécies de mamíferos de médio e grande porte detectadas no remanescente de cerrado situado no município de Campos Novos Paulista, SP

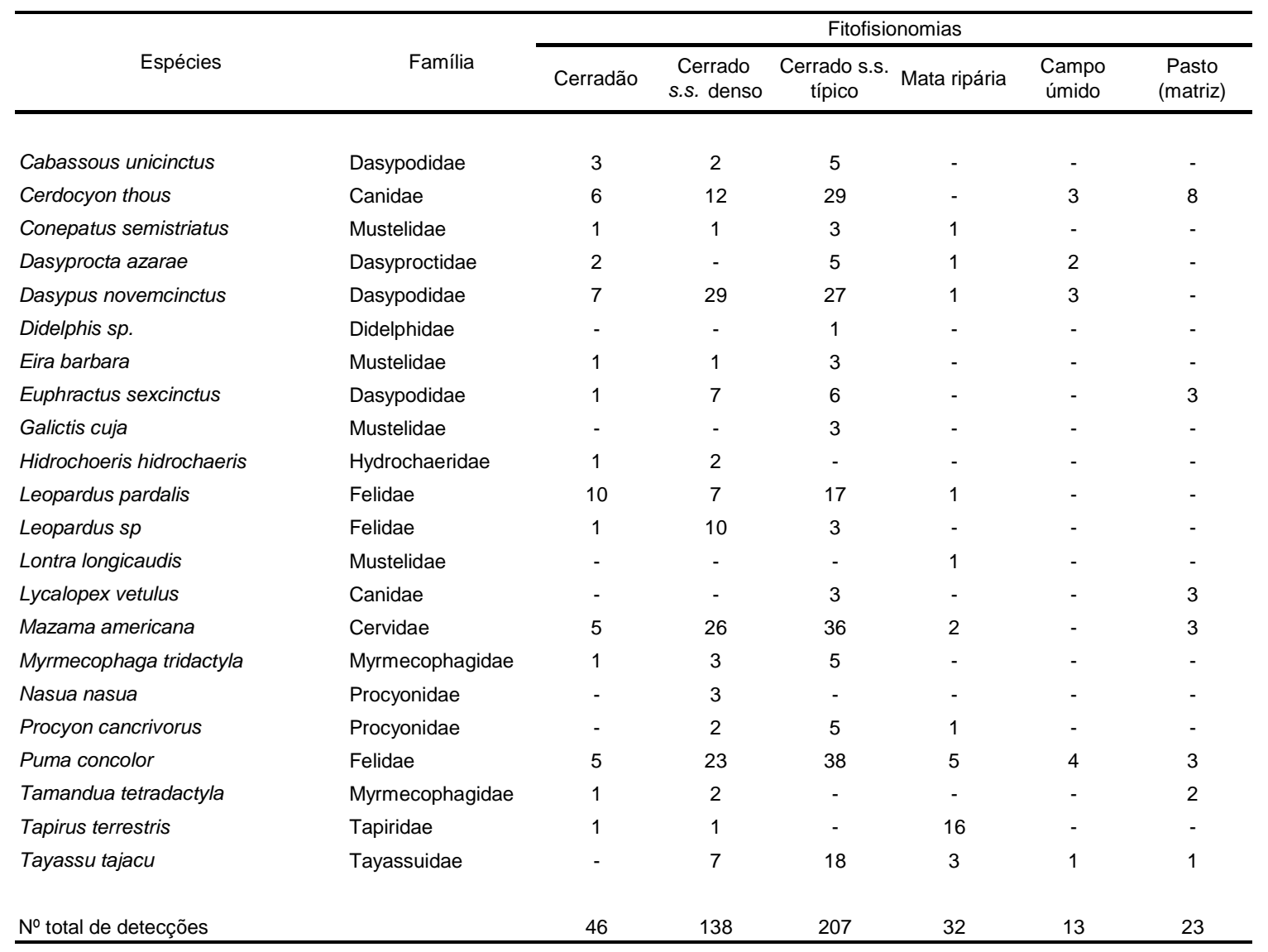

As Figuras III.7 à III.15 apresentam a localização dos pontos de detecção das espécies encontradas na área de estudo, permitindo-se observar a distribuição destes pontos ao longo dos diversos tipos de fitofisionomias. Também é possível observar os diferentes tipos de influências (positivas, como a proximidade da drenagem; ou negativas, como a proximidade com a estrada ou borda do 
Riqueza de Espécies de Mamíferos de Médio e Grande Porte em um Fragmento de Cerrado no Estado de São Paulo

fragmento) que irão influir na qualidade dos habitats do remanescente de cerrado.

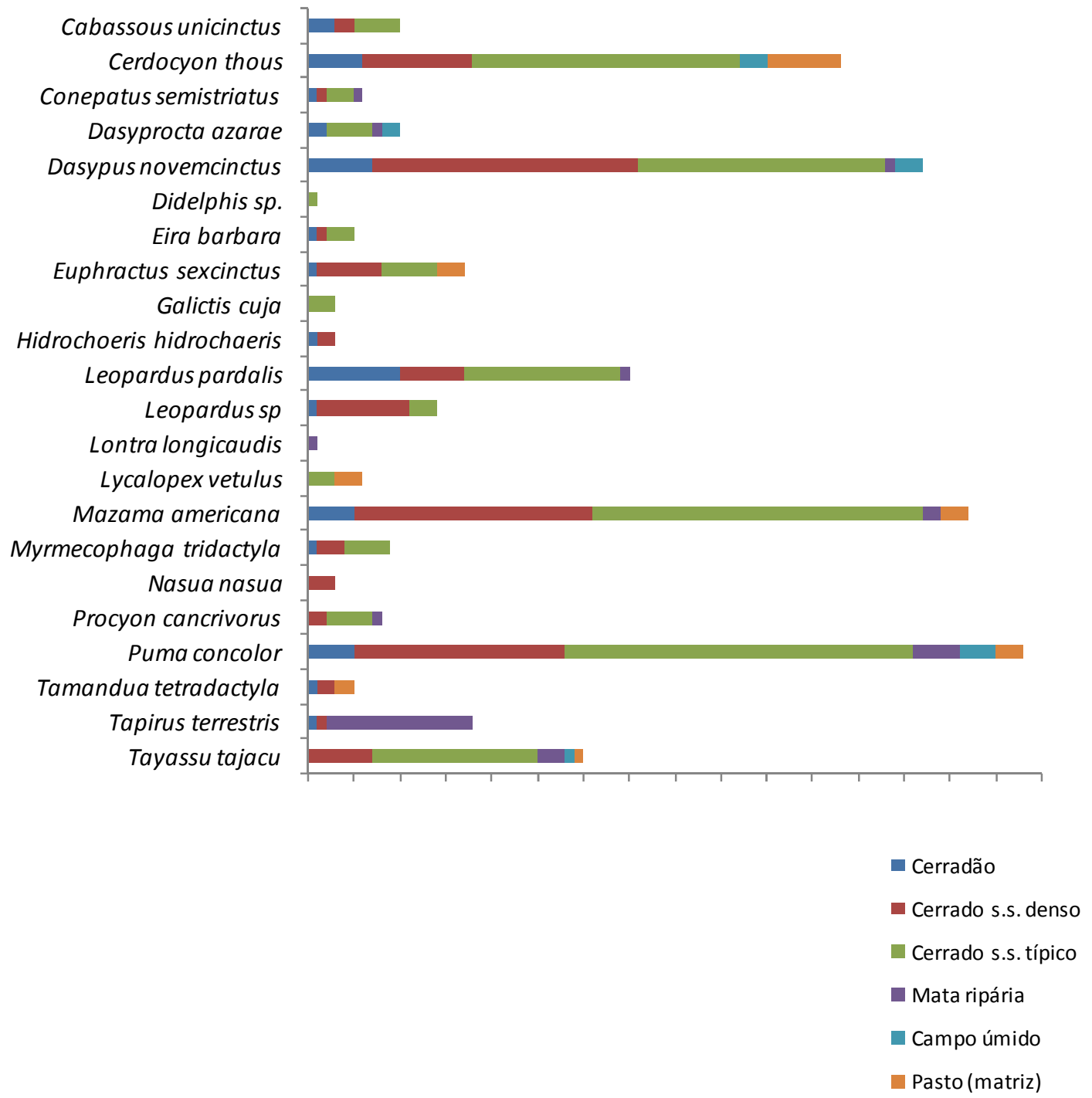

Fig.III.6. - Gráfico ilustrando a proporção de espécies de mamíferos de médio e grande porte detectadas na área de estudo. 


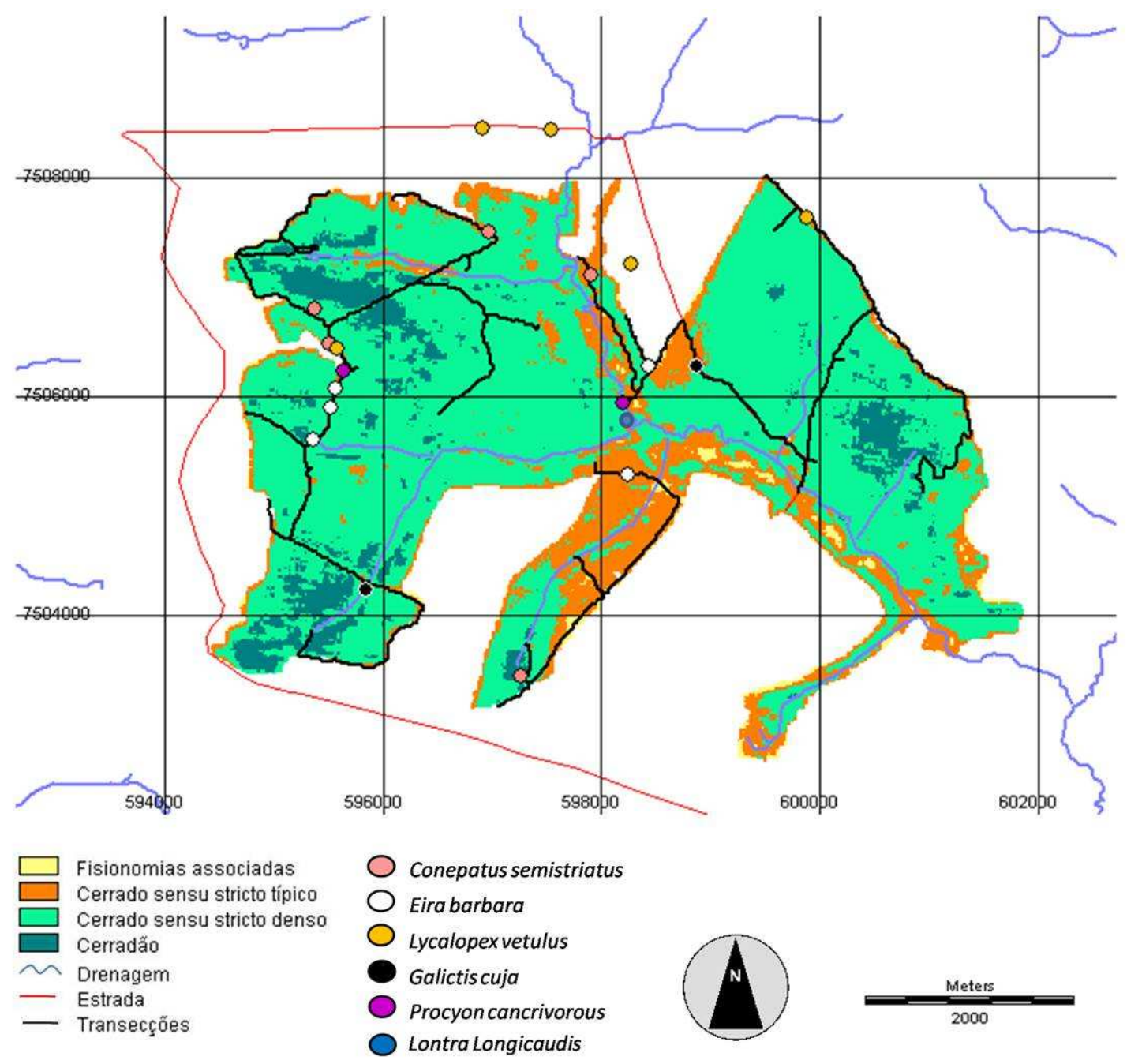

Fig.III.7. - Localização dos pontos de detecção de Conepatus semistriatus (jaratataca), Eira Barbara (irara), Lycalopex vetulus (raposinha-do-campo), Galictis cuja (furão), Procyon cancrivorous (mão-pelada) e Lontra longicaudis (lontra). 


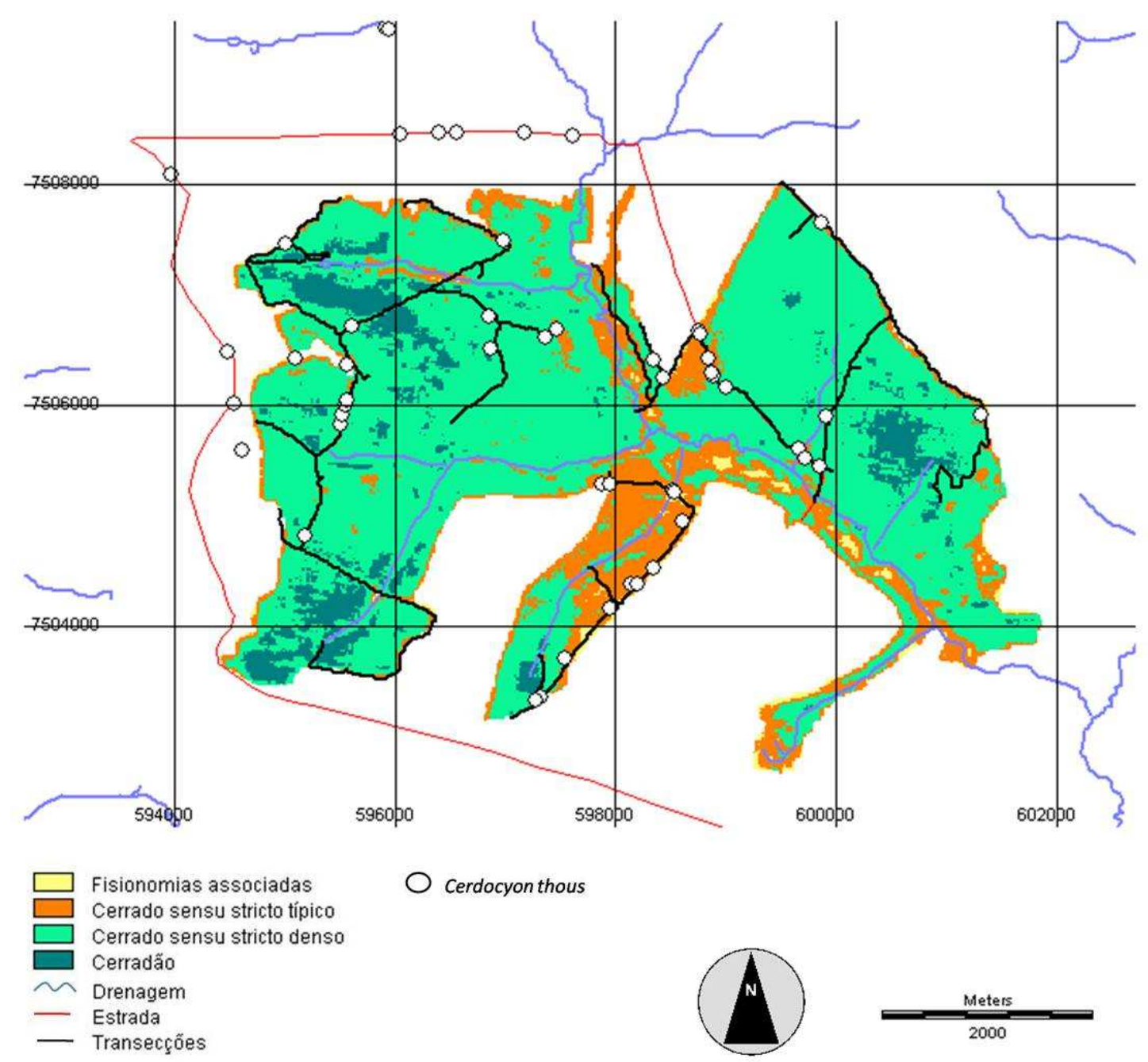

Fig.III.8. - Localização dos pontos de detecção de Cerdocyon thous (cachorro-do-mato). 


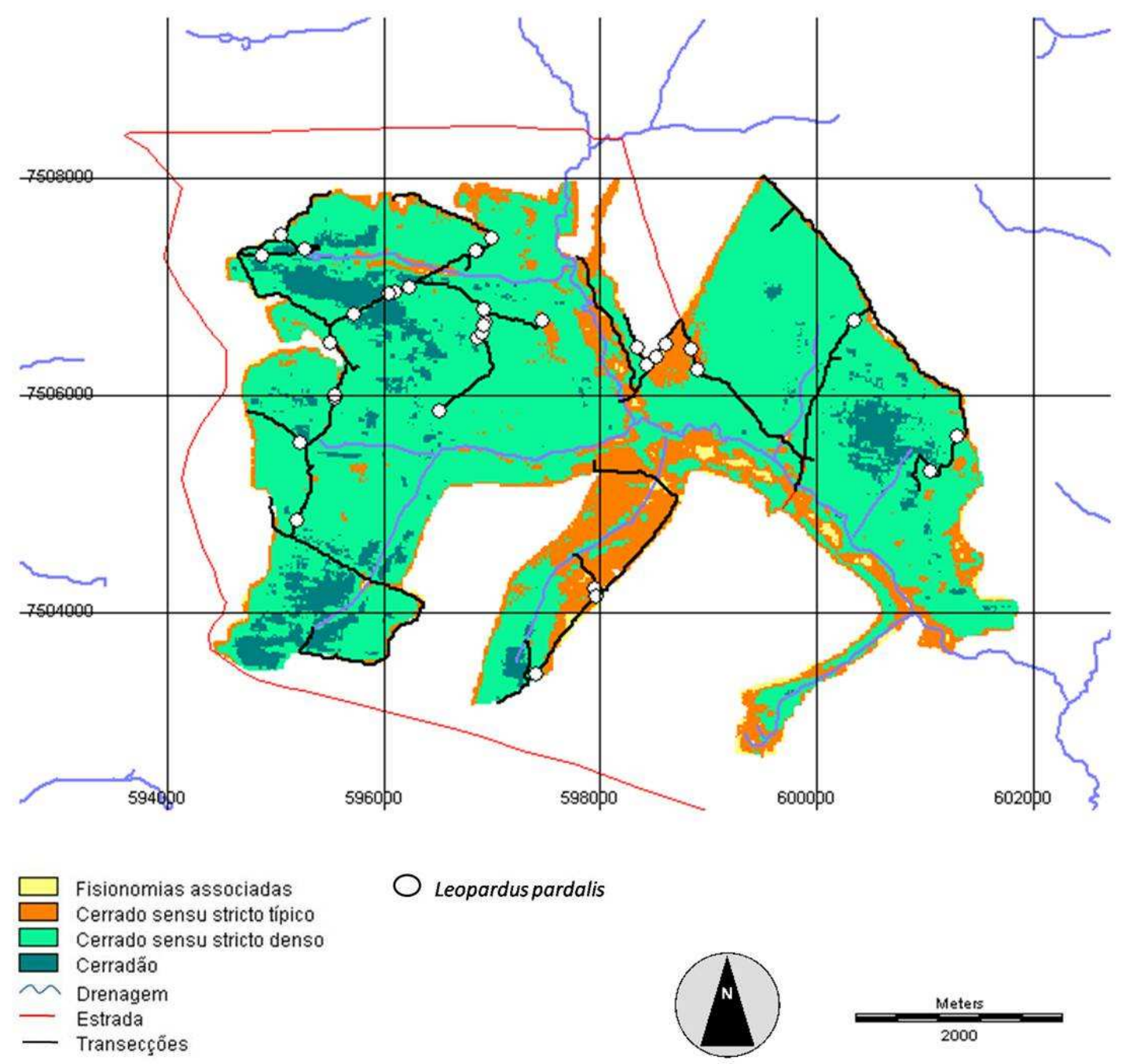

Fig.III.9. - Localização dos pontos de detecção de Leopardus pardalis (jaguatirica). 


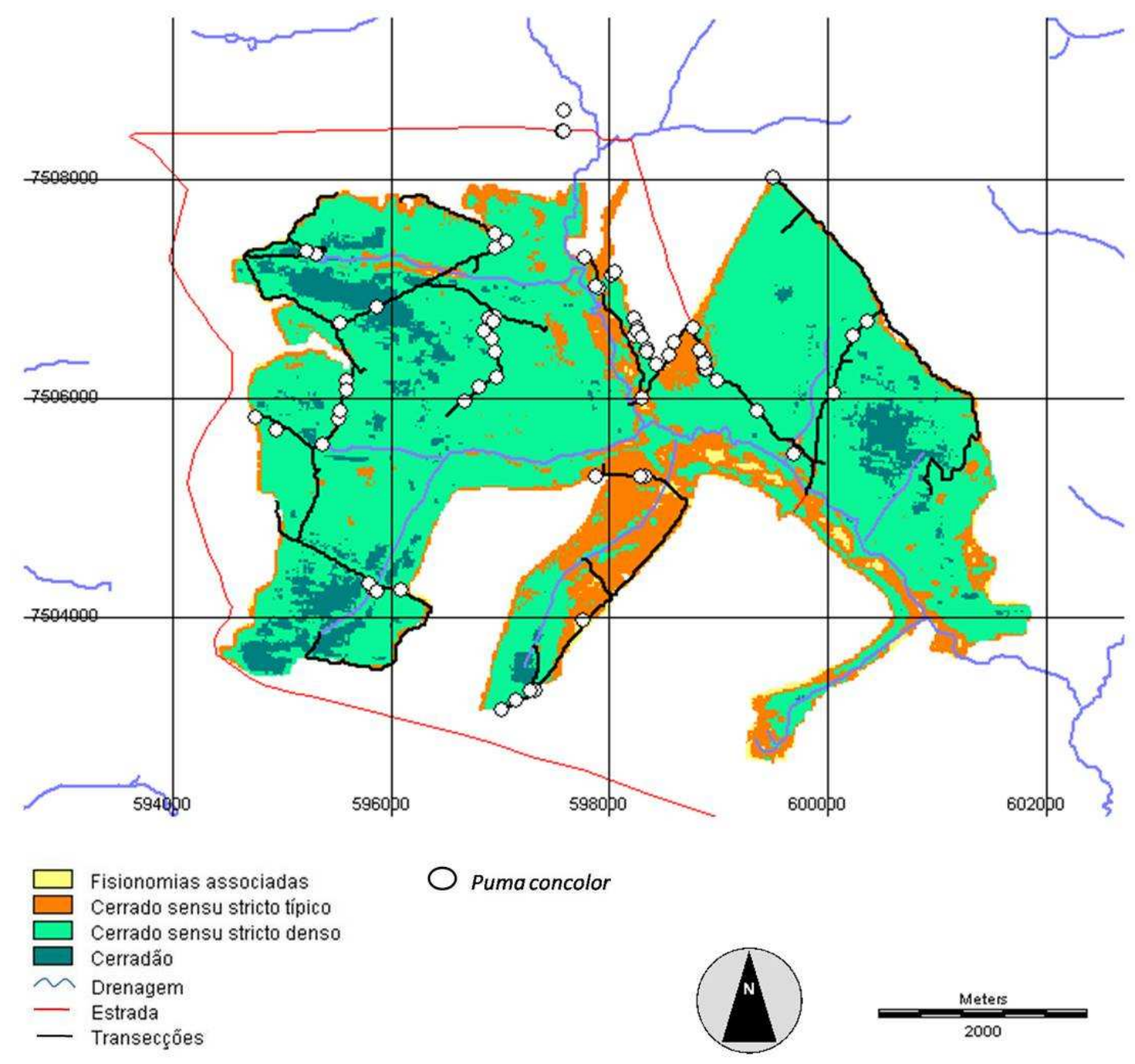

Fig.III.10. - Localização dos pontos de detecção de Puma concolor (onça-parda). 


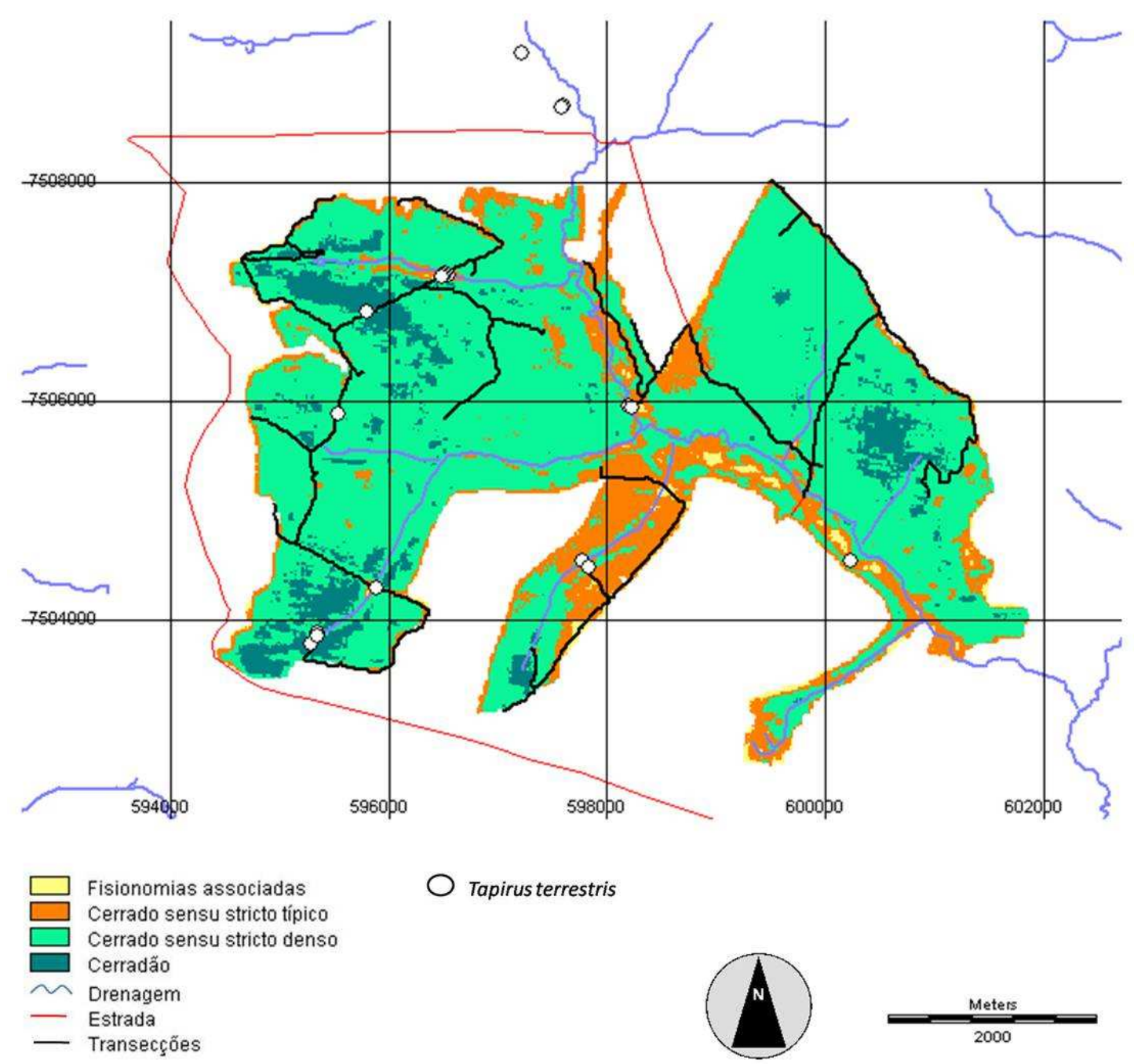

Fig.III.11. - Localização dos pontos de detecção de Tapirus terrestris (anta). 


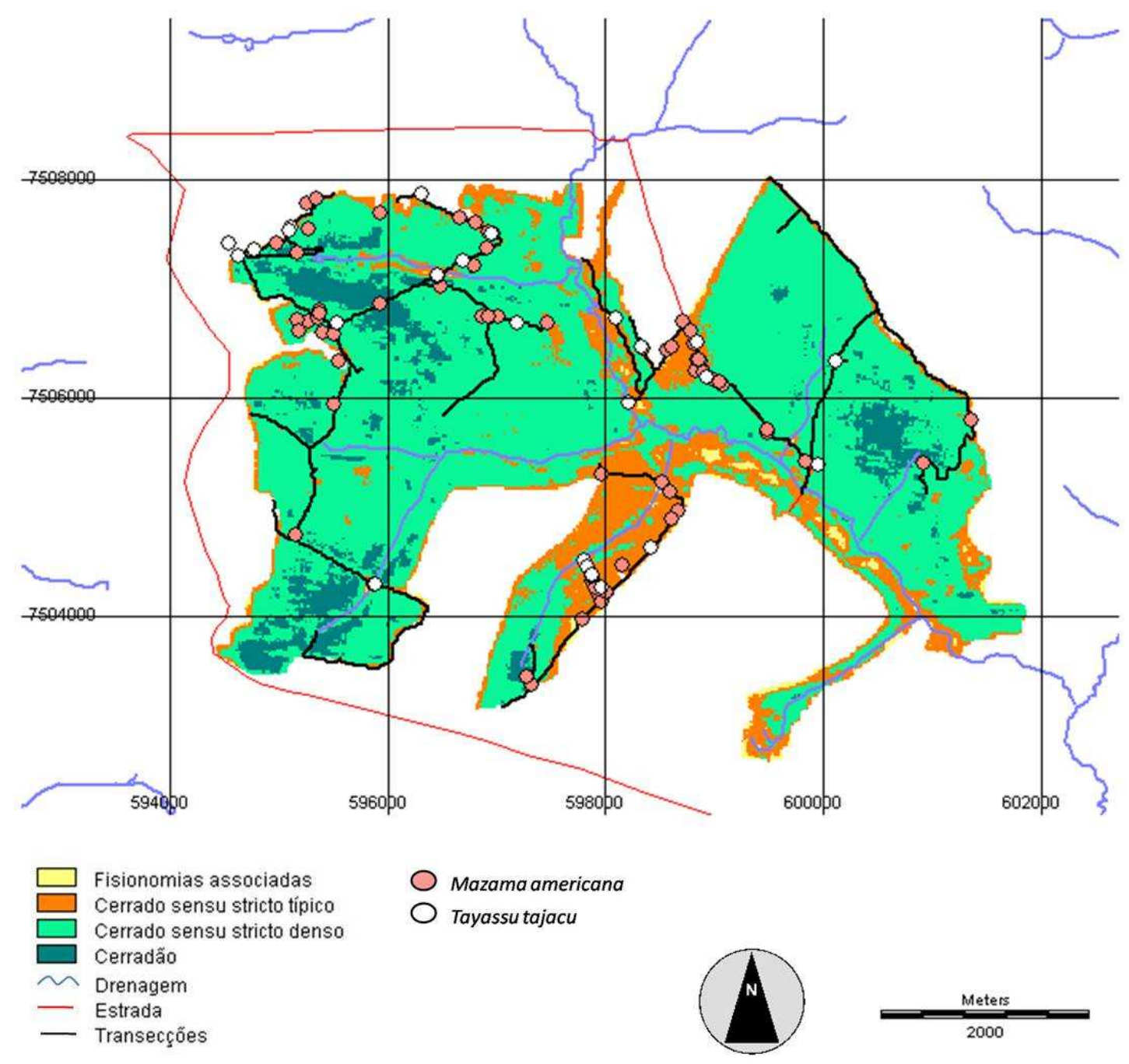

Fig.III.12. - Localização dos pontos de detecção de Mazama americana (veado-campeiro) e Tayassu tajacu (cateto). 


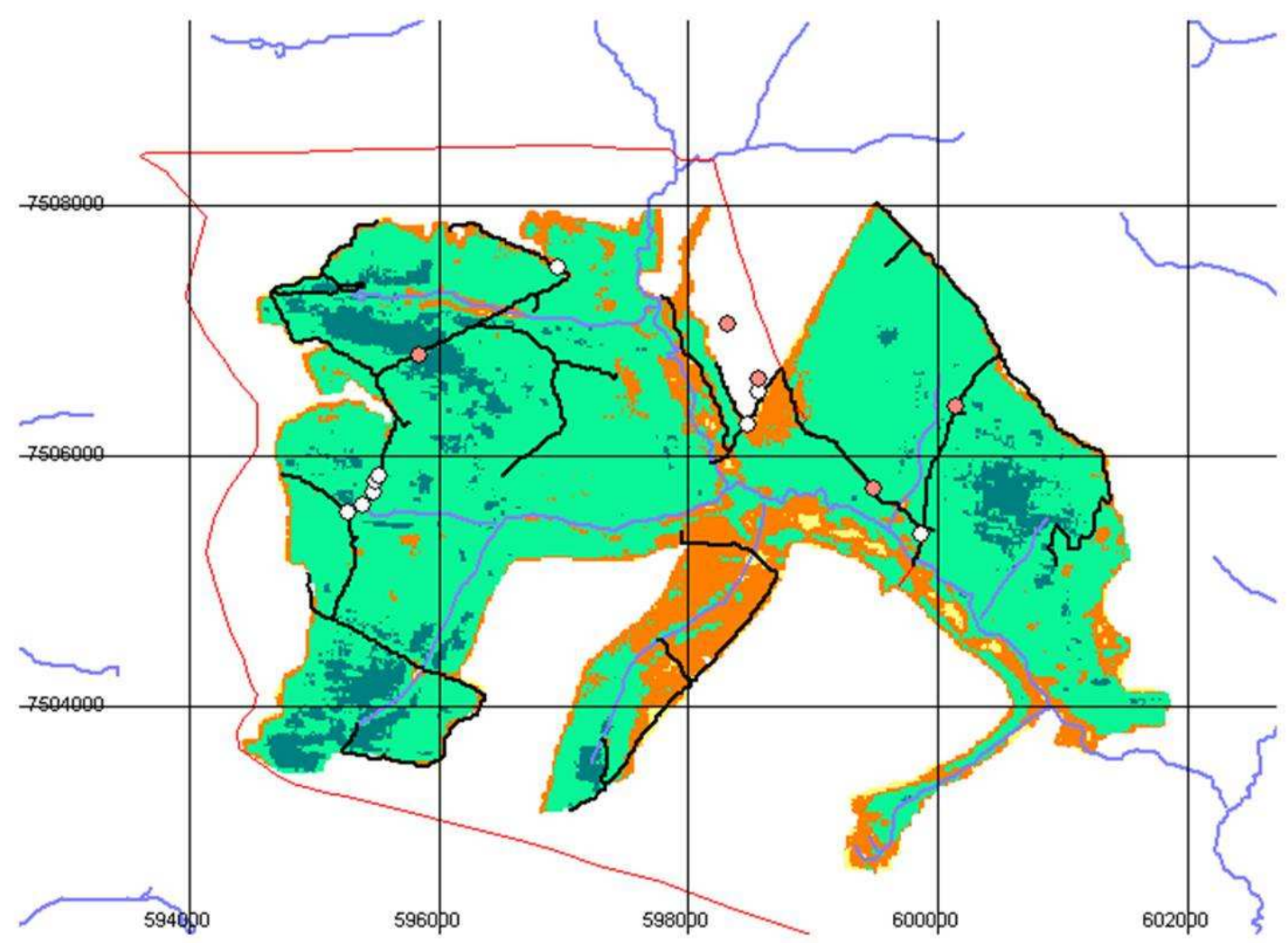

Fs aciadas

Cerrado sensu stricto típico

Tamanduatetradactyla

Cerrado sensu stricto denso

Myrmecophagatridactyla

Cerradão

$\sim$ Drenagem

- Estrada

- Transecçốes

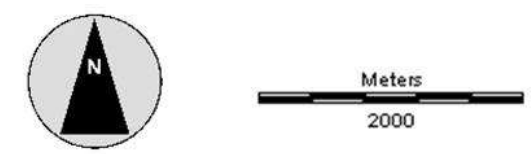

Fig.III.13. - Localização dos pontos de detecção de Tamandua tetradactyla (tamanduámirim) e Myrmecophaga tridactyla (tamanduá-bandeira). 


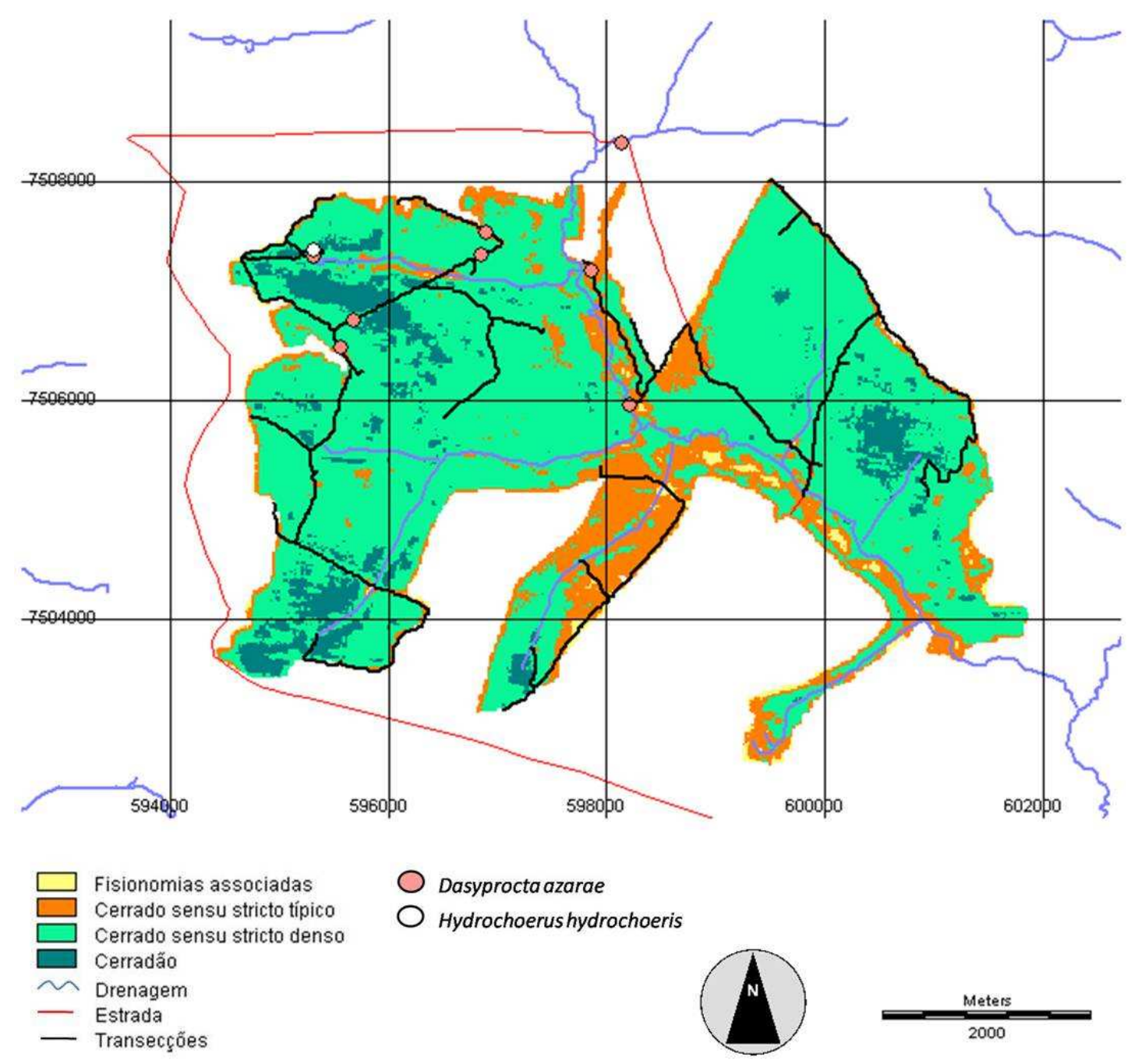

Fig.III.14. - Localização dos pontos de detecção de Dasyprocta azarae (cutia) e Hydrochoerus hydrochoeris (capivara). 


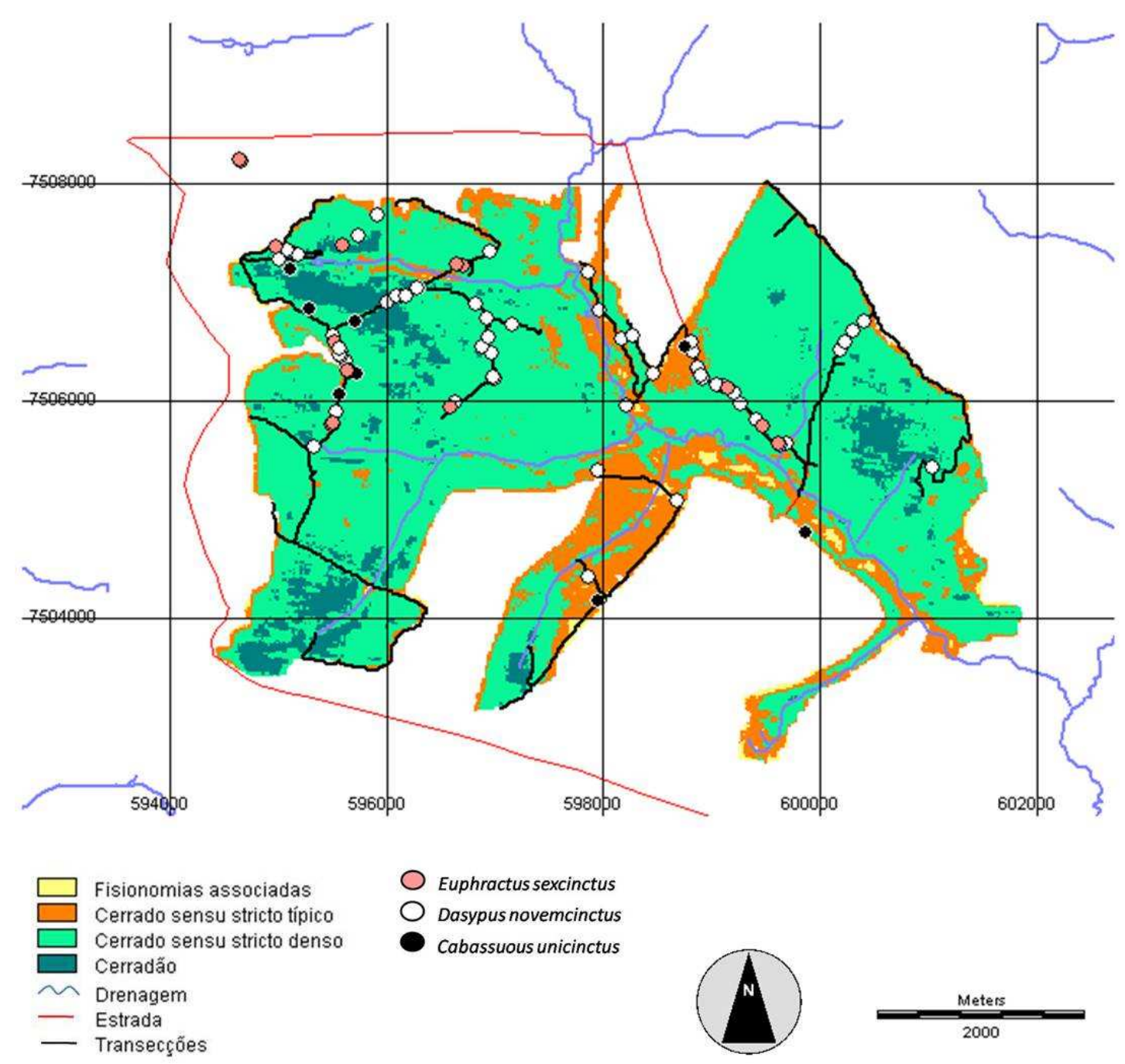

Fig.III.15. - Localização dos pontos de detecção de Euphractus sexcinctus (tatu-peba), Dasypus novemcinctus (tatu-galinha) e Cabassuous unicinctus (tatu-de-rabo-mole). 
Riqueza de Espécies de Mamíferos de Médio e Grande Porte em um Fragmento de Cerrado no Estado de São Paulo

As espécies Conepatus semistriatus, Leopardus sp, Procyon cancrivorous, Puma concolor, Tayassu tajacu, Dasypus novemcinctus, Dasyprocta azarae e Tapirus terrestris, também foram detectadas no complexo ripário. Desta forma, seus dados foram inseridos no Mapa de Caracterização Ambiental da Mata Ripária para melhor detalhamento do seu uso por estes animais (Figuras III.16 e III.17).

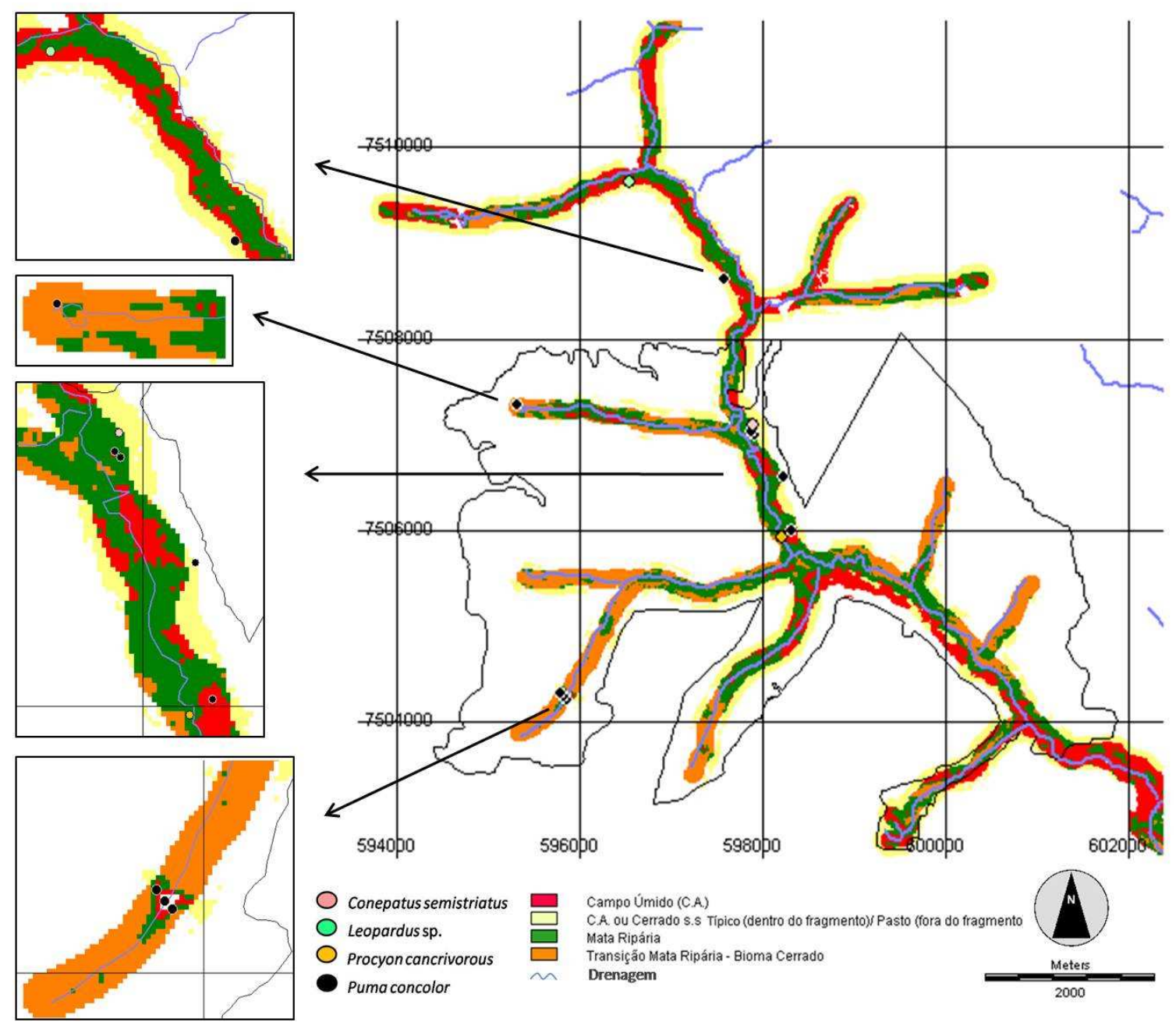

Fig.III.16. - Detalhamento dos pontos de detecção de Conepatus semistriatus, Leopardus sp, Procyon cancrivorous e Puma concolor, no complexo ripário (Silveira et al., 2009). 

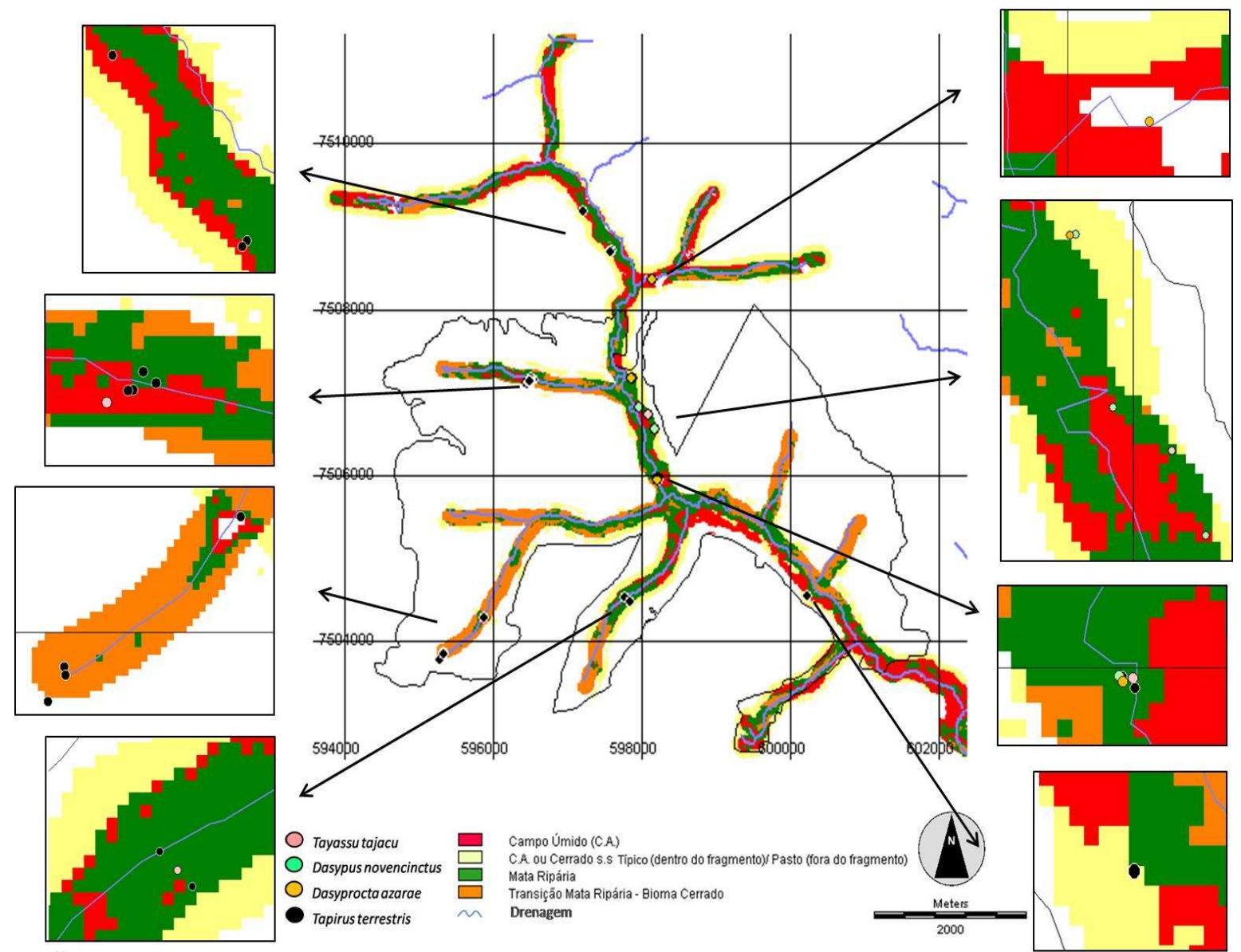

5960 0

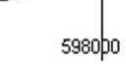

A. ou Cerrado Ss Tipico (dentro do fragmento) Pasto (fira do fragmento) Mata Ripária

Dreçao Măta Ripária - Bioma cerrado Drenagem
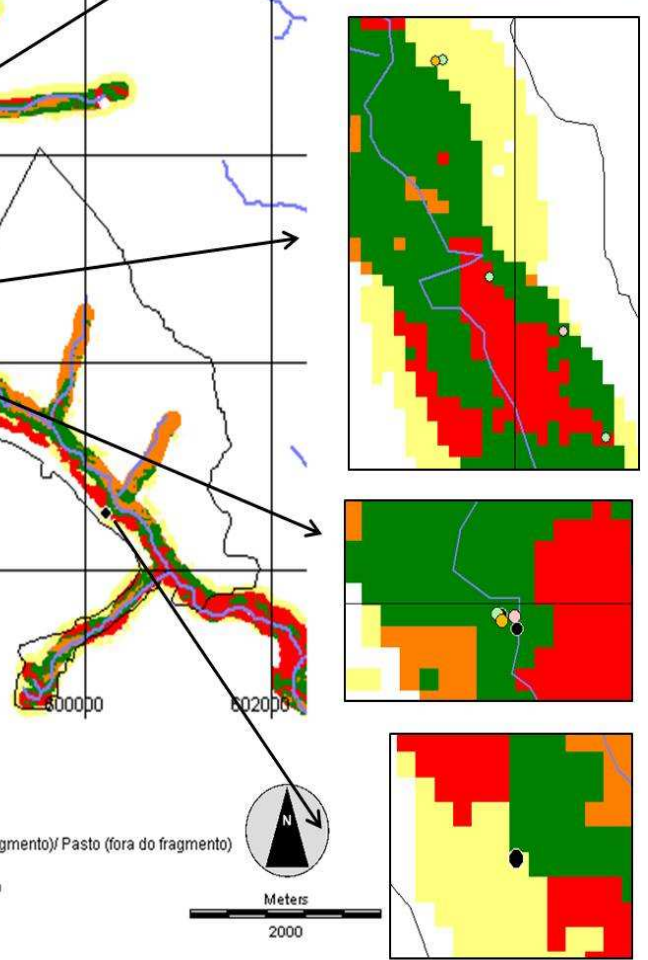

Fig.III.17. - Detalhamento dos pontos de detecção de Tayassu tajacu, Dasypus novemcinctus, Dasyprocta azarae e Tapirus terrestris, no complexo ripário (Silveira et al., 2009). 
Como foi observado na Tabela III.2 e nas Figuras III.6 à III.17, Puma concolor foi a única espécie detectada em todos os ambientes. Somente quatro espécies não foram detectadas em apenas um tipo fitofisionômico, a saber: Cerdocyon thous na mata ripária; Dasypus novemcinctus no pasto; Mazama americana no campo úmido e Tayassu tajacu no cerradão. Conepatus semistriatus, Leopardus pardalis e Procyon cancrivorous não foram detectados no campo úmido e no pasto (matriz), enquanto Eira Barbara, Leopardus sp. e Myrmecophaga tridactyla não foram detectados nestes ambientes e nem na mata ripária.

As espécies Didelphis sp., Galictis cuja e Lontra longicaudis foram detectadas em apenas um tipo fitofisionômico: cerrado sensu stricto típico (Didelphis sp. e Galictis cuja) e mata ripária (Lontra longicaudis).

O maior número de detecções das espécies de mamíferos ocorreu no cerrado sensu stricto típico, seguido do cerrado sensu stricto denso e cerradão. Poucas detecções foram realizadas no campo úmido e no pasto (matriz). A Figura III.18 apresenta a porcentagem de detecções obtidas em cada fitofisionomia e a Tabela III.3 apresenta a comparação entre as porcentagens das fitofisionomias presentes no remanescente, da área amostrada e das espécies detectadas em cada uma delas.

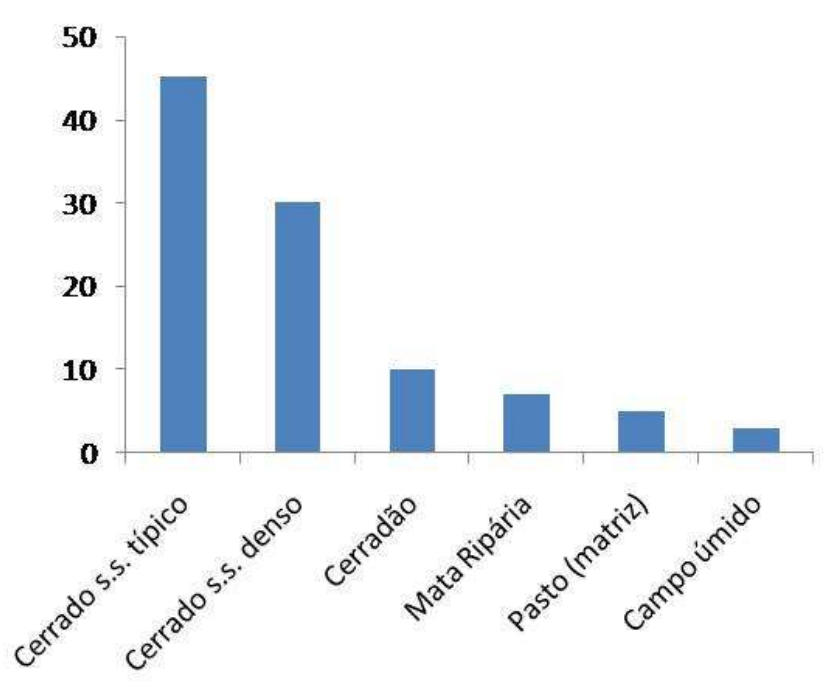

Fig.III.18. - Gráfico apresentando a porcentagem de detecções das espécies de mamíferos de médio e grande porte nas diferentes fitofisionomias. 
Riqueza de Espécies de Mamíferos de Médio e Grande Porte em um Fragmento de Cerrado no Estado de São Paulo

Tabela III.3. - Comparação entre as porcentagens das fitofisionomias presentes no remanescente, da área amostrada e das espécies detectadas em cada uma delas.

\begin{tabular}{lcccc}
\hline Fitofisionomias & $\begin{array}{c}\text { \% de cobertura no } \\
\text { remanescente }\end{array}$ & $\begin{array}{c}\text { \% da área } \\
\text { amostrada }\end{array}$ & $\begin{array}{c}\text { \% de detecção das } \\
\text { espécies }\end{array}$ & $\begin{array}{c}\text { No de espécies } \\
\text { detectadas }\end{array}$ \\
\hline Cerradão & 8,5 & 9,0 & 11,4 & 18 \\
Cerrado s.s. denso & 71,7 & 71,5 & 32,2 & 17 \\
Cerrado s.s. típico & 18,1 & 18,0 & 51,2 & 17 \\
Campo úmido & 1,7 & 1,5 & 3,2 & 5 \\
\hline
\end{tabular}

Para avaliar se há influência das fitofisionomias na composição das espécies, os dados de detecção obtidos no cerradão, cerrado sensu stricto típico, cerrado sensu stricto denso, mata ripária e campo úmido, foram submetidos ao teste do quiquadrado $\left(\chi^{2}\right)$ de Pearson (Sokal \& Rohlf, 1995).

Para aplicação deste teste foi necessário excluir o pasto, já que houve poucas detecções neste local, assim como houve a necessidade de se retirar as espécies que obtiveram menos de cinco detecções no total das amostras.

Desta forma, nesta análise foram avaliadas somente as espécies Cabassous unicinctus, Cerdocyon thous, Dasyprocta azarae, Dasypus novemcinctus, Euphractus sexcinctus, Leopardus pardalis, Leopardus sp., Mazama americana, Myrmecophaga tridactyla, Procyon cancrivorous, Puma concolor, Tapirus terrestris e Tayassu tajacu.

O resultado do teste foi significativo, com $\chi^{2}=230,2$ e 36 graus de liberdade, com valor crítico $(0,01)$ de 58 . Sendo assim, conclui-se que não há independência entre as áreas e a composição de mamíferos, ou seja, é aceita a hipótese de que existe influência da composição fitofisionômica na distribuição das espécies de mamíferos de médio e grande porte, acima citadas, no remanescente de cerrado.

Com relação aos métodos utilizados para determinar a riqueza e freqüência de ocorrência das espécies, o censo de pegadas foi o que mais detectou espécies, seguido do censo de fezes, censo de arranhões e armadilhas fotográficas, como pode ser observado na Tabela III.4 e nas Figuras III.19 e III.20. 
Riqueza de Espécies de Mamíferos de Médio e Grande Porte em um Fragmento de Cerrado no Estado de São Paulo

Tabela III.4. - Número de espécies de mamíferos de médio e grande porte detectadas na área de estudo, por tipo de amostra

\begin{tabular}{|c|c|c|c|c|c|c|c|c|}
\hline \multirow[b]{2}{*}{ Espécies } & \multicolumn{8}{|c|}{ Métodos de Detecção } \\
\hline & Pegadas & Fezes & Arm. Fot. & Arranhões & Avistamentos & Carcaças & Vocalizações & $\begin{array}{l}\text { № total de } \\
\text { deteç̧ões }\end{array}$ \\
\hline Cabassous unicinctus & 9 & - & - & - & 1 & - & - & 10 \\
\hline Cerdocyon thous & 46 & 2 & 3 & - & 4 & - & 3 & 58 \\
\hline Conepatus semistriatus & 6 & - & - & - & - & - & - & 6 \\
\hline Dasyprocta azarae & 10 & - & - & - & - & - & - & 10 \\
\hline Dasypus novemcinctus & 65 & - & 1 & - & - & 1 & - & 67 \\
\hline Didelphis sp. & - & - & - & - & - & 1 & - & 1 \\
\hline Eira barbara & 5 & - & - & - & - & - & - & 5 \\
\hline Euphractus sexcinctus & 15 & - & 1 & - & - & 1 & - & 17 \\
\hline Galictis cuja & 3 & - & - & - & - & - & - & 3 \\
\hline Hidrochoeris hidrochaeris & 3 & - & - & - & - & - & - & 3 \\
\hline Leopardus pardalis & 27 & 6 & 2 & - & - & - & - & 35 \\
\hline Leopardus sp & 10 & 4 & - & - & - & - & - & 14 \\
\hline Lontra longicaudis & 1 & - & - & - & - & - & - & 1 \\
\hline Lycalopex vetulus & 5 & 1 & - & - & - & - & - & 6 \\
\hline Mazama americana & 69 & - & 3 & - & - & - & - & 72 \\
\hline Myrmecophaga tridactyla & 9 & - & - & - & - & - & - & 9 \\
\hline Nasua nasua & - & - & 1 & - & - & - & 2 & 3 \\
\hline Procyon cancrivorus & 7 & - & - & - & - & 1 & - & 8 \\
\hline Puma concolor & 59 & 7 & - & 12 & - & - & - & 78 \\
\hline Tamandua tetradactyla & 4 & - & - & - & - & 1 & - & 5 \\
\hline Tapirus terrestris & 18 & - & - & - & - & - & - & 18 \\
\hline Tayassu tajacu & 27 & - & - & - & - & 2 & 1 & 30 \\
\hline № total de detecções & 398 & 20 & 11 & 12 & 5 & 7 & 6 & 459 \\
\hline
\end{tabular}




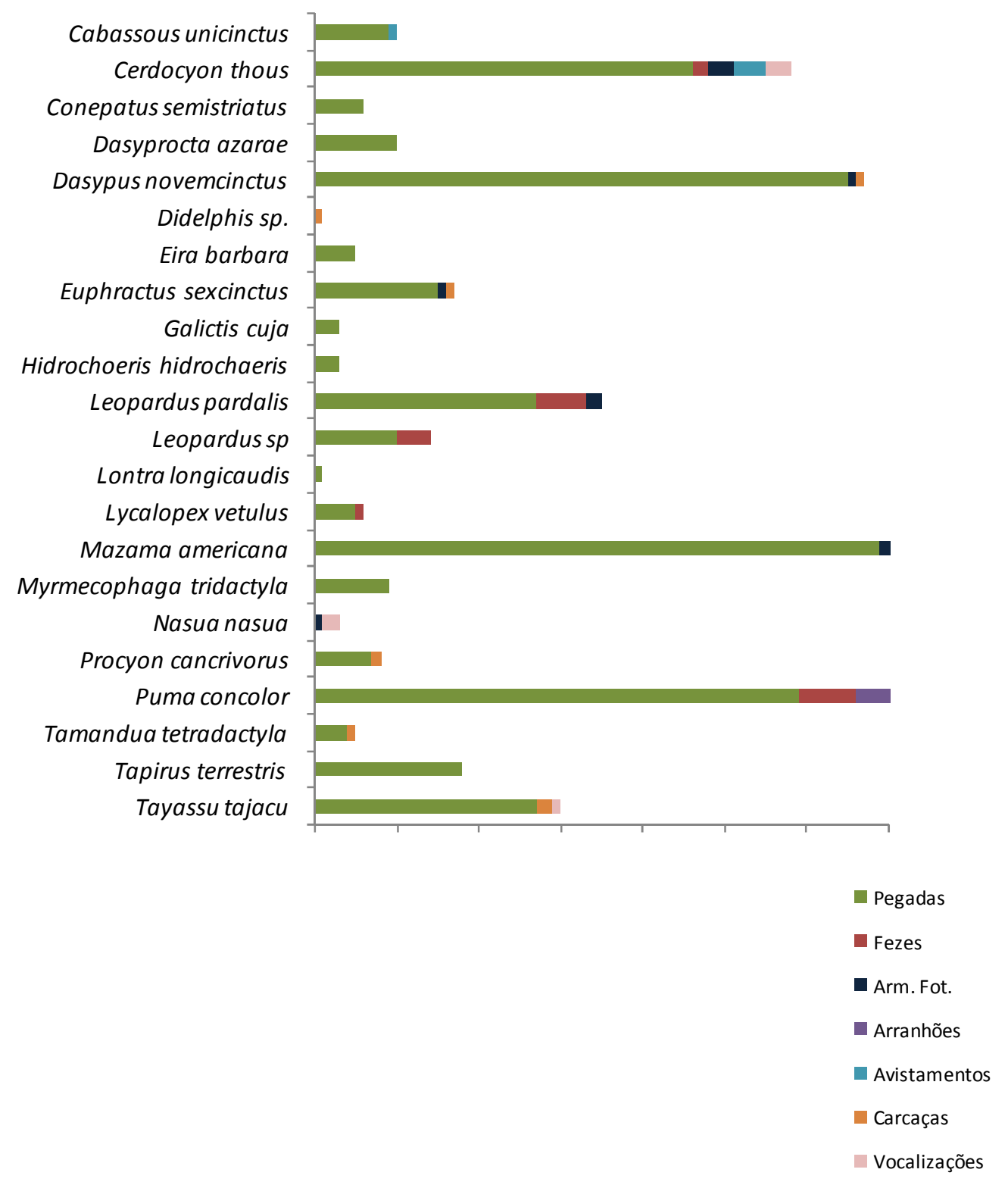

Fig.III.19. - Gráfico ilustrando a proporção de espécies de mamíferos de médio e grande porte, detectadas na área de estudo, por tipo de amostra. 


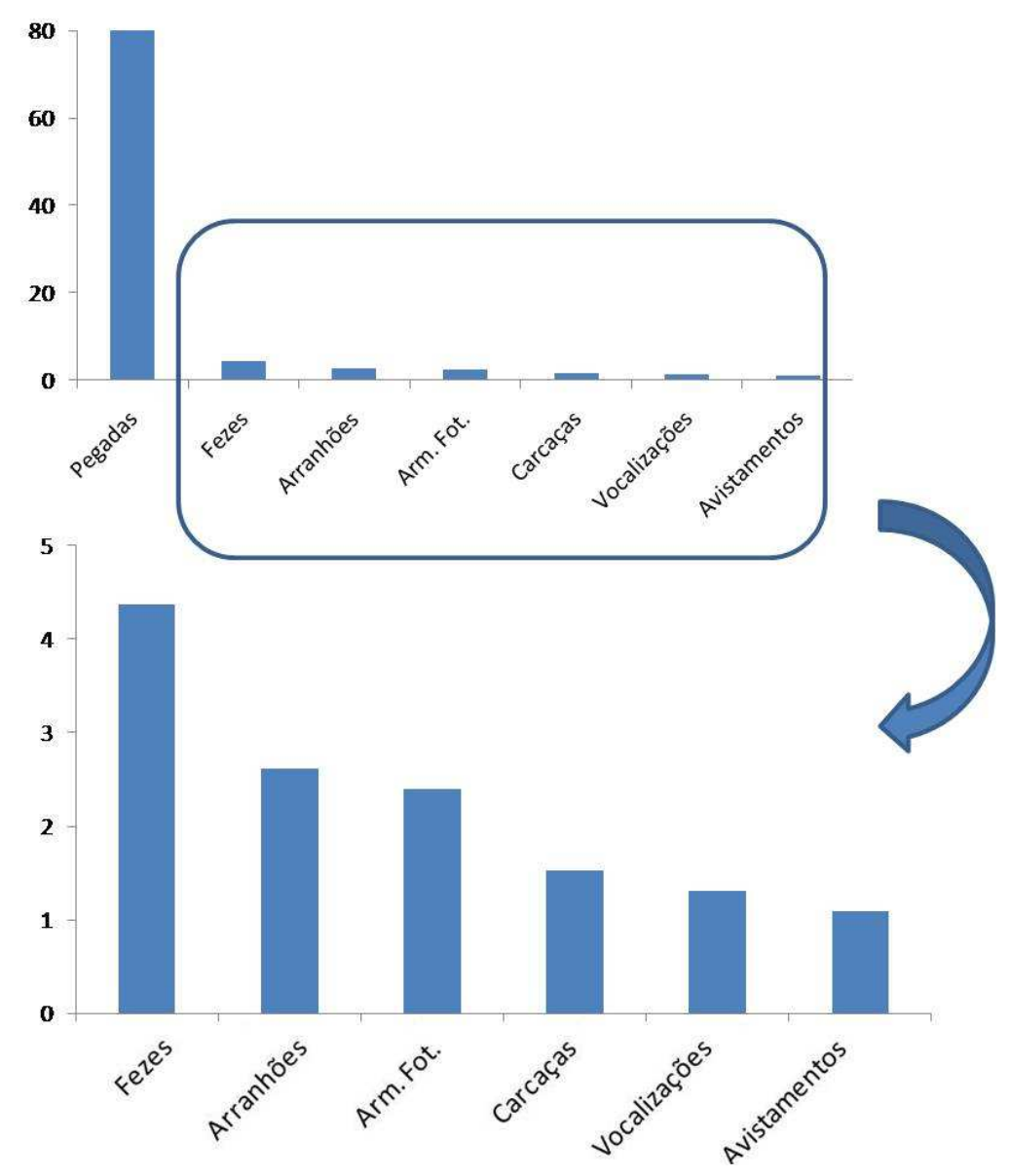

Fig.III.20. - Gráfico apresentando a porcentagem de detecção das espécies de mamíferos de médio e grande por tipo de amostra.

As Figuras III.21 à III.24 apresentam alguns registros fotográficos das detecções (fezes, carcaças, avistamentos, arranhões, pegadas e fotos obtidas das armadilhas fotográficas) das espécies de mamíferos de médio e grande porte no remanescente estudado. 
Riqueza de Espécies de Mamíferos de Médio e Grande Porte em um Fragmento de Cerrado no Estado de São Paulo

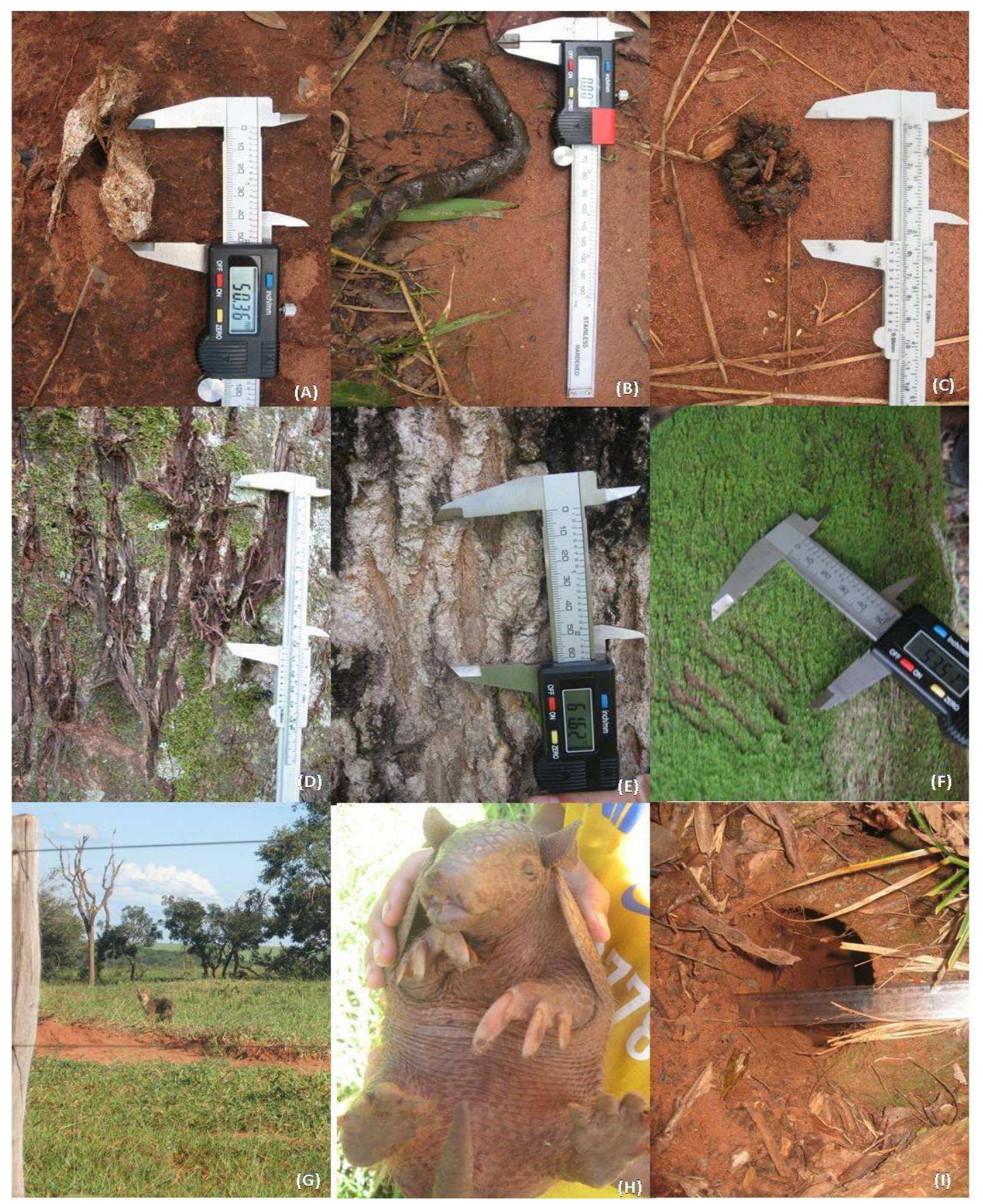

Fig.III.21. - Tipos de amostras coletadas no campo e que foram utilizadas para determinação da riqueza e freqüência de ocorrência das espécies de mamíferos de médio e grande porte, presentes no remanescente estudado: (A) fezes de Puma concolor; (B) fezes de Leopardus pardalis; (C) fezes de Cerdocyon thous; (D) e (E) arranhões de Puma concolor; (F) arranhões de Tamandua tetradactyla; (G) avistamento de Cerdocyon thous; (H) avistamento de Cabassuous unicinctus; e (I) toca de Cabassuous unicinctus. 
Riqueza de Espécies de Mamíferos de Médio e Grande Porte em um Fragmento de Cerrado no Estado de São Paulo

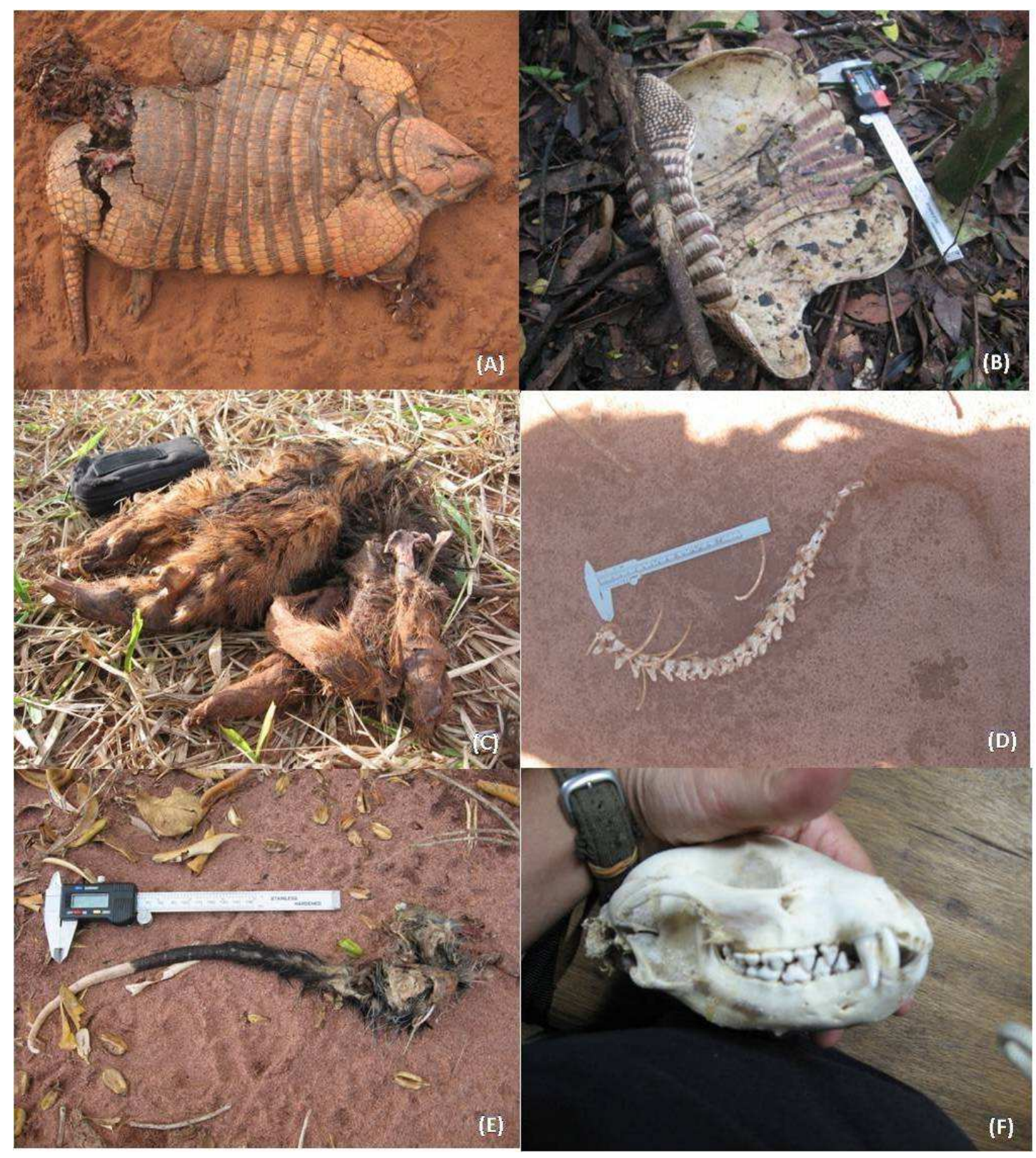

Fig.III.22. - Tipos de amostras coletadas no campo e que foram utilizadas para determinação da riqueza e freqüência de ocorrência das espécies de mamíferos de médio e grande porte, presentes no remanescente estudado: (A) carcaça de Dasypus sexcinctus; (B) carcaça de Dasypus novemcinctus; (C) carcaça de Tamandua tetradactyla; (D) e (F) coluna vertebral e crânio de Procyon cancrivorous, respectivamente; e (E) carcaça de Didelphis sp. 
Riqueza de Espécies de Mamíferos de Médio e Grande Porte em um Fragmento de Cerrado no Estado de São Paulo

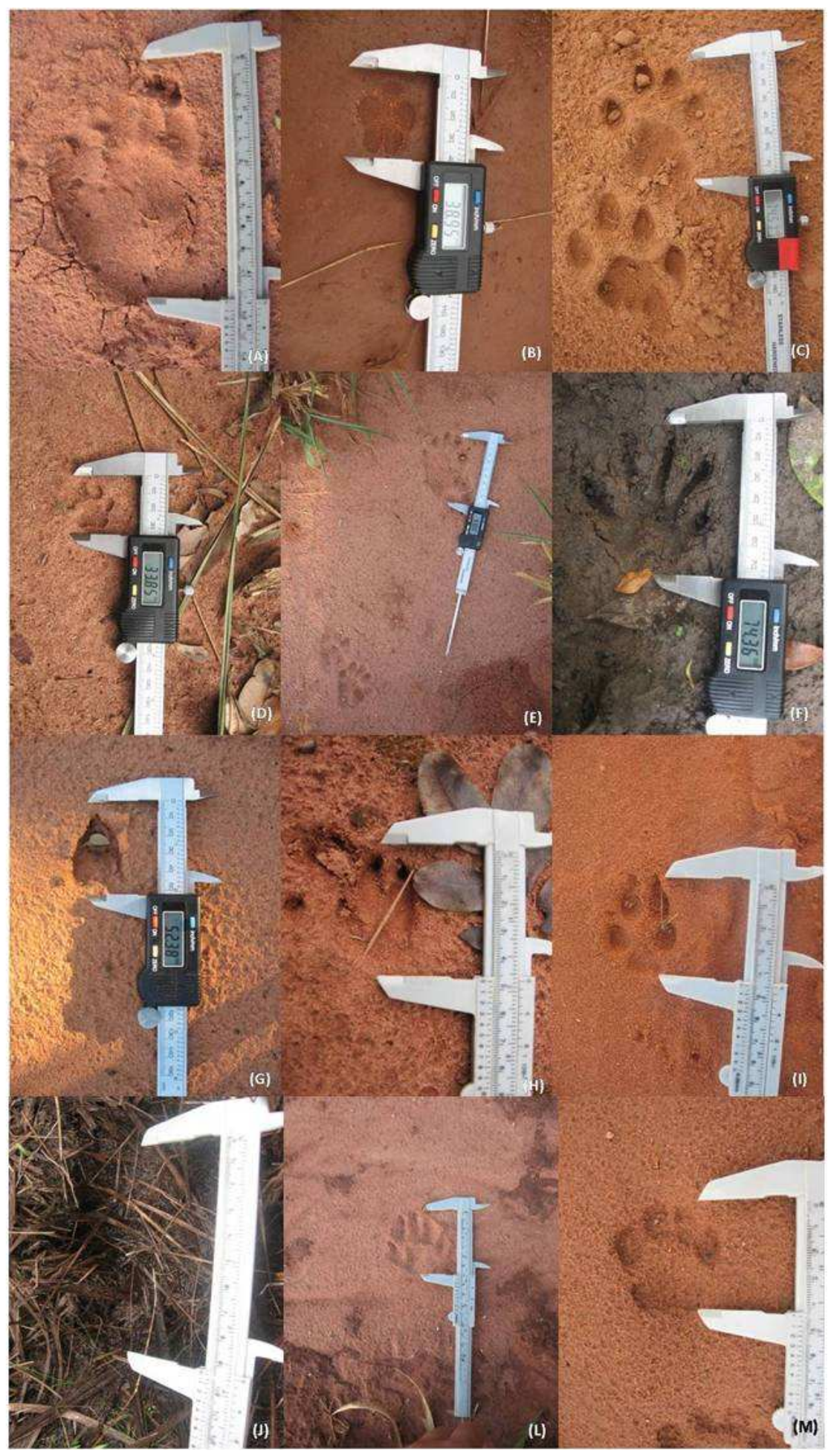

Fig.III.23. - Tipos de amostras coletadas no campo e que foram utilizadas para determinação da riqueza e freqüência de ocorrência das espécies de mamíferos de médio e grande porte, presentes no remanescente estudado: (A) pegada de Myrmecophaga 
Riqueza de Espécies de Mamíferos de Médio e Grande Porte em um Fragmento de Cerrado no Estado de São Paulo

tridactyla; (B) pegada de Lycalopex vetulus; (C) pegada de Puma concolor; (D) pegada de Leopardus sp; (E) pegada de Eira Barbara; (F) pegada de Procyon cancrivorous; (G) pegada de Mazama americana; $(\mathrm{H})$ pegada de Tayassu tajacu; (I) pegada de Cerdocyon thous; (J) pegada de Tapirus terrestris; (L) pegada de Conepatus semistriatus; e (M) pegada de Leopardus pardalis .

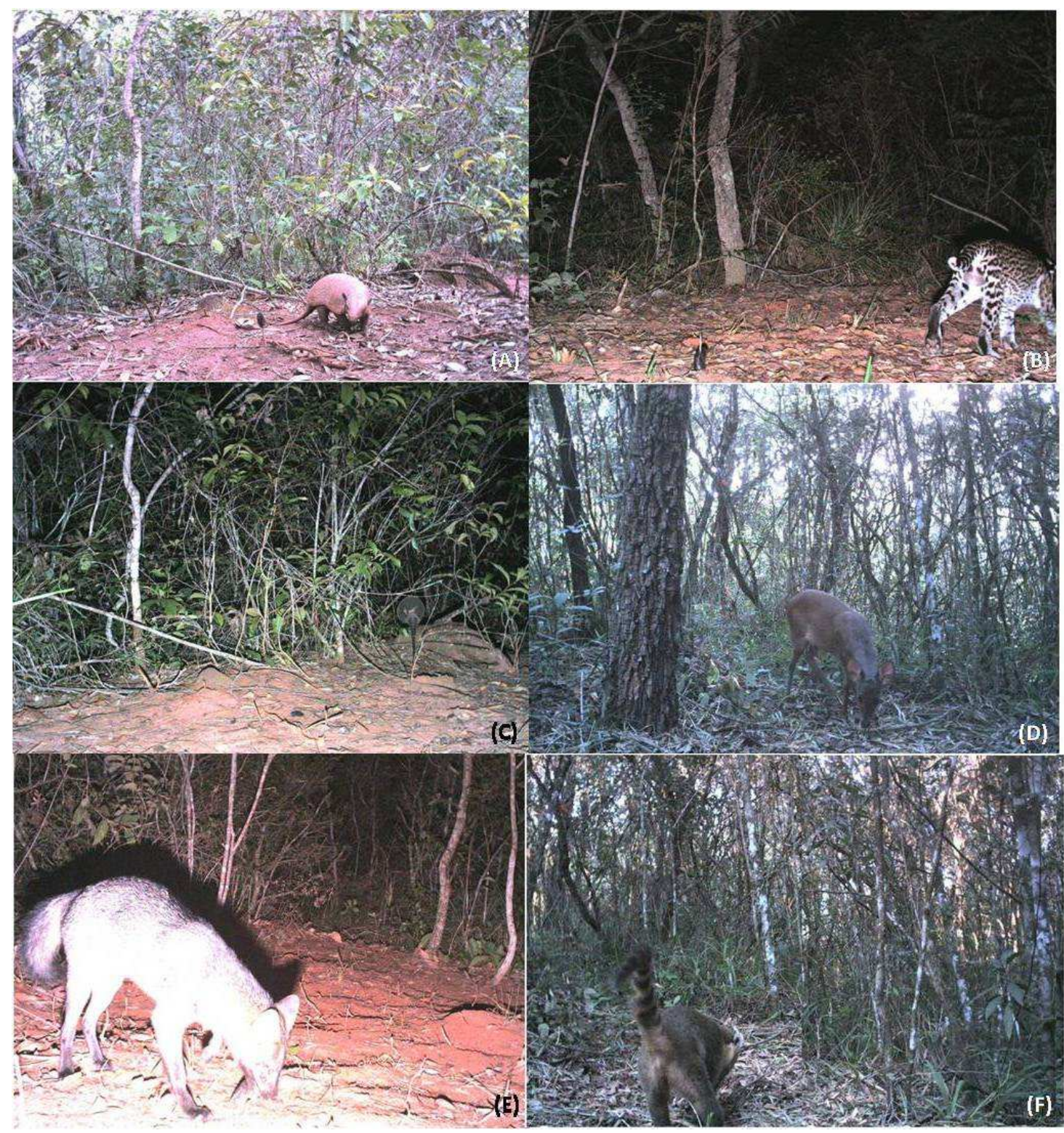

Fig.lll.24. - Dados de riqueza e freqüência de ocorrência, obtidos por armadilhamento fotográfico: (A) Dasypus sexcinctus; (B) Leopardus pardalis; (C) Dasypus novemcinctus; (D) Mazama americana; (E) Cerdocyon thous; e (F) Nasua nasua. 
Riqueza de Espécies de Mamíferos de Médio e Grande Porte em um Fragmento de Cerrado no Estado de São Paulo

Os registros das amostras coletadas no campo foram utilizados para realização do cálculo da densidade destas amostras (detecções das espécies $/ \mathrm{Km}^{2}$ ) nas fitofisionomias e no remanescente com um todo (Tabela III.5 e Figuras III.25 e III.26).

Tabela III.5. - Densidades das amostras ( $\mathrm{n}^{\circ}$ de detecções da espécie/ $/ \mathrm{Km}^{2}$ ) obtidas nas fitofisionomias e os totais obtidos no remanescente de cerrado estudado

\begin{tabular}{lccccc}
\hline Espécie & \multicolumn{5}{c}{ Densidade das Amostras ( $\mathrm{n}^{\circ}$ de detecções/Km²) } \\
\cline { 2 - 6 } & Cerradão & $\begin{array}{c}\text { Cerrado s.s. } \\
\text { denso }\end{array}$ & $\begin{array}{c}\text { Cerrado s.s. típico } \\
\text { Cabasa ripária e } \\
\text { Campo úmido }\end{array}$ & Remanescente \\
\hline Cerdocyon thous & 2,0 & 0,1 & 1,7 & - & 0,5 \\
Conepatus semistriatus & 4,0 & 0,9 & 9,6 & 1,0 & 2,8 \\
Dasyprocta azarae & 0,7 & 0,1 & 1,0 & 0,3 & 0,3 \\
Dasypus novemcinctus & 1,3 & - & 1,7 & 1,0 & 0,5 \\
Eira barbara & 4,7 & 2,1 & 8,9 & 1,4 & 3,2 \\
Euphractus sexcinctus & 0,7 & 0,1 & 1,0 & - & 0,2 \\
Galictis cuja & 0,7 & 0,5 & 2,0 & - & 0,8 \\
Hidrochoeris hidrochaeris & - & - & 1,0 & - & 0,1 \\
Leopardus pardalis & 0,7 & 0,1 & - & - & 0,1 \\
Leopardus sp & 6,7 & 0,5 & 5,6 & 0,3 & 1,7 \\
Lontra longicaudis & 0,7 & 0,7 & 1,0 & - & 0,7 \\
Lycalopex vetulus & - & - & - & 0,3 & 0,0 \\
Mazama americana & - & - & 1,0 & - & 0,3 \\
Myrmecophaga tridactyla & 3,4 & 1,9 & 11,9 & 0,7 & 3,4 \\
Nasua nasua & 0,7 & 0,2 & 1,7 & - & 0,4 \\
Procyon cancrivorus & - & 0,2 & - & - & 0,1 \\
Puma concolor & - & 0,1 & 1,7 & 0,3 & 0,4 \\
Tamandua tetradactyla & 3,4 & 1,7 & 12,5 & 3,1 & 3,7 \\
Tapirus terrestris & 0,7 & 0,1 & - & - & 0,2 \\
Tayassu tajacu & 0,7 & 0,1 & $-1,4$ & 0,9 \\
\hline & - & 0,5 & 5,9 & 1,4 \\
\hline
\end{tabular}



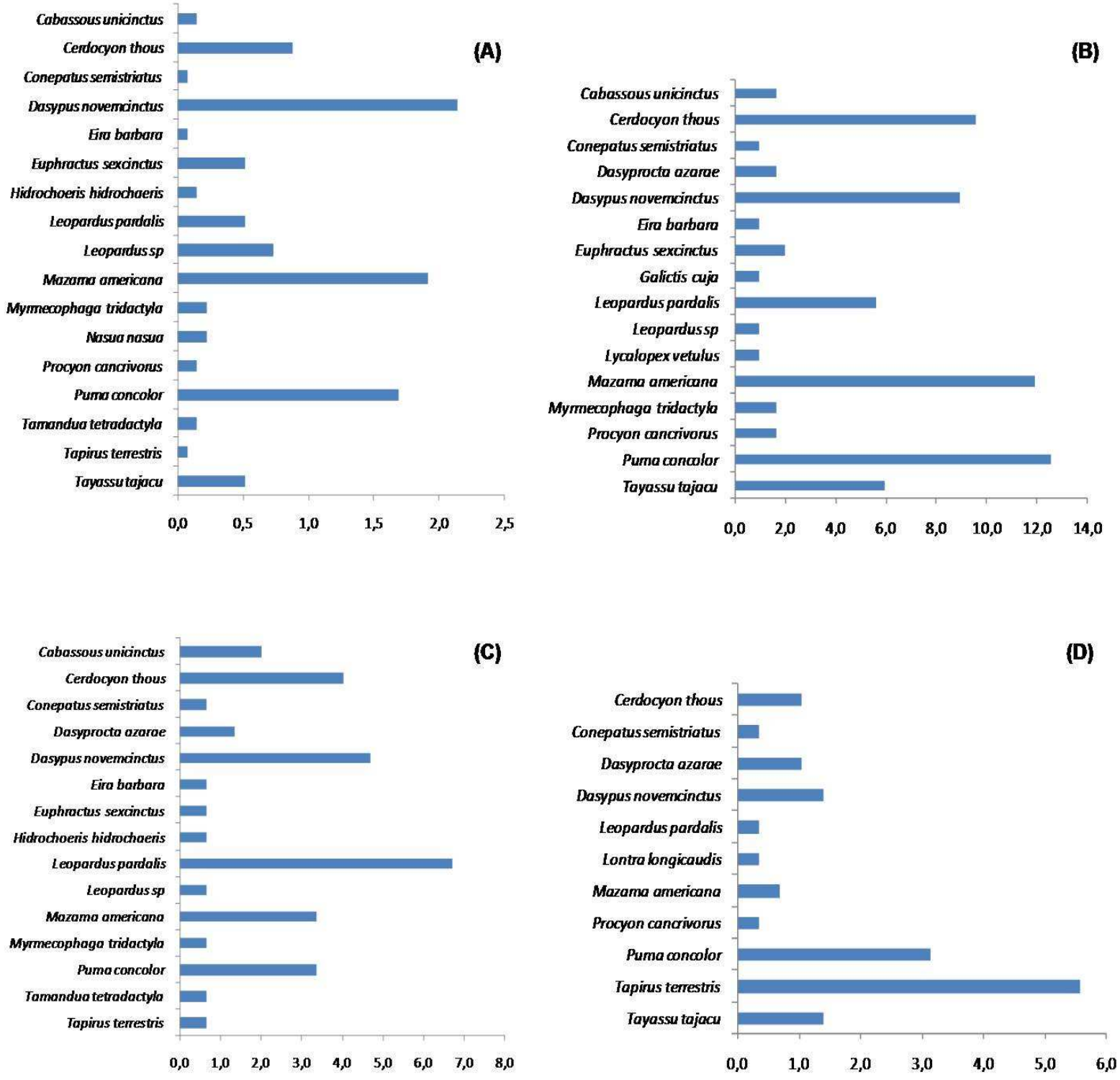

Fig.III.25. - Densidades das amostras ( $n^{0}$ de detecções da espécie/Km²) obtidas nas fitofisionomias: (A) cerrado sensu stricto denso; (B) cerrado sensu stricto típico; (C) cerradão; e (D) mata ripária e campo úmido. 


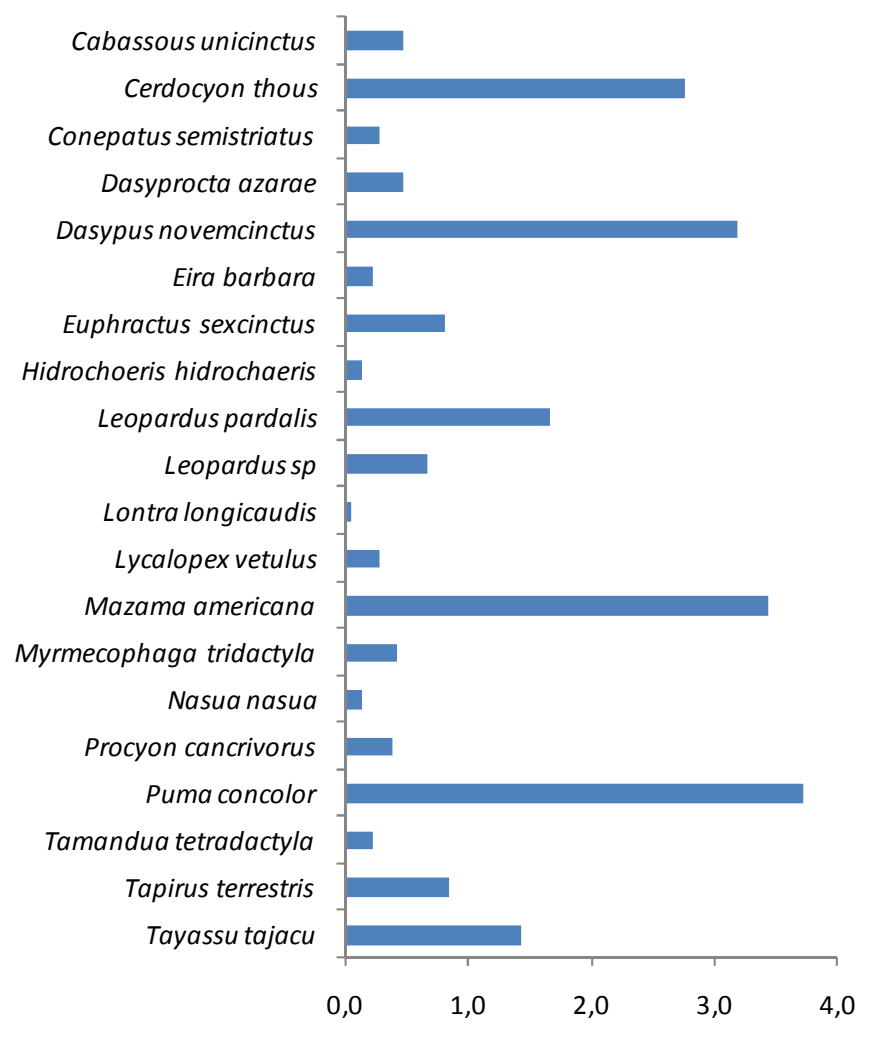

Fig.III.26. - Densidades totais das amostras ( $\mathrm{n}^{-0}$ de detecções da espécie/Km²) obtidas no remanescente de cerrado estudado.

A maior densidade obtida no remanescente foi de Puma concolor $(3,7$ amostras $\left./ \mathrm{Km}^{2}\right)$, seguido de Mazama americana (3,4 amostras $\left./ \mathrm{Km}^{2}\right)$, Dasypus novemcinctus (3,2 amostras $\left./ \mathrm{Km}^{2}\right)$, Cerdocyon thous (2,8 amostras $\left./ \mathrm{Km}^{2}\right)$, Leopardus pardalis $\left(1,7\right.$ amostras $\left./ \mathrm{Km}^{2}\right)$ e Tayassu tajacu $\left(1,4\right.$ amostras $\left./ \mathrm{Km}^{2}\right)$.

Os dados de detecção das espécies de mamíferos de médio e grande porte também foram utilizados para realização do cálculo da freqüência relativa $(F R)$, de acordo com Crooks (2002): i/N, onde i = número de ocorrência das espécies; e $\mathrm{N}=$ total de ocorrências no remanescente ou na fitofisionomia.

As Figuras III.27 e III.28 apresentam as freqüências relativas das espécies no remanescente e nas fitofisionomias, respectivamente. 
No cerrado sensu stricto denso, a maior freqüência observada foi de Dasypus novemcinctus $(0,21)$, seguido de Mazama americana $(0,19)$, Puma concolor $(0,17)$, Cerdocyon thous $(0,09)$ e Leopardus sp $(0,07)$. Por outro lado, no cerrado sensu stricto denso houve maior freqüência de Puma concolor $(0,19)$, Mazama americana $(0,18)$, Cerdocyon thous $(0,14)$, Dasypus novemcinctus $(0,13)$, Tayassu tajacu $(0,09)$ e Leopardus pardalis $(0,08)$. No cerradão, a maior freqüência foi obtida para Leopardus pardalis $(0,22)$, Dasypus novemcinctus $(0,15)$, Cerdocyon thous $(0,13)$, Mazama americana $(0,11)$ e Puma concolor $(0,11)$.

Com relação à mata ripária, a maior freqüência foi de Tapirus terrestris $(0,50)$, Puma concolor $(0,16)$, Tayassu tajacu $(0,09)$ e Mazama americana $(0,06)$. Para campo úmido, a maior freqüência obtida foi de Puma concolor $(0,31)$ e Cerdocyon thous $(0,23)$, enquanto que no pasto foi de Cerdocyon thous $(0,35)$.

As maiores freqüências relativas obtidas para todo o remanescente foram de Puma concolor $(0,17)$, Mazama americana $(0,16)$, Dasypus novemcinctus $(0,15)$, Cerdocyon thous $(0,13)$, Leopardus pardalis $(0,08)$ e Tayassu tajacu $(0,07)$. 


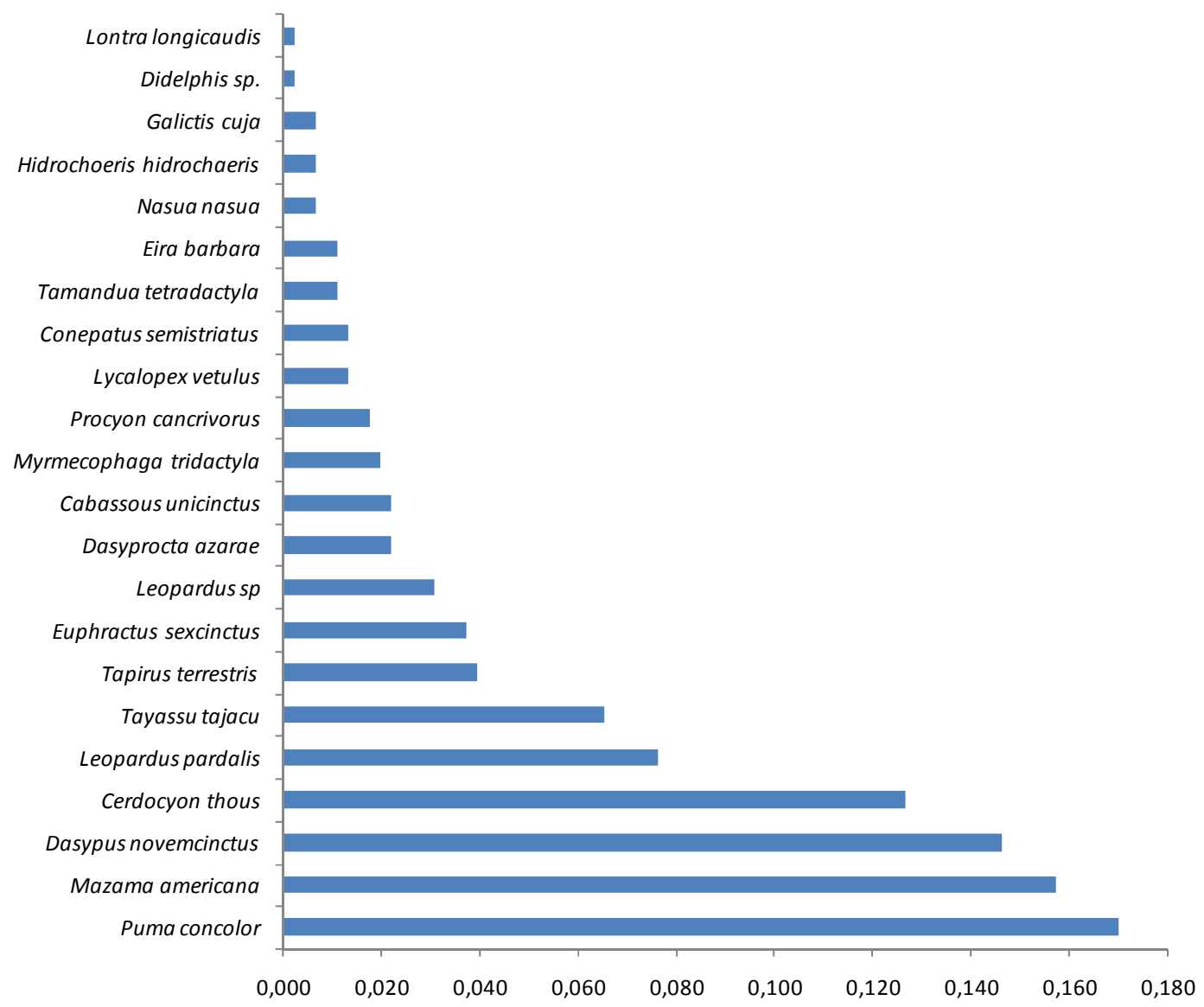

Fig.III.27. - Freqüência relativa (FR) das espécies de mamíferos de médio e grande porte no remanescente de cerrado estudado. 


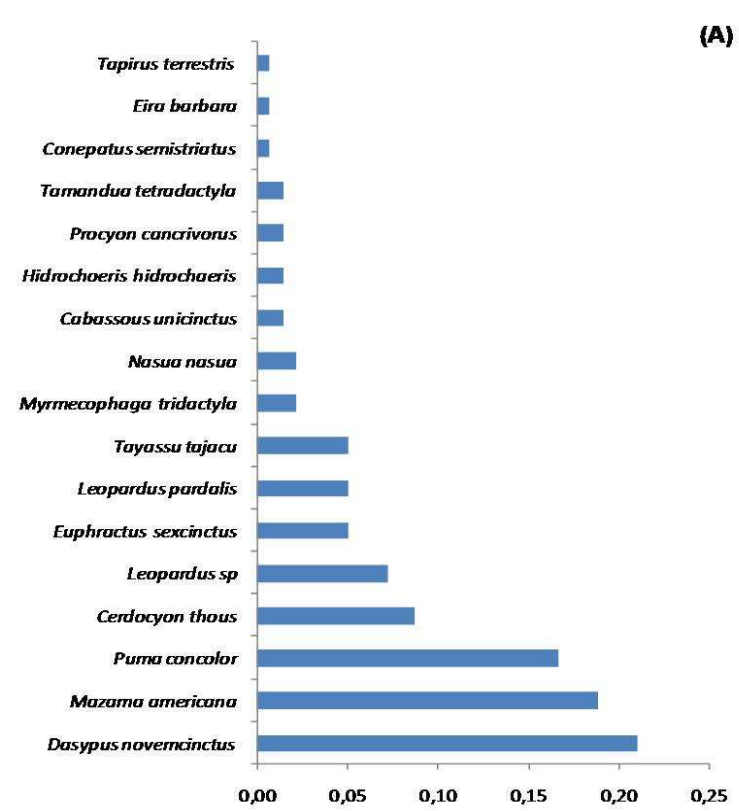

(C)

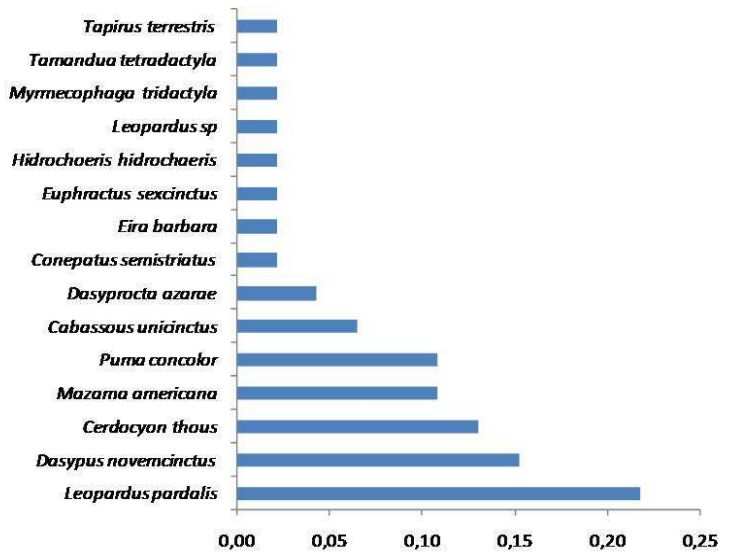

(E)

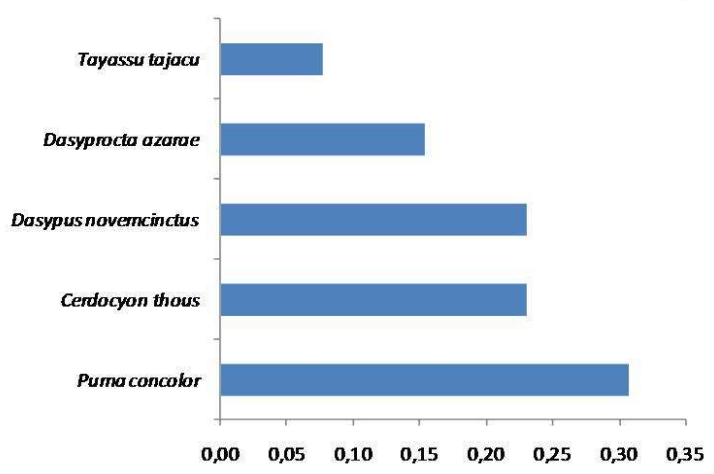

(B)

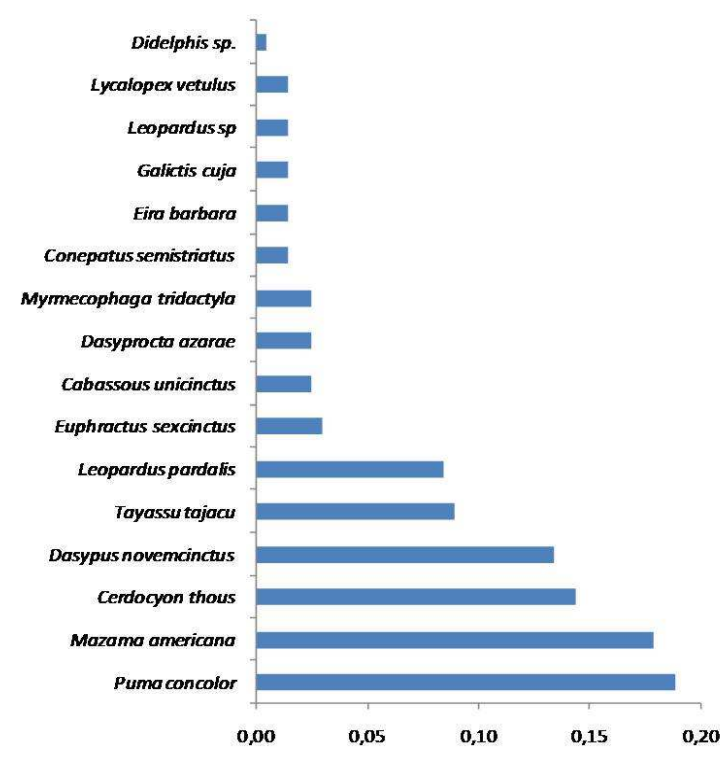

(D)

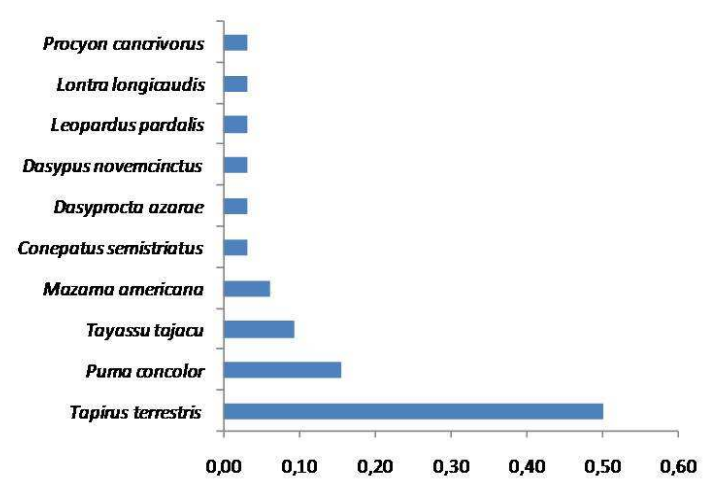

(F)

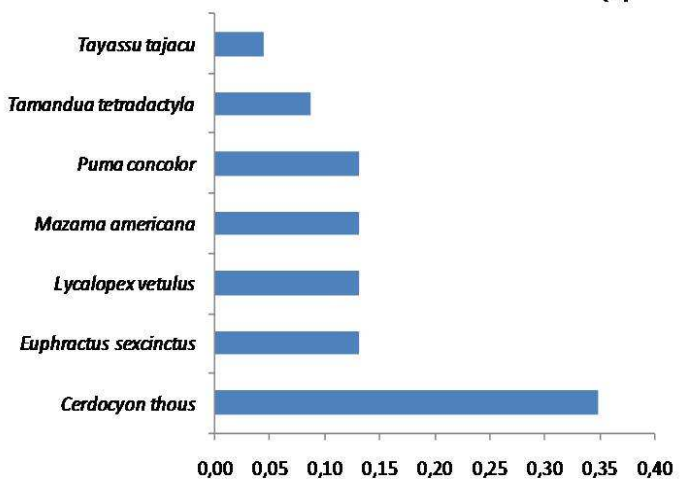

Fig.III.28. - Freqüência relativa (FR) das espécies de mamíferos de médio e grande porte: (A) cerrado sensu stricto denso; (B) cerrado sensu stricto típico; (C) cerradão; (D) mata ripária; $(E)$ campo úmido; e $(F)$ pasto. 
Para medir se o esforço despendido na amostragem das espécies foi suficiente para detectar todos os mamíferos de médio e grande porte que fazem uso do remanescente, os dados obtidos por meio dos três métodos de amostragem (censo de vestígios ao longo dos transectos, canteiros de pegadas e armadilhas fotográficas) foram inseridos no programa Estimate $S$ (Colwell, 2006) para estimativa da curva de acumulação de espécies (Sobs - Mao Tau) e da curva de riqueza estimada (Bootstrap). Foram realizadas 50 randomizações para redução do efeito da ordem da amostra.

A Figura III.29 apresenta a curva acumulativa de espécies em função do tempo de amostragem. Ao observar esta curva pode-se concluir que a mesma atingiu a sua assíntota no $28^{\circ}$ dia de amostragem, ou seja, praticamente todas as espécies que fazem uso do remanescente foram amostradas. Esta afirmativa é corroborada a partir da curva de riqueza estimada para o mesmo tempo de amostragem pelo teste Bootstrap, observada na Figura III.30. 


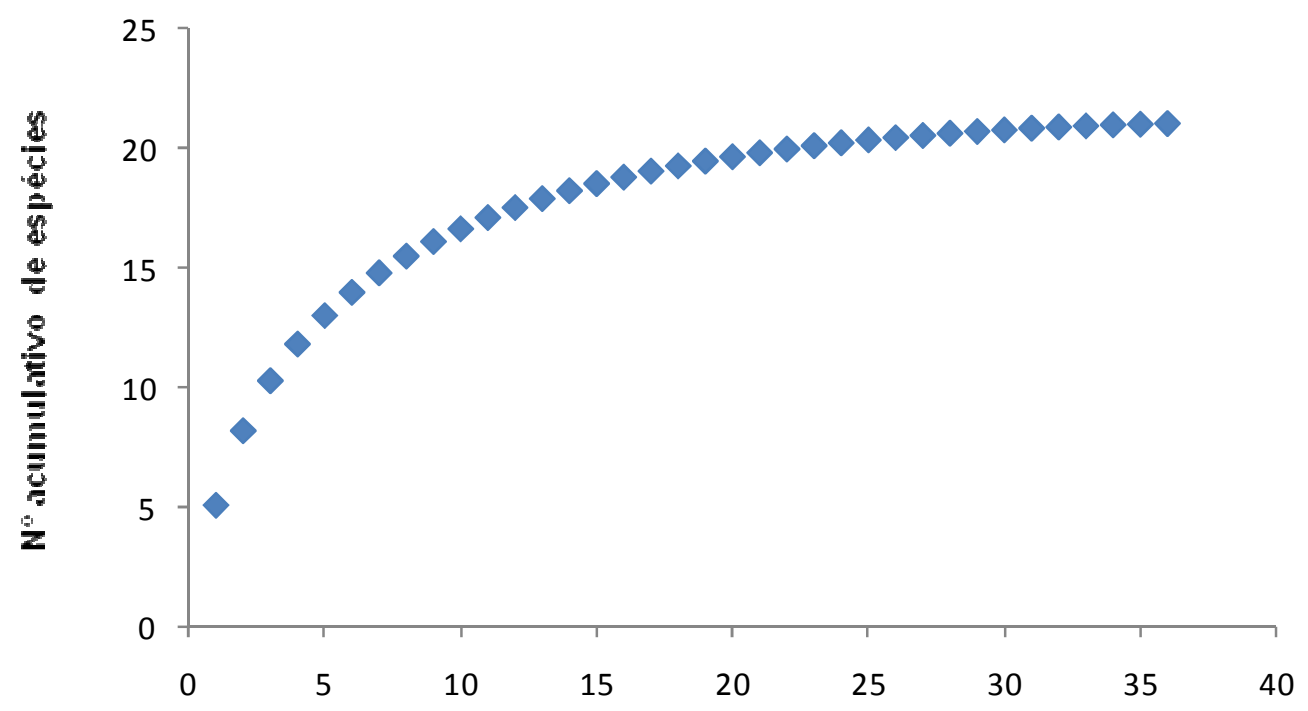

Días de amostragem

Fig.III.29. - Curva de acumulação de espécies (Sobs - Mao Tau) das espécies de mamíferos de médio e grande porte encontradas no remanescente de cerrado estudado.

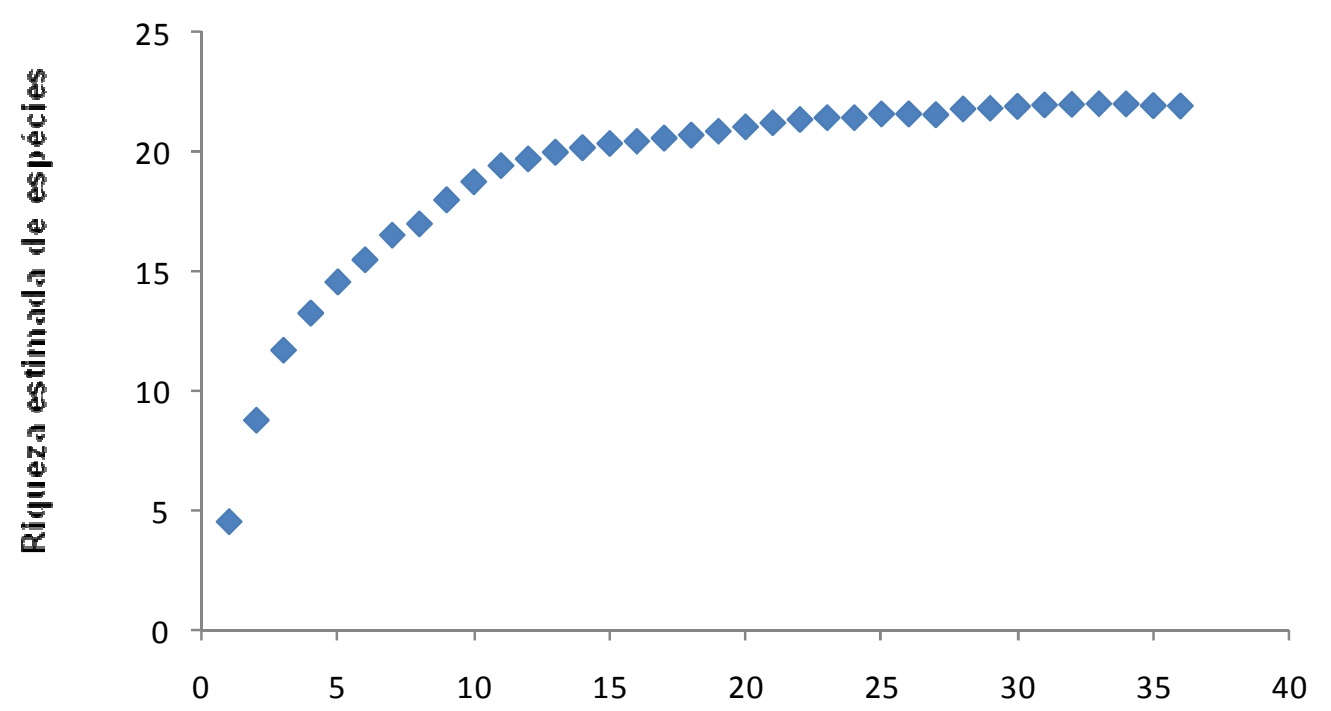

Dins de amostrayem

Fig.III.30. - Curva de riqueza estimada (Bootstrap) das espécies de mamíferos de médio e grande porte encontradas no remanescente de cerrado estudado. 


\section{Discussão}

O uso da análise geográfica computadorizada como ferramenta para caracterizar a heterogeneidade do habitat e realizar o delineamento amostral mostrou-se satisfatória no desenvolvimento de seus objetivos. A partir dela foi possível determinar as diversas feições da área de estudo, como áreas com qualidades adequadas (próximas à drenagem) ou áreas com influências negativas (próximas às estradas e borda do fragmento), assim como foi possível caracterizar as fitofisionomias. Desta forma, houve a possibilidade de se direcionar as amostragens em função dos habitats encontrados, buscando amostrar áreas heterogêneas dentro do remanescente. Sendo assim, foi possível determinar a riqueza total de espécies de mamíferos de médio e grande porte na área de estudo e ainda averiguar se houve influência das fitofisionomias na distribuição das espécies.

O remanescente de cerrado estudado apresentou uma composição de mamíferos de médio e grande porte muito diversa, com 22 espécies detectadas. Esta riqueza não era esperada para a área de estudo, onde se achava que somente algumas espécies generalistas em relação ao habitat seriam encontradas, tais como Cerdocyon thous e Eira Barbara (Michalski et al., 2006). Entretanto, muitos mamíferos com requerimentos mais específicos foram encontrados, tais como Mazama americana (Eisenberg \& Redford, 1999), Myrmecophaga tridactyla (Mourão \& Medri, 2007) e Tapirus terrestris (Bodmer \& Brooks, 1997).

No remanescente também foram detectados ao menos três indivíduos diferentes de Puma Concolor (mãe com filhote e mais outro indivíduo com pegadas maiores). A presença desta espécie, que requer grandes extensões de terras como área de vida, pode estar relacionada à grande diversidade de habitats com diferentes graus de qualidade ambiental na área e, principalmente, a grande diversidade de presas encontradas. Somando-se a isto, este remanescente não está isolado, o mesmo encontra-se interligado com outros fragmentos por meio do corredor de mata ripária. Este corredor certamente está sendo utilizado pelos animais para se movimentarem entre os fragmentos, como pode ser observado na Figura III.16. Entretanto, esta afirmativa só poderia ser confirmada a partir da análise de ocorrência desta espécie nos demais remanescentes de cerrado que se encontram 
conectados à área de estudo por meio do corredor ripário. A maior freqüência relativa obtida para todo o remanescente foi atribuída a este espécie, certamente porque se move muito mais do que as demais, em busca de alimento ou devido à sua área de vida (Dickson \& Beier, 2002).

Além desta espécie, outras dez espécies da Ordem Carnivora foram encontradas no remanescente. Novamente, esta riqueza certamente está relacionada à grande diversidade de habitats com diversos graus de qualidade e à disponibilidade de presas. A riqueza de herbívoros e onívoros também pode ser explicada pela diversidade de habitats e de recursos alimentares.

O teste do qui quadrado apontou ser significativa a influência das fitofisionomias na composição de mamíferos de médio e grande porte encontradas no local, assim como apontou ser significativa a influência de habitats com diferentes graus de qualidade para algumas destas espécies (ver Capítulo IV). Não foi possível realizar algum teste para confirmar a influência da disponibilidade de alimento. Entretanto, segundo Chiarello (1999), vários fatores podem afetar a permanência de mamíferos em fragmentos, mas os recursos alimentares são os mais importantes, se não forem cruciais para a sobrevivência destas espécies. Levando-se em consideração que a heterogeneidade dos habitats certamente influi na diversidade de recursos alimentares, podemos admitir que a grande riqueza obtida no remanescente estudado esteja principalmente relacionada à disponibilidade de recursos alimentares.

A Tabela III.6 indica as espécies encontradas na área de estudo, suas áreas de vida e graus de ameaças. Os dados referentes às áreas de vida das espécies estão condizendo com a área total do remanescente estudado (2.098 ha). As exceções são Eira Barbara, Leopardus pardalis e Puma concolor. Entretanto, já foram encontradas áreas de vida muito menores para os dois primeiros. 
Tabela III.6. - Espécies encontradas na área de estudo, suas áreas de vida e graus de ameaças

\begin{tabular}{|c|c|c|c|c|c|}
\hline \multirow{2}{*}{ Espécie } & \multirow{2}{*}{ Área de vida } & \multicolumn{4}{|c|}{ Grau de Ameaça } \\
\hline & & Lista Brasileira $^{1}$ & Lista Paulista ${ }^{2}$ & Lista Mundial (IUCN) ${ }^{3}$ & CITES $^{4}$ \\
\hline C. unicinctus & $101,6 \mathrm{ha}^{5}$ & --- & ---- & $\begin{array}{l}\text { Baixo risco ou menor preocupação/ } \\
\text { sem info. sobre status pop. }\end{array}$ & ---- \\
\hline C. thous & 450ha $(F)$ e $280-380$ ha $(M)^{6}$ & --- & ---- & $\begin{array}{l}\text { Baixo risco ou menor preocupação/ } \\
\text { população estável }\end{array}$ & Apêndice II \\
\hline C. semistriatus & $18-53 \mathrm{ha}^{7}$ & --- & $\begin{array}{l}\text { Deficiente em } \\
\text { dados }\end{array}$ & $\begin{array}{l}\text { Baixo risco ou menor preocupação/ } \\
\text { sem info. sobre status pop. }\end{array}$ & --- \\
\hline D. novemcinctus & $20,3 \mathrm{ha}^{8}$ & --- & --- & $\begin{array}{l}\text { Baixo risco ou menor preocupação/ } \\
\text { pop. aumentando }\end{array}$ & ---- \\
\hline E. barbara & $900-1600$ ha $(F)$ e $2440(M)^{9}$ & --- & --- & $\begin{array}{l}\text { Baixo risco ou menor preocupação/ } \\
\text { pop. em declínio }\end{array}$ & Apêndice III \\
\hline E. sexcinctus & $3-958 h a^{5}$ & --- & --- & $\begin{array}{l}\text { Baixo risco ou menor preocupação/ } \\
\text { sem info. sobre status pop. }\end{array}$ & --- \\
\hline G. cuja & --- & --- & $\begin{array}{l}\text { Deficiente em } \\
\text { dados }\end{array}$ & $\begin{array}{l}\text { Baixo risco ou menor preocupação/ } \\
\text { sem info. sobre status pop. }\end{array}$ & --- \\
\hline L. pardalis & $76-5090 \mathrm{ha}^{10}$ & Vulnerável & Vulnerável & $\begin{array}{l}\text { Baixo risco ou menor preocupação/ } \\
\text { pop. em declínio }\end{array}$ & Apêndice I \\
\hline L. longicaudis & --- & --- & $\begin{array}{l}\text { Quase } \\
\text { ameaçada }\end{array}$ & $\begin{array}{l}\text { Deficiente em dados/pop. em } \\
\text { declínio }\end{array}$ & Apêndice I \\
\hline L. vetulus & $380 \mathrm{ha}^{11}$ & --- & Vulnerável & $\begin{array}{l}\text { Baixo risco ou menor preocupação/ } \\
\text { sem info. sobre status pop. }\end{array}$ & ---- \\
\hline M. americana & $<100 \mathrm{ha}^{12}$ & --- & Vulnerável & $\begin{array}{l}\text { Deficiente em dados/ sem info. } \\
\text { sobre status populacional }\end{array}$ & --- \\
\hline M. tridactyla & $\begin{array}{c}\text { PNSC: 367ha (F) e } \\
\text { 274ha(M) }{ }^{13} ; \text { PNE: 693ha (F) e } \\
\text { 1080ha }(M)^{14}\end{array}$ & Vulnerável & Vulnerável & $\begin{array}{l}\text { Quase ameaçada/ população em } \\
\text { declínio }\end{array}$ & Apêndice II \\
\hline N. nasua & 630ha $(F)$ e 490ha $(M)^{15}$ & --- & --- & $\begin{array}{l}\text { Baixo risco ou menor preocupação/ } \\
\text { pop. em declínio }\end{array}$ & Apêndice III \\
\hline P. cancrivorus & --- & --- & --- & $\begin{array}{l}\text { Baixo risco ou menor preocupação/ } \\
\text { pop. em declínio }\end{array}$ & ---- \\
\hline P. concolor & $15500 \mathrm{ha}^{16}$ & Vulnerável & Vulnerável & $\begin{array}{l}\text { Baixo risco ou menor preocupação/ } \\
\text { pop. em declínio }\end{array}$ & Apêndice I \\
\hline T. tetradactyla & $100-380 \mathrm{ha}^{17}$ & --- & --- & $\begin{array}{l}\text { Baixo risco ou menor preocupação/ } \\
\text { sem info. sobre status pop. }\end{array}$ & --- \\
\hline T.terrestris & $200 \mathrm{ha}^{18}$ & ---- & Vulnerável & Vulnerável/ pop. em declínio & Apêndice II \\
\hline T. tajacu & $50-2000 \mathrm{ha}^{19}$ & --- & $\begin{array}{l}\text { Quase } \\
\text { ameaçada }\end{array}$ & $\begin{array}{l}\text { Baixo risco ou menor preocupação/ } \\
\text { população estável }\end{array}$ & Apêndice II \\
\hline
\end{tabular}


${ }^{1}$ MMA, 2008; ${ }^{2}$ SMA, 2008; ${ }^{3}$ IUCN, 2009; ${ }^{4}$ UNEP-WCMC, 2009; ${ }^{5}$ Encarnação, $1987 ;{ }^{6}$ Beisiegel, 1999 e NakanoOliveira, 2002; ${ }^{7}$ Medellin et al., 1992; ${ }^{8}$ Fitch et al., 1952 apud McBee \& Baker, 1982; ${ }^{9}$ Sunquist et al., 1989 apud Cheida et al., 2006 e Presley, 2000; ${ }^{10}$ Crawshaw, 1995 e Oliveira \& Cassaro, 2005; ${ }^{11}$ Juarez \& Marinho-Filho, 2002; ${ }^{12}$ Rivero et al., 2005 e Di Bitetti et al., 2008; ${ }^{13}$ Shaw et al, 1977; ${ }^{14}$ Miranda, 2004; ${ }^{15}$ Nakano-Oliveira, 2002; ${ }^{16}$ Crawshaw \& Quigley, 1984 apud Mendes Pontes \& Chivers, 2007; ${ }^{17}$ Montgomery \& Lubin, 1977 apud Medri et al., 2006 e Rodrigues et al., 2001; ${ }^{18}$ Rocha, 2001; ${ }^{19}$ McCoy et al., 1990

Todas as espécies detectadas na área encontram-se na lista mundial de espécies ameaçadas (IUCN). Leopardus pardalis, Puma concolor e Myrmecophaga tridactyla encontram-se em todas as listas apresentadas (lista brasileira, lista paulista, IUCN e CITES). A lista paulista de animais ameaçados apresenta dez das espécies encontradas, sendo Leopardus pardalis, Lycalopex vetulus, Mazama americana, Puma concolor, Myrmecophaga tridactyla e Tapirus terrestris, indicadas como vulnerável.

Com relação aos métodos de amostragem utilizados, o mais confiável na identificação das espécies foi o armadilhamento fotográfico, entretanto, neste trabalho foi o menos eficaz na determinação da riqueza devido à qualidade do equipamento. Muitos animais deixaram de ser fotografados porque deveriam ficar muito tempo parados em frente à câmera para que a foto fosse tirada.

O método que forneceu mais informação em relação à riqueza das espécies foi o censo de vestígios ao longo dos transectos, sendo as amostras referentes às pegadas as mais informativas, seguido das fezes. 


\section{Conclusão}

O uso da análise geográfica computadorizada como ferramenta para caracterizar a heterogeneidade dos habitats e realizar o delineamento amostral mostrou-se satisfatória no desenvolvimento de seus objetivos. A determinação da riqueza de mamíferos de médio e grande porte no remanescente pode ser obtida em 28 dias e estes dados puderam ser inseridos em um teste para averiguar se a composição das espécies de mamíferos era influenciada ou não pela fitofisionomia. Desta forma, o uso da análise espacial pode facilitar os estudos de espécies em seus ambientes naturais, permitindo a sistematização das amostragens.

As informações obtidas neste trabalho sobre a diversidade de habitats com diferentes graus de qualidade e sobre a riqueza das espécies de mamíferos de médio e grande porte no remanescente, assim como as informações relativas à área de vida e graus de ameaça destas espécies, enfatizam a necessidade de criação de uma Unidade de Conservação de Proteção Integral no local, além da necessidade de incremento da conectividade com os demais fragmentos, visando a proteção deste remanescente e, conseqüentemente, das espécies que o utilizam de alguma forma. 


\section{Referências Bibliográficas}

BEISIEGEL, B.M. 1999. Contribuição ao estudo da história natural do cachorro do mato, Cerdocyon thous, e do cachorro vinagre, Speothos venaticus. (Tese de doutorado) - IP/USP.

BODMER, R.E.; BROOKS, D.M. 1997. Status and action plan of the lowland tapir (Tapirus terrestris). In: BROOKS, D.M., BODMER, R.E. AND MATOLA, S. (Eds.). Tapirs - Status Survey and Conservation Action Plan. IUCN/SSC Tapir Specialist Group. <http://www.tapirback.com/tapirgal/iucn-ssc/tsg/action97/cover.htm>

BODMER, R.E.; EISENBERG, J.F., REDFORD, K.H. 1997. Hunting and the likelihood of extinction of Amazonian mammals. Conservation Biology, 11: 460-466.

BORGES P. A. L.; TOMÁS W. M. 2004. Guia de rastros e outros vestígios de mamíferos do Pantanal. Embrapa Pantanal.

BRITO, D. 2004. Lack of adequate taxonomic knowledge may hinder endemic mammal conservation in the brazilian Atlantic Forest. Biodiversity and Conservation, 13: $2135-2144$.

CARBONE, C.; CHRISTIE S.; CONFORTI K.; COULSON T.; FRANKLIN N.; GINSBERG J.R.; GRIFFITHS M.; HOLDEN J.; KAWANISHI K.; KINNAIRD M.; LAIDLAW R.; LYNAM A.; MACDONALD D.W.; MARTYR D.; MCDOUGAC. L; NATH L.; OBRIEN T.O.; SEIDENSTICKER J.; SMITH D.J.L.; SUNQUIST M.; TILSON R.; WAN SHAHRUDDIN W.N. 2001. The use of photographic rates to estimate densities of tigers and others cryptic mammals. Animal Conservation, 4: 75-79.

CARDILlO, M.; PURVIS, A.; SECHREST, W.; GITTLEMAN, J.L.; BIELBY, J.; MACE, G.M. 2004. Human population density and extinction risk in the world's carnivores. PLoS Biology, 2: 909-914.

CHEIDA, C.C.; NAKANO-OLIVEIRA, E.; FUSCO-COSTA, R.I.; ROCHA-MENDES, F.; QUADROS, J. 2006. Ordem Carnivora. In: REIS, N.R.; PERACCHI, A.L.; PEDRO, W.A.; LIMA, I.P (Eds.). Mamíferos do Brasil. Londrina, p. 231-275.

CHIARELLO, A.G. 1999. Effects of fragmentation of the Atlantic forest on mammal 
communities in south-eastern Brazil. Biological Conservations, 87: 71-82.

COLWELL, R.K. 2006. Estimate S: estatistical estimation of species richness and shared species from samples. Version 8. <purl.oclc.org/estimates>

COSTA, L.P.; LEITE, Y.L.R.; MENDES, S.L.; DITCHFIELD, A.D. 2005. Conservação de mamíferos no Brasil. Megadiversidade, 1: 103-112.

CRAWSHAW, P.G. 1995. Comparative ecology of ocelot (Felis pardalis) and Jaguar (Panthera onca) in a protected subtropical forest in Brazil and Argentina. (Ph.D. Thesis) - University of Florida.

CROOKS, K.R., 2002. Relative Sensitivies of Mammalian Carnivores to Habitat Fragmentation. Conservation Biology, 16: 488-502.

DALPONTE, J. C; BECKER, M. 1999. Rastros de Mamíferos Silvestres Brasileiros. Brasília: Editora UNB. $2^{\mathrm{a}}$ Edição.

De VIVO, M. 1996. Estudo da diversidade de espécies de mamíferos no Estado de São Paulo. <http://www.biota.org.br/info/historico/workshop/revisoes/mamiferos.pdf> DI BITETTI, M.S.; PAVIOLO, A.; FERRARI, C.A.; DE ANGELO, C.; DI BLANCO, Y. 2008. Differential Responses to Hunting in Two Sympatric Species of Brocket Deer (Mazama americana and M. nana). Biotropica, 40: 636-645.

DICKSON, B.G.; BEIER, P. 2002. Home range and habitat selection by adults cougars in southern California. Journal of Wildlife Management, 66: 1235-1245.

EASTMAN, J.R. 2006. IDRISI Andes. Clark University Laboratory, Clark University, Worcester, Pennsylvania.

EISENBERG, J.F.; REDFORD, K.H. 1999. Mammals of the neotropics (Ecuador, Peru, Bolivia, Brazil). Chicago \& London: The University of Chicago Press.

EMMONS, L.H.; WHITNEY B.M.; ROSS, J.D. 1998. Sounds of Neotropical Rainforest Mammals: An Audio Field Guide. Cornell Laboratory Of Ornithology; Har/Com edition.

ENCARNAÇÃO, C.D. 1987. Contribuição à ecologia dos tatus (xenarthra, dasypodidae) da Serra da Canastra, MG. (Dissertação de mestrado) - MN/UFRJ. 
FISCHER, J.; LIDENMAYER, D.B. 2007. Landscape modification and habitat fragmentation: a synthesis. Global Ecology and Biogeography, 16: 265-280.

FUNDAÇÃO BIODIVERSITAS. 2005. Lista da fauna brasileira ameaçada de extinção. Belo Horizonte: Fundação Biodiversitas <http://www.biodiversitas.org.br>

GOTELLI, N.J.; COLWELL R.K. 2001. Quantifying biodiversity: procedures and pitfalls in the measurement and comparison of species richness. Ecology Letters, 4: 379-391.

IUCN. 2009. IUCN Red List of Threatened Species. <www.iucnredlist.org> JUAREZ, K.M.; MARINHO-FILHO, J. 2002. Diet, habitat use and home ranges of sympatric canids in central Brazil. Journal of mammalogy, 83: 925-933.

KARANTH, U.; NICHOLS, J.D.; CULLEN, L. 2003, Armadilhamento fotográfico de grandes felinos: algumas considerações importantes. In: CULLEN, L., RUDRAN, R., PADUA, C.V. (Org.). Métodos de Estudos em Biologia da Conservação e Manejo da Vida Silvestre. Curitiba: Editora UFPR, 2003. p 269-285.

KIERULFF, M.C.M.; OLIVEIRA, P.P.; MARTINS, C.S.; VALLADARES-PÁDUA, C.B.; PORFÍRIO, S.; OLIVEIRA, M.M.; RYLANDS, A.B.; BEZERRA, A.R.G.F. 2007. Manejo para a conservação de primatas brasileiros. In: BICCA-MARQUES, J.C. (Ed.) A Primatologia no Brasil. Porto Alegre, p. 71-100.

KLINK, C.A.; MACHADO, R.B. 2005. A conservação do cerrado brasileiro. Megadiversidade, 1: 147-155.

KRONKA, F. 1998. Áreas de domínio do cerrado no estado de São Paulo. São Paulo: SMA.

LEWINSOHN, T.M.; PRADO, P.I. 2002. Biodiversidade brasileira: síntese do estado atual de conhecimento. MMA, Conservation International do Brasil. São Paulo: Editora Contexto.

MARINHO-FILHO, J.; RODRIGUES, F.H.; JUAREZ, K.M. 2002. The cerrado mammal's: diversity ecology and natural history. In: OLIVEIRA, P.S.; MARQUIS, R.J. The cerrados of Brazil: ecology and natural history of a Neotropical Savanna. New York: Columbia University Press. p.266-284.

MARTINS, I. A. 2004. Identificação dos canídeos brasileiros através dos seus pêlos 
guarda. (Monografia - Iniciação científica) - Universidade Estadual Paulista.

MARTINS, I. A.; ALBERTS, C.C.; FREI, F. 2005. Field key identification of the brazilian canids through their guard hairs found in their faeces. Anals of XIX Annual Meeting of the Society for Conservation Biology, 127-128.

MCBEE, K.; BAKER, R. 1982. Dasypus novemcinctus. Mammalian Species,162:1-9.

MCCOY, M.B.; VAUGHAM, C.S.; RODRIGUEZ, M.A.; KITCHEN, D. 1990. Seasonal movement, home range, activity and diet of collared peccaries (Tayassu tajacu) in Costa Rican dry Forest. Vida Silvestre Neotropical, 2: 6-20.

MEDELlin, R.; CANCINO, G.; CLEMENTE, A.; GUERRERO, R. 1992. Noteworthy records of three mammals from Mexico. The Southwestern Naturalist, 4: 427-430.

MEDRI, I.M.; MOURÃO, G.; RODRIGUES, F.H.G. 2006. Ordem Xenarthra. In: REIS, N.R.; PERACCHI, A.L.; PEDRO, W.A.; LIMA, I.P (Eds.). Mamíferos do Brasil. Londrina, p. 71-99.

MENDES PONTES, A.R.; CHIVERS, D.J. 2007. Peccary movements as determinants of the movements of large cats in Brazilian Amazonia. Journal of Zoology, 273: 257-265.

MICHALSKI, F.; CRAWSHAW, P.G.; OLIVEIRA, T.G.; FABIÁN, M.H. 2006. Notes on home range and habitat use of three small carnivore species in a disturbed vegetation mosaic of southeastern Brazil. Mammalia, 52-57.

MIRANDA, G.H.B. 2004. Ecologia e conservação do tamanduá bandeira (Myrmecophaga tridactyla) no Parque Nacional das Emas. (Tese de doutorado) ICB/UNB.

MITTERMEIER, R.A.; ROBLES GIL, P.; MITTERMEIER, C.G. 1997. Megadiversity: earth's biologically wealthiest nations. Conservation International, Agrupación Sierra Madre, Cidade do México.

MOURÃO, G.; MEDRI I.M. 2007. Activity of a specialized insectivorus mammal (Myrmecophaga tridactyla) in the Pantanal of Brazil. Journal of Zoology, 271: 187192.

MMA - MINISTÉRIO DO MEIO AMBIENTE. 2008. Livro vermelho da fauna brasileira ameaçada de extinção. MACHADO, A.B.M; DRUMMOND, G.M.; PAGLIA, 
A.P. (Eds.). Brasília: MMA. <http://www.mma.gov.br/estruturas/sbf2008_dcbio/ _publicacao/147_publicacao31032009031646.pdf>

NAKANO-OLIVEIRA, E. 2002. Ecologia alimentar e área de vida de carnívoros da Floresta Nacional de Ipanema, Iperó, SP. (Dissertação de mestrado) IB/UNICAMP.

OLIVEIRA, T.G.; CASSARO, K. 2005. Guia de identificação dos felinos brasileiros. Instituto Pró Carnívoros e Sociedade de Zoológicos do Brasil, São Paulo, SP.

PRESLEY, S.J. 2000. Eira barbara. Mammalian species, 636: 1-6.

QUADROS, J. 2002. Identificação microscópica de pêlos de mamíferos brasileiros e sua aplicação no estudo da dieta de carnívoros. (Tese doutorado) - Universidade Federal do Paraná.

REDFORD, K.H; .FONSECA, G.A.B. 1984. the mammals of IBGE's Ecological Reserve, Brasília, and an analysis of the role of gallery forests in increasing diversity. Revista Brasileira de Biologia, 4: 517-523.

RIVERO, K.; RUMIZ, D.I.; TABER, A.B. 2005. Differential habitat use by two sympatric brocket deer species (Mazama Americana and M. gouazoubira) in seasonal Chiquitano forest of Bolivia. Mammalia, 69: 169-183.

ROCHA, V.J. 2001. Ecologia de mamíferos de médio e grandes portes do Parque Estadual dos Godoy, Londrina (PR). (Tese de doutorado) - UFPR.

RODRIGUES, F.H.G.; MARINHO-FILHO, J.S.; SANTOS, H.G. 2001. Home ranges of translocated lesser anteaters Tamandua tetradactyla in the cerradão of Brazil. Oryx, 35: 166-169.

SANDERSON, J. Camera trapping protocol. Tropical Ecology, Assessment and Monitoring,<http://www.iwokrama.org/library/pdfdownload/Camera\%20Trapping\%20 Protocol\%20TEAM\%203-12-03.pdf>

SHAW, J.H.; MACHADO NETO, J.; CARTER, T.S. 1987. Behavior of free-living giant anteaters (Myrmecophaga tridactyla). Biotropica, 3: 255-259.

SILVEIRA, C.F.P.; JARDINEIRO, K.S.; MARTINS, I.A.; BITENCOURT, M. D. 2009. Análise da qualidade das matas ripárias para mamíferos, utilizando um fragmento de cerrado do estado de São Paulo, sensoriamento remoto e campo In: Anais do 
XIV Simpósio Brasileiro de Sensoriamento Remoto, Natal/RN. p.5451-5458. $<$ http://marte.dpi.inpe.br/col/dpi.inpe.br/sbsr@80/2008/11.17.17.41.43/doc/54515458.pdf>

SILVEIRA, L., JACOMO, A.T.A., DINIZ-FILHO, J.A.F., 2003. Camera Trap, line transect census and track surveys: a comparative evaluation. Biological Conservation, 114: 351-355.

SMA - SECRETARIA DO MEIO AMBIENTE DO ESTADO DE SÃO PAULO. 1999. Conhecer para conservar: as unidades de conservação do estado de São Paulo. São Paulo: SMA.

SMA - SECRETARIA DO MEIO AMBIENTE DO ESTADO DE SÃO PAULO. 2008. Lista dos animais ameaçados de extinção no Estado de São Paulo: apêndices I, III e IV. São Paulo: SMA. <http://www.ambiente.sp.gov.br/fauna.php>

SMALLWOOD, K.S.; FITZFUGH, E.L. 2005. A track count for estimating mountain lion Felis concolor califórnica population trend. Biological Conservation, 71: 251-259.

SMITH, E.P.; BELLE, G. 1984. Nonparametric estimation of species richness. Biometrics, 40: 119-129.

SOKAL, R.R.; ROHLF, F.J. 1995. Biometry: the principles practice of statistics in biological research. New York: W.H. Freeman.

UNEP-WCMC. 2009. UNEP-WCMC Species Database: CITES-Listed Species on the World Wide Web. <http://www.cites.org/eng/resources/species.html> VOSS, R.; EMMONS, L.H. 1996. Mammalian diversity in Neotropical lowland rainforest: a preliminary assessment. Bulletin of the American Museum of Natural History, 230: 1-115. 
Capítulo IV

Análise Espacial de Qualidade de Habitat para Mamíferos de Médio e Grande Porte em um Fragmento de Cerrado

Abstract 125

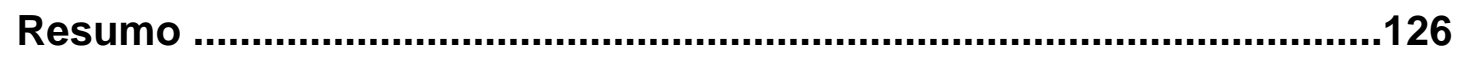

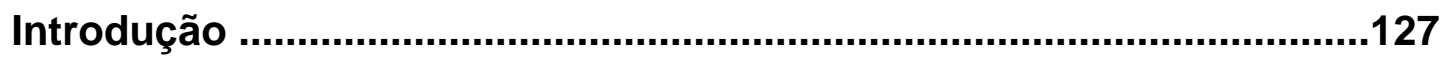

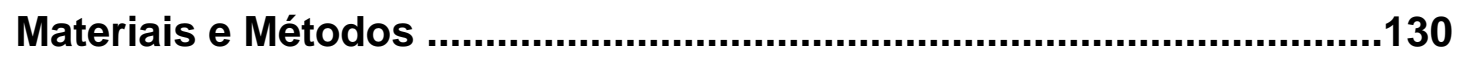

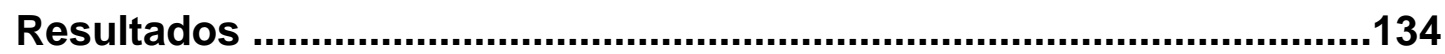

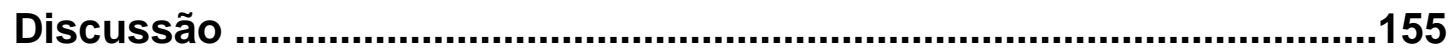

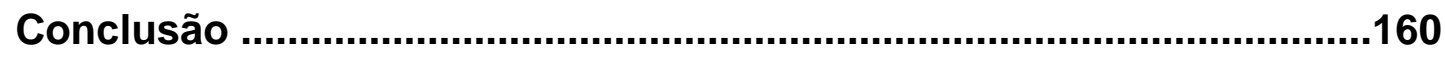

Referências Bibliográficas .................................................................161 


\begin{abstract}
The intense degradation of the Cerrado biome has had great consequences over the habitat quality available for many animals. The search for rapid and reliable methods to allocate areas with ecological values for different groups of animals has arising great interest now-a-days. The developed methodology at the present work aim to determine the variation of the habitat quality within a São Paulo State cerrado remnant (2,098ha), using remote sensing and geoprocessing techniques. According to the environmental needs of each species, were selected abiotic and biotic criteria that could be inserted on a decision making model in order to influence habitat quality and infer seven mammals species occurrence: Myrmecophaga tridactyla great anteater, Tapirus terrestris - tapir, Tayassu tajacu - collared peccary, Mazama americana - red brocket deer, Eira barbara - tayra, Puma concolor - puma and Leopardus pardalis - ocelot. Those criteria were evaluated by experts, who assign specific weights according to species environmental needs. Thus, seven Opportunity Maps were developed through a Multi Criteria Evaluation, which were validated in the field (trace sensing and cam trapping). The model used showed very robust in predicting coherently the habitat quality using the occurrence of the target species. The most detections were obtained in favorable areas (40\%), followed by very favorable areas (20\%), regular areas (18\%), unfavorable areas (15\%) and very unfavorable areas (6\%). The most species were detected more often in favorable areas and less often in very unfavorable areas, excepted T. terrestris and T. tajacu, which were detected in very favorable areas.
\end{abstract}

Key words: Remote Sensing, Geographic Information System, Geoprocessing technics, Habitat quality, Decision Making Model 


\section{Resumo}

A intensa degradação do bioma cerrado tem tido grandes conseqüências na disponibilidade de habitats de boa qualidade para muitos animais. A busca por métodos rápidos e confiáveis que localizem áreas de valor ecológico para diferentes grupos de animais tem despertado grande interesse. A metodologia desenvolvida neste trabalho objetiva determinar a variação da qualidade dos habitats inseridos em um fragmento de cerrado (2.098ha) no estado de São Paulo, utilizando análise geográfica computadorizada. Em função das necessidades ambientais de cada espécie, foram selecionados critérios abióticos e bióticos que pudessem ser inseridos no modelo de tomada de decisão e que fossem capazes de influenciar a qualidade do habitat e inferir a ocorrência de sete espécies de mamíferos: Myrmecophaga tridactyla - tamanduá-bandeira, Tapirus terrestris - anta, Tayassu tajacu - cateto, Mazama americana - veado mateiro, Eira barbara - irara, Puma concolor - onça parda e Leopardus pardalis - jaguatirica. Estes critérios foram avaliados por especialistas, os quais forneceram pesos de acordo com as exigências ambientais de cada espécie. Em seguida, foram desenvolvidos sete Mapas de Oportunidades (produto final do modelo de tomada de decisão) através da avaliação multicritério (MCE), os quais foram validados na etapa de campo (censo de vestígios e armadilhamento fotográfico). O modelo utilizado apresentouse robusto ao predizer de forma coerente a qualidade do habitat a partir da ocorrência das espécies-alvo. A maior porcentagem de detecção das espécies foi obtida em habitats favoráveis (40\%), seguido de habitats muito favoráveis (20\%), habitats regulares (18\%), habitats desfavoráveis (15\%) e habitats muito desfavoráveis $(6 \%)$. A maioria das espécies foi detectada mais vezes em habitats favoráveis e menos vezes em habitats muito desfavoráveis, com exceção de $T$. terrestris e T. tajacu, que foram detectados mais vezes em habitats muito favoráveis.

Palavras chave: Sensoriamento Remoto, Sistema de Informação Geográfica, Geoprocessamento, Qualidade de habitat, Modelo de Tomada de Decisão 


\section{Introdução}

O bioma Cerrado, o segundo maior do Brasil, foi considerado por Myers et al. (2000) um dos dois hotspots brasileiros, em vista da importância de sua biodiversidade e do grau de deterioração em que se encontra esse bioma nos dias de hoje. A degradação ambiental neste bioma tem afetado sobremaneira a disponibilidade de ambientes adequados a muitas espécies animais (Bitencourt, 2004).

Neste cenário, torna-se imperativa a busca por metodologias que possam ser utilizadas como ferramentas de conservação de espécies, auxiliando tomadores de decisão a direcionar com mais embasamento as suas estratégias de manejo e conservação. Conceitos de Ecologia da Paisagem, juntamente com técnicas de sensoriamento remoto e geoprocessamento, em particular os Sistemas de Informação Geográfica (SIG), podem ser algumas dessas ferramentas.

Segundo Aronoff (1991), um componente importante no gerenciamento da vida silvestre é a predição dos efeitos das atividades humanas e dos eventos naturais sobre a abundância e a qualidade das populações silvestres. Desta forma, esta informação pode ser utilizada no processo de tomada de decisão, na escolha para construção de uma estrada ou fechamento do acesso, ao grande público, às áreas críticas de vida silvestre.

As comunidades biológicas dependem da presença de um misto apropriado de recursos dentro de uma área geograficamente definida. A análise da disponibilidade de alimentos e abrigos, proteção contra predadores e a adequação de áreas para locais de aninhamento e permanência, pode ser desenvolvida em ambiente de SIG. O uso de técnicas de SIG tem se tornado freqüente para análise de qualidade de habitat de vários grupos animais. Esta análise será incluída no processo de tomada de decisão quanto ao planejamento de atividades que podem afetar os habitats destes animais, por exemplo (Aronoff, 1991).

Em paisagens fragmentadas, observam-se conjuntos de habitats que apresentam condições mais ou menos favoráveis para uma espécie ou comunidade, sendo o olhar sobre esta paisagem diferente para cada espécie e condicionado às suas 
características biológicas, em particular de seus requerimentos em termos de área de vida, alimentação, abrigo e reprodução (Macdonald et al. 2003; Metzger, 2001).

Clevenger et al. (2002) desenvolveu três modelos de habitat para Ursus americanus um baseado em dados empíricos e os outros dois baseados em informações de especialistas (opinião pessoal e literatura em relação aos requerimentos ambientais da espécie). Os resultados apresentados demonstraram que o modelo baseado na literatura especializada se aproximou muito do modelo baseado em dados empíricos. Macdonald et al. (2003) realizou a correspondência entre categorias de habitat e os requerimentos ambientais (recursos) para duas espécies de roedores e duas de marsupiais. As categorias de habitat forneceram boas variáveis para predizer a distribuição da espécie. Hume et al. (2007) determinaram quais as características da paisagem eram capazes de explicar e predizer os padrões de ocupação de uma espécie de esquilo planador (Pteromys volans) em manchas de habitat. Para isto, eles classificaram imagens de satélite visando categorizar a área de estudo e gerar um modelo utilizando as variáveis da paisagem.

A utilização de imagens de satélite, de mapas ou aerofotografias (sensoriamento remoto) permite que se modelem as possíveis relações entre os habitats e as espécies (Fischer et al. 2004). O Índice de Vegetação de Diferença Normalizada (IVDN), obtido a partir de imagens de satélite, tem sido utilizado para indicar as variações estruturais de fisionomias de cerrado, bem como de florestas ripária e estacional semidecidual associadas. De posse desses mapas temáticos, validados com os trabalhos de campo, é possível modelar aspectos de interesse ecológico através de análises em ambiente de SIG (Bitencourt, 2004).

Dentre os modelos desenvolvidos em ambiente de SIG, existem aqueles que analisam por múltiplos critérios ou por múltiplos objetivos. Paczek (1997) utilizou Avaliação de Multicritérios (MCE - Multi Criteria Evaluation) para determinar os habitats mais apropriados para aves de estepe arbustiva e utilizou MOLA (Multi Objective Land Allocation) para alocar área para objetivos múltiplos e resolver o conflito entre o melhor habitat para as aves e o melhor habitat para o gado.

Somente a Avaliação de Multicritérios (MCE) se aplica aos objetivos do estudo aqui desenvolvido. 
O presente estudo tem como objetivo geral apresentar uma proposta metodológica que mostre espacialmente a qualidade de habitats e que possa ser aplicado a qualquer situação. A base dessa proposta metodológica é a análise geográfica computadorizada, por meio da qual se espera chegar a Mapas de Oportunidades (qualidade de habitat) compatíveis com espécies de mamíferos de grande porte num fragmento de cerrado.

Os objetivos específicos do trabalho são: a) determinar critérios (variáveis) abióticos e bióticos que possam influenciar a qualidade do habitat; b) elaborar novos mapas temáticos a partir dos critérios selecionados; c) padronizar e atribuir pesos aos critérios; d) agregar os critérios em um mapa temático final (Mapa de Oportunidades) para cada espécie - MCE; e) avaliar a eficácia do modelo de tomada de decisão desenvolvido, por meio dos dados de freqüência de espécies obtidos na fase de campo. Todos os objetivos específicos buscam identificar as áreas com melhor qualidade de habitat para as espécies de mamíferos de médio e grande porte e, conseqüentemente, predizer sua provável ocorrência dentro do fragmento. Esta proposta metodológica poderá ser um instrumento de medida de eficácia, na compreensão do comportamento das espécies em ambientes alterados. 


\section{Materiais e Métodos}

Para o desenvolvimento do Modelo de Tomada de Decisão, foram utilizados:

\section{(A) Materiais}

- Programa IDRISI Andes, desenvolvido pela Clark University (Eastman, 2006);

- MNT, Mapa Hipsométrico, Mapa Clinográfico e Mapa de Fitofisionomias (desenvolvidos no Capítulo II);

- Vetores da drenagem, linha de transmissão de energia, estradas e contorno do fragmento (corrigidos e/ou desenvolvidos no Capítulo II);

- Dados de freqüência de espécies de mamíferos de médio e grande porte, georreferenciados com o auxílio de GPS (datum Córrego Alegre) e obtidos durante a campanha de campo (março e abril de 2008).

\section{(B) Métodos}

Para determinação dos habitats adequados para as espécies de mamíferos de grande porte, foram selecionados onze critérios capazes de influir na qualidade do habitat: sete critérios físicos - altitude, declividade, orientação de vertentes, distância de corpos d'água, distância da linha de transmissão de energia, distância de estradas e distância da borda; e quatro critérios bióticos - fitofisionomias observadas na área de estudo (Figura IV.1).

Posteriormente estes critérios foram utilizados no processo de tomada de decisão, ou seja, no desenvolvimento do modelo.

Para a elaboração dos Mapas de Oportunidades foram utilizados mapas produzidos no Capítulo II (MNT, Mapa Hipsométrico, Mapa Clinográfico e Mapa de Fitofisionomias), assim como foram desenvolvidos novos mapas temáticos para inserção no modelo de tomada de decisão. Cada imagem gerada e/ou utilizada no modelo representa um dos critérios selecionados anteriormente. 
Os novos mapas gerados para esta etapa são: (a) Mapa de Orientação de Vertentes; (b) Mapa de Distância da Borda; (c) Mapa de Distância da Linha de Transmissão de Energia; (d) Mapa de Distância de Estradas; (e) Mapa de Distância dos Corpos d'água; (f) Mapa de Ocorrência de Cerradão; (g) Mapa de Ocorrência de Cerrado sensu stricto Denso; (h) Mapa de Ocorrência de Cerrado sensu stricto Típico; e (i) Mapa de Ocorrência da Mata Ripária.

O MNT foi utilizado para produzir o Mapa de Orientação de Vertentes, que permite avaliar o grau de insolação, o nível de umidade, bem como a influência dos ventos em uma determinada área. Os mapas Hipsométrico e Clinográfico foram inseridos diretamente no modelo (critérios altitude e declividade, respectivamente). Entretanto, o Mapa de Fitofisionomias precisou ser decomposto em quatro mapas $(f, g, h, i)$, que foram inseridos individualmente no modelo, já que receberam pesos diferentes em função das espécies estudadas. Os mapas de distância (a, b, c, d, e) foram produzidos a partir dos vetores (drenagem, linha de transmissão de energia, estradas e contorno do fragmento).

Para as espécies em questão, foi estabelecido arbitrariamente que a influência do corpo d'água e da estrada seria de 500m, e a influência da linha de transmissão de energia e da borda do fragmento seria de $100 \mathrm{~m}$. Determinou-se também que quanto maior for a distância das estradas, borda do fragmento e linha de transmissão de energia, melhor será a qualidade do habitat, assim como quanto menor a distância dos corpos d'água.

Como os critérios utilizados apresentam classes com intervalos tanto qualitativos como quantitativos, houve a necessidade de padronização que foi realizada com a transformação dos dados em conjuntos fuzzy (escala de intervalo de 0 a 255, representada em variações de cores). Esta padronização é expressa na seguinte equação: $\left.X_{i}=\left(R_{i}-R_{\min }\right) / R_{\max }-R_{\min }\right)^{\star 255}$, onde $R_{i}$ é o número a ser padronizado; $X_{i}$ é o número a ser padronizado na escala de $0-255 ; R_{\min }$ é o menor valor da escala na qual pertence o número a ser padronizado; e $\mathrm{R}_{\mathrm{ma}}$ é o maior valor da escala na qual pertence o número a ser padronizado.

A seguir, os critérios foram comparados dois a dois através de matriz quadrada, utilizando-se o Processo Hierárquico Analítico (Analytic Hierarchy Process - AHP), desenvolvido por Saaty (1977) e corroborado por Eastman et al. (1995) e Eastman 
(1997). Neste processo, os critérios foram hierarquizados de acordo com a sua importância em uma escala de 1/9 (menos importante) a 9 (mais importante). Esta análise foi realizada por um conjunto de pesquisadores especialistas independentes, conforme Saaty (1977) sugere.

A taxa de consistência da matriz (CR) foi calculada para determinar se houve coerência da intensidade proporcional de um elemento da matriz em relação aos outros. A expressão utilizada no cálculo foi $C R=\left[\left(\lambda_{\max }-n\right) /(n-1)\right] / R_{i}$, onde $R_{i}$ mede o índice do acaso de uma matriz e é chamado de índice de consistência de uma matriz a ser gerada ao acaso na escala de $1 / 9$ a $9 ; \lambda_{\max }$ é o valor principal e reflete a proporção da preferência; e n é o número de linhas e colunas da matriz quadrada. Quanto mais próximo for $\lambda_{\text {Max }}$ do $n$, mais consistente será a matriz. Os dados da matriz foram, então, convertidos em pesos (autovalores) a partir do cálculo matricial proposto por Eastman (1997).

No total foram desenvolvidas sete matrizes quadradas, uma para cada espéciealvo, partindo-se do pressuposto de que estas espécies possuem exigências ambientais diferentes. Os resultados foram pesos diferentes para um mesmo critério.

A próxima etapa foi gerar os Mapas de Oportunidades (qualidade de habitat) a partir da avaliação multicritério ( $M C E)$, onde os critérios (mapas temáticos) e seus respectivos pesos foram inseridos no programa IDRISI Andes (Eastman, 2006). A eficácia do modelo final foi avaliada a partir dos dados de freqüência das espécies de mamíferos em questão, obtidos na etapa de campo. A Figura IV.1 sumariza as etapas do trabalho.

Dentre as espécies detectadas no campo, foram utilizados os dados de freqüência de ocorrência de sete espécies de mamíferos para o desenvolvimento e validação do modelo: Myrmecophaga tridactyla - tamanduá-bandeira, Tapirus terrestris - anta, Tayassu tajacu - cateto, Mazama americana - veado mateiro, Eira barbara - irara, Puma concolor - onça parda e Leopardus pardalis - jaguatirica.

Os pontos de ocorrência destas espécies foram sobrepostos aos seus respectivos Mapas de Oportunidades, para determinar se a análise espacial da qualidade do habitat poderia predizer a ocorrência das espécies em habitats com melhores condições ambientais para cada uma delas. 


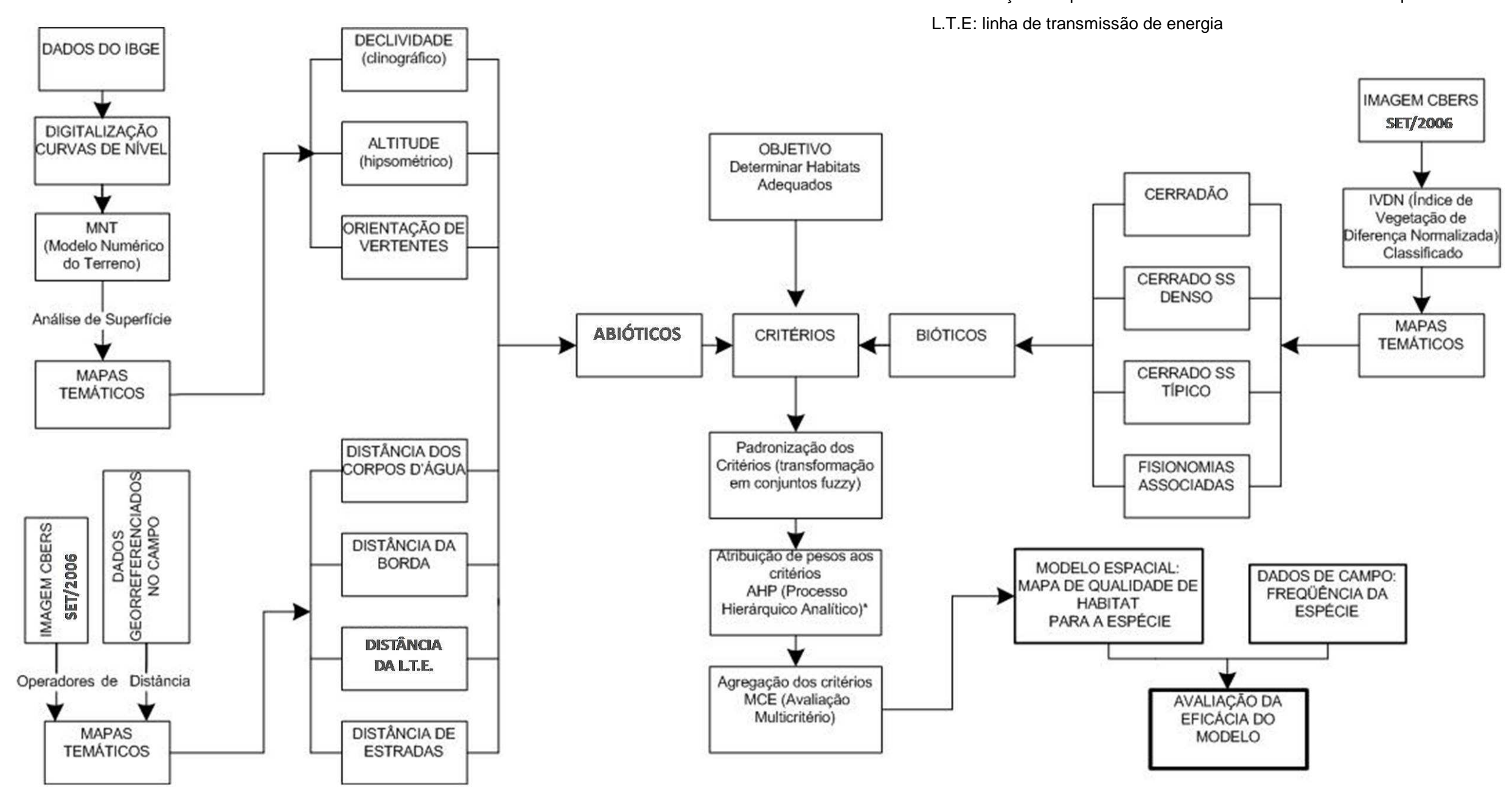

Fig.IV.1. - Fluxograma apresentando as etapas (obtenção dos dados, procedimentos e produtos finais) da análise em ambiente de SIG (Sistema de Informação Geográfica) para desenvolvimento do modelo de qualidade de habitat. 


\section{Resultados}

O produto do modelo de tomada de decisão aqui desenvolvido são sete mapas temáticos (Mapas de Oportunidades), um para cada espécie utilizada neste estudo, que retratam espacialmente a qualidade do habitat, inferida a partir dos critérios abióticos e bióticos, e das características ecológicas (exigências ambientais) intrínsecas a cada espécie. Estes Mapas de Oportunidades foram validados a partir dos dados de freqüência de ocorrência obtidos na etapa de campo (Figura IV.1).

Os critérios abióticos e bióticos foram comparados dois a dois através de uma matriz quadrada, onde a importância de uma determinada variável (linhas da matriz) foi medida em relação às outras variáveis (colunas da matriz). Sendo assim, foi julgado se o elemento da linha é mais ou menos importante, de acordo com a escala contínua apresentada na Tabela IV.1, em comparação aos elementos da coluna. Posteriormente, os dados da matriz foram utilizados para o cálculo dos pesos. No total, foram desenvolvidas sete matrizes quadradas (Tabelas IV.2 à IV.8), uma para cada espécie de mamífero selecionada, por meio de consulta ad hoc a especialistas (ecólogos e zoólogos).

Tabela IV.1.- Escala contínua de comparação entre duas variáveis. Os valores são inseridos na matriz quadrada de comparação par a par no Processo Hierárquico Analítico (AHP)

\begin{tabular}{|c|c|c|c|c|c|c|c|c|}
\hline \multicolumn{9}{|c|}{ Escala contínua de comparação entre duas variáveis } \\
\hline $1 / 9$ & $1 / 7$ & $1 / 5$ & $1 / 3$ & 1 & 3 & 5 & 7 & 9 \\
\hline Extremamente & Muito Fortemente & Fortemente & Moderadamente & & Moderadamente & Fortemente & Muito Fortemente & Extremamente \\
\hline \multicolumn{4}{|c|}{ Menos Importante } & & \multicolumn{4}{|c|}{ Mais Importante } \\
\hline
\end{tabular}

As matrizes resultantes apresentaram-se consistentes: taxa de consistência da matriz para $M$. tridactyla $=0.06$; taxa de consistência da matriz para $M$. americana $=$ 0,05; taxa de consistência da matriz para $T$. terrestris $=0,09$; taxa de consistência da matriz para $L$. pardalis, E. barbara, $P$. concolor e $T$. tajacu $=0,04$. Os autovalores dos pesos gerados para cada critério em relação a cada espécie encontram-se na Tabela IV.9. 
Tabela IV.2. - Matriz de Comparação Par a Par (Pairwise Comparison) dos critérios abióticos e bióticos selecionados. Valores atribuídos por especialistas em função da espécie $E$. barbara

\begin{tabular}{|c|c|c|c|c|c|c|c|c|c|c|c|}
\hline & $\begin{array}{l}\text { Orientação de } \\
\text { vertentes }\end{array}$ & Declividade & Altitude & $\begin{array}{l}\text { Distância de } \\
\text { estradas }\end{array}$ & $\begin{array}{c}\text { Proximidade } \\
\text { com corpos } \\
\text { d'água }\end{array}$ & $\begin{array}{l}\text { Distância da } \\
\text { borda }\end{array}$ & $\begin{array}{l}\text { Distância da } \\
\text { L.T.E }\end{array}$ & Cerradão & $\begin{array}{l}\text { Cerrado } s s \\
\text { mais denso }\end{array}$ & $\begin{array}{l}\text { Cerrado ss } \\
\text { típico }\end{array}$ & Mata Ripária \\
\hline Orientação de vertentes & 1 & & & & & & & & & & \\
\hline Declividade & $1 / 3$ & 1 & & & & & & & & & \\
\hline Altitude & $1 / 5$ & $1 / 3$ & 1 & & & & & & & & \\
\hline Distância de estradas & 7 & 7 & 9 & 1 & & & & & & & \\
\hline $\begin{array}{l}\text { Proximidade com corpos } \\
\text { d'água }\end{array}$ & 5 & 7 & 9 & 1 & 1 & & & & & & \\
\hline Distância da borda & 3 & 5 & 7 & $1 / 7$ & $1 / 7$ & 1 & & & & & \\
\hline Distância da L.T.E & $1 / 3$ & 3 & $1 / 3$ & $1 / 9$ & $1 / 9$ & $1 / 5$ & 1 & & & & \\
\hline Cerradão & 7 & 7 & 9 & 1 & 1 & 5 & 7 & 1 & & & \\
\hline Cerrado ss mais denso & 7 & 7 & 9 & 1 & 1 & 5 & 7 & 1 & 1 & & \\
\hline Cerrado ss típico & 7 & 7 & 9 & 1 & 1 & 5 & 7 & $1 / 3$ & $1 / 3$ & 1 & \\
\hline Mata Ripária & 7 & 7 & 9 & 1 & 1 & 5 & 7 & 1 & 1 & 3 & 1 \\
\hline
\end{tabular}

L.T.E.: Linha de Transmissão de Energia; ss: sensu stricto 
Tabela IV.3. - Matriz de Comparação Par a Par (Pairwise Comparison) dos critérios abióticos e bióticos selecionados. Valores atribuídos por especialistas em função da espécie $L$. pardalis

\begin{tabular}{|c|c|c|c|c|c|c|c|c|c|c|c|}
\hline & $\begin{array}{c}\text { Orientação de } \\
\text { vertentes }\end{array}$ & Declividade & Altitude & $\begin{array}{l}\text { Distância de } \\
\text { estradas }\end{array}$ & $\begin{array}{l}\text { Proximidade } \\
\text { com corpos } \\
\text { d'água }\end{array}$ & $\begin{array}{l}\text { Distância da } \\
\text { borda }\end{array}$ & $\begin{array}{l}\text { Distância da } \\
\text { L.T.E }\end{array}$ & Cerradão & $\begin{array}{l}\text { Cerrado ss } \\
\text { mais denso }\end{array}$ & $\begin{array}{l}\text { Cerrado ss } \\
\text { típico }\end{array}$ & Mata Ripária \\
\hline Orientação de vertentes & 1 & & & & & & & & & & \\
\hline Declividade & $1 / 3$ & 1 & & & & & & & & & \\
\hline Altitude & $1 / 5$ & $1 / 3$ & 1 & & & & & & & & \\
\hline Distância de estradas & 7 & 7 & 9 & 1 & & & & & & & \\
\hline $\begin{array}{l}\text { Proximidade com corpos } \\
\text { d'água }\end{array}$ & 5 & 7 & 9 & 1 & 1 & & & & & & \\
\hline Distância da borda & 5 & 7 & 9 & $1 / 7$ & $1 / 7$ & 1 & & & & & \\
\hline Distância da L.T.E & $1 / 3$ & 3 & $1 / 3$ & $1 / 9$ & $1 / 9$ & $1 / 5$ & 1 & & & & \\
\hline Cerradão & 7 & 7 & 9 & 1 & 1 & 5 & 7 & 1 & & & \\
\hline Cerrado ss mais denso & 7 & 7 & 9 & 1 & 1 & 5 & 7 & 1 & 1 & & \\
\hline Cerrado ss típico & 7 & 7 & 9 & 1 & 1 & 5 & 7 & $1 / 3$ & $1 / 3$ & 1 & \\
\hline Mata Ripária & 7 & 7 & 9 & 1 & 1 & 5 & 7 & 1 & 1 & 3 & 1 \\
\hline
\end{tabular}

L.T.E.: Linha de Transmissão de Energia; ss: sensu stricto 
Tabela IV.4. - Matriz de Comparação Par a Par (Pairwise Comparison) dos critérios abióticos e bióticos selecionados. Valores atribuídos por especialistas em função da espécie $M$. americana

\begin{tabular}{|c|c|c|c|c|c|c|c|c|c|c|c|}
\hline & $\begin{array}{l}\text { Orientação de } \\
\text { vertentes }\end{array}$ & Declividade & Altitude & $\begin{array}{l}\text { Distância de } \\
\text { estradas }\end{array}$ & $\begin{array}{l}\text { Proximidade } \\
\text { com corpos } \\
\text { d'água }\end{array}$ & $\begin{array}{l}\text { Distância da } \\
\text { borda }\end{array}$ & $\begin{array}{l}\text { Distância da } \\
\text { L.T.E }\end{array}$ & Cerradão & $\begin{array}{l}\text { Cerrado } s s \\
\text { mais denso }\end{array}$ & $\begin{array}{l}\text { Cerrado ss } \\
\text { típico }\end{array}$ & Mata Ripária \\
\hline Orientação de vertentes & 1 & & & & & & & & & & \\
\hline Declividade & 3 & 1 & & & & & & & & & \\
\hline Altitude & $1 / 3$ & $1 / 7$ & 1 & & & & & & & & \\
\hline Distância de estradas & 9 & 5 & 9 & 1 & & & & & & & \\
\hline $\begin{array}{l}\text { Proximidade com corpos } \\
\text { d'água }\end{array}$ & 7 & 5 & 9 & 1 & 1 & & & & & & \\
\hline Distância da borda & 5 & $1 / 5$ & 9 & $1 / 9$ & $1 / 9$ & 1 & & & & & \\
\hline Distância da L.T.E & 3 & $1 / 7$ & $1 / 5$ & $1 / 9$ & $1 / 9$ & $1 / 5$ & 1 & & & & \\
\hline Cerradão & 7 & 5 & 9 & 1 & 1 & 5 & 7 & 1 & & & \\
\hline Cerrado ss mais denso & 7 & 5 & 9 & 1 & 1 & 5 & 7 & 1 & 1 & & \\
\hline Cerrado ss típico & 7 & 5 & 9 & 1 & 1 & 5 & 7 & 1 & 1 & 1 & \\
\hline Mata Ripária & 7 & 5 & 9 & 1 & 1 & 5 & 7 & 1 & 1 & 1 & 1 \\
\hline
\end{tabular}

L.T.E.: Linha de Transmissão de Energia; ss: sensu stricto 
Tabela IV.5. - Matriz de Comparação Par a Par (Pairwise Comparison) dos critérios abióticos e bióticos selecionados. Valores atribuídos por especialistas em função da espécie M. tridactyla

\begin{tabular}{|c|c|c|c|c|c|c|c|c|c|c|c|}
\hline & $\begin{array}{l}\text { Orientação de } \\
\text { vertentes }\end{array}$ & Declividade & Altitude & $\begin{array}{l}\text { Distância de } \\
\text { estradas }\end{array}$ & $\begin{array}{l}\text { Proximidade } \\
\text { com corpos } \\
\text { d'água }\end{array}$ & $\begin{array}{l}\text { Distância da } \\
\text { borda }\end{array}$ & $\begin{array}{l}\text { Distância da } \\
\text { L.T.E }\end{array}$ & Cerradão & $\begin{array}{l}\text { Cerrado ss } \\
\text { mais denso }\end{array}$ & $\begin{array}{c}\text { Cerrado ss } \\
\text { típico }\end{array}$ & Mata Ripária \\
\hline Orientação de vertentes & 1 & & & & & & & & & & \\
\hline Declividade & 3 & 1 & & & & & & & & & \\
\hline Altitude & $1 / 3$ & $1 / 5$ & 1 & & & & & & & & \\
\hline Distância de estradas & 7 & 5 & 9 & 1 & & & & & & & \\
\hline $\begin{array}{l}\text { Proximidade com corpos } \\
\text { d'água }\end{array}$ & 9 & 5 & 9 & 3 & 1 & & & & & & \\
\hline Distância da borda & 5 & 7 & 9 & $1 / 7$ & 1 & 1 & & & & & \\
\hline Distância da L.T.E & $1 / 3$ & $1 / 3$ & 5 & $1 / 7$ & $1 / 7$ & 3 & 1 & & & & \\
\hline Cerradão & 3 & 3 & 7 & 3 & 1 & 7 & 7 & 1 & & & \\
\hline Cerrado ss mais denso & 3 & 3 & 7 & 3 & 1 & 7 & 7 & 5 & 1 & & \\
\hline Cerrado ss típico & 1 & 3 & 7 & 3 & 1 & 7 & 7 & 5 & 1 & 1 & \\
\hline Mata Ripária & 3 & 3 & 7 & 3 & 1 & 7 & 7 & 7 & 1 & 1 & 1 \\
\hline
\end{tabular}

L.T.E.: Linha de Transmissão de Energia; ss: sensu stricto 
Tabela IV.6. - Matriz de Comparação Par a Par (Pairwise Comparison) dos critérios abióticos e bióticos selecionados. Valores atribuídos por especialistas em função da espécie $P$. concolor

\begin{tabular}{|c|c|c|c|c|c|c|c|c|c|c|c|}
\hline & $\begin{array}{l}\text { Orientação de } \\
\text { vertentes }\end{array}$ & Declividade & Altitude & $\begin{array}{l}\text { Distância de } \\
\text { estradas }\end{array}$ & $\begin{array}{l}\text { Proximidade } \\
\text { com corpos } \\
\text { d'água }\end{array}$ & $\begin{array}{l}\text { Distância da } \\
\text { borda }\end{array}$ & $\begin{array}{l}\text { Distância da } \\
\quad \text { L.T.E }\end{array}$ & Cerradão & $\begin{array}{l}\text { Cerrado ss } \\
\text { mais denso }\end{array}$ & $\begin{array}{l}\text { Cerrado ss } \\
\text { típico }\end{array}$ & Mata Ripária \\
\hline Orientação de vertentes & 1 & & & & & & & & & & \\
\hline Declividade & $1 / 5$ & 1 & & & & & & & & & \\
\hline Altitude & $1 / 9$ & $1 / 9$ & 1 & & & & & & & & \\
\hline Distância de estradas & 3 & 7 & 9 & 1 & & & & & & & \\
\hline $\begin{array}{l}\text { Proximidade com corpos } \\
\text { d'água }\end{array}$ & 7 & 7 & 9 & 3 & 1 & & & & & & \\
\hline Distância da borda & $1 / 7$ & 3 & 9 & $1 / 7$ & $1 / 7$ & 1 & & & & & \\
\hline Distância da L.T.E & $1 / 7$ & $1 / 3$ & 9 & $1 / 9$ & $1 / 9$ & $1 / 3$ & 1 & & & & \\
\hline Cerradão & 3 & 7 & 9 & 3 & 3 & 5 & 7 & 1 & & & \\
\hline Cerrado ss mais denso & 7 & 9 & 9 & 3 & 3 & 5 & 7 & 7 & 1 & & \\
\hline Cerrado ss típico & 3 & 9 & 9 & 3 & 3 & 5 & 7 & 5 & 1 & 1 & \\
\hline Mata Ripária & 3 & 9 & 9 & 3 & 1 & 7 & 7 & 7 & 3 & 3 & 1 \\
\hline
\end{tabular}

L.T.E.: Linha de Transmissão de Energia; ss: sensu stricto 
Tabela IV.7. - Matriz de Comparação Par a Par (Pairwise Comparison) dos critérios abióticos e bióticos selecionados. Valores atribuídos por especialistas em função da espécie T. terrestris

\begin{tabular}{|c|c|c|c|c|c|c|c|c|c|c|c|}
\hline & $\begin{array}{l}\text { Orientação de } \\
\text { vertentes }\end{array}$ & Declividade & Altitude & $\begin{array}{l}\text { Distância de } \\
\text { estradas }\end{array}$ & $\begin{array}{l}\text { Proximidade } \\
\text { com corpos } \\
\text { d'água }\end{array}$ & $\begin{array}{l}\text { Distância da } \\
\text { borda }\end{array}$ & $\begin{array}{l}\text { Distância da } \\
\text { L.T.E }\end{array}$ & Cerradão & $\begin{array}{l}\text { Cerrado } s s \\
\text { mais denso }\end{array}$ & $\begin{array}{l}\text { Cerrado ss } \\
\text { típico }\end{array}$ & Mata Ripária \\
\hline Orientação de vertentes & 1 & & & & & & & & & & \\
\hline Declividade & $1 / 3$ & 1 & & & & & & & & & \\
\hline Altitude & $1 / 9$ & $1 / 9$ & 1 & & & & & & & & \\
\hline Distância de estradas & 5 & 5 & 9 & 1 & & & & & & & \\
\hline $\begin{array}{l}\text { Proximidade com corpos } \\
\text { d'água }\end{array}$ & 7 & 7 & 9 & 7 & 1 & & & & & & \\
\hline Distância da borda & $1 / 3$ & 3 & 9 & $1 / 5$ & $1 / 9$ & 1 & & & & & \\
\hline Distância da L.T.E & $1 / 7$ & $1 / 7$ & 5 & $1 / 9$ & $1 / 9$ & $1 / 3$ & 1 & & & & \\
\hline Cerradão & 1 & 5 & 9 & 7 & $1 / 3$ & 7 & 7 & 1 & & & \\
\hline Cerrado ss mais denso & 1 & 5 & 9 & 7 & 1 & 7 & 7 & 5 & 1 & & \\
\hline Cerrado ss típico & 1 & 5 & 9 & 7 & $1 / 3$ & 7 & 7 & 1 & $1 / 3$ & 1 & \\
\hline Mata Ripária & 3 & 7 & 9 & 9 & 1 & 9 & 9 & 7 & 1 & 7 & 1 \\
\hline
\end{tabular}

L.T.E.: Linha de Transmissão de Energia; ss: sensu stricto 
Tabela IV.8. - Matriz de Comparação Par a Par (Pairwise Comparison) dos critérios abióticos e bióticos selecionados. Valores atribuídos por especialistas em função da espécie T. tajacu

\begin{tabular}{|c|c|c|c|c|c|c|c|c|c|c|c|}
\hline & $\begin{array}{l}\text { Orientação de } \\
\text { vertentes }\end{array}$ & Declividade & Altitude & $\begin{array}{c}\text { Distância de } \\
\text { estradas }\end{array}$ & $\begin{array}{l}\text { Proximidade } \\
\text { com corpos } \\
\text { d'água }\end{array}$ & $\begin{array}{l}\text { Distância da } \\
\text { borda }\end{array}$ & $\begin{array}{l}\text { Distância da } \\
\text { L.T.E }\end{array}$ & Cerradão & $\begin{array}{l}\text { Cerrado } s s \\
\text { mais denso }\end{array}$ & $\begin{array}{l}\text { Cerrado ss } \\
\text { típico }\end{array}$ & Mata Ripária \\
\hline Orientação de vertentes & 1 & & & & & & & & & & \\
\hline Declividade & 3 & 1 & & & & & & & & & \\
\hline Altitude & $1 / 3$ & $1 / 7$ & 1 & & & & & & & & \\
\hline Distância de estradas & 9 & 5 & 9 & 1 & & & & & & & \\
\hline $\begin{array}{l}\text { Proximidade com corpos } \\
\text { d'água }\end{array}$ & 7 & 5 & 9 & 1 & 1 & & & & & & \\
\hline Distância da borda & 5 & $1 / 5$ & 9 & $1 / 9$ & $1 / 9$ & 1 & & & & & \\
\hline Distância da L.T.E & 3 & $1 / 7$ & $1 / 5$ & $1 / 9$ & $1 / 9$ & $1 / 5$ & 1 & & & & \\
\hline Cerradão & 7 & 5 & 9 & 1 & 1 & 5 & 7 & 1 & & & \\
\hline Cerrado ss mais denso & 7 & 5 & 9 & 1 & 1 & 5 & 7 & 1 & 1 & & \\
\hline Cerrado ss típico & 7 & 5 & 9 & 1 & 1 & 5 & 7 & 1 & 1 & 1 & \\
\hline Mata Ripária & 7 & 5 & 9 & 1 & 1 & 5 & 7 & 1 & 1 & 1 & 1 \\
\hline
\end{tabular}

L.T.E.: Linha de Transmissão de Energia; ss: sensu stricto 
Análise Espacial de Qualidade de Habitat para Mamíferos de Médio e Grande Porte em um Fragmento de Cerrado

Tabela IV.9. - Autovalores dos pesos gerados no Processo Hierárquico Analítico (AHP) para cada critério em relação às espécies-alvo

\begin{tabular}{|c|c|c|c|c|c|c|c|}
\hline \multirow{2}{*}{ Critérios } & \multicolumn{7}{|c|}{ Autovalores dos Pesos } \\
\hline & E. barbara & L. pardalis & M. americana & M. tridactyla & P. concolor & T. terrestris & T. tajacu \\
\hline Orientação de vertentes & 0,02 & 0,02 & 0,02 & 0,02 & 0,02 & 0,03 & 0,02 \\
\hline Declividade & 0,02 & 0,02 & 0,02 & 0,03 & 0,02 & 0,02 & 0,02 \\
\hline Altitude & 0,02 & 0,01 & 0,01 & 0,02 & 0,02 & 0,02 & 0,01 \\
\hline Distância de estradas & 0,09 & 0,12 & 0,08 & 0,09 & 0,06 & 0,07 & 0,07 \\
\hline Proximidade com corpos d'água & 0,10 & 0,13 & 0,11 & 0,08 & 0,08 & 0,16 & 0,13 \\
\hline Distância da borda & 0,10 & 0,12 & 0,09 & 0,06 & 0,04 & 0,05 & 0,07 \\
\hline Distância da L.T.E. & 0,04 & 0,03 & 0,03 & 0,05 & 0,03 & 0,04 & 0,03 \\
\hline Cerradão & 0,18 & 0,16 & 0,17 & 0,12 & 0,14 & 0,12 & 0,17 \\
\hline Cerrado ss denso & 0,14 & 0,17 & 0,17 & 0,17 & 0,20 & 0,15 & 0,15 \\
\hline Cerrado ss típico & 0,18 & 0,11 & 0,17 & 0,22 & 0,20 & 0,09 & 0,15 \\
\hline Mata Ripária & 0,12 & 0,11 & 0,13 & 0,14 & 0,19 & 0,25 & 0,18 \\
\hline
\end{tabular}

L.T.E.: Linha de Transmissão de Energia; ss: sensu stricto

A análise da Tabela IV.9 permite inferir que os especialistas consultados consideram os critérios orientação de vertentes, declividade e altitude menos importantes em relação aos demais quando se pretende determinar a qualidade de habitats para as espécies em questão, enquanto que os critérios bióticos (fitofisionomias) receberam os maiores pesos, ou seja, o grau de importância atribuído foi maior para as espécies analisadas.

A mata ripária recebeu maior peso para $T$. terrestris e $T$. tajacu. Para E. barbara, os critérios cerradão e cerrado sensu stricto típico receberam os maiores pesos; para L. pardalis, o maior peso foi atribuído para cerrado sensu stricto denso; para $M$. americana, os maiores pesos foram atribuídos para os parâmetros cerradão, cerrado sensu stricto típico e cerrado sensu stricto denso; para T. tridactyla, o maior peso foi atribuído para o critério cerrado sensu stricto típico; e para $P$. concolor, os maiores pesos foram atribuídos para cerrado sensu stricto típico e cerrado sensu stricto denso.

Os pesos e seus respectivos critérios, na forma de imagens, foram inseridos no modelo de Avaliação Multicritério (MCE) disponível no IDRISI, gerando Mapas de Oportunidades em escala contínua de qualidade (Figura IV.2), envolvendo habitats encontrados no interior do fragmento e matriz, composta predominantemente por pastagem. 


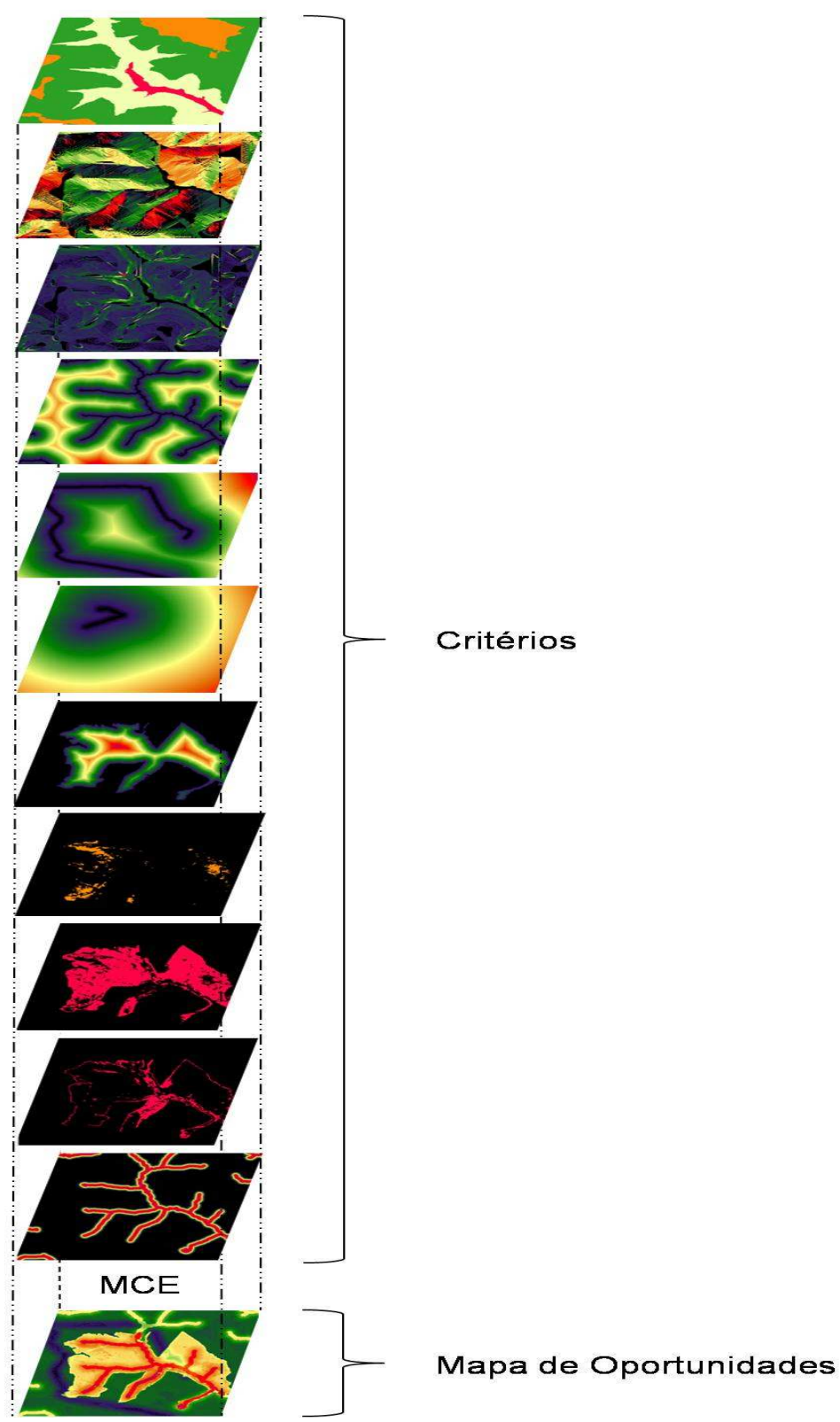

Fig.IV.2. - Esquema apresentando a entrada dos dados (critérios), em ambiente de SIG, para elaboração do modelo de tomada de decisão (MCE). As imagens de entrada equivalem aos critérios: altitude, orientação de vertentes, declividade, proximidade com corpos d'água, distância de estradas, distância da linha de transmissão de energia, distância da borda, cerradão, cerrado sensu stricto denso, cerrado sensu stricto típico e mata ripária, respectivamente. Cada critério recebeu seu respectivo peso, em função das características de cada espécie selecionada, quando da sua entrada no MCE. O produto final da análise foi o Mapa de Oportunidades. 
Análise Espacial de Qualidade de Habitat para Mamíferos de Médio e Grande Porte em um Fragmento de Cerrado

As Figuras IV.3 a IV.9 apresentam os Mapas de Oportunidades desenvolvidos para as espécies alvo deste estudo.

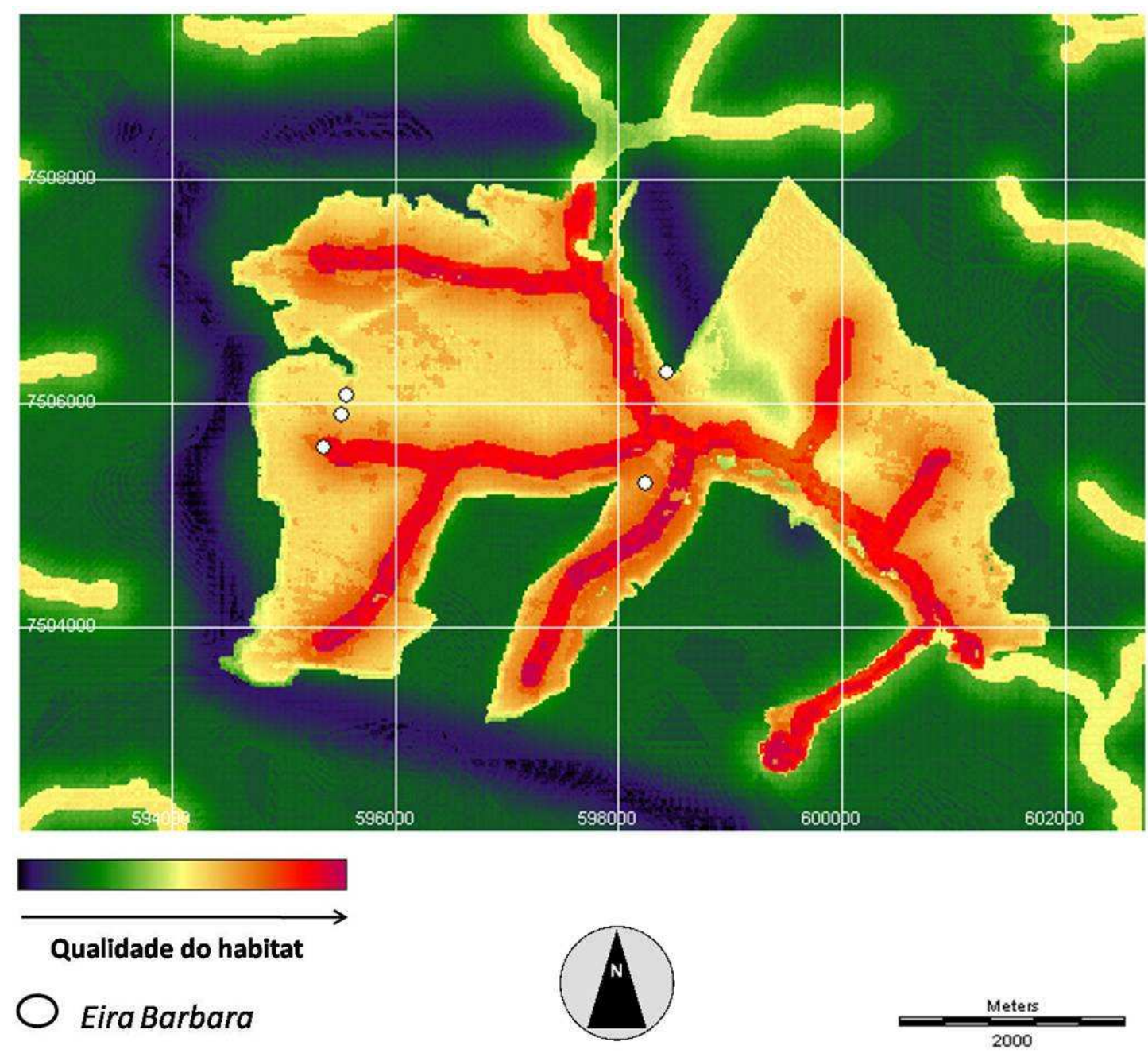

Fig.IV.3. - Mapa de Oportunidades desenvolvido em ambiente de SIG (MCE) para irara (E. barbara), apresentando escala contínua de qualidade dos habitats encontrados no fragmento e matriz (pasto), e os pontos de detecção obtidos na etapa de campo. 

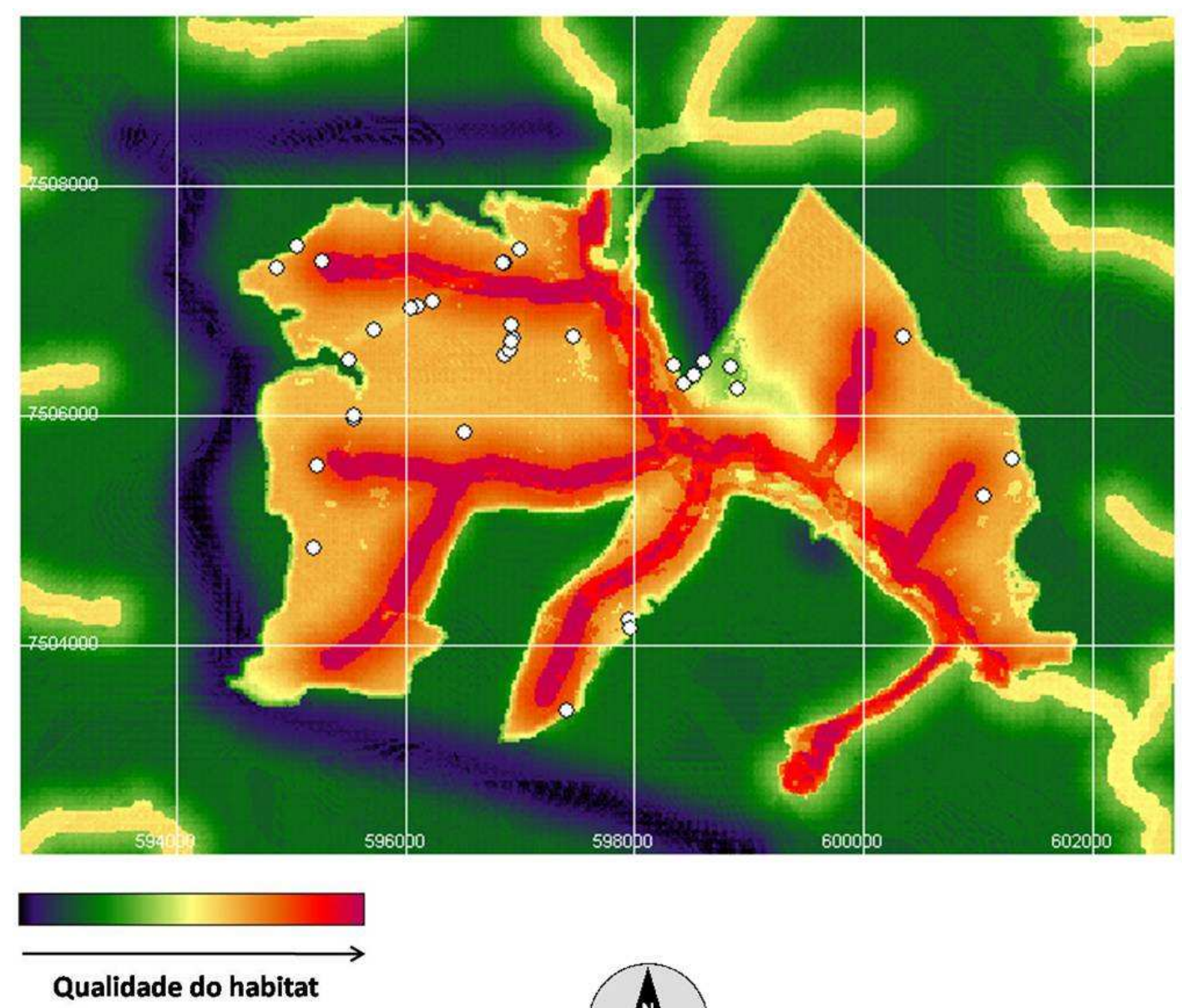

\section{Leopardus pardalis}
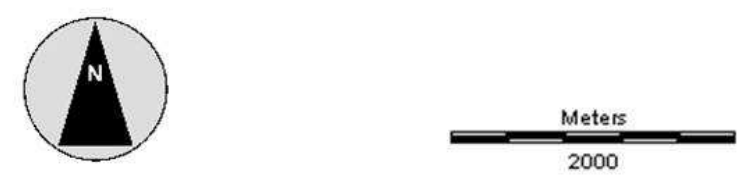

Fig.IV.4. - Mapa de Oportunidades desenvolvido em ambiente de SIG (MCE) para jaguatirica (L. pardalis), apresentando escala contínua de qualidade dos habitats encontrados no fragmento e matriz (pasto), e os pontos de detecção obtidos na etapa de campo. 


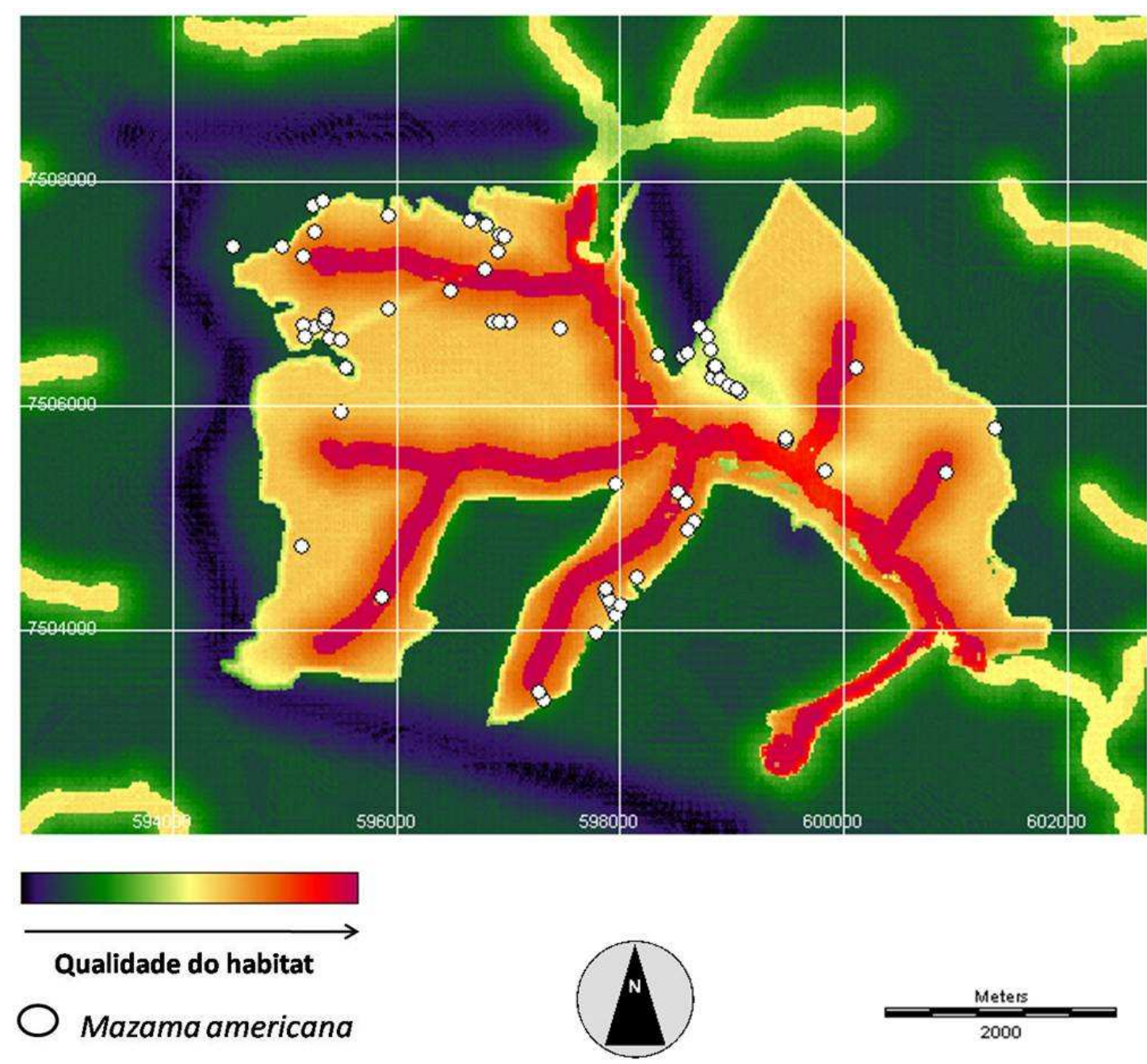

Fig.IV.5. - Mapa de Oportunidades desenvolvido em ambiente de SIG (MCE) para veado mateiro (M. americana), apresentando escala contínua de qualidade dos habitats encontrados no fragmento e matriz (pasto), e os pontos de detecção obtidos na etapa de campo. 

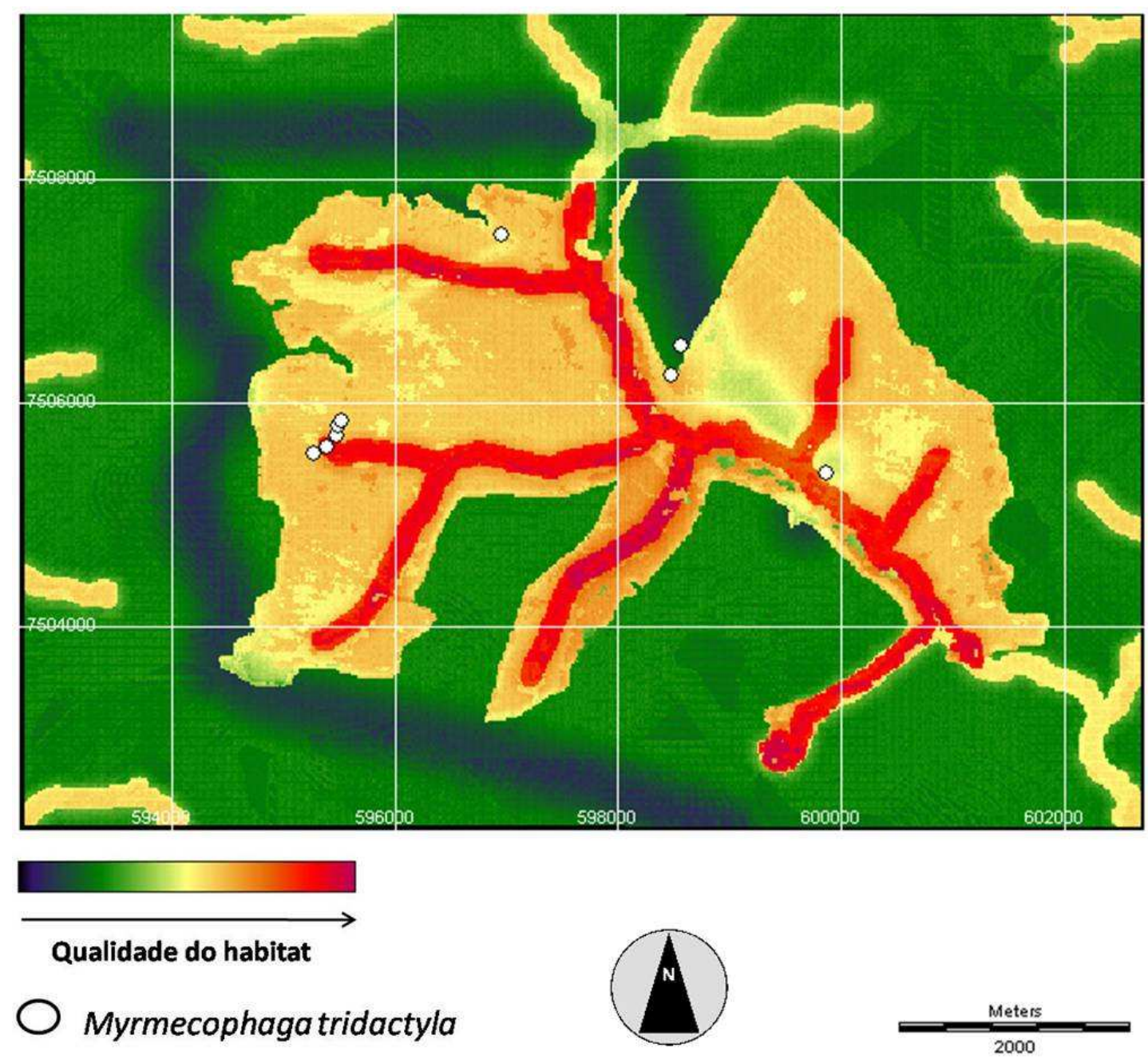

Fig.IV.6. - Mapa de Oportunidades desenvolvido em ambiente de SIG (MCE) para tamanduá bandeira (M. tridactyla), apresentando escala contínua de qualidade dos habitats encontrados no fragmento e matriz (pasto), e os pontos de detecção obtidos na etapa de campo. 

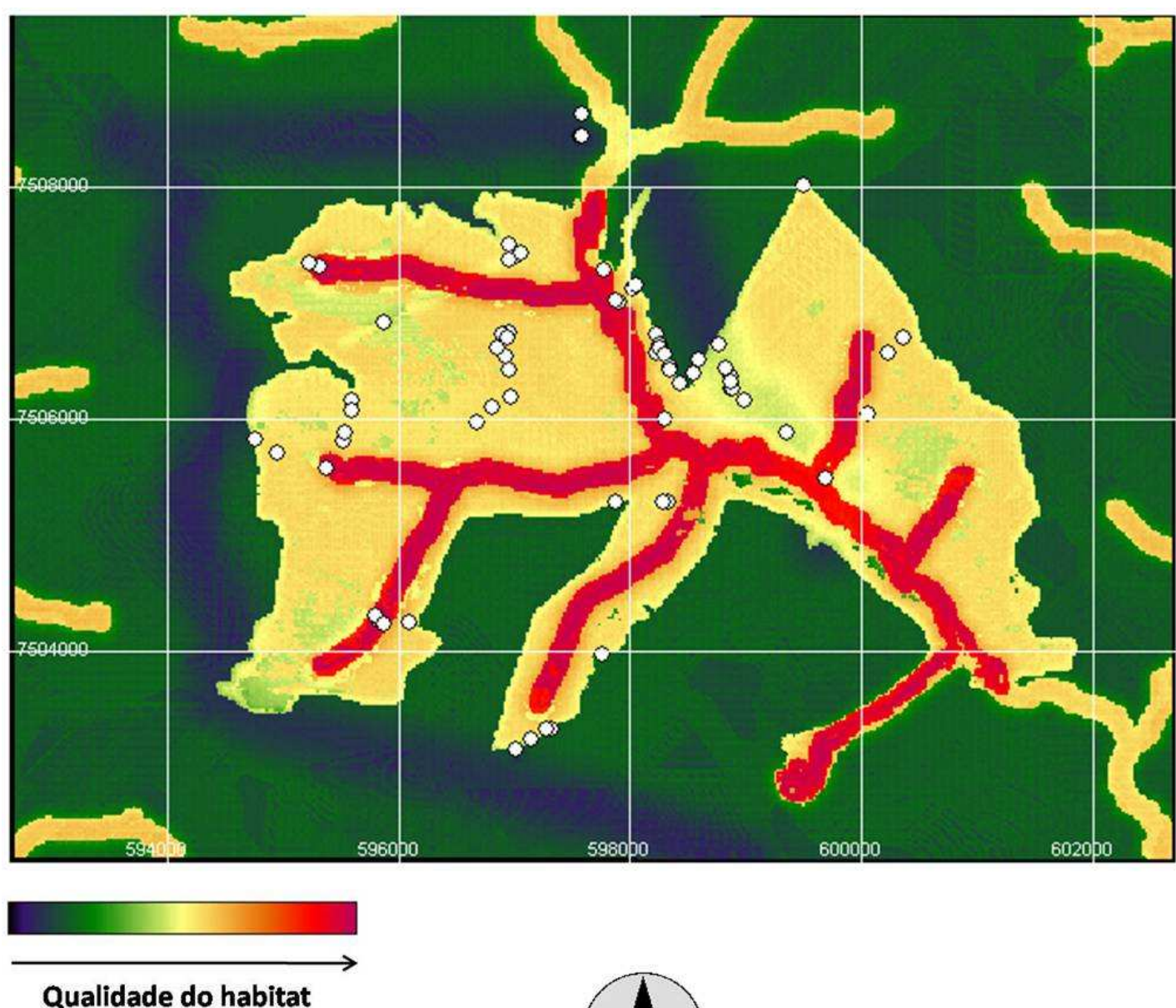

\section{Qualidade do habitat \\ Pumaconcolor}
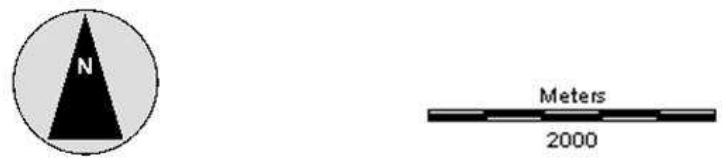

Fig.IV.7. - Mapa de Oportunidades desenvolvido em ambiente de SIG (MCE) para onça parda ( $P$. concolor), apresentando escala contínua de qualidade dos habitats encontrados no fragmento e matriz (pasto), e os pontos de detecção obtidos na etapa de campo. 


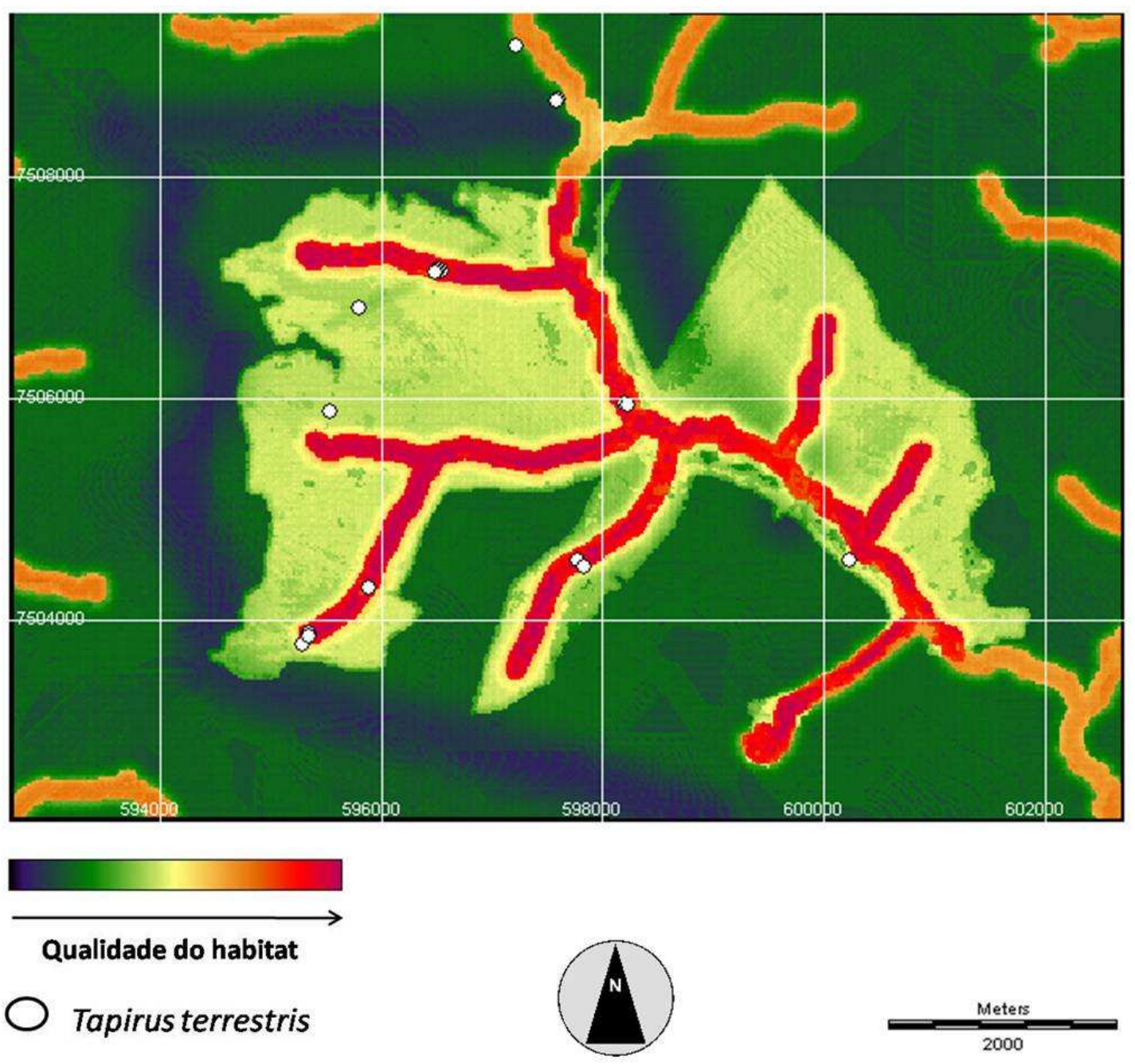

Fig.IV.8. - Mapa de Oportunidades desenvolvido em ambiente de SIG (MCE) para anta ( $T$. terrestris), apresentando escala contínua de qualidade dos habitats encontrados no fragmento e matriz (pasto), e os pontos de detecção obtidos na etapa de campo. 

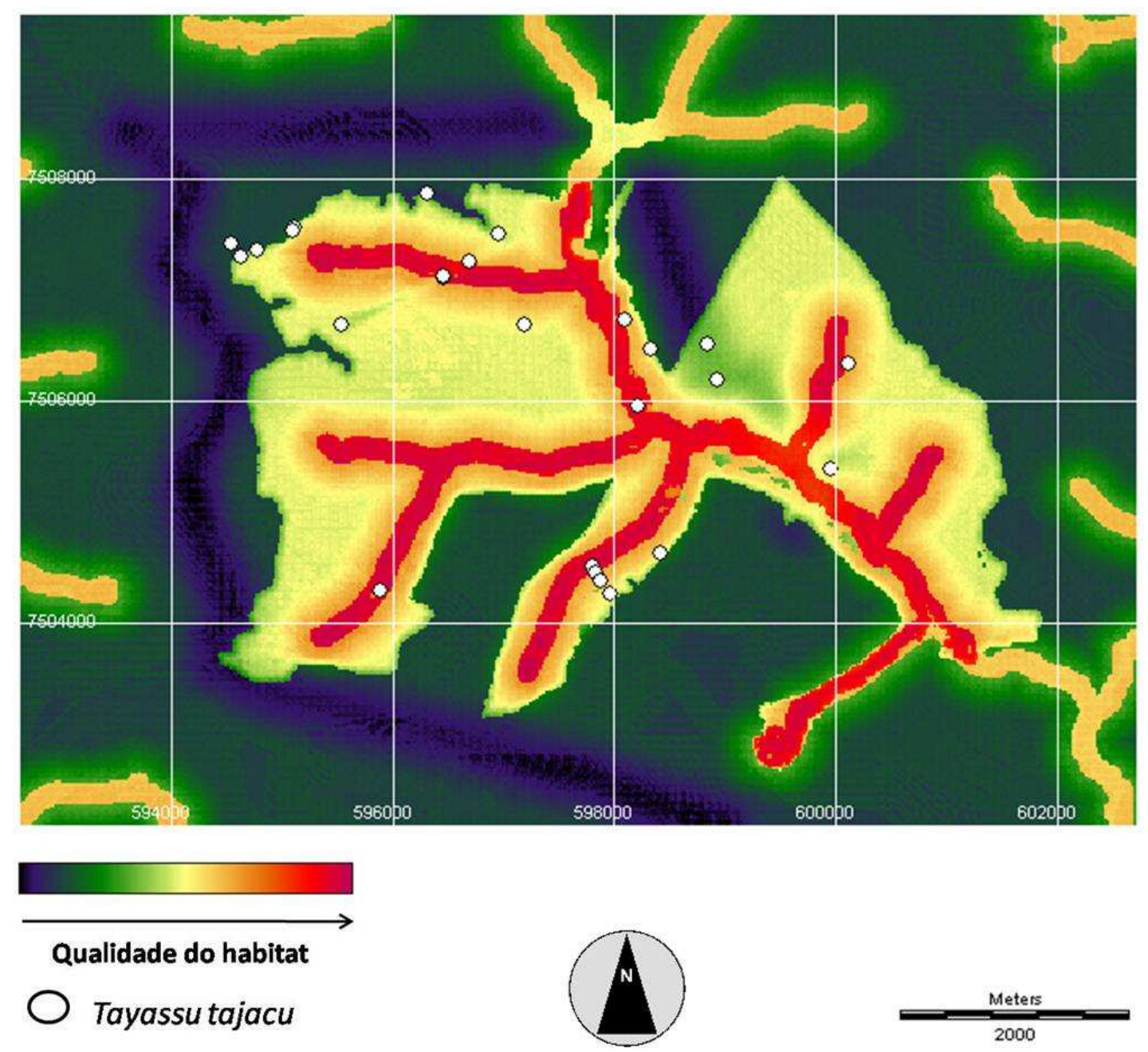

Fig.IV.9. - Mapa de Oportunidades desenvolvido em ambiente de SIG (MCE) para cateto ( $T$. tajacu), apresentando escala contínua de qualidade dos habitats encontrados no fragmento e matriz (pasto), e os pontos de deteç̧ão obtidos na etapa de campo. 
Os Mapas de Oportunidades gerados apresentam em comum uma faixa muito desfavorável, que corresponde à estrada. Nestes mapas, também é possível observar que a qualidade da mata ripária diminui quando esta sai do fragmento e entra em contato direto com a matriz antrópica, constituída predominantemente por pasto, o qual apresenta influência negativa na qualidade do habitat. A influência negativa da linha de transmissão de energia é menos intensa em relação à influência da estrada. O rio e a mata ripária foram os grandes contribuidores para a determinação dos habitats com melhores qualidades.

Os mapas apresentados foram desenvolvidos em escala contínua de qualidade de habitat. Para quantificar e melhor analisar o uso dos habitats pelas espécies-alvo do estudo, foi necessário criar uma escala booleana de qualidade (Figura IV.10).

Escala de Qualidade de Habitat

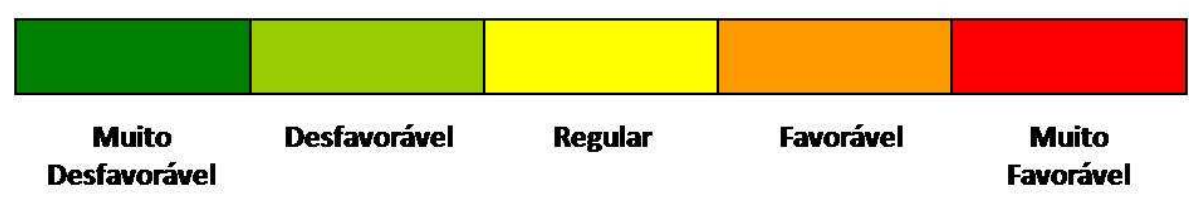

Fig.IV.10. - Escala booleana de qualidade de habitat.

Desta forma, os pontos de detecção das espécies foram sobrepostos aos seus respectivos mapas e analisados no nível dos pixels para se determinar o grau de qualidade, representado pelo pixel onde o ponto de detecção se encontrava (Figura IV.11). 


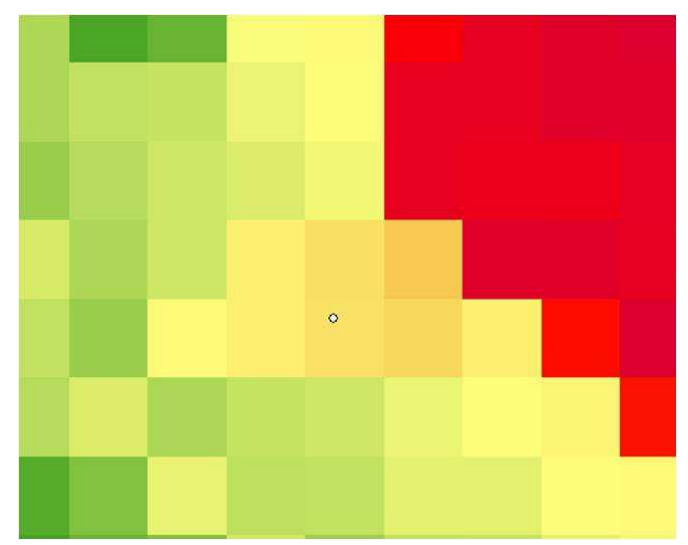

Fig.IV.11. - Ponto de detecção de T. terrestris, inserido em um pixel considerado de qualidade favorável, segundo a escala booleana.

A Tabela IV.10 apresenta os dados de ocorrência das espécies-alvo em função da qualidade do habitat, medida neste momento por meio da escala booleana de qualidade. Estes dados buscam validar o modelo de tomada de decisão aqui proposto, ou seja, busca medir se este modelo é capaz de predizer a ocorrência das espécies em função da qualidade de habitat.

Tabela IV.10. - Dados de ocorrência (número e porcentagem de detecções) das espéciesalvo do estudo em função da qualidade do habitat

\begin{tabular}{lcccccc}
\hline \multirow{2}{*}{ Espécies } & $\begin{array}{c}\text { No de } \\
\text { Deteções }\end{array}$ & \multicolumn{5}{c}{ \% Detecção/habitat } \\
\cline { 3 - 7 } & & $\begin{array}{c}\text { Muito } \\
\text { Desfavorável }\end{array}$ & Desfavorável & Regular & Favorável & $\begin{array}{c}\text { Muito } \\
\text { Favorável }\end{array}$ \\
\hline Eira barbara & 5 & - & - & 20 & 60 & 20 \\
Leopardus pardalis & 35 & - & 11 & 3 & 83 & 3 \\
Mazama americana & 72 & 10 & 19 & 18 & 40 & 13 \\
Myrmecophaga tridactyla & 9 & 11 & 11 & 11 & 44 & 22 \\
Puma concolor & 78 & 6 & 10 & 33 & 33 & 17 \\
Tapirus terrestris & 18 & - & 11 & - & 17 & 72 \\
Tayassu tajacu & 30 & 7 & 30 & 10 & 20 & 33 \\
Total & 247 & 6 & 15 & 18 & 40 & 20 \\
\hline
\end{tabular}

A partir do Mapa de Oportunidades (Figura IV.3) e dos dados de ocorrência (Tabela IV.10) de E. Barbara foi possível afirmar que não houve detecção desta espécie em habitats muito desfavoráveis e desfavoráveis. A maioria das detecções foi obtida em habitats favoráveis (60\%). Os habitats regulares e muito favoráveis contribuíram 
igualmente na ocorrência de desta espécie ( $20 \%$ cada).

Não ouve detecção de L. Pardalis em habitats muito desfavoráveis. Segundo o Mapa de Oportunidades (Figura IV.4) e os dados de ocorrência (Tabela IV.10) desta espécie, a maioria das detecções ocorreu em habitats favoráveis (83\%), seguido por habitats desfavoráveis (11\%). Os habitats regulares e muito favoráveis contribuíram igualmente na ocorrência de desta espécie (3\% cada).

Com relação à M. americana (Figura IV.5 e Tabela IV.10), a maioria das detecções ocorreu em habitats favoráveis (40\%), seguido de habitats desfavoráveis (19\%) e regulares (18\%). Habitats muito desfavoráveis representaram apenas $10 \%$ das detecções.

Os habitats muito desfavoráveis, desfavoráveis e regulares contribuíram igualmente na ocorrência de $M$. tridactyla (11\% cada). A maioria das detecções ocorreu em habitats favoráveis (44\%), seguido de habitats muito favoráveis (22\%), como pode ser observado na Figura IV.6 e Tabela IV.10.

P. concolor foi detectada mais vezes em habitats favoráveis e regulares (33\% cada), seguido de habitats muito favoráveis (17\%). Em habitats muito desfavoráveis ouve a menor porcentagem de deteç̧ões, apenas 6\% (Figura IV.7 e Tabela IV.10).

T. terrestris foi detectada mais vezes em habitats muito favoráveis (72\%), seguido de habitats favoráveis (17\%) e habitats desfavoráveis (11\%). Não ouve detecção em habitats muito desfavoráveis e regulares (Figura IV.8 e Tabela IV.10).

Com relação a T.tajacu, a maioria das deteç̧ões foi realizada em habitats muito favoráveis $(33 \%)$, seguido de habitats desfavoráveis $(30 \%)$, favoráveis $(20 \%)$, regulares $(10 \%)$ e muito desfavoráveis $(7 \%)$, como pode ser observado na Figura IV.9 e Tabela IV.10.

A maior porcentagem de detecção (Tabela IV.10) das espécies-alvo deste estudo foi obtida em habitats favoráveis (40\%), seguido de habitats muito favoráveis $(20 \%)$, habitats regulares (18\%), habitats desfavoráveis (15\%) e habitats muito desfavoráveis $(6 \%)$.

Para avaliar se houve influência da qualidade dos habitas no uso destas espécies, os dados de detecção obtidos nestes cinco tipos de habitats foram submetidos ao teste do qui-quadrado $\left(\chi^{2}\right)$ de Pearson (Sokal \& Rohlf, 1995). 
O resultado do teste foi significativo, com $\chi^{2}=315,2$ e 24 graus de liberdade, com valor crítico $(0,01)$ de 43 . Sendo assim, conclui-se que não há independência entre os habitats com diferentes graus de qualidade e o uso destes habitats por estas espécies, ou seja, é aceita a hipótese de que existe influência da qualidade do habitat na distribuição destas espécies de mamíferos utilizadas neste estudo. 


\section{Discussão}

A metodologia proposta no presente estudo foi desenvolvida através de um processo dedutivo-indutivo, onde houve a aplicação do modelo de tomada de decisão e a sua validação, permitindo apresentar sete cenários diferentes para as espécies E. barbara, L. pardalis, M. americana, M. tridactyla, P. concolor, T. terrestris e T. tajacu.

O modelo de tomada de decisão foi aplicado em escala local, as variáveis ambientais são espacialmente explícitas e a validação é simples, sendo assim, a aplicabilidade do modelo se mostrou viável e pôde gerar resultados robustos, mais próximos da realidade.

A viabilidade do modelo está relacionada ao fato de que existem informações acessíveis para o desenvolvimento de uma análise espacial voltada para a caracterização ambiental de áreas naturais ou antropizadas: a determinação dos pesos das variáveis ambientais é realizada por meio de consulta a especialistas; 0 uso do AHP é simples e garante consistência no desenvolvimento dos modelos de tomada de decisão (MCE), incluídos no SIG do software Idrisi; as imagens do satélite CBERS-2 são gratuitas e acessíveis.

O modelo de tomada de decisão foi capaz de predizer a ocorrência das espécies no remanescente de cerrado, em função da qualidade dos habitats. Isto pode ser observado a partir da Tabela IV.10, onde a maior porcentagem de detecção foi obtida em habitats favoráveis (40\%), seguido de habitats muito favoráveis $(20 \%)$, habitats regulares (18\%), habitats desfavoráveis (15\%) e habitats muito desfavoráveis (6\%).

A maioria das espécies foi detectada mais vezes em habitats favoráveis e menos vezes em habitats muito desfavoráveis, com exceção de $T$. terrestris e T. tajacu, que foram detectados mais vezes em habitats muito favoráveis.

O uso destes habitats foi testado por meio do qui quadrado e o resultado obtido permitiu afirmar que existe a influência da qualidade do habitat na distribuição das espécies de mamíferos utilizadas neste estudo. Esta informação enfatiza que o modelo de tomada de decisão aplicado pode ser uma ferramenta muito importante 
em estudos relacionados ao uso de habitats, alterados ou intactos, por espécies de mamíferos de médio e grande porte, em função de suas necessidades ambientais, ou seja, cada espécie possui requerimentos ambientais específicos e que devem ser levados em consideração para o desenvolvimento de qualquer plano de manejo e conservação em um determinado local.

E. barbara possui área de vida variando entre 900 ha a 1600 ha para fêmeas e 2440 ha para machos (Sunquist et al., 1989 apud Cheida et al., 2006). Apresentou considerável flexibilidade de uso de habitat em áreas perturbadas, de acordo com a disponibilidade existente na sua área de vida (Michalski et al., 2006). Segundo Eisenberg \& Redford (1999), esta espécie é mais comum em áreas densas, alimentando-se de pequenos vertebrados, frutos e mel. A sobreposição dos dados de detecção no Mapa de Oportunidades mostrou que esta espécie esteve associada ao complexo ripário e ao cerrado sensu stricto típico e denso.

L. pardalis possui área de vida variando entre 76 ha e 5090 ha, dependendo do sexo e das características do habitat (Crawshaw, 1995; Oliveira e Cassaro, 2005), podendo utilizar áreas abertas e florestais (Emmons \& Feer, 1997). Isto pode ser notado a partir dos dados de detecção inseridos no Mapa de Oportunidades, onde esta espécie é encontrada em áreas florestais e em áreas abertas, utilizando também o corredor da linha de transmissão de energia para se locomover, onde a vegetação é baixa. São animais de hábitos alimentares oportunistas (Ludlow \& Sunquist, 1987), consumindo predominantemente pequenos mamíferos (Martins et al., 2008). Entretanto, presas maiores, como as integrantes da ordem xenarthra e artiodactyla (Abreu, et al., 2008), também são importantes na dieta.

Pouco se conhece sobre o uso de habitat, comportamento social e status de conservação de M. americana (Di Bitetti et al., 2008). Sabe-se que esta espécie possui hábitos estritamente florestais, preferindo matas contínuas e densas, passando a maior parte do tempo forrageando (Eisenberg \& Redford, 1999). Nos cerrados preferem o complexo ripário e formações florestais, evitando áreas abertas (Tiepolo \& Tomas, 2006). Entretanto, os resultados obtidos da análise espacial aqui realizada, mostraram que esta espécie estava fazendo uso de áreas mais abertas, como as áreas de cerrado sensu stricto típico e também o corredor formado pela linha de transmissão de energia. Sua área de vida é pequena, menor que 100 ha 
(Rivero et al., 2005; Di Bitetti et al., 2008). Com relação à alimentação, esta espécie é considerada generalista (Rivero et al., 2005), alimentando-se de frutos, flores, gramíneas, leguminosas, arbustos e ervas (Tiepolo \& Tomas, 2006).

A área de vida média encontrada para M. tridactyla foi de 367 ha (fêmea) e 274 ha (macho) no PNSC, enquanto que no PNE foi de 693 ha (fêmea) e 1080 ha (machos), havendo intensa sobreposição de área de vida para ambos os sexos (Shaw et al., 1987; Miranda, 2004; Medri \& Mourão, 2005). Esta espécie utiliza uma ampla variedade de habitats e encontra-se associada às áreas abertas, inundáveis e florestais, mas também é freqüentemente observada forrageando em áreas de lavoura (Miranda, 2004; observação pessoal). As áreas abertas são utilizadas com mais freqüência para forrageio do animal, no entanto, estes tipos de habitat não estão protegidos contra ventos frios e não oferecem abrigo contra temperaturas extremas, como as áreas florestadas o fazem, já que são animais com baixa taxa metabólica e, portanto, sensíveis às condições ambientais (Mourão \& Medri, 2007). Desta forma, tanto as áreas abertas quanto áreas florestadas devem ser levadas em consideração quando se pensa em manejo e conservação de M. tridactyla.

P. concolor possui área de vida em torno de 15500 ha (Crawshaw \& Quigley, 1984 apud Mendes Pontes \& Chivers, 2007), ocorrendo em baixas densidades nas áreas que ocupam (Mendes Pontes, 2004). Esta espécie é considerada generalista, adaptada a diversos tipos de habitat e consumidora de uma grande variedade de presas (Iriarte et al., 1990; Emmons, 1997; Santos-Filho \& Silva, 2002; Oliveira \& Cassaro, 2005). Apesar dessa flexibilidade, esta espécie necessita de áreas florestadas para abrigo, mata ripária para atravessar áreas fragmentadas e grande disponibilidade de presas (Oliveira \& Cassaro, 2005; observação pessoal). O uso da mata ripária como corredor pode ser observado na sobreposição dos dados de detecção desta espécie sobre o seu respectivo Mapa de Oportunidades. Além disso, foram detectadas pegadas de pelo menos três indivíduos, sendo dois adultos e um filhote. Considerando a área total do remanescente e a área de vida desta espécie, é muito provável que ela esteja utilizando o complexo ripário para se movimentar dentro e fora do remanescente. A grande oferta de presas encontradas no remanescente pode indicar que o mesmo é utilizado como fonte de recursos. Somando-se a isso, a grande densidade de corpos d'água e a heterogeneidade de habitats de boa qualidade, encontrados no interior do remanescente, podem estar 
favorecendo a persistência desta espécie nesta região.

T. terrestris necessita de 200 ha de área de vida (Rocha, 2001) e frequentemente é encontrado em planícies úmidas, onde existe abundância de corpos d'água (Bodmer \& Brooks, 1997). No entanto, a utilização dos habitats é variável; durante o dia, a espécie permanece escondida em áreas florestadas e, durante a noite, sai para forragear, procurando por folhas de árvores, pequenas plantas, arbustos, lianas, cascas de árvores e frutos, utilizando a mata ripária como trilha (Noss et al., 2003; Bodmer \& Brooks, 1997, Rocha, 2001). Estas informações corroboram aquelas obtidas a partir da sobreposição dos pontos de detecção desta espécie em seu respectivo Mapa de Oportunidades. Desta forma, em termos de conservação e manejo, deve-se considerar áreas florestadas com grande densidade de corpos d'água, como o complexo ripário.

Tanto $T$. terrestris quanto $P$. concolor utilizaram corredores ripários para se deslocar para fora do fragmento. Este dado enfatiza a importância de corredores ripários como corredores de deslocamento e dispersão de animais.

T. tajacu é uma espécie generalista em relação ao habitat, utilizando uma grande variedade de tipos florestais em áreas perturbadas ou não perturbadas (ReynaHurtado \&Tanner, 2005; Mendes Pontes \& Chivers, 2007). Segundo Tiepolo \& Tomas (2006), habita ambientes florestais e abertos, alimentando-se de frutas, raízes, tubérculos, bulbos, rizomas e invertebrados. Sua área de vida varia entre 50 e 2000 ha (McCoy et al., 1990). A detecção de grande parte dos vestígios dentro da área de influência dos corpos d'água e mata ripária, permite inferir que esta espécie pode estar utilizando o complexo ripário para se deslocar, além de obter recursos, como alimento e água. Desta forma, o complexo ripário, o cerradão e o cerrado sensu stricto denso, devem ter grande peso de decisão quando há necessidade de se estabelecer prioridades para manejo e conservação desta espécie, pois são áreas com maior disponibilidade de recursos (alimento e água), assim como permitem refúgio contra caçadores.

Em suma, a espacialização de informações relacionadas à biologia e ecologia das espécies permitiu produzir novas informações importantes em relação à qualidade dos habitats e o uso dos mesmos pelas espécies-alvo deste estudo, por meio da sobreposição dos dados de detecção nos Mapas de Oportunidades gerados 
(validação do modelo de tomada de decisão desenvolvido). Desta forma, espera-se que este modelo espacial sirva como uma ferramenta de manejo e conservação de espécies de mamíferos e não mamíferos, já que o mesmo pode ser aplicado amplamente. 


\section{Conclusão}

O modelo de tomada de decisão aqui desenvolvido apresentou-se robusto ao predizer a qualidade do habitat a partir da ocorrência das espécies-alvo. No entanto, o modelo apresenta algumas restrições: a) restringe-se às fitofisionomias do domínio do cerrado; b) a priori foi desenvolvido para áreas que sofrem pressão antrópica; c) não foi levado em consideração o efeito da sazonalidade das espécies, sendo que os resultados aqui apresentados são válidos para a estação seca. Não houve a possibilidade de realização de mais campanhas de campo por escassez de recursos. Isto não significa que o modelo não possa ser validado por outros pesquisadores em outras épocas do ano.

Em linhas gerais, pode-se concluir que o foco das práticas de conservação em paisagens modificadas pode obter mais sucesso se for direcionado aos requerimentos ambientais da espécie em questão, levando em consideração que cada organismo possui requerimentos diferentes de habitat. Os Mapas de Oportunidades podem subsidiar a investigação e/ou planejamento de cenários relevantes de mudança de habitat e o seu efeito na composição de mamíferos em determinada área (Schroder, 2000; Peterson, 2003), tornando-se uma ferramenta importante na conservação de espécies principalmente em um bioma tão degradado quanto o cerrado. 


\section{Bibliografia}

ABREU, K.C.; MORO-RIOS, R.F.; SILVA-PEREIRA, J.E.; MIRANDA, J.M.D.; JABLONSKI, E.F.; PASSOS, F.C. 2008. Feeding habits of ocelots (Leopardus pardalis) in Southern Brazil. Mammalian Biology, 73: 407-411.

ARONOFF, S. 1991. Geographic Information Systems: a management perspective. Otawa: WDL Publications.

BITENCOURT, M.D. 2004. Diagnóstico cartográfico dos remanescentes de cerrado em São Paulo. Pp. 17-28. In: BITENCOURT, M.D.; MENDONÇA R.R. (Eds.). Viabilidade de conservação dos remanescentes de cerrado do estado de São Paulo. São Paulo: Annablume/FAPESP.

BODMER, R.E.; BROOKS, D.M. 1997. Status and action plan of the lowland tapir (Tapirus terrestris). In: BROOKS, D.M., BODMER, R.E. AND MATOLA, S. (Eds.). Tapirs - Status Survey and Conservation Action Plan. IUCN/SSC Tapir Specialist Group. <http://www.tapirback.com/tapirgal/iucn-ssc/tsg/action97/cover.htm>

CHEIDA, C.C.; NAKANO-OLIVEIRA, E.; FUSCO-COSTA, R.I.; ROCHA-MENDES, F.; QUADROS, J. 2006. Ordem Carnivora. In: REIS, N.R.; PERACCHI, A.L.; PEDRO, W.A.; LIMA, I.P (Eds.). Mamíferos do Brasil. Londrina, p. 231-275.

CLEVENGER, A.P.; WIERZCHOWSKI, J.; CHRUSZCZ, B.; GUNSON, K. 2002. GIS-generated, expert-based models for identifying wildlife habitat linkages and planning mitigation passages. Conservation Biology, 16: 503-514.

CRAWSHAW, P.G. 1995. Comparative ecology of ocelot (Felis pardalis) and Jaguar (Panthera onca) in a protected subtropical forest in Brazil and Argentina. (Ph.D. Thesis) - University of Florida.

DI BITETTI, M.S.; PAVIOLO, A.; FERRARI, C.A.; DE ANGELO, C.; DI BLANCO, Y. 2008. Differential Responses to Hunting in Two Sympatric Species of Brocket Deer (Mazama americana and M. nana). Biotropica, 40: 636-645.

EASTMAN, J.R.; JIN, W.; KYEM, P.A.K.; TOLEDO, J. 1995. Raster procedure for multi-criteria/multi-objectives decisions. Photogrammetric Engineering \& Remote Sensing, 61: 539-547. 
EASTMAN, J.R. 1997. Idrisi for Windows user's guide. Clark University Laboratory, Clark University, Worcester, Pennsylvania.

EASTMAN, J.R. 2006. IDRISI Andes. Clark University Laboratory, Clark University, Worcester, Pennsylvania.

EISENBERG, J.F.; REDFORD, K.H. 1999. Mammals of the neotropics (Ecuador, Peru, Bolivia, Brazil). Chicago \& London: The University of Chicago Press.

EMMONS, L.H.; FEER, F. 1997. Neotropical Rainforest Mammals: a field guide. Chicago: The University of Chicago Press.

FISCHER, J.; LIDENMAYER, D.B.; FAZEY, I. 2004. Appreciating Ecological Complexity: habitat contours as a conceptual landscape model. Conservation Biology, 18: 1245-1253.

HUME, E.; REUNANEN, P.; MÖNKKÖNEN, M.; NIKULA, A.; NIVALA, V.; OKSANEN, J. 2007. Local habitat patch pattern of the siberian flying squirrel in a managed boreal forest landscape. Ecoghraphi, 30: 277-287.

IRIARTE, J.A.; FRANKLIN, W.L.; JOHNSON, W.E.; REDFORD, K.H. 1990. Biogeographic variations of food habitats and body size of the America puma (Felis concolor). Oecologia, 85: 185-190.

LUDLOW, M.E.; SUNQUIST, M.E. 1987. Ecology and behavior of ocelots in Venezuela. Nat. Geogr. Res. 3: 447-461.

MARTINS, R.; QUADROS, J.; MAZZOLLI, M. 2008. Hábito alimentar e interferência antrópica de marcação territorial do Puma concolor e Leopardus pardalis (Carnívora: Felidae) e outros carnívoros na Estação Ecológica de Juréia-Itatins, São Paulo, Brazil. Revista Brasileira de Zoologia, 25: 427-435.

MACDONALD, D.W.; RUSHTON, S. 2003. Modelling space use and dispersal of mammals in real landscapes: a tool for conservation. Journal of Biogeography, 30 : 607-620.

MCCOY, M.B.; VAUGHAM, C.S.; RODRIGUEZ, M.A.; KITCHEN, D. 1990. Seasonal movement, home range, activity and diet of collared peccaries (Tayassu tajacu) in Costa Rican dry Forest. Vida Silvestre Neotropical, 2: 6-20.

MEDRI, I.M.; MOURÃO, G. 2005. Home range of giant anteaters (Myrmecophaga 
tridactyla) in the Pantanal Wetland, Brazil. Journal of Zoology, 266: 365-375.

MENDES PONTES, A.R. 2004. Ecology of a community of mammals in a seasonally-dry forest in Roraima, Brazilian Amazon. Mammalian Biology, 69: 319336.

MENDES PONTES, A.R.; CHIVERS, D.J. 2007. Peccary movements as determinants of the movements of large cats in Brazilian Amazonia. Journal of Zoology, 273: 257-265.

METZGER, J.P. 2001. O que é ecologia de paisagem. Biota Neotropica. <http://www.biotaneotropica.org.br/v1n12/pt/abstract?thematic-review+BN00701122001>

MICHALSKI, F.; CRAWSHAW, P.G.; OLIVEIRA, T.G.; FABIÁN, M.H. 2006. Notes on home range and habitat use of three small carnivore species in a disturbed vegetation mosaic of southeastern Brazil. Mammalia, 52-57.

MIRANDA, G.H.B. 2004. Ecologia e conservação do tamanduá bandeira (Myrmecophaga tridactyla) no Parque Nacional das Emas. (Tese de doutorado) ICB/UNB.

MOURÃO, G.; MEDRI I.M. 2007. Activity of a specialized insectivorus mammal (Myrmecophaga tridactyla) in the Pantanal of Brazil. Journal of Zoology, 271: 187192.

MYERS, N. 2003. Biodiversity Hotspots revisited. Bio-Science, 53: 916-917.

NOSS A.J.; CUÉLLAR R.L.; BARRIENTOS J.; MAFFEI, L.; CUÉLLAR E.; ARISPE R.; RÚMIZ D.; RIVERO, K. 2003. A Camera Trapping and Radio Telemetry Study of Lowland Tapir (Tapirus terrestris) in Bolivian Dry Forests. Tapir Conservation Newsletter of the IUCN/SSC Tapir Specialist Group, 12: 24-32.

OLIVEIRA, T.G.; CASSARO, K. 2005. Guia de identificação dos felinos brasileiros. Instituto Pró Carnívoros e Sociedade de Zoológicos do Brasil, São Paulo, SP.

PACZEK, S. 1997. Habitat Management of Shrub Steppe birds in the South Okanagan: applications of GIS. Term Project for Geography, University of British Columbia. <http://www.geog.ubc.ca/courses/klink/g470/class97/paczek/project.html> REYNA-HURTADO, R.; TANNER, G.W. 2003. Habitat preferences of ungulates in hunted and nonhunted areas in the Calakmul Forest, Campeche, Mexico. Biotropica, 
37: 676-685.

RIVERO, K.; RUMIZ, D.I.; TABER, A.B. 2005. Differential habitat use by two sympatric brocket deer species (Mazama Americana and M. gouazoubira) in seasonal Chiquitano forest of Bolivia. Mammalia, 69: 169-183.

ROCHA, V.J. 2001. Ecologia de mamíferos de médio e grandes portes do Parque Estadual dos Godoy, Londrina (PR). (Tese de doutorado) - UFPR.

SAATY, T. 1977. A scaling method for priorities in hierarchical structures. J. Math Psychol, 15: 234-281.

SANTOS-FILHO, M.; SILVA, M.N.F. 2002. Uso de habitats por mamíferos em área de cerrado do Brasil central: um estudo com armadilhas fotográficas. Revista Bras. de Zoociências, 4: 57-73.

SHAW, J.H.; MACHADO NETO, J.; CARTER, T.S. 1987. Behavior of free-living giant anteaters (Myrmecophaga tridactyla). Biotropica, 3: 255-259.

SOKAL, R.R.; ROHLF, F.J. 1995. Biometry: the principles practice of statistics in biological research. New York: W.H. Freeman.

TIEPOLO, L.M.; TOMAS, W.M. 2006. Ordem Artiodactyla. In: REIS, N.R.; PERACCHI, A.L.; PEDRO, W.A.; LIMA, I.P (Eds.). Mamíferos do Brasil. Londrina, p. 283-303. 


\section{Considerações Finais}

As informações obtidas neste trabalho sobre a diversidade de habitats com diferentes graus de qualidade e sobre a riqueza das espécies de mamíferos de médio e grande porte no remanescente, assim como as informações relativas à área de vida e graus de ameaça destas espécies, enfatizam a necessidade de criação de uma Unidade de Conservação de Proteção Integral no local, além da necessidade de incremento da conectividade com os demais fragmentos, visando a proteção deste remanescente e, conseqüentemente, das espécies que o utilizam de alguma forma.

A espacialização de informações relacionadas à biologia e ecologia das espécies permitiu produzir novas informações importantes em relação à qualidade dos habitats e o uso dos mesmos pelas espécies-alvo deste estudo, por meio do modelo de tomada de decisão desenvolvido. Desta forma, espera-se que o mesmo sirva como uma ferramenta de manejo e conservação de espécies de mamíferos e não mamíferos, já que o mesmo pode ser aplicado amplamente.

O direcionamento das práticas de conservação em paisagens modificadas pode obter mais sucesso se for direcionado aos requerimentos ambientais da espécie em questão, levando em consideração que cada organismo possui requerimentos diferentes de habitat. $O$ modelo de tomada de decisão aqui desenvolvido pode subsidiar a investigação e/ou planejamento de cenários relevantes de mudança de habitat e o seu efeito na composição de mamíferos em determinada área, tornandose uma ferramenta importante na conservação de espécies principalmente em um bioma tão degradado quanto o cerrado. 


\section{Resumo Geral}

A intensa degradação do bioma cerrado tem tido grandes conseqüências na disponibilidade de habitats de boa qualidade para muitos animais e a busca por métodos rápidos e confiáveis que localizem áreas de valor ecológico para diferentes grupos de animais tem despertado grande interesse.

A análise geográfica computadorizada foi utilizada como ferramenta para caracterização da heterogeneidade (diversos graus de qualidade e tipo de cobertura fitofisionômica) dos habitats existentes no remanescente estudado, buscando fornecer informações que pudessem levar ao entendimento de como as espécies de mamíferos de médio e grande porte utilizam estes habitats alterados, além de fornecer informações que pudessem ser utilizadas para o delineamento da amostragem.

Desta forma, a primeira etapa foi a elaboração de uma base cartográfica que produziu dois mapas de caracterização ambiental, um mapa geral e outro da mata ripária. O primeiro foi utilizado para a realização de uma análise preliminar da qualidade dos habitats e distribuição das armadilhas fotográficas, transecções e canteiros de pegadas, buscando capturar toda a heterogeneidade existente no remanescente. Desta forma, houve a sistematização das amostragens.

A utilização destes métodos permitiu a detecção de 22 espécies de mamíferos de médio e grande porte em 28 dias de amostragem, quando a curva acumulativa de espécies (Sobs - Mao Tau) atingiu sua assíntota. O teste do qui quadrado permitiu afirmar que houve influência das fitofisionomias na distribuição das espécies observadas. Desta forma, partindo-se do pressuposto de que a heterogeneidade de habitats certamente irá influir na diversidade de recursos alimentares, admitiu-se que a grande riqueza obtida no remanescente estudado esteja principalmente relacionada à disponibilidade de recursos alimentares.

A segunda etapa da análise espacial foi a elaboração de um modelo de tomada de decisão que espacializou as informações relacionadas à biologia e ecologia de algumas espécies de mamíferos. O modelo desenvolvido permitiu produzir novas informações importantes em relação à qualidade dos habitats e o uso dos mesmos pelas espécies-alvo, por meio da sobreposição dos dados de detecção nos Mapas de Oportunidades gerados (validação do modelo de tomada de decisão desenvolvido). 
O uso destes habitats também foi testado por meio do qui quadrado e o resultado obtido permitiu afirmar que houve a influência da qualidade do habitat na distribuição das espécies neste estudo. Esta informação enfatiza que o modelo de tomada de decisão aplicado pode ser uma ferramenta muito importante em estudos relacionados ao uso de habitats, alterados ou intactos, por espécies de mamíferos de médio e grande porte, em função de suas necessidades ambientais, ou seja, cada espécie possui requerimentos ambientais específicos e que devem ser levados em consideração para o desenvolvimento de qualquer plano de manejo e conservação em um determinado local. 